\title{
Essays on Income Taxation
}

\section{Tianying $\mathrm{He}$}

Zhuhai, China

Bachelor in Economics and B.S. in Statistics, Peking University, 2010

M.A. Economics, University of Virginia, 2011

A Dissertation presented to the Graduate Faculty of the University of Virginia in Candidacy for the Degree of Doctor of Philosophy

\section{Department of Economics}

University of Virginia

August, 2016 


\section{Abstract}

My dissertation examines empirically how the tax code influences household deductions, how the availability of deductions alters the elasticity of taxable income (ETI), and how deductions change deductible commodities' prices. I develop theoretical results linked with my estimates and draw conclusions about base-broadening reform design.

The first chapter, "Substitutability among Federal Income Tax Deductions: Implications for Optimal Tax Policy", studies households making joint decisions about two tax-deductible activities: charitable giving and paying interest on home equity lines of credit (HELOC). By allowing for interactions, either substitutability or complementarity, between deductions, I provide a fuller understanding of the elasticity of taxable income (ETI) and the tax-price elasticity of charitable giving. The tax-price of paying HELOC interest depends on the tax schedule as well as current interest rates. Therefore, the two activities have different tax-prices and the identification of their interaction is possible. Using the Survey of Consumer Finances, I find that the level of each activity falls with its own tax-price and rises with the other activity's tax-price. I show that in theory the ETI is a weighted sum of such own and cross tax-price effects between activities. I then apply this theory and my estimates to illustrate the trade-offs of three base-broadening tax policies. A conventional policy which removes a subset of deductions while keeping other deductions intact cannot guarantee either more tax revenue or greater efficiency. In contrast, an optimal policy would lower all deductions by differing degrees. However, designing an optimal policy requires knowing the values of all own and cross tax-price elasticities between deductions. Instead, I recommend a second-best policy of "uniform partial deductibility" which lowers all deductions to the same degree; it can guarantee improvement without prior knowledge about elasticities between deductions.

In the second chapter, "The Impact of Taxation on Charitable Giving by Itemizers and Non-Itemizers", co-authored with Leora Friedberg, we estimate how the income tax code affects charitable giving by exploiting variation in the federal tax schedule arising between 1988 and 2006. We make two contributions to the literature. We use the Survey of Consumer Finances (SCF) for our analysis. The SCF reports donations for both itemizers and non-itemizers, which is important because non-itemizers do not appear in tax return data. Besides, the SCF has detailed information on individual correlates of giving and covers a long time period. Second, we estimate how giving responds to marginal tax rates not only for "exogenous itemizers", who have high enough non-charity deductions to itemize, and who have been well studied in the literature, but also for "exogenous non-itemizers," who face a non-convex budget constraint in their price of giving. We characterize the incentives of non-itemizers based on the tax-price they will face if they give enough to itemize, as well as the "distance" in giving required for them to reach this itemization threshold. Our results show that (1) exogenous itemizers are responsive to tax incentives, with an estimated price elasticity of around -1 for the full sample (which is similar to representative studies in the literature) and more than double for the self-employed; (2) "exogenous non-itemizers" also respond to tax incentives involving both the price and distance associated with itemizing, with sensitivity to the tax price diminishing as distance increases. 
The third chapter, "Do mortgage borrowers gain the full benefit of the mortgage interest deduction?", estimates the incidence of the mortgage interest deduction. This chapter studies whether the mortgage interest deduction benefits lenders by raising mortgage interest rates and, if so, by how much. I link the Fannie Mae Single Family Loan Level dataset and Freddie Mac Single Family Loan Level dataset with the Home Mortgage Disclosure dataset. Under both of my empirical approaches I find that rising tax rates raise mortgage interest rates, and translate these results into the incidence results that lenders capture between $3.2 \%$ and $9.3 \%$ of the benefit of the mortgage interest deduction. 


\section{Acknowledgements}

To date, the sunny early morning sessions of the public economics course in fall 2011 remain a vivid memory. After Prof. Leora Friedberg's first lecture, I knew that taxation might be my area. 4 years and 11 months later, I have written up this dissertation on taxation. This dissertation was nurtured by Prof. Friedberg's immeasurable amount of time put into teaching and advising, by her countless meetings and discussions with me, by the innumerable insightful comments, suggestions and edits she gave, and the opportunities of speaking to many economists and non-economists she provided me with. I will forever be grateful to her commitment, patience, and initiatives taken in helping develop my human capital and making me an economist.

My heartfelt thanks also go to Prof. John Pepper. I could not have written this dissertation without his teaching in public economics and his mentorship on my research. I benefited so much from his expertise in economics as well as econometrics. His comments and suggestions provided much inspiration and sharpened my writing. I could never forget the thought provoking conversations with him. I am greatly indebted to his guidance, support, and encouragement.

I thank Prof. Ed Olsen and Prof. Patrik Sandas for their service on my committee. I appreciate the opportunities to draw on Prof. Olsen's expertise in housing economics and to have Prof. Sandas's input about finance and mortgages. Since the summer of 2011, I had the privilege of working as Prof. Sandas's TA and RA, and learnt much from these experiences.

I thankfully acknowledge the financial support for my dissertation work from the Bankard Fund for Political Economy.

I want to thank other faculty members at UVA for their help. I am grateful to Prof. Bruce Reynolds and Prof. Dukpa Kim for their recommending me to study at UVA. After starting my Ph.D. study, I continued to benefit professionally and personally from conversations with Prof. Reynolds. I am thankful to Prof. Kim for his teaching in econometrics and his suggestions on Ph.D. study. I thank Prof. Sarah Turner for her feedback during the applied microeconomics research group meetings. I am grateful to comments and suggestions from Profs. Monika Abramenko, Zachary Bethune, Maxim Engers, Wayne-Roy Gayle, and Steven Stern.

I have also benefited from talking to scholars outside UVA. I am thankful to Profs. Raj Chetty, R. Morris Coats, John Friedman, Don Fullerton, Jonathan Gruber, Damon Jones, Sarah Reber, and Dan Silverman for listening to my formal and informal presentations of my research and providing feedback.

I could also not forget all the positive influence I received from professors at my undergraduate institutions, Guanghua School of Management and the School of Mathematical Sciences at Peking University. My undergraduate advisor, Prof. Yining Li, inspired me with his books and his experiences and involvement in China's economic reform, and instilled in me a sense of social responsibility and belief in hard work. I am very much grateful to Profs. Hansheng Wang, Ziming Wang, Shanggong Sun, and Li-An Zhou for their teaching of knowledge and values. Without them, I couldn't have pursued my Ph.D. study.

I thank my friends from whom I received input and support in writing this dissertation. I thank Murat Demirci, Meltem Poyraz, and especially Scott Laughery for 
their help with using the cluster. Murat Demiri has also offered many writing suggestions. I thank Meng Hua and Cary Xing for automation codes they wrote that sped up my work on the cluster. While I cannot name everyone, I wholeheartedly thank every fellow grad student who provided feedback to me in research group meetings, presentations, writing classes, and other occasions.

I dedicate this dissertation to my parents, Jingbo Li and Dage He. As a line of Chinese poetry puts it, "such kindness as young grass receives from the warm sun can't be repaid". I have been bathed in their unconditional love and excellent education. Over the years, they would never spare any effort and are always ready to make any sacrifice in order to help me fulfill my dreams. I am happy that I as their child could write this dissertation, an accomplishment that they could take pride in. 


\section{Contents}

1. Substitutability among Federal Income Tax Deductions: Implications for Optimal Tax Policy

2. The Impact of Taxation on Charitable Giving by Itemizers and Non-Itemizers (coauthored with Leora Friedberg)

3. Do Mortgage Borrowers Gain the Full Benefit of the Mortgage Interest Deduction? 


\section{Chapter 1}

\section{Substitutability among Federal Income Tax Deductions: Implications for Optimal Tax Policy}

\section{Introduction}

The elasticity of taxable income (ETI), which shows how taxable income changes in response to the marginal tax rate, is a key parameter for tax analysis for two reasons. First, the ETI indicates whether cutting tax rates will decrease or increase tax revenue. This relationship is sometimes depicted through the well-known "Laffer Curve". Second, the ETI characterizes the dead-weight loss of taxation; under certain assumptions, the ETI is a sufficient statistic to estimate the efficiency costs of taxation (Feldstein 1999; Saez, Slemrod and Giertz 2012) and plays an important role in optimal tax theory (Diamond and Saez 2011).

Researchers have estimated the ETI, defined with respect to the net of tax rate 1- $\tau$, with $\tau$ being the marginal income tax rate, to be significantly above zero and perhaps even above one (Feldstein 1999; Gruber and Saez 2002). Kopczuk (2005) argues that the ETI is not a constant, immutable parameter, however, meaning that it varies with individuals' access to tax-deductible items and can be altered by tax policies such as policies on deductions.

On the one hand, the ETI literature examines the overall responsiveness of taxable income to tax rate changes. On the other hand, many studies have considered isolated components of taxable income, for example, by estimating the tax-price elasticity of charitable giving or the labor supply elasticity with respect to the tax rate. Arguably, however, there are important interactions between the different components of taxable income. For example, if the home mortgage interest deduction becomes more generous, a household may take out a larger mortgage to finance a more expensive house. As a result, their property tax deduction will also become larger. ${ }^{1}$

\footnotetext{
${ }^{1}$ Normally itemized deductions reduce taxable income dollar for dollar (for households who itemize). The "Pease Limitation" complicates this, but does not change the way of interaction between different itemized deductions per se. This rule limits the amount of itemized deductions for households with Adjusted Gross Income over a threshold (e.g. \$128,950 in 2000 for married households); for more details about the rule see, for example, 2000 Tax Form 1040 Schedule A's Line 28 and the accompanied Form 1040 Instructions.
} 
In this paper I consider the implication of allowing the decisions on different deductions to interact. That is, I am interested in not only own tax-price elasticities but also the cross price elasticities of deductions with respect to the tax-price of other deductions. This allows for either substitutability or complementarity between deductions and reveals whether households make joint decisions on different tax expenditures. ${ }^{2}$ In addition, examining the cross price elasticities between deductions is important for two other reasons.

First, it deepens our understanding of the ETI. In Section VI and Appendix 1 I derive the mathematical relationship between the ETI and the underlying cross price elasticities. As these cross price elasticities correspond to different components of taxable income and their interactions, tax systems that define taxable income differently will generally have different ETIs. This reasoning is similar to Kopczuk (2005). ${ }^{3}$ Additionally, these elasticities can cause bias in estimating the ETI for one particular tax system using observed changes in taxable income caused by a tax reform. As Slemrod (1998) explains, if a tax reform removes deductions while changing rates, the ETI estimate could bias from the true values of both the pre-reform ETI and the after reform ETI. This is because, during a tax reform that lowers tax rates and removes deductions at the same time, households change their taxable incomes responding to both the rate change and the deduction change. Thus, the rate change's effect on taxable income (i.e. the ETI) will be confounded by the deduction change, if the latter is not accounted for. In Appendix 2 I quantify this bias in terms of cross price elasticities and also graphically illustrate possible directions of the bias.

This rule alters "tax-prices", but not the way how "tax-prices" affect deduction amounts. I account for this rule in my empirical work.

${ }^{2}$ I view the substitutability or complementarity as arising mainly from the fact that different deductions encourage different types of consumptions that enter the utility function, for example charitable giving and housing. In addition, certain deductions may have very obvious substitutability from an accounting perspective. For example, the deductibility for personal interest is gradually phased out following TRA 86. In this process, households may shift away from personal loans to home equity loans, with the latter's interest always deductible.

${ }^{3}$ Kopczuk (2005) provides a theoretical relationship between the so called "broad income" (sum of beforetax labor income and many other types of incomes) elasticity and deductions, but not a theoretical relationship between the ETI and deductions. In his empirical work, he examines both the broad income elasticity and the ETI. 
Second, it has important implications for the design of tax reform. Broadening the tax base, by removing all deductions for example, reduces the deadweight loss per dollar of collected revenue (Kopczuk 2005). However, in light of the cross price elasticities between deductions, not all base broadening methods are equal. For example, ceteris paribus, removing the deductibility of a consumption item that is a complement of (i.e. having negative cross price elasticities with) other deductible items will broaden the tax base more than if it is a substitute. The reasoning is as follows. Both tax reform options will broaden the tax base directly by removing a deduction, but indirectly the former will cause the remaining deductions to shrink (adding to the direct broadening effect) while the latter will cause the remaining deductions to expand (offsetting the direct broadening effect). If cross price elasticities are unknown, I demonstrate that a second best policy of lowering all deductions together to the same extent - which will maintain their relative tax-prices and avoid triggering any substitution between them - broadens the base as well as reduces dead weight loss. I discuss this in Section VI.

In addition to examining the theoretical relationships, I empirically demonstrate the importance of the cross price elasticities between deductions. To do so, I use data from the Survey of Consumer Finances to examine the cross price elasticities of two taxdeductible activities, charitable giving and paying interest on home equity lines of credit (HELOC). To my knowledge, this is the first empirical paper that considers interactions across tax deductible items.

I pick these two components of taxable income for the following reasons. First, out of the many components of taxable income, I study two deductions rather than two types of income because I suspect that the responsiveness of taxable income may arise largely from deductions. In fact, the literature finds that overall labor supply responds little to tax incentives (Saez, Slemrod and Giertz 2012; Gruber and Saez 2002) while the ETI is typically estimated to be much higher than labor supply elasticities (Feldstein 1999; Gruber and Saez 2002). In contrast, many studies have found that charitable giving is responsive to tax rates (Peloza and Steel 2005). The dollar amount of deductions is also large, so their responsiveness to tax rate changes influences the overall responsiveness of taxable income. In 2011 the total amount of itemized deductions was over \$1.2 trillion. The sum of itemized deductions and standard deductions amounted to $34.6 \%$ of taxable 
income. Second, home collateral borrowing and charitable giving are important deductions. In 2012, total giving by individuals in the US was $\$ 316.23$ billion, with $\$ 199.27$ billion claimed as itemized deductions (the amount subtracted from taxable income), and the total amount of the home mortgage interest claimed was \$332.61 billion (Giving USA 2013; Internal Revenue Service 2014). ${ }^{4}$

Third, among forms of borrowing on home collateral, HELOC repayments are flexible: after entering a HELOC agreement which determines the credit limit (the maximum amount allowed to be borrowed), the borrower is often able to borrow up to the credit limit whenever he or she wants (FRB 2012h) and faces a flexible payback schedule. ${ }^{5}$ Thus, I treat the payback decision as annual. This makes static modeling feasible.

Fourth, for these two deductions the identification of cross-price elasticities is possible. Many tax-deductible items face the same tax-price, $1-\tau$. In order to separately identify the own-price effect and the cross-price effect of the change in 1- $\tau$, I rely on the fact that the price of a home equity loan depends not only on $1-\tau$ but also on $r$, the interest rate, which for HELOCs is often variable. The cross-price effect of the home equity line price on giving is captured when $r$ changes but $1-\tau$ remains unchanged. Conversely, the cross-price effect of the giving price on home equity debt is captured by comparing households with the same price of home equity line but different net-of-tax rates. As will be elaborated in Sections III and V, the HELOC tax-price will be endogenous to the amount of repayment, so I will employ an instrument and run 3SLS regressions.

I use data from the Surveys of Consumer Finances (SCF). The SCF has detailed information on demographics, income, wealth, and education, and covers a long time period with several federal tax changes (see Appendix 3). ${ }^{6}$ I find evidence that each of the

\footnotetext{
${ }^{4}$ Other large tax expenditures are state and local taxes ( $\$ 251.66$ billion) and real estate taxes $(\$ 167.78$ billion).

${ }^{5}$ The Survey of Consumer Finances data that I use confirm this flexibility. While the survey usually asks for whether there is a fixed repayment amount per month on other types of loans, for HELOCs the survey simply does not ask this question (instead, only "typical payment" and frequency is asked).

${ }^{6}$ The SCF surveys ask households' ages, years of education, and the amounts of different kinds of assets and liabilities. It is not possible to obtain these information from administrative tax data. The main drawback with SCF is not observing the marginal tax rate and itemized deductions without error. I discuss how I impute them in Section IV.
} 
two activities, giving to charities and repaying HELOCs, responds to their own and to cross tax-prices. I examine two specifications, one with marginal tax-prices and the other with average tax-prices. I do the latter because Liebman and Zeckhause (2004) develops theory about and finds evidence that people may respond to average prices rather than marginal prices. My two specifications produce qualitatively similar results although the average price results are more precise. I find that each activity is reduced by an increase in its own price or a decrease in the other activity's price. Under the average tax-price specification, the estimated own price elasticity and cross price elasticity of giving are, respectively, -2.83 and 3.90, with p-values of $15.2 \%$ and $8.9 \%$. The own and cross price elasticities for HELOC are -5.38 and 1.49 , with p-values of $0.0 \%$ and $4.6 \%$. $^{7}$ Not all these estimates are significant at conventional levels. It is difficult to find a pair of deductions with different but measurable tax-prices. Studying those with HELOC deduction leaves me with a relatively small sample and results in relatively large standard errors.

The rest of this paper is divided into six sections. Section II reviews the literature. Section III constructs the tax-prices. Section IV describes the data. Section V gives the estimation results. In Section VI, I apply my estimates to the theory of ETI, develop new theoretical results, and discuss policy implications. Section VII concludes.

\section{Literature Review}

I examine the responsiveness of charitable giving and HELOC payments to their own and each other's tax-prices. There is no relevant literature on the sensitivity of HELOC payments to tax rates, but a large literature on the tax-price elasticity of charitable giving including Bakija and Heim (2011), Auten, Sieg and Clotfelter (2002), Reece and Zieschang (1985), and Friedberg and He (2015). These studies mostly find the tax-price elasticity of charitable giving to be around -1 . This literature shares the following four characteristics, which I adapt to my research purpose.

First, the tax-price of giving is defined as the amount of personal income foregone for each dollar given to charity, or 1 minus the marginal tax rate applied to taxable income at zero giving. In this paper, I similarly define the tax-price of giving, while the

\footnotetext{
${ }^{7}$ The Slutsky symmetry indicates that the two cross price elasticities should have the same sign, as they are here.
} 
tax-price for HELOC payments will be more involved. Second, I follow most studies in using a log-linear specification that regresses Log (giving amount) on Log (tax-price) together with other covariates. The coefficient for Log (tax-price) is thus the tax-price elasticity. Third, most studies except Friedberg and He (2015) restrict the sample to "exogenous itemizers", defined as taxpayers who have more non-charity deductions than their standard deduction, so that any giving on top of other deductions reduces taxable income and forgoes only $\$(1-\tau)$ of after-tax consumption for each additional dollar of giving. I similarly restrict my analysis to taxpayers who have more non-charity and nonHELOC-interest-payments deductions than their standard deduction.

Lastly, the literature on charitable deductions has treated all non-charity itemized deductions as exogenous. I move a step away from this by focusing on joint decisions about charity and HELOC repayment, and treat non-charity, non-HELOC deductions as exogenous. As in the charitable giving literature, I assume that the amount of giving and the amount of HELOC repayment are not otherwise correlated with their tax-prices because of unobserved preferences. I discuss this in more details later.

My research is also relevant to the ETI literature. Gruber and Saez (2002) find the overall ETI, defined as the elasticity of taxable income with respect to the net of tax rate $1-\tau$, to be 0.4 , implying a revenue maximizing tax rate of $71 \%$. Kopczuk (2005) finds that the ETI increases with individuals' access to deductions. For example, a tax system that allows more deductions will yield a higher ETI; in the cross-section, a household spending a larger proportion of income on tax-deductible commodities has a higher ETI. In Section VI and Appendix 2 I derive the precise relation between ETI and deductions, taking into account interactions among deductions. It shows that the ETI decreases in the tax-price elasticity of the deductible item and increases in the proportions of income spent on the deductions. Using the formula, in Section VI I show that, due to the possible substitutability between deductions, removing a subset of deductions does not necessarily increases revenue.

Appendices 1 and 2 provide a theoretical analysis of the ETI and review the literature on the ETI, labor supply elasticity, charitable giving elasticity, and "broad income" elasticity. "Broad income" is the sum of certain kinds of incomes and defined differently in different studies. The labor supply elasticity and broad income elasticity are 
not directly related to my research, but nonetheless in Appendix 2 I discuss them from the perspective of the ETI analysis.

\section{The Economic Model and Tax-Prices}

In this paper I estimate the own and cross tax-price elasticities of two tax-deductible activities. The critical empirical issue in choosing deductible activities to focus on is to find two that have different tax-prices. For this reason, I focus on giving to charities and making interest repayments on home equity lines of credit (HELOC). In this section I will develop a model to determine the two tax-prices. Before writing down the model, I discuss sources of substitutability between deductions and endogeneity issues.

\section{III.1 Background}

Different tax-deductible activities could be substitutes or complements for two reasons. First, people who need to borrow because they lack assets may cut down on other spending, and various forms of borrowing, such as borrowing on home collateral, and spending, such as charitable giving, are tax-preferred. Second, tax planning under the progressive tax system could also generate substitutability. For example, if a taxpayer wants to reduce taxable income by $x$ dollars, then allocating the $x$ dollars between interest payments and charitable giving makes the two activities substitutes.

Unobservable heterogeneity is a potential concern - some types of people might give more to charities and also pay down their debt more slowly. ${ }^{8}$ At first glance, this "type" issue, as it creates a negative correlation between giving and repayment in the cross section, will lead one to find a spurious substitutability between the two activities. However, this will not be an empirical concern as long as the "type" does not correlate with the tax-prices (which are functions of the marginal tax rate and the interest rate). I make a similar assumption to the rest of the literature estimating tax-price elasticities (for example Gruber and Saez 2002), that unobserved heterogeneity does not generate a correlation among tax expenditures and tax-prices, conditional on controls for income and wealth; however, I move beyond the literature in investigating interactions among

\footnotetext{
${ }^{8}$ Vice versa, there could be some types who like paying down their own debt faster and may not give much to charity.
} 
two of these tax expenditures instead of assuming that a single tax expenditure that is studied is uncorrelated with all others. ${ }^{9}$

\section{III.2 The Economic Model and the Tax-prices}

In this section I model the tax-prices for giving, $G$, and HELOC repayments, $Q$. Notice that $Q$ includes both interest and principal payments. I model both rather than just interest payments since the marginal tax rate affects principal payments too - in a given year, paying back the principal in this year rather than later reduces future interest payments, which are tax-deductible.

Based on the static model from Auten and Joulfaian (1996), I construct my model where future consumption enter the household's utility function (whereas Auten and Joulfaian let children's income enter an individual's utility function). ${ }^{10} \mathrm{D}$ denotes the amount of itemized deductions other than charitable giving $G$ and HELOC interest payments. Other consumption this year, which is $t=0$, including saving, is denoted by $C_{0}$. Let $\left\{C_{1}, C_{2} \ldots C_{n} \ldots\right\}$ denote the set of future yearly after-tax consumption levels. Let $B$ denote the HELOC balance and $r$ the interest rate. Under this notation, the first $B \cdot r$ dollars of repayment $Q$ is tax-deductible interest. A household solves the following problem (given other itemized deductions $D$ and income)

$$
\operatorname{Max}_{\{G, Q\}} U\left(C_{0}, G, D,\left\{C_{1}, C_{2} \ldots C_{n} \ldots\right\}\right)
$$

s.t. the budget constraint

Now consider the budget constraint. Let $I_{0}$ denote the household's total pre-tax income this year and $A G I$ the adjusted gross income. ${ }^{11}$ Then, the household's taxable income is $A G I-D-G-\operatorname{Min}(Q, B \cdot r)$; here $Q$ enters the calculation because a household may pay less than the interest due, in which case the deduction amount they can take will

\footnotetext{
${ }^{9}$ One can perhaps come up with stories of correlation between "type" and the marginal tax rate or the interest rate, but these are likely to be rare scenarios that do not make a case for a reasonable identification threat. For example, suppose that among households with similar income, wealth and other demographics which are observable, people who are much more generous than others in donating may have been so enthusiastic in giving that they were occasionally overstretched and missed debt payments due, worsening their credit record. As a result, they have to pay high interest rate for borrowing on home equity. This would cause a positive correlation between interest rates and charitable giving. However, this may happen only rarely.

${ }^{10}$ In Auten and Joulfaian (1996), utility is determined by own consumption, life-time charitable contributions, charitable bequests, and child heirs' own income and gifts/bequests from the individual. In this paper I do not consider offspring or bequests.

${ }^{11}$ I omit the personal exemption $E$ to simplify notation.
} 
be $Q=\operatorname{Min}(Q, B \cdot r)<B \cdot r .{ }^{12}$ Let $T($.$) denote the tax function applied to taxable income,$ so the tax paid by the household is then $T(A G I-D-G-\operatorname{Min}(Q, B \cdot r))$. Then, the budget constraint for the current period's spending is:

$$
D+C_{0}+G+Q=I_{0}-T(A G I-D-G-\operatorname{Min}(Q, B \cdot r))
$$

Now, I rearrange Equation (1) to let the tax-prices appear. ${ }^{13}$ First, I decompose the taxes on the right hand side of (1) into two parts as

$$
T(A G I-D-G-\operatorname{Min}(Q, B \cdot r))=T(A G I-D)-T \mathrm{~s} .
$$

On the right hand side of (2), $T(A G I-D)$ is the tax liability that would apply if the household gives zero to charities, repays zero on their HELOC and thus has a taxable income of $A G I-D$. Suppose that such taxable income puts the household in the tax bracket that has a marginal tax rate of $\tau$. Then, a dollar of giving or HELOC repayment will reduce taxable income from $A G I-D$ and reduce the tax liability by $\tau$ this year. Therefore $T s$ on the right hand side of (2) is the amount of taxes reduced in this year from giving and repaying HELOC interest and $\mathrm{I}$ write it out as $T \mathrm{~s}=[G+\operatorname{Min}(Q, B \cdot r)] \cdot \tau .^{14}$ With this and (2), I transform (1) to

$$
C_{0}+(1-\tau) G+(1-\tau) \operatorname{Min}(Q, B \cdot r)+(Q-B \cdot r)^{+}=I_{0}-T(A G I-D)-D,
$$

where $(Q-B \cdot r)^{+}$is the part of $Q$ exceeding $B \cdot r$, or principal payments. The coefficient (1$\tau)$ on $G$ is the tax-price of charitable giving, $p_{\mathrm{g}}$. The coefficients preceding $\operatorname{Min}(Q, B \cdot r)$ and $(Q-B \cdot r)^{+}$, i.e. $(1-\tau)$ and 1 , are not yet the tax-prices of, respectively, interest payments and principal payments. A dollar repaid now on average reduces after-tax consumption by $1-\tau$ (if it is a dollar of interest payment) or 1 (if it is a dollar of principal payment). Meanwhile, if it is repaid next year, it will have grown to $1+r$, with 1 regarded as principal and $r$ as interest and reduce after-tax consumption by $1+r(1-\tau)$ then. In general, repaying a dollar in $n$ years means forgoing $(1+r)^{n-1}+(1+r)^{n-1} r(1-\tau)$ of after-

\footnotetext{
${ }^{12}$ For some but not all HELOCs, this underpayment may lead to a HELOC freeze (no more drawing of funds allowed) or a reduction (reduced credit limit), or even put the home at risk of foreclosure (Federal Reserve Board 2012h; Federal Trade Commission 2012; Citizens Financial Group, Inc 2015).

${ }^{13}$ Only interest on the first $\$ 100,000$ of home equity debt balance is tax deductible. The effect on (1) and the subsequent equations is minimal: for households exceeding the $\$ 100,000$ limit on balance (about $10 \%$ of my sample), simply replace $B \cdot r$ with $\$ 100,000 * r$ (or a smaller amount if there is a second mortgage; see Appendix 4). My empirical results take this into account.

${ }^{14}$ I am aware that $G+\operatorname{Min}(Q, B \cdot r)$ may become larger enough and taxable income may drop below the $\tau$ bracket. Above this amount, taxes reduced from an additional dollar spent on $G+\operatorname{Min}(Q, B \cdot r)$ will be smaller than $\tau$. Here, I make the simplification of only considering the marginal tax rate associated with the first dollar of $G+\operatorname{Min}(Q, B \cdot r)$. This is similar to some charitable giving studies such as Barrett (1991).
} 
tax consumption then. So, the price of a dollar of HELOC repayment should be defined as current consumption forgone, which is $1-\tau$ for interest payments or 1 for principal payments, minus the benefit of saving future interest that would otherwise accrue on this dollar. Define the future benefit as the after-tax interest saved compared to repaying next year, or $r \cdot(1-\tau)$, so the final expressions of the tax-prices are $p_{i n}=1-\tau-r \cdot(1-\tau)$ for interest payments and $p_{p r}=1-r \cdot(1-\tau)$ for principal payments. It follows that the marginal tax-price at $q=Q$ is

$$
p_{q}= \begin{cases}p_{\text {in }}=1-\tau-r(1-\tau), & Q<B \cdot r \\ p_{p r}= & 1-r(1-\tau),\end{cases}
$$

In my empirical analysis, I will examine the effect of the marginal prices, $p_{g}$ and $p_{q}$, on $G$ and $Q$. From Expression (4) it is clear that $p_{q}$ depends on $Q$, so later when I regress the $\log$ of $Q$ on the $\log$ of $p_{q}$, I will instrument for the $\log$ of $p_{q}$ with the $\log$ of $p_{\text {in }}$ (the first line of Expression (4)). It is a valid instrument as it correlates with $p_{q}$ but does not depend on $Q$.

\section{III.3 Average tax-prices}

In light of the "schmeduling theory" by Liebman and Zeckhauser (2004), I develop another specification for HELOCs' tax-price. People may respond to the average taxprice (instead of the marginal tax price), in the way of the "ironing" approach that Liebman and Zeckhauser find evidence of in their analysis of schmeduling. They formally test for ironing behavior in households' responses to the introduction of child credit, and estimate that 54 percent of taxpayers are ironers.

Therefore, I will also consider the effect of average tax-prices, $p_{h}=\frac{\sum_{q=1}^{Q} p_{q} \cdot q}{Q}$ (with $p_{q}$ being the marginal tax-price defined in the previous subsection) i.e. ${ }^{15}$

$$
p_{h}=\left\{\begin{aligned}
1-\tau-r(1-\tau), & Q<B \cdot r \\
1-\frac{B \cdot r \cdot \tau}{Q}-r(1-\tau), & Q \geq B \cdot r .
\end{aligned}\right.
$$

In my study, an ironer would misperceive the tax benefit falling on interest payment dollars as spreading over all payment dollars. As shown in Figure 1, the actual tax-price schedule for HELOC payment $Q$, the "marginal price" line (defined in Equation (4)),

\footnotetext{
${ }^{15}$ Due to the $\$ 100,000$ on the amount of equity debt that is tax deductible, about $4 \%$ of the households have a tax-price that differs from (5). See Appendix 4.
} 
would be misperceived as the "average price" line (defined in Equation (5)). The lines show that the average price is always equal to or smaller than the marginal price, implying that an ironer pays off the line of credit faster.

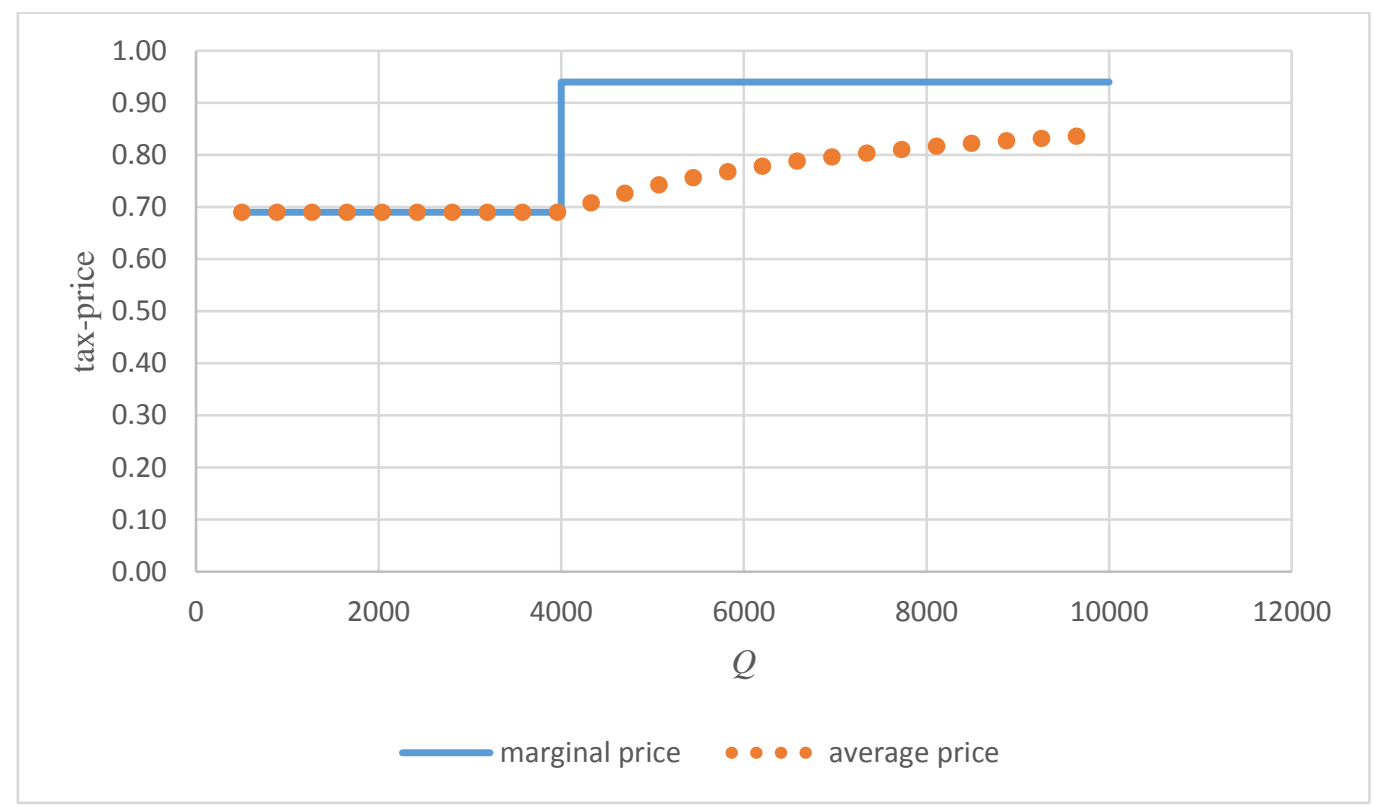

Figure 1 marginal and average tax-prices of HELOC payment

In this paper I do not formally test for ironing behavior. Rather, I estimate models using both average and marginal prices, noting that the average price model is justified by the ironing theory.

\section{The Data}

\section{IV.1 The Data Source and Sample Selection}

I use data from the Survey of Consumer Finances (SCF), a repeated cross-section conducted every three years between 1989-2007 with detailed financial data for approximately 4,000 households each year. I exclude the 1983, 1986 and 2010 SCF because they lack necessary information. ${ }^{16}$ These surveys give me a total of 29,031 observations. The surveys oversampled high income individuals so as to obtain reasonable sample sizes of the wealthy, and I use survey weights to make sample statistics and regression results nationally representative. As complement for results in the main text (Section V), I present the unweighted regression results in Appendix 7. The

\footnotetext{
${ }^{16}$ The 1986 and 2010 SCF do not report Adjusted Gross Income, which makes the computation of the marginal tax rate less accurate. The 1983 SCF does not report charitable giving.
} 
weighted and unweighted results are broadly similar; in particular, the price elasticity estimates are somewhat smaller but have the same signs with the weighted results.

Following the literature that I described earlier, I restrict my sample to "exogenous itemizers", though my definition is broader than for taxpayers that focus on a single deduction. Exogenous itemizers are defined as taxpayers who have more non-charity and non-HELOC-interest-payments than their standard deduction. It is under this restriction that any giving and repayment on top of other deductions change tax liabilities. Further, I restrict my sample to exogenous itemizers who have a HELOC with positive outstanding balance, so that they face the choice on how much to give and how much to repay on HELOCs. This means that the analysis is restricted to people who have elected to borrow. ${ }^{17}$

The sample selection leaves 1,103 observations. Out of the 29,031 observations in the unrestricted sample, about $16 \%$ did not file a tax return in the year surveyed, and $47 \%$ filed tax returns but are not exogenous itemizers. Of the remaining $36 \%$, or 10,501 observations, only about one tenth had a HELOC in the year surveyed.

\section{IV.2 The Variables}

In my model, the left-hand side variables are charitable giving and payments on the HELOC balance. The key right-hand side variables are the tax-prices $1-\tau, p_{q}$ and $p_{h}$ specified in equations (4) and (5). My other right-hand side variables, which I include for reasons discussed below, control for wealth, income, age, marital status and years of education. I construct the variables as follows.

My left-hand side variables are charity and payment. Following studies on charitable giving such as Bakija and Heim (2011), I add \$10 to each giving amount to get charity. I

\footnotetext{
${ }^{17}$ Perhaps someone who borrows to finance current consumption may not be very interested in donating to charity to help others. However, summary statistics in Section V suggest that households in my sample have a similar distribution of donation amounts with the broader group of all exogenous itemizers. In addition to this concern of the selected sample being unrepresentative of the broader population in terms of the willingness of giving (external validity), one may also worry about sample selection bias; perhaps estimated price elasticities are not unbiased estimates of the effects of exogenous changes in tax-prices even for the selected population of HELOC borrowers (internal validity) because an unobservable factor that affects the choice of whether to borrow also correlates with both the tax-prices and donation/HELOC repayment amounts. However, it is difficult to imagine such factors that threaten the internal validity. In Appendix 5 I try to construct a story for such a factor; nonetheless, I conclude that it is at most a minor issue.
} 
do this in order to take logs even for zero donations. ${ }^{18}$ I also try estimating a tobit model later, though it does not work particularly well. The total payment to the HELOC, payment, includes both principal and interest payments. For the 5 observations with zero payment, I take logs after treating them as repaying $\$ 10$.

The key right-hand side variables are the tax-prices of giving and HELOC repayment. $p_{g}$ is the tax-price of giving. It is the after-tax cost of giving to charity, defined as $1-\tau$, with $\tau$ being the household's marginal tax rate (MTR). As discussed in the economic model in Section III.3, the $\tau$ here is the marginal tax rate applied to taxable income at zero giving and zero interest payment to HELOC. I do not observe a household's exact MTR or taxable income prior to giving and paying HELOC interests, so I calculate them using the equation

taxable income prior to giving and paying HELOC interests $=A G I-$ exemptions - itemized deductions except giving and HELOC interests

I observe $A G I$ in the data. Exemptions and standard deduction depend on the filing status and the number of dependents. ${ }^{19}$ I observe whether the filing status is married filing jointly (the majority) or not. Number of people in the Primary Economic Unit (PEU), marital status, whether a respondent lives with a spouse/partner, and whether the spouse/partner is included in the PEU allow me to tell which one of the other three filing status the respondent falls in, and allow me to calculate the number of dependents. ${ }^{20}$

I observe some of the most important itemized deductions in addition to the ones I consider, but not all. Studies that use survey data to estimate the tax-price of charitable giving also have to impute itemized deductions (see footnote), and the SCF offers much

\footnotetext{
${ }^{18}$ A robustness check by Bakija and Heim (2011) shows that this specification works well. They analyzed the sensitivity of estimates to the size of the constant added to charity by varying the value of this constant and then run regressions. The values tried include $\$ 1, \$ 100$, and $\$ 1000$.

${ }^{19}$ Although standard deduction is not in the taxable income formula, I nevertheless need to use it here. This is because, as mentioned earlier, I restrict my sample to "exogenous itemizers", i.e. people whose itemized deductions except giving and HELOC interests are larger than their standard deduction.

${ }^{20}$ In SCF, the PEU consists of an economically dominant single individual or couple (married or living as partners) in a household and all other individuals who are financially dependent on that individual or couple. Therefore, the number of people in PEU combined with the information on whether the respondent has a spouse or partner and whether the spouse or partner is included in PEU allows me to calculate the number of dependents and thus whether a respondent is married filing separately, single or head of household. There are also tens of observations of widow(er)s who may qualify to be in a fifth status, "qualifying widow(er)s with dependent child". I simply exclude these observations for simplicity.
} 
more concrete information for doing so than many other types of surveys. ${ }^{21}$ Therefore, I impute itemized deductions except giving and HELOC interests as follows. They are the sum of the mortgage interest deduction except that on HELOC, state income tax deduction, real estate tax deduction and vehicle property tax deduction. ${ }^{22}$ I observe the amount of real estate tax. I compute the mortgage interest deduction from information on the loan balances at the time of the survey, the annual interest rates and total mortgage payments per period. ${ }^{23}$ The state income tax rate varies by state and the vehicle property tax rate varies by county, but I do not observe the respondents' states or counties.

Therefore, I set the state income tax rate based the respondent's total income and based on Davis et al. (2009) which reports the national averages of all states' income tax rates for different income groups. About 20 states have vehicle property taxes. I extensively surveyed these states and their counties' websites online, and set the national average at $0.44 \%$, applied to the value of vehicles reported in the data.

The tax-price of HELOC repayment is specified in Equations (4) and (5) in its marginal and average price forms. Their expressions involve the marginal tax rate $\tau$, the HELOC interest rate $r$, and payments $Q$. The SCF reports $r$ and $Q$.

I define and control for the covariates balance, wealth, disposable income, $u, e d u$, married, age and its dummies. balance is the balance of the HELOC at the beginning of the relevant tax year. wealth is calculated as the sum of all assets less the sum of all liabilities. The SCF surveys different types of assets and liabilities thoroughly. disposable

\footnotetext{
${ }^{21}$ Among other surveys, the Consumer Expenditure Survey provides relatively detailed records for such imputation, while other surveys only allow for assigning itemized deduction amounts proportional to income. Examples of the former are Reece (1979) and Reece and Zieschange (1985) who add up all interest payments, state and local taxes paid, and medical deductions (not considering real estate and vehicle property taxes). Examples of the latter are Tiehen (2001) using the Independent Sector Surveys on Giving and Volunteering and Boskin and Feldstein (1977) using the National Survey of Philanthropy. Meanwhile, studies that use administrative data cannot consider the possible itemization behavior of non-itemizers at all.

${ }^{22}$ The itemized deductions I am missing are medical and dental expenses in excess of $7.5 \%$ of AGI, home mortgage deductible points, investment interest, casualty and theft losses, job expenses and other miscellaneous deductions. According to IRS statistics, for 2010, the non-exclusive percentages of taxpayers that took these 6 types of deductions were, respectively, $7.3 \%, 2.0 \%, 1.1 \%, 0.07 \%$ and $9.07 \%$. In addition, I also miss non-vehicle personal property tax deduction, and the IRS statistics does not report categories of personal property tax deductions. However, the impact of missing this deduction should be very small, since vehicles are the major component of personal properties (which is defined not to include real properties).

${ }^{23}$ Specifically, I compute the interest payment in the relevant tax year by first calculating the balance at the beginning of the tax year and then multiply the balance by the annual interest rate.
} 
income is AGI less tax liabilities at zero giving and payment to HELOC and other deductions. I control for wealth and income in order to avoid omitted variable bias, as they could affect both the amount one gives/pays on debt and the interest rate one gets which enters HELOC repayment's tax-price. Besides, income affects the marginal tax rate, and controlling for income separately helps isolate exogenous variation in the tax schedule arising from the arbitrary location of tax kinks and from tax reforms (Gruber and Saez 2002). ${ }^{24}$

$u$ is the annual national unemployment rate obtained from the website of Bureau of Labor Statistics. I control for this to avoid omitted variable bias. When the economy is bad and the unemployment rate is high, people might give less or repay less because they have less income. Meanwhile, the Fed may target a lower interest rate when the unemployment rate is higher (Nechio 2011). This means that the unemployment rate has an effect on $p_{q}$ and $p_{h}$, which contain interest rates. I define age as the household head's age. I also define two age dummies, one for households with age between 40 (included) and 60, and the other one for age at or above 60. edu is a household head's years of education. married is a dummy variable, equal to 1 for married households and 0 for others.

For the variables charity, payment, distance, wealth, and disposable income, all values are in 2011 dollars.

\section{IV.3 Summary Statistics}

I report summary statistics for my SCF sample of 1,103 exogenous itemizers with HELOC balances in Table 1. As mentioned in an earlier footnote, I discuss sample selection in Appendix 5. In Table 1, $r$ is the HELOC interest rate. $p_{g}$ is the tax-price of giving, equal to $1-\tau$. The marginal tax rate $\tau$ has 10 different values falling between 0 and $39.6 \%$. The marginal tax rate reaches the maximum of $28 \%, 31 \%, 33 \%, 35 \%$, or $39.6 \%$, depending on the year, for $6.0 \%$ of the households in the sample. ${ }^{25} p_{i n}, p_{q}$, and $p_{h}$ are,

\footnotetext{
${ }^{24}$ A potential concern is that unobservable heterogeneity may determine both income and giving. For example, someone with a strong sense of social responsibility may both work hard and be selfless, and as a result, earns more income and also gives more. However, the literature suggests that it is more important to deal with omitted variable bias by including income controls than to worry about unobservable heterogeneity.

${ }^{25}$ As mentioned earlier, the surveys oversampled high income individuals and provide survey weights to inform the degree of oversampling. The $6 \%$ is the proportion computed using the survey weights; in other words, it is a nationally representative statistic. Without weighting, the proportion is $18.7 \%$; in other words,
} 
respectively, the tax-price of interest payment, the marginal tax-price of all payment, and the average tax-price of all payment, defined by equations (4), and (5).

Table 1 Summary Statistics

\begin{tabular}{|c|c|c|c|c|c|}
\hline & Label & Mean & Median & $\mathrm{P} 75 \%$ & P90\% \\
\hline Charity & charitable giving & 3,564 & 1,303 & 3,339 & 7,439 \\
\hline Payment & HELOC repayment & 7,677 & 5,342 & 9,069 & 15,174 \\
\hline$\tau$ & marginal tax rate & $23 \%$ & $25 \%$ & $28 \%$ & $31 \%$ \\
\hline$p_{g}$ & tax-price of giving & 0.77 & 0.75 & 0.85 & 0.85 \\
\hline$r$ & interest rate & $7.9 \%$ & $8.0 \%$ & $9.5 \%$ & $11.0 \%$ \\
\hline$p_{\text {in }}$ & $\begin{array}{l}\text { tax-price of HELOC } \\
\text { interest }\end{array}$ & 0.71 & 0.69 & 0.77 & 0.80 \\
\hline$p_{q}$ & $\begin{array}{l}\text { HELOC marginal } \\
\text { tax-price }\end{array}$ & 0.91 & 0.94 & 0.95 & 0.97 \\
\hline$p_{h}$ & $\begin{array}{l}\text { HELOC average tax- } \\
\text { price }\end{array}$ & 0.82 & 0.83 & 0.88 & 0.93 \\
\hline balance & HELOC balance & 51,500 & 31,822 & 58,683 & 107,232 \\
\hline wealth & wealth & 990,888 & 442,409 & 927,725 & $2,054,249$ \\
\hline income & disposable income & 120,847 & 90,653 & 136,477 & 206,292 \\
\hline age & age & 48 & 47 & 55 & 62 \\
\hline$e d u$ & years of education & 15 & 16 & 17 & 17 \\
\hline$u$ & unemployment rate & 5.3 & 5.5 & 6 & 6.1 \\
\hline
\end{tabular}

This table reports the summary statistics for a subsample of the Survey of Consumer Finances between 1989 and 2007 that I use for regressions. This subsample consists of 1,103 households with positive income and wealth whose largest line of credit is secured by home equity with positive balance and whose tax filing status is not married filing separately. The means and medians are weighted with the survey weights (variable X42001 in the SCF datasets.) All monetary values are in 2011 dollars.

The 10th and 90th percentiles of the HELOC interest rate $r$ are $4.25 \%$ and $11 \%$. The ratio of HELOC payment to balance has a median of 0.16 . The distribution of charitable giving is right-skewed. The median giving level is $\$ 1,303$ and $29.6 \%$ of the sample give zero; but at the $75 \%, 90 \%$, and $99 \%$ percentiles, the giving levels are, respectively, $\$ 3,339, \$ 7,439$ and $\$ 33,389.80 .3 \%$ of the households are married, $14.7 \%$ are single and $5.0 \%$ have a head of household filing status. ${ }^{26}$ In Appendix 6 I compare statistics in this

$1,103 \times 18.7 \%=206$ households in my sample have a top marginal tax rate. For other proportions in the rest of this subsection, the weighted and unweighted figures are similar and I only present the weighted proportions.

${ }^{26}$ The sample covers 7 years, and the years of 2003 and 2006 contribute about $47 \%$ of all observations, reflecting increased use of HELOCs in the 2000s. However, this increase does not mean that lenders began to give out HELOCs to many households with lower ability to repay. In fact, in my sample households from these two years have higher real wealth and income than those from earlier years. 
table with their counterparts in the broader sample that is not restricted to HELOC borrowers but that are still exogenous itemizers with positive income and wealth. Overall, my smaller sample is a little wealthier, while the samples have similar distributions of charitable giving.

Table 2 lists the means of giving and repayment by low, medium, and high levels of the average tax-prices of giving and HELOC, $p_{g}$ and $p_{h}$. It displays how (charity, HELOC payment) vary with $\left(p_{g}, p_{h}\right)$, without controlling for other covariates from Table 1.

Holding the level of $p_{h}$ constant, both charity and payment fall with $p_{g}$. Holding the level of $p_{g}$ constant, payment rises with $p_{h}$ while charity does not systematically vary with $p_{h}$.

Table 2 The means of charity and payment by tax-price brackets

\begin{tabular}{crrrrrrr}
\hline \hline & \multicolumn{2}{c}{$p_{g} \leq 0.69$} & \multicolumn{2}{c}{$0.69<p_{g}<0.85$} & & \multicolumn{2}{c}{$p_{g} \geq 0.85$} \\
\cline { 2 - 8 } & charity & payment & charity & payment & charity & payment \\
$p_{h} \leq 0.7907$ & 12,616 & 9,587 & 2,968 & 6,671 & 616 & 4,467 \\
$0.7907<p_{h} \leq 0.8614$ & 7,779 & 13,398 & 2,396 & 7,066 & 1,480 & 5,155 \\
$p_{h}>0.8614$ & 13,987 & 23,653 & 2,883 & 9,653 & 1,683 & 5,829 \\
\hline
\end{tabular}

The brackets for $p_{h}$ are chosen as follows: 0.7907 is the 33 th percentile and 0.8614 is the $66^{\text {th }}$ percentile. $p_{g}$ is a discrete variable and does not allow for brackets with $33 \%$ probability mass.

\section{Empirical Specification and Results}

\section{V.1 Log-linear regression specification with marginal tax-prices}

I jointly regress giving $G$ and HELOC payment $Q$ on their own and each other's marginal tax-prices. In other words:

$$
\begin{aligned}
& \log (G)=\beta_{0}+\beta_{1} \log \left(p_{g}\right)+\beta_{2} \log \left(p_{q}\right)+X^{\prime} B+\varepsilon_{1} \quad \ldots(6) \\
& \log (Q)=\gamma_{0}+\gamma_{1} \log \left(p_{q}\right)+\gamma_{2} \log \left(p_{g}\right)+X^{\prime} C+\varepsilon_{2} \quad \ldots(7)
\end{aligned}
$$

$X$ includes the log of wealth, the log of income, age, dummies for age groups, years of education, unemployment rate, and the log of balance, where balance is the beginning balance in a year. The error terms $\varepsilon_{1}$ and $\varepsilon_{2}$ are allowed to be correlated, in order to account for the correlation between giving and HELOC payment that results from unobserved factors such as unexpected medical expenses, say, or preferences for giving or paying debt. $p_{g}$ is the tax-price of charitable giving, $1-\tau . \log \left(p_{q}\right)$ is endogenous 
because $p_{q}$ depends on the amount of the HELOC payment $Q$, as revealed in Equation (4). ${ }^{27}$ Therefore I instrument for $\log \left(p_{q}\right)$. The instrument is $\log \left(p_{\text {in }}\right)$, with $p_{\text {in }}$ being the price of interest payment specified in Equation (4). $\log \left(p_{i n}\right)$ correlates with $\log \left(p_{q}\right)$ and is exogenous. In particular, it does not depend on $Q$.

I ran a 3SLS regression. This method has three steps. In the first step, it regresses $\log \left(p_{q}\right)$ on its instrument, $\log \left(p_{i n}\right), \log \left(p_{g}\right)$ and other control variables, and obtains the predicted values $\left.\widehat{\log \left(p_{q}\right.}\right)$. Then in the second and the third steps, instead of just running OLS separately for (6) and (7) as the second stage of a 2SLS regression does, it uses seemingly unrelated regression. This allows for a correlation between $\boldsymbol{\varepsilon}_{\mathbf{1}}$ and $\boldsymbol{\varepsilon}_{\mathbf{2}}$. Specifically, in the second step, it estimates (6) and (7) separately using OLS to obtain residuals, and then uses the residuals to estimate $\widehat{\boldsymbol{\Sigma}}$, the $2 * 2$ variance covariance matrix of $\left(\varepsilon_{1}, \varepsilon_{2}\right)$. In the third step, it estimates the coefficients in (6) and (7) using $\widehat{\boldsymbol{\Sigma}}$ with the Feasible GLS method. ${ }^{28}$

\section{V.2 Log-linear regression specification with average tax-prices}

The specification with average prices is the same with that in Section V.1, except that I replace the marginal tax-price of HELOC repayment, $p_{q}$, with the average tax-price, $p_{h}$. They are defined in Equations (4) and (5). This regression uses the 3SLS method as well and has the same instrument, $\log \left(p_{i n}\right)$.

\section{V.3 Regression results from both specifications}

Table 3 shows the regression results for the marginal price specification (Section $V .1$ ) and for the average price specification (Section V.2). The first stage results show that the instruments are strong (see Appendix 8).

Under the marginal price specification, the two own-price elasticities, -1.21 (not statistically significant, p-value 44.2\%) and -9.24 (significant, p-value 0.0\%), and the cross effect of the HELOC repayment's price on giving, 6.65 (p-value 8.5\%), have the expected signs, while the cross-price effect of giving's price $p_{g}$ on HELOC repayment is negative but insignificant, -0.76 (p-value $34.0 \%$ ).

\footnotetext{
${ }^{27}$ In contrast, $p_{g}$ is not a function of $G$ or $Q$, so it is not endogenous.

${ }^{28}$ As the two equations (15) and (16) have the same set of regressors and the same instrument, the 3SLS method produces the same results with the 2SLS method.
} 
Under the average price specification, all 4 price parameter estimates have the expected signs and p-values are similar or smaller: the own-price elasticities, $\partial \operatorname{Ln}(\operatorname{charlt}) / \partial \operatorname{Ln}\left(p_{g}\right)=-2.83$ and $\partial \operatorname{Ln}($ payment $) / \partial \operatorname{Ln}\left(p_{h}\right)=-5.38$ are negative (p-values $15.2 \%$ and $0.0 \%$ ), and the cross-price effects, $\partial \operatorname{Ln}(\operatorname{charit}) / \partial \operatorname{Ln}\left(p_{h}\right)=3.90$ and $\partial \operatorname{Ln}($ payment $) / \partial \operatorname{Ln}\left(p_{g}\right)=1.49$ are positive (p-values $8.9 \%$ and $4.6 \%$ ). The narrower confidence intervals suggest that the average price model fits the data better than does the marginal price model.

In various respects, the average price specification works better than the marginal price specification. The marginal price specification and the average price specification produce similar estimates for three of the four key parameters. Under either specification, the two own price elasticities are negative and the cross price elasticity of charitable giving with respect to HELOC repayment's tax-price is positive, with two of the three elasticities significant at the $10 \%$ level. The own and cross price elasticities with respect to $p_{q}$ (marginal price), -9.24 and 6.65, are larger in absolute value than those with respect to $p_{h}$ (average price), -5.38 and 3.90 .

The two specifications produce different estimates for the cross price elasticity of HELOC repayment with respect to giving's tax-price. The marginal price specification produces an insignificant negative estimate of -0.76 (standard error $=0.80$, pvalue $=34.0 \%$ ), while the average price specification produces a significant positive estimate of 1.49 (standard error $=0.75, \mathrm{p}$-value $=4.6 \%$ ). They are statistically different at the $5 \%$ level. ${ }^{29}$ A positive sign for this cross elasticity, together with the positive sign of the cross price elasticity of giving with respect to HELOC's tax-price (under either specification), suggests that giving and HELOC repayment are substitutes. A negative sign is difficult to interpret as it differs from the positive sign of the other cross elasticity. In this paper I do not formally test whether households more often respond to marginal prices (rational) or average prices (ironing). ${ }^{30}$ However, in the policy implication section

\footnotetext{
${ }^{29}$ Roughly, their difference is $1.49-(-0.76)=2.25$ with a standard error of $\sqrt{0.80^{2}+0.75^{2}}=1.10$ and a tstatistic of 2.05. As $p_{g}$ and $p_{h}$ are positively correlated by construction, the covariance between the two estimates should be positive. This will only make the difference's standard error even smaller and the difference more significant.

${ }^{30}$ Although I do not formally test for ironing, I would like to emphasize that I do not observe obvious bunching at paying exactly the amount of interest due (Appendix 9). This can be regarded as evidence of ironing. In their child credit analysis, Liebman and Zeckhauser (2004) point out that the rational model
} 
Table 3 Regression Results

\begin{tabular}{|c|c|c|c|c|c|c|}
\hline \multirow[b]{2}{*}{ Regressors } & \multicolumn{2}{|c|}{ Marginal Price } & \multicolumn{2}{|c|}{ Average Price } & \multicolumn{2}{|c|}{ Regular Giving Elasticity } \\
\hline & $\begin{array}{l}\text { Estimate } \\
\text { (Standard Error) }\end{array}$ & $\mathrm{p}$-value & $\begin{array}{l}\text { Estimate } \\
\text { (Standard Error) }\end{array}$ & $\mathrm{p}$-value & $\begin{array}{l}\text { Estimate } \\
\text { (Standard Error) }\end{array}$ & $\mathrm{p}$-value \\
\hline \multicolumn{7}{|l|}{ The $\operatorname{Ln}$ (charit) equation } \\
\hline Intercept & $-12.93(2.25)^{* * *}$ & $0.0 \%$ & $-12.26(2.24) * * *$ & $0.0 \%$ & $-11.12(2.38)^{* * *}$ & $0.0 \%$ \\
\hline $\operatorname{Ln}\left(p_{\mathrm{g}}\right)$ & $-1.21(1.57)$ & $44.2 \%$ & $-2.83(1.97)$ & $15.2 \%$ & $-2.08(1.62)$ & $20.1 \%$ \\
\hline $\operatorname{Ln}\left(p_{q}\right)$ & $6.65(3.86)^{*}$ & $8.5 \%$ & & & & \\
\hline $\operatorname{Ln}\left(p_{h}\right)$ & & & $3.90(2.29)^{*}$ & $8.9 \%$ & & \\
\hline $\operatorname{Ln}($ wealth $)$ & $0.28(0.08)^{* * *}$ & $0.1 \%$ & $0.27(0.08) * * *$ & $0.1 \%$ & $0.34(0.08) * * *$ & $0.0 \%$ \\
\hline $\operatorname{Ln}($ income $)$ & $0.68(0.26)^{* * *}$ & $0.8 \%$ & $0.60(0.25)^{* *}$ & $1.7 \%$ & $0.45(0.27)$ & $10.1 \%$ \\
\hline Dummy for middle aged & $0.36(0.28)$ & $20.5 \%$ & $0.43(0.26)$ & $10.2 \%$ & $0.45(0.26)^{*}$ & $9.1 \%$ \\
\hline Dummy for the elder & $0.82(0.51)$ & $10.9 \%$ & $0.85(0.50)^{*}$ & $8.9 \%$ & $0.83(0.50)^{*}$ & $9.6 \%$ \\
\hline Age & $0.01(0.02)$ & $37.5 \%$ & $0.01(0.02)$ & $46.9 \%$ & $0.01(0.01)$ & $39.2 \%$ \\
\hline Years of education & $0.21(0.04)^{* * *}$ & $0.0 \%$ & $0.20(0.04)^{* * *}$ & $0.0 \%$ & $0.20(0.09)^{* *}$ & $4.6 \%$ \\
\hline Married & $0.61(0.22)^{* * *}$ & $0.7 \%$ & $0.64(0.22)^{* * *}$ & $0.4 \%$ & $0.75(0.22)^{* * *}$ & $0.1 \%$ \\
\hline Ln(balance) & $0.29(0.13)^{* *}$ & $2.4 \%$ & $0.32(0.14)^{* *}$ & $2.0 \%$ & $0.18(0.09)^{* *}$ & $4.6 \%$ \\
\hline Unemployment rate & $0.09(0.09)$ & $33.3 \%$ & $0.10(0.09)$ & $28.4 \%$ & $0.15(0.08)^{* *}$ & $6.9 \%$ \\
\hline \multicolumn{7}{|l|}{ The Ln(payment) equation } \\
\hline Intercept & $2.64(1.19)^{* *}$ & $2.7 \%$ & $1.91(1.03)^{*}$ & $6.3 \%$ & & \\
\hline $\operatorname{Ln}\left(p_{q}\right)$ & $-9.24(1.94)^{* * *}$ & $0.0 \%$ & & & & \\
\hline $\operatorname{Ln}\left(p_{h}\right)$ & & & $-5.38(0.88)^{* * *}$ & $0.0 \%$ & & \\
\hline $\operatorname{Ln}\left(p_{\mathrm{g}}\right)$ & $-0.76(0.80)$ & $34.0 \%$ & $1.49(0.75)^{* *}$ & $4.6 \%$ & & \\
\hline $\operatorname{Ln}($ wealth $)$ & $0.12(0.05)^{* *}$ & $1.8 \%$ & $0.14(0.04)^{* * *}$ & $0.0 \%$ & & \\
\hline Ln(income) & $-0.22(0.14)$ & $11.0 \%$ & $-0.10(0.11)$ & $36.7 \%$ & & \\
\hline Dummy for middle aged & $0.26(0.16)^{*}$ & $9.6 \%$ & $0.16(0.12)$ & $19.7 \%$ & & \\
\hline Dummy for the elder & $0.06(0.29)$ & $83.2 \%$ & $0.02(0.22)$ & $92.6 \%$ & & \\
\hline Age & $0.00(0.01)$ & $79.2 \%$ & $0.01(0.01)$ & $39.1 \%$ & & \\
\hline Years of education & $-0.01(0.02)$ & $63.1 \%$ & $-0.00(0.02)$ & $98.0 \%$ & & \\
\hline Married & $0.40(0.13)^{* * *}$ & $0.2 \%$ & $0.36(0.10)^{* * *}$ & $0.0 \%$ & & \\
\hline Ln(balance) & $0.47(0.06)^{* * *}$ & $0.0 \%$ & $0.43(0.05)^{* * *}$ & $0.0 \%$ & & \\
\hline Unemployment rate & $0.08(0.05)$ & $14.2 \%$ & $0.07(0.04)^{*}$ & $7.2 \%$ & & \\
\hline \multicolumn{7}{|c|}{$\begin{array}{l}\text { Notes: } \mathrm{N}=1,103 \quad * * * \text { Significant at } 1 \% \text { level } * * \text { significant at } 5 \% \text { level } * \text { significant at } 10 \% \text { level } \\
\text { This table presents results for the two-equation regressions of } \mathrm{Ln}(\mathrm{charity}+10) \text { and } \mathrm{Ln} \text { (payment), defined in the text, on a } \\
\text { group of covariates. The weights for the regression are used to make the results nationally representative. The sample } \\
\text { consists of households who are "exogenous itemizers" (defined in the text) and whose largest line of credit is a home } \\
\text { equity line of credit with a positive balance. The observations are drawn from the Surveys of Consumer Finances between } \\
1989 \text { and } 2007 \text {. }\end{array}$} \\
\hline
\end{tabular}

(Section VI), I will use the average price results rather than the marginal price results to demonstrate the advantage of my recommended policies when deductions are substitutes.

Although I do not assert which set of results is right or wrong, the average price results seem more sensible. The marginal price results do not satisfy the Slutsky symmetry that

\footnotetext{
would predict bunching at $\$ 25,000$ while the ironing model would predict no bunching. When using marginal prices, in addition to a linear regression, I also estimate a maximum likelihood model similar to and extending to my higher-dimensional case Friedberg (2000) and Moffit (1986), but the results are odd and difficult to interpret, and also not robust across the Survey of Consumer Finance's five implicate datasets.
} 
requires symmetric cross price elasticities to have the same sign. Moreover, in Section VI I will introduce a type of policy that is especially appropriate when the correct values of cross price elasticities are uncertain.

The interpretations for the average price results are as follows. When the tax-price of charitable giving increases by $1 \%$ (while holding the HELOC price constant), giving decreases by $2.83 \%$ and HELOC payments increase by $1.49 \%$; when the tax-price of HELOC payment increases by $1 \%$ (while holding the tax-price of giving constant), HELOC payments decrease by $5.38 \%$ and charitable giving increases by $3.90 \%$. Meanwhile, when the net-of-tax rate $1-\tau$ increases by $1 \%$, which affects both tax-prices, giving decreases by $2.83 \%-3.90 \% * 0.36=1.41 \%$ and HELOC repayments decrease by $5.38 \% * 0.36-1.49 \%=0.46 \%$ for a household with median levels of balance, payment, $r$, and $\tau .{ }^{31}$ For a household repaying less than interest due on their HELOC, giving increases by $3.90 \%-2.83 \%=1.08 \%$, and HELOC payments decrease by $5.38 \%-1.49 \%$ $=3.89 \%$.

The two specifications produce similar estimates for the overall effect of changing 1- $\tau$ (i.e. the effect without holding $p_{q}$ or $p_{h}$ constant) on giving; as calculated earlier, at the covariates' medians, a $1 \%$ increase $1-\tau$ in leads to a $1.63 \%$ (the marginal price specification) or $1.41 \%$ (the average price specification) decrease in giving. The numbers -1.63 (standard error=1.65) and -1.41 (standard error $=1.52$ ) are the estimates for the regular tax-price elasticity of charitable giving.

In this paper elasticities are computed from the two-equation coefficients. In the charitable giving literature, the tax-price elasticity of giving is mostly estimated using single-equation models that regress the log of giving on the $\log$ of $1-\tau$. In the last two columns of Table 2, I replicate the conventional single-equation method in the charitable giving literature and estimate a charitable giving tax-price elasticity of -2.08 (standard error $=1.62$ ), similar to the -1.63 and -1.41 above. These estimates' magnitudes are

\footnotetext{
${ }^{31} \mathrm{By}(5)$, when $Q$ is larger than $B \cdot r$, a $1 \%$ increase in 1- $\tau$ does not lead to a $1 \%$ increase in $p_{h}$ (it does when $\mathrm{Q}$ is smaller than $B \cdot r)$. Under $Q \geq B \cdot r$, we have $p_{h}=1-\frac{B \cdot r \cdot \tau}{Q}-r(1-\tau)=1+\frac{B \cdot r \cdot(-\tau)}{Q}-$ $r(1-\tau)=1+\frac{B \cdot r \cdot(1-\tau)-B \cdot r}{Q}-r(1-\tau)=1-\frac{B \cdot r}{Q}+\frac{B \cdot r \cdot(1-\tau)}{Q}-r(1-\tau)=\left(1-\frac{B \cdot r}{Q}\right)+\left(\frac{B}{Q}-1\right) r(1-\tau)$. As $(1-\tau)$ increases by $1 \%, p_{h}$ increases by $\left(\frac{B}{Q}-1\right) r(1-\tau) * 1 \% /\left[\left(1-\frac{B \cdot r}{Q}\right)+\left(\frac{B}{Q}-1\right) r(1-\tau)\right]$, which is $0.36 \%$ at $B=31822, r=8.0 \%, Q=5342(>31822 * 8.0 \%=2546)$ and $\tau=25 \%$.
} 
higher than a few representative estimates in the literature (mostly between -1.09 and 1.26, see Table A.2 in Appendix 2). This appears to be driven by the sample selection criteria. In particular, if my sample is expanded to non-HELOC borrowers in SCF, the estimate would be -0.74 (standard error $=0.46$ ). These estimates perhaps suggest that the HELOC borrowers are more sensitive to tax incentives compared with others, although their difference $(2.08-0.74=1.34)$ is not statistically different (standard error=1.68).

An alternative way to handle 0 giving levels is Tobit regression. I ran Tobit regression for charitable giving, where the independent variables are $p_{g}, p_{\text {in }}$ (the instrument for $p_{q}$ and $p_{h}$ ), and other covariates. The two price coefficients, $-28,181$ and 46,522 , have the right signs and are significant at the $1 \%$ level. ${ }^{32}$ They are large because they are the regressions coefficients of giving on the tax-prices, rather than those of the $\log$ of giving on the logs of the tax-prices. They imply that giving decreases in its own tax-price and increases in HELOC's tax-price. Since there are only 5 observations of zero HELOC repayments, I did not run a Tobit regression for HELOCs.

\section{Links with the ETI and Optimal Tax Policy}

In this section I demonstrate the implications of my results for understanding estimates of the elasticity of taxable income (ETI) that appear in the literature. I also compare different base broadening tax reform approaches, highlighting the role of cross price elasticities among deductions. I prove theoretically that, when we do not know exactly the signs and magnitudes of cross price elasticities among deductions, reducing all deductions rather than removing a subset of deductions can guarantee improved efficiency and revenue.

\section{VI.1 Towards a Fuller Understanding of the ETI}

As discussed in my introduction and literature review, in order to have a full picture of the ETI, it is necessary to decompose it into parts that correspond to the various components of taxable income. In Appendix 1 I have derived a decomposition built on Kopczuk (2005) and Varian (1992). This decomposition indicates that, when taxable

\footnotetext{
${ }^{32}$ However, in the two-stage IV tobit regression, the coefficient for the tax-price of giving is 135 (wrong sign) and not significant under the average price specification, and is 12,580 (wrong sign) and significant at the $10 \%$ level under the marginal price specification.
} 
income has $N$ components (i.e. $N$ different types of incomes and deductions), the ETI is the sum of $N \times N$ terms. These terms are additive, and in this section I isolate and discuss $2 \times 2$ of them (Expression (8) below). In other words, I am essentially looking at a "subETI", or the charitable giving-HELOC portion of the ETI when other deductions are exogenous (but the basic intuition and implications implied in my analysis of this subETI applies to a full ETI):

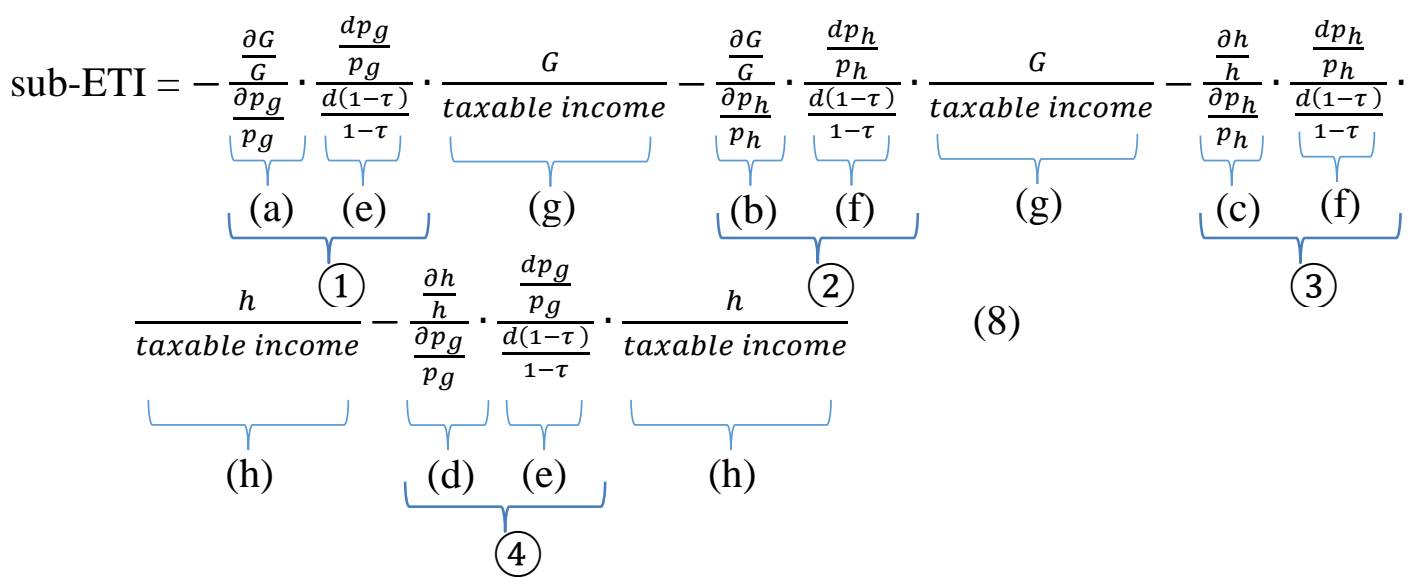

This expression shows that the ETI is not an invariant parameter, as it is the sum of all four terms. Terms (1) to (4) measure the effect of changes in the net-of-tax rate 1- $\tau$ on the 2 deductions (1) and (2) for $G$; (3) and (4) for $h$ ) through changing the 2 tax-prices, therefore there are $2 * 2=4$ of these terms. It depends, for instance, on whether $G$ is deductible. If $G$ were no longer deductible, $p_{g}$ would equal 1 and $d p_{g}$ would equal 0 . As a result, Terms (1) and (4) will become 0, altering the value of the ETI. I estimated the terms (a), (b), (c) and (d) in the above Equation (8). The other terms' values depend on the tax system in place and the households' expenditure allocation, which I will explain further in Subsections VI.2 and VI.3 with examples.

\section{VI.2 Conventional policy vs. optimal policy}

In this and the next subsections I compare different base broadening policies and show how this comparison depends on the ETI and sub ETI that I have derived. I will supply both theoretical results and simulations. I evaluate to what extent each policy can achieve the desired outcomes of (1) increasing tax revenue, and (2) reducing the deadweight loss per dollar of tax base. This boils down to evaluating whether each policy can reduce the ETI, because a smaller ETI means both higher revenue and less deadweight loss per dollar of tax base (Feldstein 1999; Saez, Slemrod and Giertz 2012). 
I begin with the conventional base broadening policy of eliminating some deductions and keeping others (for example the "blank-slate" approach proposed by the Senate Finance Committee in June 2013). In theory, this type of policy cannot guarantee reducing the ETI. To show this, I continue with Equation (8). If legislation eliminates the HELOC deduction, then terms (3) and (4), which represent the change in HELOC deduction with respect to changes in $1-\tau$, will disappear, helping to reduce the ETI. But term (2), the effect of changes in 1- $\tau$ on $G$ through changing $p_{h}$, will also disappear, working against the reduction. The sub-ETI in (8) (and hence the ETI, which depends additively on the sub-ETI) will only fall if the two deductions are not extremely substitutable. In the extreme case, if they are sufficiently substitutable, then eliminating one deduction will lead to so much more of the other deduction that tax revenue could fall.

Applying my estimates, I simulate outcomes for two conventional policy reforms, eliminating either the deduction for charitable giving or for HELOC interest. Suppose, for example, that a household's pretax income is $\$ 106$. When the tax rate is zero, suppose that the amounts of giving $G$, HELOC interest payment $h$, and other ordinary consumption $C$ are, respectively, $\$ 2, \$ 4$, and $\$ 100$. Actual $G$ and $h$ depend on the tax rate.

Then, under the current system, with both giving and HELOC payment deductible, the inputs for percentage terms $(\mathrm{g})$ and $(\mathrm{h})$ in Equation (8) are $\frac{G}{\text { taxable income }}=\frac{G}{C}=\frac{2}{100}$ and $\frac{h}{\text { taxable income }}=\frac{h}{C}=\frac{4}{100} \cdot{ }^{33}$ Further, plugging in my price elasticity estimates into Equation (8) too, I have a sub-ETI value of $-(-2.83) \times 1 \times \frac{2}{100}-3.90 \times 1 \times \frac{2}{100}-$ $(-5.38) \times 1 \times \frac{4}{100}-1.49 \times 1 \times \frac{4}{100}=0.134 .{ }^{34}$ Figure 2 draws the "Laffer curve", labelled "before reform", that depicts the relation between the tax revenue and the tax

\footnotetext{
${ }^{33}$ Here I plug in 2 and 4, the values when the tax rate of 0 , because I evaluate the ETI at tax rate equal 0 , following Feldstein (1999). For simplicity, I do not evaluate ETI at other tax rates and also treat the ETI as constant when plotting Laffer curves later on. Evaluating the ETI at other tax rates will not change the policy implications.

${ }^{34}$ To see where the numbers come from, notice that I estimated terms (a), (b), (c), and (d), or the average tax-price elasticities of $G$ and $h$ with respect to $p_{g}$ and $p_{h}$. As for the other partial derivative terms (e) and (f), $p_{g}=1-\tau$ and $p_{h}=1-\tau-\mathrm{r}(1-\tau)$ give $\frac{\frac{d p_{g}}{p_{g}}}{\frac{d(1-\tau)}{1-\tau}}=\frac{\frac{d p_{h}}{p_{h}}}{\frac{d(1-\tau)}{1-\tau}}=1$.
} 
rate under this sub-ETI of $0.134 .{ }^{35} \mathrm{I}$ also record this result for the sub-ETI in Table 4's "before reform" row.

The first conventional Policy, named Policy G1, eliminates the HELOC interest deduction, and thus increases the tax base from $\$ 100$ to $\$ 104$ and leaves a sub-ETI of $-(-2.83) \times 1 \times \frac{2}{104}=0.054$. Figure 2 plots the resulting Laffer curve, labelled "G1". It lies above the "before reform" curve, because it starts with a larger tax base at zero tax rate, and also has a smaller ETI.

The second conventional Policy, named Policy h1, eliminates the charitable giving deduction, thus increasing the tax base from $\$ 100$ to $\$ 102$ and leaving a sub-ETI of - (- 5.38) $\times 1 \times \frac{4}{102}=0.211$, even larger than the before reform ETI. Figure 2 draws the corresponding Laffer curve, labelled "h1". Notice that Policy h1 raises slightly more revenue than the "before reform" system at small tax rates, because it closes off the charitable giving deduction and has a larger tax base when the tax rate is zero. But the tax base is much more elastic. Once the tax rate goes above a threshold level (22.7\%), Policy h1 raises less revenue. Table 4's “conventional” panel records G1's and h1's key results.

Figure 2 the Laffer Curves

Revenue

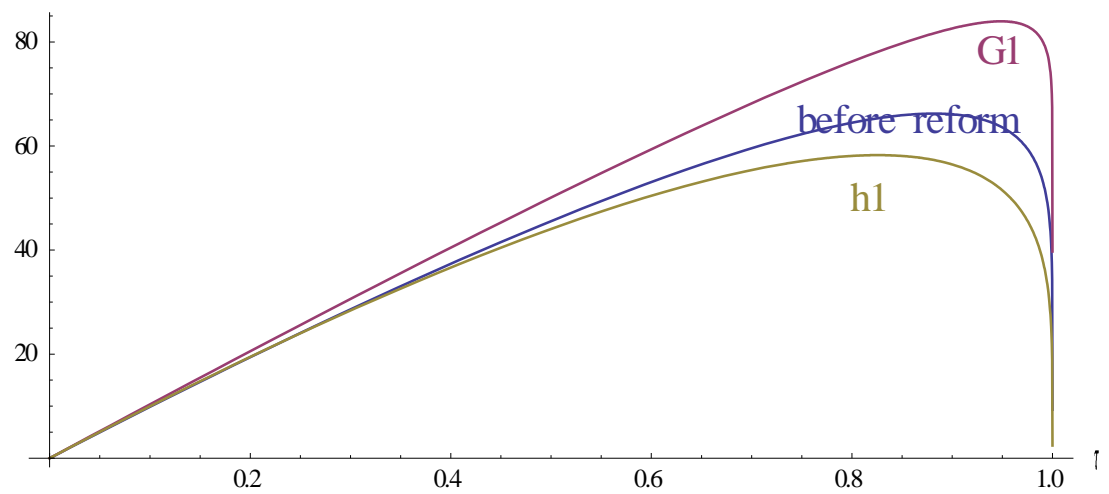

Now, I discuss optimal base broadening policies that preserve both the tax rate and the size of the tax base under conventional policies while maximizing tax revenue (and simultaneously minimizing deadweight loss, since they are interdependent). While a conventional policy stipulates that a deduction is either $100 \%$ deductible or $0 \%$

\footnotetext{
${ }^{35}$ The equation for the curve is Revenue $=100(1-\tau)^{0.134} \tau$. It is derived as follows. First, I have Taxable Income $=100 *(1-\tau)^{0.134}$, pinned down by two conditions, Taxable Income $(\tau=0)=100$ and ETI $=$ $\partial \operatorname{Ln}($ Taxable Income $) / \partial \operatorname{Ln}(1-\tau)=0.134$. Then, I have Revenue $=$ Taxable Income $\cdot \tau=100(1-\tau)^{0.134} \tau$. The equations for other policies will be the same except that I replace 0.134 with their respective ETIs.
} 
deductible, for an optimal policy I consider a "deductible proportion" between 0 and $100 \%$ for each deduction. For example, if we stipulate that charitable giving is $80 \%$ deductible, then each dollar of charitable giving will reduce taxable income by 80 cents rather than by 1 dollar, and, under a tax rate of $10 \%$, decreases tax liability by 8 cents rather than by 10 cents. To be prepared for the ensuing simulations, notice that reducing deductible proportions from $100 \%$ to $x \%$ will increase the tax-price of giving from $1-\tau$ to 1- $x \% \cdot \tau$ (affecting Terms (1) and (4) in Expression (8)), and increase the tax-price of HELOC interest payment from $1-\tau-r(1-\tau)$ to $1-x \% \cdot \tau-r(1-x \% \cdot \tau)$ ) (affecting Terms (2) and (3) in Expression (8)). ${ }^{36}$ In a base broadening reform, given the tax authority's chosen tax base, an optimal policy chooses a set of optimal deductible proportions that minimizes the after reform ETI. ${ }^{37}$

The conventional Policy G1 has a tax base of $\$ 104$ and sets the deductible proportions for $G$ and $h$ to be, respectively, $100 \%$ and $0 \%$. In contrast, given my cross price elasticity estimates, the optimal policy with the same tax base (\$104), which I name Policy G2, sets the deductible proportions to be $49 \%$ for $G$ and $25 \%$ for $h$ (see Appendix 12 for calculations). The ETI is $-(-2.83) * 49 \% * \frac{49 \% * 2}{104}-3.90 * 25 \% * \frac{25 \% * 2}{104}-$ $(-5.38) * 25 \% * \frac{25 \% * 4}{104}-1.49 * 49 \% * \frac{49 \% * 4}{104}=0.010$ (see Appendix 12). The optimal Policy G2 produces a lower ETI, or in other words higher revenue and lower dead weight loss per dollar of tax base, than both the conventional Policy G1 or the before reform system.

The conventional Policy h1 has a tax base of $\$ 102$ and sets the deductible proportions for $G$ and $h$ to be, respectively, $0 \%$ and $100 \%$. In contrast, given my cross price elasticity estimates, the optimal policy with the same tax base, named h2, sets the

\footnotetext{
${ }^{36}$ (1) To see the calculation, notice that under the usual system we currently have $(\boldsymbol{x} \%=100 \%)$, each dollar of giving reduces tax liability by $\boldsymbol{\tau}$ dollar, while if only $\boldsymbol{x} \%$ is deductible, then each dollar of giving reduces tax liability by $\boldsymbol{x} \% \cdot \boldsymbol{\tau}$ dollar. For more rigorous proof, please see Appendix 10. (2) Feldstein (1999) shows that, in a tax system with fully tax deductible items, the dead weight loss is proportional to the ETI. Here my proposed tax system is different: each tax deductible item is partially $(x \%)$ instead of $100 \%$ deductible. However, the result that the dead weight loss is proportional to the ETI still holds approximately. Yet, although the approximation error is small, it can be shown that my proposed system has smaller deadweight loss than the traditional tax system. I provide a proof in Appendix 11.

${ }^{37}$ Under either full or partial deductibility, the positive externality of the extra private spending on deductible activities induced by the deductibility has to be bigger than the deadweight loss (see Appendix 11 for its formula) to justify keeping the deductibility, or in other words, the tax expenditures.
} 
deductible proportions to be $99 \%$ for $G$ and $51 \%$ for $h$ (see Appendix 12 for calculations). The ETI is $-(-2.83) * 99 \% * \frac{99 \% * 2}{102}-3.90 * 51 \% * \frac{51 \% * 2}{102}-(-5.38) * 51 \% * \frac{51 \% * 4}{102}-$ $1.49 * 99 \% * \frac{99 \% * 4}{102}=0.041$ (see Appendix 12). The optimal Policy h2 does better in ETI, revenue, and efficiency than the conventional Policy h1 or before reform. Table 4's “optimal” panel records G2's and h2's key elements.

In sum, in base broadening attempts, the optimal policies that are based on the own and cross tax-price elasticity values outperform the conventional policies. In particular, an optimal policy can guarantee reducing the ETI. This is not only true in the above two deduction case, but also true in the general situation where taxable income has $N$ components (theoretically proved in Appendix 12). Further, by definition an optimal policy reduces the ETI to the minimum subject to a constraint on the tax base. In contrast, a conventional policy cannot guarantee reducing the ETI (e.g. Policy h1 does not).

\section{VI.3 Uniform partial deductibility: the second best policy under uncertainty}

The previous subsection illustrates the advantage of optimal policy design in reducing the ETI (to the minimum). However, it requires knowing the correct values of all own and cross tax-price elasticities of taxable income's components (see Appendix 12). Designing policy based on estimates fail to reduce the ETI. This subsection shows that implementing a "uniform partial deductibility" policy can guarantee a reduction in the ETI even when the own and cross price elasticities are unknown.

As my naming suggests, a uniform partial deductibility policy sets one same deductible proportion for all deductions, e.g. legislating that only $x \%$ of $h$ and $x \%$ of $G$ are deductible in the previous subsection's example. Theoretically this policy can guarantee reducing the ETI, and this is not only true for my two deduction case but also true in general under an $N$-component taxable income definition (see Appendix 12 for my proof).

Continuing with previous simulations, consider a uniform partial deductibility Policy G3 that sets the tax base to be $\$ 104$ as Policy G1 does. It deducts from pretax income 106-104 $=2$ dollars, or 33\% of total amounts of $G$ and $h$ at 0 tax rate (6 dollars). So Policy G3 sets all deductions to be $33 \%$ deductible and produces an ETI of

$$
-(-2.83) * 33 \% * \frac{33 \% * 2}{104}-3.90 * 33 \% * \frac{33 \% * 2}{104}-(-5.38) * 33 \% * \frac{33 \% * 4}{104}-1.49 *
$$


Table 4 Policy simulation results

\begin{tabular}{|c|c|c|c|c|}
\hline \multicolumn{2}{|l|}{ Policy } & Description & ETI & $\begin{array}{c}\text { Achieved desired } \\
\text { outcomes? }\end{array}$ \\
\hline \multicolumn{2}{|l|}{ Before reform } & $\begin{array}{l}G \text { deductible } \\
h \text { deductible } \\
\text { tax base }=100\end{array}$ & 0.134 & $\mathrm{n} / \mathrm{a}$ \\
\hline Conventional & G1 & $\begin{array}{l}G \text { deductible } \\
h \text { not } \\
\text { tax base }=104 \\
G \text { not deductible } \\
h \text { not } \\
\text { tax base }=102\end{array}$ & 0.054 & Yes \\
\hline Optimal & $\mathrm{G} 2$ & $\begin{array}{l}G 49 \% \\
\text { deductible } \\
h 25 \% \text { deductible } \\
\text { tax base }=104 \\
G 99 \% \\
\text { deductible } \\
h 51 \% \text { deductible } \\
\text { tax base }=102\end{array}$ & 0.010 & $\begin{array}{l}\text { Yes; } \\
\text { the best under tax } \\
\text { base }=104 \\
\text { Yes; } \\
\text { the best under tax } \\
\text { base }=102\end{array}$ \\
\hline $\begin{array}{c}\text { Uniform } \\
\text { partial } \\
\text { deductibility }\end{array}$ & G3 & $\begin{array}{l}G 33 \% \\
\text { deductible } \\
h 33 \% \text { deductible } \\
\text { tax base }=104 \\
G 67 \% \\
\text { deductible } \\
h 67 \% \text { deductible } \\
\text { tax base }=102\end{array}$ & 0.014 & Yes \\
\hline
\end{tabular}


$33 \% * \frac{33 \% * 4}{104}=0.014$. This is not as small as the optimal Policy G2's ETI (0.010), but it is smaller than the before reform ETI (0.134), as predicted by theory. In addition, it dominates Policy G1 (0.054).

A uniform partial deductibility Policy h3 sets the tax base to be $\$ 102$ as Policy h1 does. It sets all deductions to be $67 \%$ deductible and produces an ETI of $-(-2.83) *$ $67 \% * \frac{67 \% * 2}{104}-3.90 * 67 \% * \frac{67 \% * 2}{104}-(-5.38) * 67 \% * \frac{67 \% * 4}{104}-1.49 * 67 \% * \frac{67 \% * 4}{104}=$ 0.058. This is not as small as the optimal Policy h2's ETI (0.041), but it is smaller than the before reform ETI (0.134), as predicted by theory. In addition, it is also better than Policy h1 (0.211).

Above, I show the advantages of optimal policies (in guaranteeing reducing the ETI) and the advantages of uniform partial deductibility policies (in both guaranteeing reducing the ETI and requiring less information) under the same chosen tax base.

An additional feature of uniform partial deductibility is the predictability of its effects. So far, I have demonstrated that under any desired tax base target, the optimal and uniform partial deductibility policies dominate the conventional policy of removing a single deduction (or a subset of deductions in general). The next step is to predict the revenue and efficiency outcomes under the new tax base (or, alternatively, what tax base leads to a particular revenue and efficiency target). In this regard, the uniform partial deductibility policy has a unique advantage: one only needs to know the before reform ETI to predict the effect on revenue and efficiency. In contrast, under a conventional policy or an optimal policy, one needs to know the own and cross tax-price elasticities (since these policies change the relative prices of deductions). The intuitive reason is that a uniform partial deductibility policy maintains the deductions' relative prices. In fact, a simple relationship exists between the ETI under the uniform partial policy and the before reform ETI, which is uniform partial ETI $=\left(x^{\prime}\right)^{2} \frac{\text { before reform tax base }}{\text { new (broader) tax base }} *$ before reform ETI, with $x^{\prime}$ being the uniform deductible proportion. This formula holds not only for the two deduction case but also for multiple deductions (see Appendix 12 for proof). This relation does not depend on the own and cross price elasticity values. Since the ETI is a sufficient statistic for computing the deadweight loss (Feldstein 1999) as well as for forecasting revenue (by definition), this relation means the following: in 
order to predict the revenue and deadweight loss under a uniform partial deductibility policy, knowing the before reform ETI is enough.

While estimates of a before reform ETI could be biased due to the confounding effect of deduction changes in a reform (elaborated in Section I and Appendix 2), estimating an overall ETI is a less formidable task than measuring all own and cross elasticities. Moreover, it is relatively straight forward to undertake an informative sensitivity analysis based on a range of plausible values for the ETI. For example, suppose that the tax authority believes that the true before reform ETI value today is somewhere between 0.4 and 0.8 (taken from existing estimates in Appendix 2's Table A.1 that are smaller than 1). Also, suppose that the total amount of itemized deductions is $40 \%$ of the current taxable income and the current tax rate is $20 \%$. Then, if the tax authority aims to increase revenue by $10 \%$ by broadening the tax base, then the correct uniform deductible proportion $x^{\prime}$ will be somewhere between $78.6 \%$ and $81.4 \%$ (see Figure 3 for the correct $x^{\prime}$ as a function of ETI; see calculations in Appendix 12's Section A12.5). This range is narrow enough for it to provide meaningful guidance.

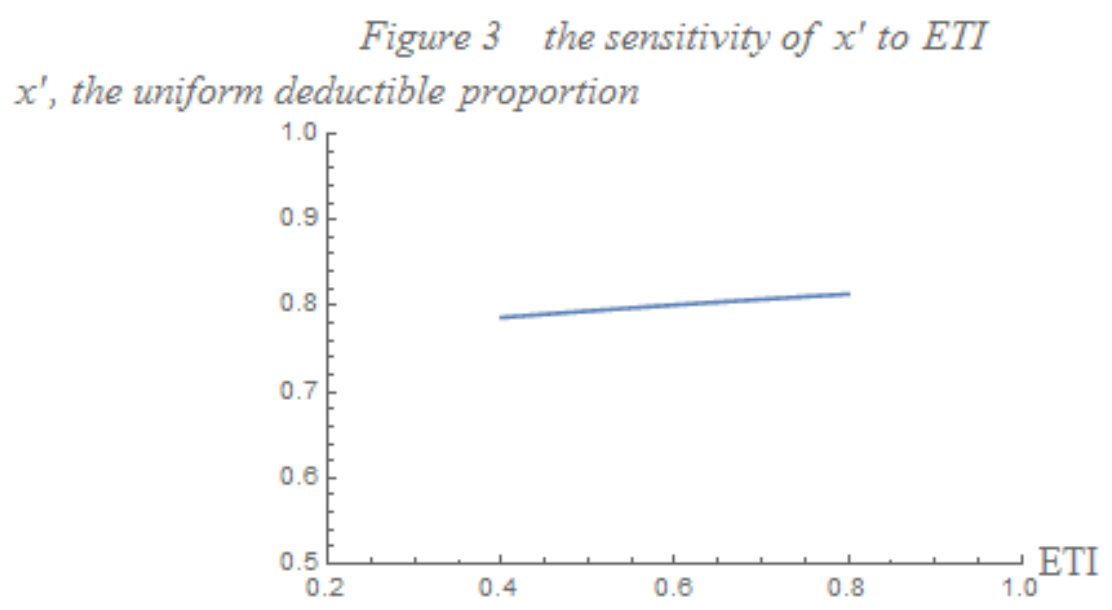

Lastly, even if no narrow range of $x^{\prime}$ can be determined as in Figure 3 due to the high degree of uncertainty about the true ETI value, there is still a reasonable approach to base broadening. For example, suppose that the true ETI is 0.58 and thus the correct $x^{\prime}$ is $80 \%$, but the tax authority knows neither number. Nonetheless, it can gradually phase in a uniform partial deductibility policy over the course of several years - e.g. start from the existing full deductibility of $x^{\prime}=100 \%$, and then bring it down by, say $2 \%$ every year, until it reaches $x^{\prime}=80 \%$ when they find that the revenue goal is reached. Along the way, it 
can accelerate the pace (just like the acceleration of the Bush tax cut) if it finds that the $2 \%$ steps increase revenue too slowly. ${ }^{38}$

\section{Conclusions}

This paper finds evidence of households making joint decisions on different deductions, using the Survey of Consumer Finances (SCF). The SCF has detailed information on demographics such as income, wealth, age, and education. The key to identify the interaction between deductions is to find a pair of two deductions with different tax-prices. For this purpose I have studied the charitable giving deduction and the HELOC interest payment deduction. I find negative own price elasticities consistent with downward sloping demand curves; and positive cross price elasticities in my preferred specification. The latter indicates substitutability between the two deductions.

By considering interactions between deductions, I move beyond the charitable giving literature that studies one deduction in isolation. I decompose the ETI as a weighted sum of taxable income's components' elasticities. This theoretical framework allows me to discuss the design of base broadening policies. Illustrating with simulations, I show that a conventional base broadening policy cannot guarantee increasing revenue (and improving efficiency) due to substitutability between deductions. In contrast, under a tax base target, an optimal policy involves reducing different deductions to optimal degrees that maximize the revenue raising capacity and efficiency. Calculating these optimal degrees requires knowing the correct values of all own and cross tax-price elasticities of taxable income's components, such as those I estimated in this paper. Contrary to the optimal policy, we can implement a "uniform partial deductibility" policy that reduces all deductions to the same degree, even when the own and cross price elasticities are unknown. This policy can guarantee improved outcomes.

\footnotetext{
${ }^{38}$ Alternatives to partial deductibility for cutting itemized deductions are: (1) a lump sum reduction of itemized deduction, i.e. stipulating that the first $S$ dollars of charitable giving and HELOC interest payment are not tax deductible, but that subsequent dollars are; (2) a cap of itemized deductions, i.e. stipulating that only the first $C$ dollars of charitable giving and HELOC interest payment are tax deductible, and that subsequent dollars are not. Partial deductibility reduces the difference between the marginal tax-prices of the ordinary, non-deductible consumption and a deductible consumption, and thus reduces the distortion of the tax code. Under (1) however, households with over $S$ dollars of itemized deductions still face the bigger distortion in relative tax-prices under the full deductibility. Similarly under (2), households with below C dollars of itemized deductions still face the bigger distortion. Households with itemized deductions around $S$ or $C$ have to deal with a kinked budget constraint, which is an extra layer of distortion.
} 
This paper extends the static modelling methods employed in the charitable giving literature and the ETI literature to considering the interaction between a pair of deductions. The results can thus be compared with the charitable giving tax price elasticity and the ETI. Future research could attempt to model interactions between longer term decisions about deductions, such as the home purchase mortgage interest deduction and charitable giving literature. This kind of research will give us more insight about the structure of the long run ETI.

\section{Appendix 1 Decomposing the Elasticity of Taxable Income (ETI)}

Taxable income consists of more basic components. As a result, the responsiveness of taxable income to tax rate can be decomposed into more basic parts too. In this appendix I provide a formal decomposition, built on Kopczuk (2005) and Varian (1992). I will present that the elasticity of taxable income (ETI) is the summation of more basic elasticities, including several "own-price" elastiticies and several "cross-price" elasticities.

Suppose that taxable income has $N$ components, i.e.

$$
\text { Taxable Income }=I_{1}+I_{2}+\cdots+I_{J}-D_{J+1}-D_{J+2}-\cdots-D_{N},
$$

where $I_{j}(1 \leq j \leq J)$ is the amount of a type of income, e.g. labor income of $\$ 5,000$, and $D_{j}(J+1 \leq$ $j \leq N)$ is the amount of a type of tax-deductible consumption, e.g. $\$ 1,000$ given to charities.

Let $p_{1}, p_{2}, \ldots, p_{N}$ denote the tax-prices for $I_{1}, I_{2}, \ldots, D_{N}$, respectively. A household chooses the levels of $I_{1}, I_{2}, \ldots, D_{N}$ based on the tax-prices. For example, the tax-price of charitable giving is defined as the forgone after-tax money from giving 1 dollar, i.e. $1-\tau$, with $\tau$ being the marginal tax rate. As another example, the tax-price of labor income could also be written as $1-\tau$. This is because, choosing labor supply is equivalent to choosing the amount of leisure, and the after-tax money forgone for having 1 hour of leisure is $(1-\tau) \times$ hourly wage. ${ }^{39}$ In general, $p_{1}, p_{2}, \ldots, p_{N}$ are all functions of $1-\tau$, but not necessarily exactly $1-\tau$. Therefore the above formula is in fact

\footnotetext{
${ }^{39}$ Thus one implicit assumption for $1-\tau$ to suffice as the tax-price for labor income is that the hourly wage does not change when $\tau$ changes, so the only variable part in $(1-\tau) \times$ hourly wage is $1-\tau$. However, this assumption may not be true when $\tau$ changes for a large number of households, for example in a tax reform. In fact, Kubik (2004) finds that as the marginal tax rates changed differently for different industries after the 1986 tax reform, wages also changed differently in different industries. In this appendix I do not discuss how tax rates affect the tax base through changing market equilibrium prices, and instead examines only how tax rate changes alter individual households' choices directly. This does not mean that market equilibrium price changes do not play an important part in the ETI. In Chapter 3 of this dissertation I examine the effect of changing tax rates on home mortgage interest rates, and discuss how much this effect increases the ETI.
} 
Taxable Income

$$
\begin{aligned}
& =I_{1}\left(p_{1}, p_{2}, \ldots, p_{N}\right)+I_{2}\left(p_{1}, p_{2}, \ldots, p_{N}\right)+\cdots+I_{J}\left(p_{1}, p_{2}, \ldots, p_{N}\right) \\
& -D_{J+1}\left(p_{1}, p_{2}, \ldots, p_{N}\right)-D_{J+2}\left(p_{1}, p_{2}, \ldots, p_{N}\right)-\cdots-D_{N}\left(p_{1}, p_{2}, \ldots, p_{N}\right) .
\end{aligned}
$$

Then I have

$$
\begin{aligned}
& \frac{d(\text { Taxable Income })}{d(1-\tau)}=\frac{d\left(I_{1}+I_{2}+\cdots+I_{J}-D_{J+1}-D_{J+2}-\cdots-D_{N}\right)}{d(1-\tau)} \\
& =\sum_{j=1}^{J} \frac{d I_{j}}{d(1-\tau)}-\sum_{j=J+1}^{N} \frac{d D_{j}}{d(1-\tau)}=\sum_{j=1}^{J} \sum_{n=1}^{N} \frac{\partial I_{j}}{\partial p_{n}} \frac{d p_{n}}{d(1-\tau)}-\sum_{j=J+1}^{N} \sum_{n=1}^{N} \frac{\partial D_{j}}{\partial p_{n}} \frac{d p_{n}}{d(1-\tau)} .
\end{aligned}
$$

The ETI is

$$
\begin{aligned}
\frac{d(\text { Taxable Income })}{d(1-\tau)} \frac{1-\tau}{\text { Taxable Income }}=\left[\sum_{j=1}^{J} \frac{d I_{j}}{d(1-\tau)}-\sum_{j=J+1}^{N} \frac{d D_{j}}{d(1-\tau)}\right] \frac{1-\tau}{\text { Taxable Income }} \\
=\sum_{j=1}^{J} \frac{1-\tau}{\text { Taxable Income }} \frac{d I_{j}}{d(1-\tau)}-\sum_{j=J+1}^{N} \frac{1-\tau}{\text { Taxable Income }} \frac{d D_{j}}{d(1-\tau)} \\
=\sum_{j=1}^{J} \frac{I_{j}}{\text { Taxable Income }} \frac{1-\tau}{I_{j}} \frac{d I_{j}}{d(1-\tau)}-\sum_{j=J+1}^{N} \frac{D_{j}}{\text { Taxable Income }} \frac{1-\tau}{D_{j}} \frac{d D_{j}}{d(1-\tau)} \\
=\sum_{j=1}^{J} \frac{I_{j}}{\text { Taxable Income }} \times \text { the Elasticiy of } I_{j} \text { with respect to }(1-\tau) \\
-\sum_{j=J+1}^{N} \frac{D_{j}}{\text { Taxable Income }} \times \text { the Elasticiy of } D_{j} \text { with respect to }(1-\tau) .
\end{aligned}
$$

This expressions says that the ETI is the weighted average of its components' elasticities, with weights being the respective components' shares in taxable income. For example, suppose that $I_{j}$ is labor income, then, assuming that the hourly wage for the taxpayer does not change when $(1-\tau)$ changes, the Elasticiy of $I_{j}$ with respect to $(1-\tau)$ is nothing but the labor supply elasticity. As another example, suppose that $D_{j}$ is the amount of charitable giving, then the Elasticiy of $D_{j}$ with respect to $(1-\tau)$ is nothing but the tax-price elasticity of charitable giving talked about in the charitable giving literature.

However, these weighted component elasticities are still not the most basic building blocks of the ETI. In what follows, I further decompose the ETI. Along the way, I also show that the components' elasticities, for example the labor supply elasticity and the charitable giving elasticity, are also not immutable parameters; in other words, they could potentially change if the definition of taxable income changes, for example if the mortgage interests paid are no longer deductible after a tax reform.

Continuing with the above expression, I decompose each total derivative into $N$ partial derivatives corresponding to $N$ tax-prices. I have 


$$
\begin{aligned}
\text { ETI }= & \sum_{j=1}^{J} \frac{I_{j}}{\text { Taxable Income }} \frac{1-\tau}{I_{j}} \frac{d I_{j}}{d(1-\tau)}-\sum_{j=J+1}^{N} \frac{D_{j}}{\text { Taxable Income }} \frac{1-\tau}{D_{j}} \frac{d D_{j}}{d(1-\tau)} \\
& =\sum_{j=1}^{J} \frac{I_{j}}{\text { Taxable Income }} \frac{1-\tau}{I_{j}}\left[\sum_{n=1}^{N} \frac{\partial I_{j}}{\partial p_{n}} \frac{d p_{n}}{d(1-\tau)}\right] \\
& -\sum_{j=J+1}^{N} \frac{D_{j}}{\text { Taxable Income }} \frac{1-\tau}{D_{j}}\left[\sum_{n=1}^{N} \frac{\partial D_{j}}{\partial p_{n}} \frac{d p_{n}}{d(1-\tau)}\right]
\end{aligned}
$$

To make it clearer, I now extend the terms without using the summation signs to get

$$
E T I=\frac{I_{1}}{\text { Taxable Income }} \frac{\mathbf{1}-\tau}{I_{1}}\left[\frac{\partial I_{1}}{\partial p_{1}} \frac{d p_{1}}{d(1-\tau)}+\frac{\partial I_{1}}{\partial p_{2}} \frac{d p_{2}}{d(1-\tau)}+\cdots+\frac{\partial I_{1}}{\partial p_{N}} \frac{d p_{N}}{d(1-\tau)}\right]
$$

(the tax-price elasticity of $I_{1}$ )

$$
+\frac{I_{2}}{\text { Taxable Income }} \frac{1-\tau}{I_{2}}\left[\frac{\partial I_{2}}{\partial p_{1}} \frac{d p_{1}}{d(1-\tau)}+\frac{\partial I_{2}}{\partial p_{2}} \frac{d p_{2}}{d(1-\tau)}+\cdots+\frac{\partial I_{2}}{\partial p_{N}} \frac{d p_{N}}{d(1-\tau)}\right]
$$

(the tax-price elasticity of $I_{2}$ )

$$
+\frac{I_{J}}{\text { Taxable Income }} \frac{1-\tau}{I_{J}}\left[\frac{\partial I_{J}}{\partial p_{1}} \frac{d p_{1}}{d(1-\tau)}+\frac{\partial I_{J}}{\partial p_{2}} \frac{d p_{2}}{d(1-\tau)}+\cdots+\frac{\partial I_{J}}{\partial p_{N}} \frac{d p_{N}}{d(1-\tau)}\right]
$$

(the tax-price elasticity of $I_{J}$ )

$$
-\frac{D_{J+1}}{\text { Taxable Income }} \frac{1-\tau}{D_{J+1}}\left[\frac{\partial D_{J+1}}{\partial p_{1}} \frac{d p_{1}}{d(1-\tau)}+\frac{\partial D_{J+1}}{\partial p_{2}} \frac{d p_{2}}{d(1-\tau)}+\cdots+\frac{\partial D_{J+1}}{\partial p_{N}} \frac{d p_{N}}{d(1-\tau)}\right]
$$

(the tax-price elasticity of $D_{J+1}$ )

$$
-\frac{D_{J+2}}{\text { Taxable Income }} \frac{1-\tau}{D_{J+2}}\left[\frac{\partial D_{J+2}}{\partial p_{1}} \frac{d p_{1}}{d(1-\tau)}+\frac{\partial D_{J+2}}{\partial p_{2}} \frac{d p_{2}}{d(1-\tau)}+\cdots+\frac{\partial D_{J+2}}{\partial p_{N}} \frac{d p_{N}}{d(1-\tau)}\right]
$$

(the tax-price elasticity of $D_{J+2}$ )

$$
-\frac{D_{N}}{\text { Taxable Income }} \frac{1-\tau}{D_{N}}\left[\frac{\partial D_{N}}{\partial p_{1}} \frac{d p_{1}}{d(1-\tau)}+\frac{\partial D_{N}}{\partial p_{2}} \frac{d p_{2}}{d(1-\tau)}+\cdots+\frac{\partial D_{N}}{\partial p_{N}} \frac{d p_{N}}{d(1-\tau)}\right] .
$$

(the tax-price elasticity of $D_{N}$ ) 
This final expression says that the ETI is, again, the weighted average of taxable income's components' elasticities (the bold and shadowed terms) e.g. the labor supply elasticity and the charitable giving elasticity under the US tax system, and that each component's elasticity consists of

one own-price part (e.g. the $\frac{\partial D_{J+1}}{\partial p_{J+1}} \frac{d p_{J+1}}{d(1-\tau)} \frac{1-\tau}{D_{J+1}}$ term for the tax-price elasticity of $D_{J+1}$ ) and $N-1$ cross price parts. It is thus clear that not only the value of the ETI but also taxable income's components' elasticities depend on tax law. For example, if the legislation makes $D_{J+1}$ no longer deductible, then all own-price and cross-price terms with $\boldsymbol{\partial} \boldsymbol{p}_{\boldsymbol{J}+\mathbf{1}}$ will disappear from the ETI expression, changing the ETI as well as the components' elasticities such as the charitable giving tax-price elasticity. In summary, there are $N \times N$ channels through which 1- $\tau$ affects taxable income: 1- $\tau$ affects $N$ tax-prices, and each of the $N$ tax-prices affects each of the $N$ taxable income components. The above expression rigorously exhibits this structure.

\section{Appendix 2 Mathematical analysis of the relation between the ETI and other types of elasticities and review of existing estimates}

In this appendix I thoroughly analyze mathematically the relation between different elasticities. In Secion A2.2 I address a topic I alluded to in the introduction, namely the potential bias associated with estimating the ETI using tax reform data. The bias is caused by removal/addition of deductions which affects taxable income and correlates with tax rate change.

In what follows, I start with an ETI decomposition formula. It follows that different categories of empirical studies estimate different parameters in this formula.

\section{A2.1 A decomposition of the ETI}

The tax literature has estimated different types of elasticities with respect to $1-\tau$, such as the labor supply elasticity, the tax-price elasticity of charitable giving, the ETI, and the elasticity of broad income. In Appendix 1 I have provided a decomposition of the ETI for a generic tax system where taxable income has $N$ components. Here, to keep expressions short, I present a simple version of it with $N$ set to 4 which suffices for my purpose here: that is, to put all kinds of elasticities in one picture and clearly illustrate their relations.

Consider a simple, generic tax system defining taxable income as $T I=L+R-D_{1}-D_{2}$, with $L$ and $R$ being the amounts of two types of income and $D_{1}$ and $D_{2}$ being the amounts spent on two taxdeductible commodities. Let $\tau$ denote the marginal tax rate and let $p_{L}, p_{R}, p_{1}$, and $p_{2}$ denote, respectively, the tax-prices $L, R, D_{1}$, and $D_{2}$. The four tax-prices may or may not be $1-\tau$. Based on Appendix 1, the ETI is 
$E T I=\frac{L}{T I} \frac{d \operatorname{Ln}(L)}{d \operatorname{Ln}(1-\tau)}+\frac{R}{T I} \frac{d \operatorname{Ln}(R)}{d \operatorname{Ln}(1-\tau)}-\frac{D_{1}}{T I} \frac{d \operatorname{Ln}\left(D_{1}\right)}{d \operatorname{Ln}(1-\tau)}-\frac{D_{2}}{T I} \frac{d \operatorname{Ln}\left(D_{2}\right)}{d \operatorname{Ln}(1-\tau)}$

Elasticity of $D_{1}$

$=\frac{L}{T I}\left[\frac{\partial \operatorname{Ln}(L)}{\partial \operatorname{Ln}\left(p_{L}\right)} \frac{d \operatorname{Ln}\left(p_{L}\right)}{d \operatorname{Ln}(1-\tau)}+\frac{\partial \operatorname{Ln}(L)}{\partial \operatorname{Ln}\left(p_{R}\right)} \frac{d \operatorname{Ln}\left(p_{L}\right)}{d \operatorname{Ln}(1-\tau)}+\frac{\partial \operatorname{Ln}(L)}{\partial \operatorname{Ln}\left(p_{1}\right)} \frac{d \operatorname{Ln}\left(p_{1}\right)}{d \operatorname{Ln}(1-\tau)}+\frac{\partial \operatorname{Ln}(L)}{\partial \operatorname{Ln}\left(p_{2}\right)} \frac{d \operatorname{Ln}\left(p_{2}\right)}{d \operatorname{Ln}(1-\tau)}\right]$

$+\frac{R}{T I}\left[\frac{\partial \operatorname{Ln}(R)}{\partial \operatorname{Ln}\left(p_{L}\right)} \frac{d \operatorname{Ln}\left(p_{L}\right)}{d \operatorname{Ln}(1-\tau)}+\frac{\partial \operatorname{Ln}(R)}{\partial \operatorname{Ln}\left(p_{R}\right)} \frac{d \operatorname{Ln}\left(p_{L}\right)}{d \operatorname{Ln}(1-\tau)}+\frac{\partial \operatorname{Ln}(R)}{\partial \operatorname{Ln}\left(p_{1}\right)} \frac{d \operatorname{Ln}\left(p_{1}\right)}{d \operatorname{Ln}(1-\tau)}+\frac{\partial \operatorname{Ln}(R)}{\partial \operatorname{Ln}\left(p_{2}\right)} \frac{d \operatorname{Ln}\left(p_{2}\right)}{d \operatorname{Ln}(1-\tau)}\right]$

$-\frac{D_{1}}{T I}\left[\frac{\partial \operatorname{Ln}\left(D_{1}\right)}{\partial \operatorname{Ln}\left(p_{L}\right)} \frac{d \operatorname{Ln}\left(p_{L}\right)}{d \operatorname{Ln}(1-\tau)}+\frac{\partial \operatorname{Ln}\left(D_{1}\right)}{\partial \operatorname{Ln}\left(p_{R}\right)} \frac{d \operatorname{Ln}\left(p_{R}\right)}{d \operatorname{Ln}(1-\tau)}+\frac{\partial \operatorname{Ln}\left(D_{1}\right)}{\partial \operatorname{Ln}\left(p_{1}\right)} \frac{d \operatorname{Ln}\left(p_{1}\right)}{d \operatorname{Ln}(1-\tau)}+\frac{\partial \operatorname{Ln}\left(D_{1}\right)}{\partial \operatorname{Ln}\left(p_{2}\right)} \frac{d \operatorname{Ln}\left(p_{2}\right)}{d \operatorname{Ln}(1-\tau)}\right]$

$-\frac{D_{2}}{T I}\left[\frac{\partial \operatorname{Ln}\left(D_{2}\right)}{\partial \operatorname{Ln}\left(p_{L}\right)} \frac{d \operatorname{Ln}\left(p_{L}\right)}{d \operatorname{Ln}(1-\tau)}+\frac{\partial \operatorname{Ln}\left(D_{2}\right)}{\partial \operatorname{Ln}\left(p_{R}\right)} \frac{d \operatorname{Ln}\left(p_{R}\right)}{d \operatorname{Ln}(1-\tau)}+\frac{\partial \operatorname{Ln}\left(D_{2}\right)}{\partial \operatorname{Ln}\left(p_{1}\right)} \frac{d \operatorname{Ln}\left(p_{1}\right)}{d \operatorname{Ln}(1-\tau)}+\frac{\partial \operatorname{Ln}\left(D_{2}\right)}{\partial \operatorname{Ln}\left(p_{2}\right)} \frac{d \operatorname{Ln}\left(p_{2}\right)}{d \operatorname{Ln}(1-\tau)}\right]$

$=\left[\frac{L}{T I} \frac{R}{T I} \quad-\frac{D_{1}}{T I} \quad-\frac{D_{2}}{T I}\right] \frac{\partial\left(\operatorname{Ln}(L), \operatorname{Ln}(R), \operatorname{Ln}\left(D_{1}\right), \operatorname{Ln}\left(D_{2}\right)\right)}{\partial\left(\operatorname{Ln}\left(p_{L}\right), \operatorname{Ln}\left(p_{R}\right), \operatorname{Ln}\left(p_{1}\right), \operatorname{Ln}\left(p_{2}\right)\right)} \frac{d\left(\operatorname{Ln}\left(p_{L}\right), \operatorname{Ln}\left(p_{R}\right), \operatorname{Ln}\left(p_{1}\right), \operatorname{Ln}\left(p_{2}\right)\right.}{d \operatorname{Ln}(1-\tau)}$

Expression (A.3) is a succinct form of (A.2). I will use this form frequently for ease of writing.

In (A.3), $\frac{\partial\left(\operatorname{Ln}(L), \operatorname{Ln}(R), \operatorname{Ln}\left(D_{1}\right), \operatorname{Ln}\left(D_{2}\right)\right)}{\partial\left(\operatorname{Ln}\left(p_{L}\right), \operatorname{Ln}\left(p_{R}\right), \operatorname{Ln}\left(p_{1}\right), \operatorname{Ln}\left(p_{2}\right)\right)}$ equals the matrix of

$$
\left[\begin{array}{llll}
\frac{\partial \operatorname{Ln}(L)}{\partial \operatorname{Ln}\left(p_{L}\right)} & \frac{\partial \operatorname{Ln}(L)}{\partial \operatorname{Ln}\left(p_{R}\right)} & \frac{\partial \operatorname{Ln}(L)}{\partial \operatorname{Ln}\left(p_{1}\right)} & \frac{\partial \operatorname{Ln}(L)}{\partial \operatorname{Ln}\left(p_{2}\right)} \\
\frac{\partial \operatorname{Ln}(R)}{\partial \operatorname{Ln}\left(p_{L}\right)} & \frac{\partial \operatorname{Ln}(R)}{\partial \operatorname{Ln}\left(p_{R}\right)} & \frac{\partial \operatorname{Ln}(R)}{\partial \operatorname{Ln}\left(p_{1}\right)} & \frac{\partial \operatorname{Ln}(R)}{\partial \operatorname{Ln}\left(p_{2}\right)} \\
\frac{\partial \operatorname{Ln}\left(D_{1}\right)}{\partial \operatorname{Ln}\left(p_{L}\right)} & \frac{\partial \operatorname{Ln}\left(D_{1}\right)}{\partial \operatorname{Ln}\left(p_{R}\right)} & \frac{\partial \operatorname{Ln}\left(D_{1}\right)}{\partial \operatorname{Ln}\left(p_{1}\right)} & \frac{\partial \operatorname{Ln}\left(D_{1}\right)}{\partial \operatorname{Ln}\left(p_{2}\right)} \\
\frac{\partial \operatorname{Ln}\left(D_{2}\right)}{\partial \operatorname{Ln}\left(p_{L}\right)} & \frac{\partial \operatorname{Ln}\left(D_{2}\right)}{\partial \operatorname{Ln}\left(p_{R}\right)} & \frac{\partial \operatorname{Ln}\left(D_{2}\right)}{\partial \operatorname{Ln}\left(p_{1}\right)} & \frac{\partial \operatorname{Ln}\left(D_{2}\right)}{\partial \operatorname{Ln}\left(p_{2}\right)}
\end{array}\right],
$$

and $\frac{d\left(\operatorname{Ln}\left(p_{L}\right), \operatorname{Ln}\left(p_{R}\right), \operatorname{Ln}\left(p_{1}\right), \operatorname{Ln}\left(p_{2}\right)\right)}{d \operatorname{Ln}(1-\tau)}$ equals the matrix of 


$$
\left[\begin{array}{c}
\frac{d \operatorname{Ln}\left(p_{L}\right)}{d \operatorname{Ln}(1-\tau)} \\
\frac{d \operatorname{Ln}\left(p_{R}\right)}{d \operatorname{Ln}(1-\tau)} \\
\frac{d \operatorname{Ln}\left(p_{1}\right)}{d \operatorname{Ln}(1-\tau)} \\
\frac{d \operatorname{Ln}\left(p_{2}\right)}{d \operatorname{Ln}(1-\tau)}
\end{array}\right]
$$

In (A.1) to (A.3), all quantities are evaluated at $\tau=0$. Expressions (A.1) says that the ETI is the weighted average of taxable income's 4 components' elasticities - the elasticity of $L$, the elasticity of $R$, the elasticity of $D_{1}$, and the elasticity of $D_{2}$, all with respect to $1-\tau$. If $L$ is labor income, then $\frac{d \operatorname{Ln}(L)}{d \operatorname{Ln}(1-\tau)}$ is the labor supply elasticity. ${ }^{40}$ If $D_{1}$ is charitable giving, then its elasticity is the tax-price elasticity of charitable giving. The weights, $\frac{L}{T I}, \frac{R}{T I}, \frac{-D_{1}}{T I}$, and $\frac{-D_{2}}{T I}$, are the components' relative sizes as proportions of taxable income, signed positively or negatively based on whether a component is an income or a deduction. The weights sum up to 1 since $T I$ equals $L+R-D_{1}-D_{2}$. Expression (A.2) says that each of the 4 component elasticities in (A.1) consists of one own price elasticity with respect to the component's own tax-price and three cross price elasticities with respect to, respectively, the other three components' tax-prices, weighted by each tax-price's derivative with respect to $1-\tau$. So if the tax rule regarding any one component changes, the ETI and all 4 component elasticities in (A.1) could potentially change. For example, if $p_{1}$ changes from $1-\tau$ to 1 as a result of the repealing of the deductibility of $D_{1}$, then all derivatives in (A.2) involving $p_{1}$ (in the vertical dashed box in (A.2)) would change. As a result, aside from the ETI and the elasticity of $D_{1}$ with respect to 1- $\tau$, (A.1)'s elasticities of $L, R$, and $D_{2}$ (all with respect to 1- $\tau$ ) will change as well through the cross price effects. In this paper I estimate a pair of cross price effects in a case study of two specific deductions. In other words, the interests of this paper are terms like $\frac{\partial \operatorname{Ln}\left(D_{1}\right)}{\partial \operatorname{Ln}\left(p_{2}\right)}$ and $\frac{\partial \operatorname{Ln}\left(D_{2}\right)}{\partial \operatorname{Ln}\left(p_{1}\right)}$ in (A.2). In the rest of this section, I review the literature. For each category of empirical studies, I point out what parameter(s) it estimates in terms of (A.1) and (A.2). This will clarify relations of the studies, and evidence the importance of understanding ETI's own and cross elasticity structure.

\section{A2.2 the ETI}

In terms of (A.1) and (A.2), empirical studies on ETI estimate the single parameter, ETI, on the left hand side of (A.1). Feldstein (1996) estimates it to be between 1 and 3, and the subsequent literature have lower estimates. A representative estimate is Gruber and Saez's (2002) 0.40. Table A.1

\footnotetext{
${ }^{40}$ More rigorously, it is the labor supply elasticity only if wage is not affected by marginal tax rates. Otherwise it can only be called the labor income elasticity. Kubik (2004) finds that TRA86 affected equilibrium sector wages. Please see the footnote in Appendix 1 for more details.
} 
lists existing estimates varying between -1.3 and $2 .{ }^{41}$ Saez, Slemrod and Giertz (2012) do a thorough literature review, and conclude that the best available long-run estimates range from 0.12 to $0.4{ }^{42}$

Table A.1 Estimates on the Elasticities of Taxable Income and Other Types of Incomes [Except for the last 3 rows, this table reproduces Gruber and Saez (2002)'s Table 1, Columns (1), (3), (6) and (7)]

\begin{tabular}{|c|c|c|c|}
\hline Author (date) & Tax change & Income definitions & Elasticity results \\
\hline \multirow[t]{2}{*}{ Lindsey (1987) } & ERTA 81 & Taxable income & Elast.: $1.05-2.75$ \\
\hline & & & Central estimate: 1.6 \\
\hline \multirow[t]{2}{*}{ Feldstein (1995) } & TRA 86 & AGI & Elast. of AGI: $0.75-1.3$ \\
\hline & & Taxable income & Elast. of taxable income: $1.1-3.05$ \\
\hline Navratil (1995) & ERTA 81 & Taxable Income & Elast. of taxable income: 0.8 \\
\hline \multirow[t]{2}{*}{ Auten and Carroll (1997) } & TRA 86 & Gross Income & Elast. of gross inc.: 0.66 \\
\hline & & Taxable Income & Elast. of taxable income: 0.75 \\
\hline Sammartino and Weiner (1997) & OBRA 1993 & AGI & $\begin{array}{l}\text { Close to zero permanent response of } \\
\text { AGI }\end{array}$ \\
\hline \multirow[t]{2}{*}{ Goolsbee (1998) } & OBRA 1993 & Wages, Bonus and & Short run elast.: 1 \\
\hline & & Stock Options & Long run elast.: 0.1 \\
\hline Carroll (1998) & OBRA 1993 & Taxable Income & Elast.: 0.5 \\
\hline \multirow[t]{2}{*}{ Saez (1999) } & Bracket Creep & AGI & Elast. of AGI: 0.25 \\
\hline & & Taxable Income & Elast. of taxable income: 0.4 \\
\hline Moffitt and Wilhelm (2000) & TRA 86 & AGI & $\begin{array}{l}\text { Elast. of AGI: } 0 \text { to } 2 \\
\text { depends on instruments }\end{array}$ \\
\hline Goolsbee (1999) & Various tax ref. & Taxable Income & $\begin{array}{l}\text { Elast. from }-1.3 \text { to } 2 \\
\text { depending on tax reform }\end{array}$ \\
\hline \multirow[t]{2}{*}{ Gruber and Saez (2002) } & ERTA 81 & Broad Income & Elasticity of Broad Income: 0.12 \\
\hline & TRA 86 & Taxable Income & Elasticity of Taxable Income: 0.4 \\
\hline \multirow[t]{2}{*}{ Auten, Carroll, and Gee (2008) } & EGTRRA 2001 & Taxable Income & Elasticity of Taxable Income: 0.4 \\
\hline & JGTRRA 2003 & & \\
\hline \multirow[t]{2}{*}{ Heim (2008) } & EGTRRA 2001 & Broad Income & Elasticity of Broad Income: 0.1-0.2 \\
\hline & JGTRRA 2003 & Taxable Income & Elasticity of Taxable Income: 0.4 \\
\hline
\end{tabular}

Source: Gruber and Saez (2002)

Tax reforms often redefine taxable income. Expressions (A.1) and (A.2) make it clear that the tax system before such a reform and the system after it can have different ETIs. A related estimation issue highlights the importance of the own and cross elasticity structure in (2). If the pre-reform taxable income definition differs from the post-reform taxable income definition, estimating the ETI by "naively" regressing the difference between the two differently defined taxable incomes on the change in tax rate is wrong. It will confound tax-induced changes in behavior with definitional changes (Slemrod 1998). For example, consider a hypothetical tax reform that removes the charitable giving

\footnotetext{
${ }^{41}$ This table also contains estimates of the elasticity of broad income, which I discuss later.

${ }^{42}$ Meanwhile, they also conclude that there are not truly convincing estimates of the long-run elasticity, because it is very hard to identify the effect of tax rate changes separately from other factors changing the income distribution.
} 
deduction and decreases the tax rate from $20 \%$ to $10 \%$. A hypothetical household does not respond to tax law changes at all, and always earn $\$ 100$ in income and donate $\$ 20$ to charities. Although their ETI is always zero, the aforementioned "naive" regression will find their taxable income increasing from $\$ 100-\$ 20=\$ 80$ to $\$ 100$ responding to the $10 \%$ tax cut. Aware of this, researchers have used either a consistent pre- or post-definition of taxable income (Slemrod 1998). However, the more hidden issue is: as long as the responsiveness to tax rates is not zero, even if we use a consistent preor post-definition, the ETI estimate using data before and after the reform may be neither an unbiased estimate of the pre-reform ETI nor an unbiased estimate of the post-reform ETI. In addition, it may be neither an unbiased estimate of the responsiveness of the post-reform style taxable income to tax rates under the pre-reform system, nor an unbiased estimate of the responsiveness of the pre-reform style taxable income to tax rates under the post-reform system. In short, the estimate may bias from any meaningful elasticity. I will explain why thoroughly. Gruber and Saez (2002) briefly refer to this issue pertaining to their estimation. Slemrod (1998) discusses this issue in more details with an example. In both papers, the biases have certain directions. Now I explain this issue more formally and more systematically from the perspective of expression (A.2). Along the way I will pick up Gruber and Seaz (2002)'s and Slemrod (1998)'s examples.

Consider a tax reform that broadens the base from $T I_{0}=L+R-D_{1}-D_{2}$ to $T I_{1}=L+R-D_{1}$, and cuts the tax rate from $\tau=t_{0}$ to $\tau=t_{1}$. Call the tax system before the reform System 0 and the tax system after the reform System 1. Now we are perhaps the most interested in the elasticity of taxable income under System 1. Call it $E T I_{11}$. This is the elasticity of $T I_{1}=L+R-D_{1}$ with respect to 1- $\tau$ under System 1. In addition, we may also want to know ETI 00 , the elasticity of $L+R-D_{1}-D_{2}$ with respect to 1- $\tau$ under System 0; $E T I_{10}$, the elasticity of $L+R-D_{1}$ with respect to 1- $\tau$ under System 0; and $E T I_{01}$, the elasticity of $L+R-D_{1}-D_{2}$ with respect to 1- $\tau$ under System 0 . Now I illustrate that, in light of the structure in (A.2), the reform-induced change in $\operatorname{Ln}\left(L+R-D_{1}\right)$ (or the change in $\operatorname{Ln}\left(L+R-D_{1}-D_{2}\right)$ as well $)$ divided by $\operatorname{Ln}\left(1-t_{1}\right)-\operatorname{Ln}\left(1-t_{0}\right)$, i.e. $\widehat{e_{1}}=\frac{\Delta \operatorname{Ln}\left(L+R-D_{1}\right)}{\Delta \operatorname{Ln}(1-\tau)}$ (or $\widehat{e_{0}}=$ $\left.\frac{\Delta L n\left(L+R-D_{1}-D_{2}\right)}{\Delta L n(1-\tau)}\right)$ may not be an unbiased estimate of any of the four elasticities of $E T I_{11}, E T I_{00}, E T I_{10}$, and $E T I_{01}$. Without loss of generality, normalize the amount of $\operatorname{Ln}\left(L+R-D_{1}\right)$ at $\tau=0$ to 1 and the amount of $\operatorname{Ln}\left(L+R-D_{1}-D_{2}\right)$ at $\tau=0$ to $w<1$. By definition of the elasticities, the relations between $L+R-D_{1}-D_{2}$ as well as $L+R-D_{1}$ and $1-\tau$ satisfy the following four equations:

$$
\begin{aligned}
\text { Under System 0: } & \operatorname{Ln}\left(L+R-D_{1}-D_{2}\right)=w+E T I_{00} \times \operatorname{Ln}(1-\tau) \quad \ldots(A .4) \\
& \operatorname{Ln}\left(L+R-D_{1}\right)=1+\operatorname{ETI}_{10} \times \operatorname{Ln}(1-\tau) \quad \ldots(A .5) \\
\text { Under System 1: } & \operatorname{Ln}\left(L+R-D_{1}-D_{2}\right)=w+E T I_{01} \times \operatorname{Ln}(1-\tau) \quad \ldots(A .6) \\
& \operatorname{Ln}\left(L+R-D_{1}\right)=1+\operatorname{ETI}_{11} \times \operatorname{Ln}(1-\tau) \quad \ldots(A .7)
\end{aligned}
$$


Now I plot all four equations on one graph. They will be four straight lines with slopes of, respectively, $E T I_{00}, E T I_{10}, E T I_{01}$, and $E T I_{10}$, and with intercepts of, respectively, w, 1, w, and 1 . The plot will demonstrate how $\widehat{e_{1}}$ and $\widehat{e_{0}}$ could be biased from $E T I_{00}, E T I_{10}, E T I_{01}$, and $E T I_{10}$. Before plotting, I discuss the relative magnitudes of the four slopes. In succinct expressions like (A.3), the four slopes are:

$E T I_{00}$

$=\left[\frac{L}{T I_{0}} \quad \frac{R}{T I_{0}} \quad-\frac{D_{1}}{T I_{0}} \quad-\frac{D_{2}}{T I_{0}}\right] \frac{\partial\left(\operatorname{Ln}(L), \operatorname{Ln}(R), \operatorname{Ln}\left(D_{1}\right), \operatorname{Ln}\left(D_{2}\right)\right)}{\partial\left(\operatorname{Ln}\left(p_{L}\right), \operatorname{Ln}\left(p_{R}\right), \operatorname{Ln}\left(p_{1}\right), \operatorname{Ln}\left(p_{2}\right)\right)} \frac{d\left(\operatorname{Ln}\left(p_{L}\right), \operatorname{Ln}\left(p_{R}\right), \operatorname{Ln}\left(p_{1}\right), \operatorname{Ln}\left(p_{2}\right)\right)}{d \operatorname{Ln}(1-\tau)}$, $\operatorname{ETI}_{10}$

$=\left[\begin{array}{lll}\frac{L}{T I_{1}} & \frac{R}{T I_{1}} & -\frac{D_{1}}{T I_{1}}\end{array}\right] \frac{\partial\left(\operatorname{Ln}(L), \operatorname{Ln}(R), \operatorname{Ln}\left(D_{1}\right)\right)}{\partial\left(\operatorname{Ln}\left(p_{L}\right), \operatorname{Ln}\left(p_{R}\right), \operatorname{Ln}\left(p_{1}\right), \operatorname{Ln}\left(p_{2}\right)\right)} \frac{d\left(\operatorname{Ln}\left(p_{L}\right), \operatorname{Ln}\left(p_{R}\right), \operatorname{Ln}\left(p_{1}\right), \operatorname{Ln}\left(p_{2}\right)\right)}{d \operatorname{Ln}(1-\tau)}$,

$\operatorname{ETI}_{01}=\left[\begin{array}{llll}\frac{L}{T I_{0}} & \frac{R}{T I_{0}} & -\frac{D_{1}}{T I_{0}} & -\frac{D_{2}}{T I_{0}}\end{array}\right] \frac{\partial\left(\operatorname{Ln}(L), \operatorname{Ln}(R), \operatorname{Ln}\left(D_{1}\right), \operatorname{Ln}\left(D_{2}\right)\right)}{\partial\left(\operatorname{Ln}\left(p_{L}\right), \operatorname{Ln}\left(p_{R}\right), \operatorname{Ln}\left(p_{1}\right)\right)} \frac{d\left(\operatorname{Ln}\left(p_{L}\right), \operatorname{Ln}\left(p_{R}\right), \operatorname{Ln}\left(p_{1}\right)\right)}{d \operatorname{Ln}(1-\tau)}$,

and

$$
E T I_{11}=\left[\frac{L}{T I_{1}} \frac{R}{T I_{1}} \quad-\frac{D_{1}}{T I_{1}}\right] \frac{\partial\left(\operatorname{Ln}(L), \operatorname{Ln}(R), \operatorname{Ln}\left(D_{1}\right)\right)}{\partial\left(\operatorname{Ln}\left(p_{L}\right), \operatorname{Ln}\left(p_{R}\right), \operatorname{Ln}\left(p_{1}\right)\right)} \frac{d\left(\operatorname{Ln}\left(p_{L}\right), \operatorname{Ln}\left(p_{R}\right), \operatorname{Ln}\left(p_{1}\right)\right)}{d \operatorname{Ln}(1-\tau)}
$$

Their differences depend on various own and cross elasticities in (A.2). For example, $E T I_{10}$ and $E T I_{11}$ differ by $\left[\frac{L}{T I_{1}} \frac{\partial \operatorname{Ln}(L)}{\partial \operatorname{Ln}\left(p_{2}\right)}+\frac{R}{T I_{1}} \frac{\partial \operatorname{Ln}(R)}{\partial \operatorname{Ln}\left(p_{2}\right)}-\frac{D_{1}}{T I_{1}} \frac{\partial \operatorname{Ln}\left(D_{1}\right)}{\partial \operatorname{Ln}\left(p_{2}\right)}\right] \frac{d \operatorname{Ln}\left(p_{2}\right)}{d \operatorname{Ln}(1-\tau)}$, whose sign is uncertain. In general, depending on the values of the own and cross elasticities, any one of the four slopes can possibly be larger, smaller, or equal to another. Figure A.1 is plotted under one possible scenario of $E T I_{11}>$ $E T I_{10}, E T I_{00}>E T I_{10}$ and $E T I_{00}>E T I_{01}$. The four thin lines plot (A.4) to (A.7), with slopes labelled. I claim without showing the tedious proof that, one set of sufficient conditions that could produce this ordinal relationship is: (c1) $\frac{\partial \operatorname{Ln}(L)}{\partial \operatorname{Ln}\left(p_{2}\right)}, \frac{\partial \operatorname{Ln}\left(D_{2}\right)}{\partial \operatorname{Ln}\left(p_{L}\right)}, \frac{\partial \operatorname{Ln}(R)}{\partial \operatorname{Ln}\left(p_{2}\right)}$, and $\frac{\partial \operatorname{Ln}\left(D_{2}\right)}{\partial \operatorname{Ln}\left(p_{R}\right)}$ are negligible; (c2) $\frac{\partial \operatorname{Ln}\left(D_{2}\right)}{\partial \operatorname{Ln}\left(p_{1}\right)}<0, \frac{\partial \operatorname{Ln}\left(D_{1}\right)}{\partial \operatorname{Ln}\left(p_{2}\right)}>0, \frac{\partial \operatorname{Ln}\left(D_{2}\right)}{\partial \operatorname{Ln}\left(p_{1}\right)}>0$; and (c3) $\frac{\partial \operatorname{Ln}\left(D_{2}\right)}{\partial \operatorname{Ln}\left(p_{1}\right)} \frac{d \operatorname{Ln}\left(p_{1}\right)}{d \operatorname{Ln}(1-\tau)}+\frac{\partial \operatorname{Ln}\left(D_{2}\right)}{\partial \operatorname{Ln}\left(p_{2}\right)} \frac{d \operatorname{Ln}\left(p_{2}\right)}{d \operatorname{Ln}(1-\tau)}<$ $0, \frac{D_{1}}{T I_{0}} \frac{\partial \operatorname{Ln}\left(D_{1}\right)}{\partial \operatorname{Ln}\left(p_{2}\right)} \frac{d \operatorname{Ln}\left(p_{2}\right)}{d \operatorname{Ln}(1-\tau)}+\frac{D_{2}}{T I_{0}} \frac{\partial \operatorname{Ln}\left(D_{2}\right)}{\partial \operatorname{Ln}\left(p_{2}\right)} \frac{d \operatorname{Ln}\left(p_{2}\right)}{d \operatorname{Ln}(1-\tau)}<0$. Condition (c1) says that incomes do not respond to the tax-price of $D_{2}$ and vice versa. Condition (c2) says that $D_{2}$ decreases in its own tax-price and that $D_{1}$ and $D_{2}$ are substitutes. An example of substitutable deductions are consumer interest and home equity loan interest, both deductible before TRA 86 (Slemrod 1998). Condition (c3) says that the absolute value of the own price elasticity of $D_{2}$ is larger than the cross elasticities between $D_{1}$ and $D_{2}$.

In Figure A.1, Point A marks the pre reform level of $\operatorname{Ln}\left(L+R-D_{1}\right)$ under $\tau=t_{0}$. Point B marks the post reform level of $\operatorname{Ln}\left(L+R-D_{1}\right)$ under $\tau=t_{1}$. Therefore the slope of line $\mathrm{AB}$ is $\widehat{e_{1}}=$ $\frac{\Delta L n\left(L+R-D_{1}\right)}{\Delta L n(1-\tau)}$. The graph shows that $\widehat{e_{1}}$ can be different from $E T I_{11}$, and deviate from the other three meaningful taxable income elasticities as well. Similarly, Point C and Point D mark the pre- and post- 
reform levels of $\operatorname{Ln}\left(L+R-D_{1}-D_{2}\right)$, and the slope of line CD is $\widehat{e_{0}}=\frac{\Delta L n\left(L+R-D_{1}-D_{2}\right)}{\Delta L n(1-\tau)}$. As in Figure A.1, $\widehat{e_{0}}$ deviates from $E T I_{00}$ and $E T I_{01}$, and is not guaranteed to be close to $E T I_{10}$ or $E T I_{11}$ either. Despite all the lengthy discussion above, the underlying intuition is simple. Both $\widehat{e_{0}}$ and $\widehat{e_{1}}$ embody the effects of both the tax rate change and the taxable income definition change, while all the taxable elasticities we are interested in, especially $E T I_{11}$ and $E T I_{00}$, purely measure the effect of tax rate changes. So the biases of $\widehat{e_{0}}$ and $\widehat{e_{1}}$ from $E T I_{11}$ and $E T I_{00}$ are essentially omitted variable bias. The directions of the biases depend on values of terms in (A.2).

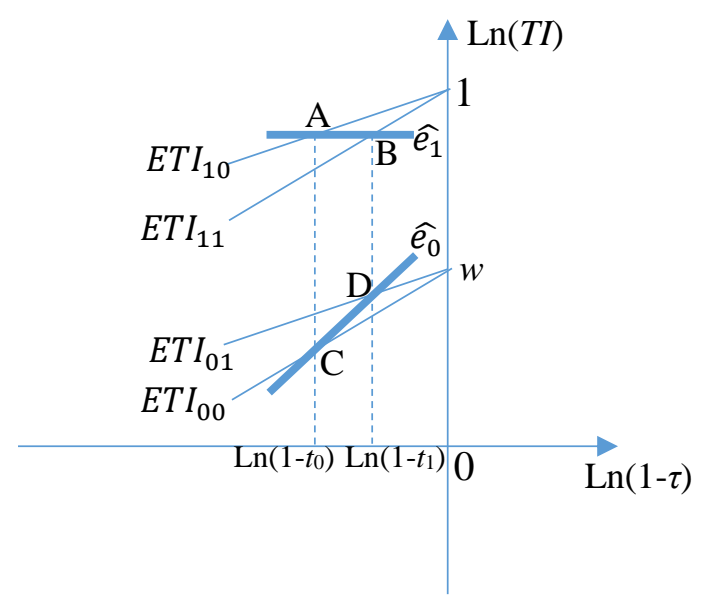

Figure A.1

Conditions (c1) to (c3) are chosen such that Figure A.1 displays the same bias directions with special cases in Gruber and Saez (2002) and Slemrod (1998). Gruber and Saez (2002) say that "we potentially understate the responsiveness of taxable income to taxation, even from the perspective of 1990 [p. 8]". "What causes it is the substitutability between different "avoidance avenues". This resembles that $E T I_{10}$ understates $E T I_{11}$ due to the substitutability between $D_{1}$ and $D_{2}$. In Slemrod (1998) [p. 784], the actual response of the broader base (this response is measured as $\widehat{e_{1}}$ in Figure A.1) understates the would-be response of the broader base with $t_{0}$ dropping to $t_{1}$ but without changing the definition of taxable income (this response is $E T I_{10}$ in Figure A.1; "understate" means $\widehat{e_{1}}<E T I_{10}$ ). And, the actual response of the narrower base (this response is $\widehat{e_{0}}$ in Figure A.1) overstates the wouldbe response of the broader base with $t_{0}$ dropping to $t_{1}$ but without changing the definition of taxable income (this response is $E T I_{10}$ in Figure A.1; "overstate" means $\widehat{e_{0}}>E T I_{10}$ ).

${ }^{43}$ They also mention that this understatement is offset by overstatement due to income shifting from individual to corporate income tax base. 
Figure A.1 only displays a baseline scenario of the biases in $\widehat{e_{0}}$ and $\widehat{e_{1}}$. Without restrictions like (c1) to (c3), magnitudes and directions of the biases can be arbitrary, depending on values of the own and cross price elasticities.

\section{A2.3 the labor supply elasticity and the tax-price elasticity of charitable giving}

Both elasticities are for a taxable income component with respect to 1- $\tau$. As I mentioned earlier, in my simple hypothetical example with $T I=L+R-D_{1}-D_{2}$, if $L$ represents labor income and $D_{1}$ represents charitable giving amount, $\frac{d \operatorname{Ln}(L)}{d \operatorname{Ln}(1-\tau)}$ and $\frac{d \operatorname{Ln}\left(D_{1}\right)}{d \operatorname{Ln}(1-\tau)}$ in (A.1) will be, respectively, the labor supply elasticity with respect to $1-\tau$ and the charitable giving tax-price elasticity. ${ }^{44}$ However, notice that what the tax-price elasticity of charitable giving literature attempts to estimate is not the same with $\frac{d \operatorname{Ln}\left(D_{1}\right)}{d \operatorname{Ln}(1-\tau)}$. Based on the literature's assumptions of other deductions are exogenous and that $\tau$ is constructed to be the marginal tax rate calculated using zero giving but the full amounts of other deductions, what supposedly estimated in the literature is $\frac{\partial \operatorname{Ln}\left(D_{1}\right)}{\partial \operatorname{Ln}(1-\tau)}$. Before the focus on the ETI, researchers analyzing the income tax primarily focused on estimating the elasticity of labor supply with respect to $1-\tau$; existing estimates suggest that it is fairly small overall and even close to zero for prime-age males, although it is higher for secondary earners (Saez, Slemrod and Giertz 2012; Gruber and Saez 2002) ${ }^{45}$ In contrast, existing studies find significant tax-price elasticities of charitable giving. Table A.2 lists a few representative estimates, all around -1. Peloza and Steel (2005)'s meta analysis provides a summary of findings, showing that the estimates range between -7.07 and 0.12.

Table A.2 Estimates on the Tax-price Elasticities of Charitable Giving

\begin{tabular}{|c|c|c|}
\hline Study & $\begin{array}{l}\text { Price Elasticity } \\
\text { Estimate (Standard } \\
\text { Error) }\end{array}$ & Data \\
\hline Bakija and Heim (2011) & $-1.10(0.45)^{a}$ & $1979-2006$ tax returns, panel \\
\hline $\begin{array}{l}\text { Auten, Sieg, and } \\
\text { Clotfelter(2002) }\end{array}$ & $-1.26(0.04) ;-0.46^{b}$ & $1979-1993$ tax returns, panel \\
\hline Barrett (1991) & $-1.09(0.11)$ & $1979-1986$ tax returns, panel \\
\hline Friedberg and $\mathrm{He}$ (2015) & $-1.23(0.55)$ & $\begin{array}{l}1989 \text { - } 2007 \text { Survey of Consumer } \\
\text { Finances }\end{array}$ \\
\hline Tiehen (2001) & $-1.15(0.68)$ & $\begin{array}{l}1987-1995 \text { Independent Sector } \\
\text { Surveys on Giving and Volunteering }\end{array}$ \\
\hline Reece (1979) & $-1.19(0.29)$ & $\begin{array}{l}1972-73 \text { Consumer Expenditure } \\
\text { Survey }{ }^{c}\end{array}$ \\
\hline Reece and Zieschang (1985) & -0.85 & $\begin{array}{l}1972-73 \text { Consumer Expenditure } \\
\text { Survey }{ }^{c}\end{array}$ \\
\hline
\end{tabular}

${ }^{44}$ Again, $\frac{d \operatorname{Ln}(L)}{d \operatorname{Ln}(1-\tau)}$ is labor supply elasticity assuming away wage change. See an earlier footnote . ${ }^{45}$ Blundell and MaCurdy (1999) and McClelland and Mok (2012) provide thorough reviews of the literature on labor supply elasticity. 
b: -1.26, is their core estimate under certain econometric assumptions for the change of permanent and transitory income and price; -0.46 , which only appears in a footnote, is from a pooled regression model using fixed effects and therefore more comparable to other estimates in the literature.

c: these two studies used the same data, but Reece (1979) does a reduced form regression while Reece and Zieschang (1985) uses the Hausman method.

\section{A2.4 The broad income elasticity}

The literature frequently estimate the elasticity of a measure of income broader than taxable income (see Table A.1 earlier). In my illustrative example with $T I=L+R-D_{1}-D_{2}$, a "broad income" could be defined as $B=L+R$, and a "broad income elasticity" refers to the elasticity of $B$ with respect to 1- $\tau$. In forms like Expressions (A.1) and (A.2), this means rewriting taxable income as $T I=B-D_{1}$ $D_{2}$ and rewriting Expressions (A.1) and (A.2) as

$$
\begin{gathered}
E T I=\frac{B}{T I} \frac{d \operatorname{Ln}(B)}{d \operatorname{Ln}(1-\tau)}-\frac{D_{1}}{T I} \frac{d \operatorname{Ln}\left(D_{1}\right)}{d \operatorname{Ln}(1-\tau)}-\frac{D_{2}}{T I} \frac{d \operatorname{Ln}\left(D_{2}\right)}{d \operatorname{Ln}(1-\tau)} \\
=\frac{B}{T I}\left[\frac{\partial \operatorname{Ln}(B)}{\partial \operatorname{Ln}\left(p_{B}\right)} \frac{d \operatorname{Ln}\left(p_{B}\right)}{d \operatorname{Ln}(1-\tau)}+\frac{\partial \operatorname{Ln}(B)}{\partial \operatorname{Ln}\left(p_{1}\right)} \frac{d \operatorname{Ln}\left(p_{1}\right)}{d \operatorname{Ln}(1-\tau)}+\frac{\partial \operatorname{Ln}(B)}{\partial \operatorname{Ln}\left(p_{2}\right)} \frac{d \operatorname{Ln}\left(p_{2}\right)}{d \operatorname{Ln}(1-\tau)}\right] \\
-\frac{D_{1}}{T I}\left[\frac{\partial \operatorname{Ln}\left(D_{1}\right)}{\partial \operatorname{Ln}\left(p_{B}\right)} \frac{d \operatorname{Ln}\left(p_{L}\right)}{d \operatorname{Ln}(1-\tau)}+\frac{\partial \operatorname{Ln}\left(D_{1}\right)}{\partial \operatorname{Ln}\left(p_{1}\right)} \frac{d \operatorname{Ln}\left(p_{1}\right)}{d \operatorname{Ln}(1-\tau)}+\frac{\partial \operatorname{Ln}\left(D_{1}\right)}{\partial \operatorname{Ln}\left(p_{2}\right)} \frac{d \operatorname{Ln}\left(p_{2}\right)}{d \operatorname{Ln}(1-\tau)}\right] \\
-\frac{D_{2}}{T I}\left[\frac{\partial \operatorname{Ln}\left(D_{2}\right)}{\partial \operatorname{Ln}\left(p_{B}\right)} \frac{d \operatorname{Ln}\left(p_{L}\right)}{d \operatorname{Ln}(1-\tau)}+\frac{\partial \operatorname{Ln}\left(D_{2}\right)}{\partial \operatorname{Ln}\left(p_{1}\right)} \frac{d \operatorname{Ln}\left(p_{1}\right)}{d \operatorname{Ln}(1-\tau)}+\frac{\partial \operatorname{Ln}\left(D_{2}\right)}{\partial \operatorname{Ln}\left(p_{2}\right)} \frac{d \operatorname{Ln}\left(p_{2}\right)}{d \operatorname{Ln}(1-\tau)}\right] \\
=\left[\frac{B}{T I} \quad-\frac{D_{1}}{T I}-\frac{D_{2}}{T I}\right] \frac{\partial\left(\operatorname{Ln}(B), \operatorname{Ln}\left(D_{1}\right), \operatorname{Ln}\left(D_{2}\right)\right)}{\partial\left(\operatorname{Ln}\left(p_{B}\right), \operatorname{Ln}\left(p_{1}\right), \operatorname{Ln}\left(p_{2}\right)\right)} \frac{d\left(\operatorname{Ln}\left(p_{B}\right), \operatorname{Ln}\left(p_{1}\right), \operatorname{Ln}\left(p_{2}\right)\right)}{d \operatorname{Ln}(1-\tau)}
\end{gathered}
$$

The broad income elasticity would be $\frac{d \operatorname{Ln}(B)}{d \operatorname{Ln}(1-\tau)}$ in (A.1'), equal to the three-term sum in (A.2')'s first bracket. So broad income elasticity characterizes the "average" responsiveness of $L$ and $R$ to 1- $\tau$. In this view the broad income elasticity is more like a component elasticity such as the charitable giving elasticity than the ETI in nature.

Gruber and Saez (2002) find a large difference between the broad income elasticity (0.120) and the ETI (0.400). In terms of (A.1'), it is the difference between $\frac{d \operatorname{Ln}(B)}{d \operatorname{Ln}(1-\tau)}$ and ETI. They mention two 
sources of the difference, one "mechanical" (see footnote) and one "behavioral" (i.e. the itemized deductions being responsive) ${ }^{46}$ Equation (A.1') has the ETI on the left hand side and the broad income elasticity $\left(\frac{d \operatorname{Ln}(B)}{d \operatorname{Ln}(1-\tau)}\right)$ on the right hand side and thus makes crystal clear what exactly the two sources of difference are: the "mechanical" source is $\frac{B}{T I}$ and the "behavioral" source is $-\frac{D_{1}}{T I} \frac{d \operatorname{Ln}\left(D_{1}\right)}{d \operatorname{Ln}(1-\tau)}-$ $\frac{D_{2}}{T I} \frac{d \operatorname{Ln}\left(D_{2}\right)}{d \operatorname{Ln}(1-\tau)}$. From (A.1') we also know that these two sources of difference Gruber and Saez (2002) give are exhaustive, i.e. there are no other sources of difference.

\section{A2.5 Cross price effect portions of the broad income elasticity and the ETI}

Kopczuk (2005) estimates the broad income elasticity as a function of the proportion of spending on tax deductible commodities. Similar to previous sections, I describe what he estimates in terms of notations in my simple example.

The broad income part of the decomposition from (A.1') to (A.2') is

$$
\frac{d \operatorname{Ln}(B)}{d \operatorname{Ln}(1-\tau)}=\frac{\partial \operatorname{Ln}(B)}{\partial \operatorname{Ln}\left(p_{B}\right)} \frac{d \operatorname{Ln}\left(p_{B}\right)}{d \operatorname{Ln}(1-\tau)}+\frac{\partial \operatorname{Ln}(B)}{\partial \operatorname{Ln}\left(p_{1}\right)} \frac{d \operatorname{Ln}\left(p_{1}\right)}{d \operatorname{Ln}(1-\tau)}+\frac{\partial \operatorname{Ln}(B)}{\partial \operatorname{Ln}\left(p_{2}\right)} \frac{d \operatorname{Ln}\left(p_{2}\right)}{d \operatorname{Ln}(1-\tau)}
$$

In terms of this decomposition, what Kopczuk (2005) examines is the role of a certain average of the last two terms. I illustrate his process below.

I condense the last two terms on the right hand side. In Kopczuk (2005), all prices equal $1-\tau$. In my example, this means $p_{B}=p_{1}=p_{2}=1-\tau$ and $\frac{d \operatorname{Ln}\left(p_{B}\right)}{d \operatorname{Ln}(1-\tau)}=\frac{d \operatorname{Ln}\left(p_{1}\right)}{d \operatorname{Ln}(1-\tau)}=\frac{d \operatorname{Ln}\left(p_{2}\right)}{d \operatorname{Ln}(1-\tau)}=1$. It follows that

$$
\frac{d \operatorname{Ln}(B)}{d \operatorname{Ln}(1-\tau)}=\frac{\partial \operatorname{Ln}(B)}{\partial \operatorname{Ln}\left(p_{B}\right)}+\frac{\partial \operatorname{Ln}(B)}{\partial \operatorname{Ln}\left(p_{1}\right)}+\frac{\partial \operatorname{Ln}(B)}{\partial \operatorname{Ln}\left(p_{2}\right)}=\frac{\partial \operatorname{Ln}(B)}{\partial \operatorname{Ln}\left(p_{B}\right)}+\left[\frac{\partial \operatorname{Ln}(B)}{\partial \operatorname{Ln}\left(p_{1}\right)}+\frac{\partial \operatorname{Ln}(B)}{\partial \operatorname{Ln}\left(p_{2}\right)}\right]
$$

Using the symmetry of the Slutsky matrix gives ${ }^{47}$

$$
\frac{d \operatorname{Ln}(B)}{d \operatorname{Ln}(1-\tau)}=\frac{\partial \operatorname{Ln}(B)}{\partial \operatorname{Ln}\left(p_{B}\right)}+\left[\frac{D_{1}}{B} \frac{\partial \operatorname{Ln}\left(D_{1}\right)}{\partial \operatorname{Ln}\left(p_{B}\right)}+\frac{D_{2}}{B} \frac{\partial \operatorname{Ln}\left(D_{2}\right)}{\partial \operatorname{Ln}\left(p_{B}\right)}\right] .
$$

\footnotetext{
${ }^{46}$ To understand their meaning of "mechanical", consider a household who respond to a tax rate change by increasing broad income by $x$ dollars. As broad income is larger than taxable income (by Gruber and Saez (2002)'s definition, taxable income equals broad income less deductions and exemptions), the resulted percentage change in broad income, $x$ /broad income, will be smaller than the resulted percentage change in taxable income, $x /$ taxable income. Since these percentage changes are numerators of the broad income elasticity and the ETI, mechanically the broad income elasticity will be smaller than the ETI even though they are measuring the same $\$ x$ change in broad income.

${ }^{47}$ This symmetry only holds for compensated elasticities. Therefore, for all the math steps onwards to hold, all elasticities should be treated as compensated elasticities. Empirically though, the difference (which is the income effect of tax rate changes) between uncompensated and compensated elasticity of broad income or taxable income is not important. Gruber and Saez (2002) find the income effect of tax rate changes on taxable income as well as broad income quite small and highly insignificant, and believe it safe to assume that the compensated and uncompensated elatisity are identical. The review of the ETI literature by Saez, Slemrod and Giertz (2012) says that compelling evidence about significant income effects is absent. Hendren (2015) points out that causal effects, which can be uncompensated elasticity and not necessarily compensated elasticity, are meaningful welfare measurement as well.
} 
Introducing the "tax base" measure of $\gamma=\frac{D_{1}+D_{2}}{B}$, or the total of deductions as a proportion of broad income, the above equation becomes

$$
\begin{aligned}
\frac{d \operatorname{Ln}(B)}{d \operatorname{Ln}(1-\tau)}= & \frac{\partial \operatorname{Ln}(B)}{\partial \operatorname{Ln}\left(p_{B}\right)}+\left[\frac{D_{1}}{D_{1}+D_{2}} \frac{\partial \operatorname{Ln}\left(D_{1}\right)}{\partial \operatorname{Ln}\left(p_{B}\right)}+\frac{D_{2}}{D_{1}+D_{2}} \frac{\partial \operatorname{Ln}\left(D_{2}\right)}{\partial \operatorname{Ln}\left(p_{B}\right)}\right] \frac{D_{1}+D_{2}}{B} \\
= & \frac{\partial \operatorname{Ln}(B)}{\partial \operatorname{Ln}\left(p_{B}\right)}+\left[\frac{D_{1}}{D_{1}+D_{2}} \frac{\partial \operatorname{Ln}\left(D_{1}\right)}{\partial \operatorname{Ln}\left(p_{B}\right)}+\frac{D_{2}}{D_{1}+D_{2}} \frac{\partial \operatorname{Ln}\left(D_{2}\right)}{\partial \operatorname{Ln}\left(p_{B}\right)}\right] \frac{D_{1}+D_{2}}{B} .
\end{aligned}
$$

Let $\varepsilon$ denote $\frac{\partial \operatorname{Ln}(B)}{\partial \operatorname{Ln}\left(p_{B}\right)}$ and let $\beta$ denote everything in the bracket in the previous line. Then the above equation becomes

$$
\frac{d \operatorname{Ln}(B)}{d \operatorname{Ln}(1-\tau)}=\varepsilon+\beta \gamma
$$

So in terms of my simplified 4-component example, what Kopczuk (2005) does is to condense the decomposed broad income elasticity in (A.2')'s first bracket into one own price elasticity, $\varepsilon$, and an average of all cross price elasticities, $\beta$. It says that the broad income elasticity varies in the proportion of deductions $\gamma$. The corresponding form of regression equation with panel data is then

$$
\Delta \operatorname{Ln}(B)=\varepsilon \Delta \operatorname{Ln}(1-\tau)+\beta \gamma \Delta \operatorname{Ln}(1-\tau)+\text { other controls. }
$$

Further, Kopczuk considers the effect of changes in $\gamma$, denoted as $\Delta \gamma$, from introductions of new deductions. For example, if the tax law adds a new deduction $-D_{3}$ to $T I$ 's definition, $\gamma$ will increase from $\frac{D_{1}+D_{2}}{B}$ to $\frac{D_{1}+D_{2}+D_{3}}{B}$. The differential relation that incorporates $\Delta \gamma$ can be written as

$$
\Delta \operatorname{Ln}(B)=\varepsilon \Delta \operatorname{Ln}(1-\tau)+\beta \Delta[\gamma \operatorname{Ln}(1-\tau)]+\text { other constrols, }
$$

under an assumption. The assumption is that the cross elasticities of newly added deductions with respect to $p_{\mathrm{B}}$, e.g. $\frac{\partial \operatorname{Ln}\left(D_{3}\right)}{\partial \operatorname{Ln}\left(p_{B}\right)}$, are equal to $\beta=\frac{D_{1}}{D_{1}+D_{2}} \frac{\partial \operatorname{Ln}\left(D_{1}\right)}{\partial \operatorname{Ln}\left(p_{B}\right)}+\frac{D_{2}}{D_{1}+D_{2}} \frac{\partial \operatorname{Ln}\left(D_{2}\right)}{\partial \operatorname{Ln}\left(p_{B}\right)}$, i.e. the average of existing deductions' cross elasticities with respect to $p_{B}$. In this paper I examine the heterogeneity among different cross elasticities.

Kopczuk (2005) also estimates a similar equation for taxable income, which is $\Delta \operatorname{Ln}(T I)=$ $\varepsilon^{\prime} \Delta \operatorname{Ln}(1-\tau)+\beta^{\prime} \Delta[\gamma \operatorname{Ln}(1-\tau)]+$ other constrols. He finds that both the broad income elasticity and the ETI increases in the proportion of deductions $\gamma$. This implies that broadening the tax base, by removing deductions for example, reduces the deadweight loss per dollar of collected revenue. However, not all base broadening methods are equal. Depending on the values of cross elasticities such as $\frac{\partial \operatorname{Ln}\left(D_{1}\right)}{\partial \operatorname{Ln}\left(p_{2}\right)}$ and $\frac{\partial \operatorname{Ln}\left(D_{2}\right)}{\partial \operatorname{Ln}\left(p_{1}\right)}$ in (A.2), removing certain deductions will reduce the deadweight loss more effectively than removing others. If we are agnostic on the cross elasticity values, lowering all deductions can more safely reduce the deadweight loss and increase revenue than removing a subset of deductions. 
Kopczuk (2005) concludes that models in previous ETI studies neglecting $\gamma$ are misspecified. In addition, he concludes that ETI is not an immutable parameter - meaning that it can be to some extent controlled by policy makers - as it varies with individual's access to tax-deductible items.

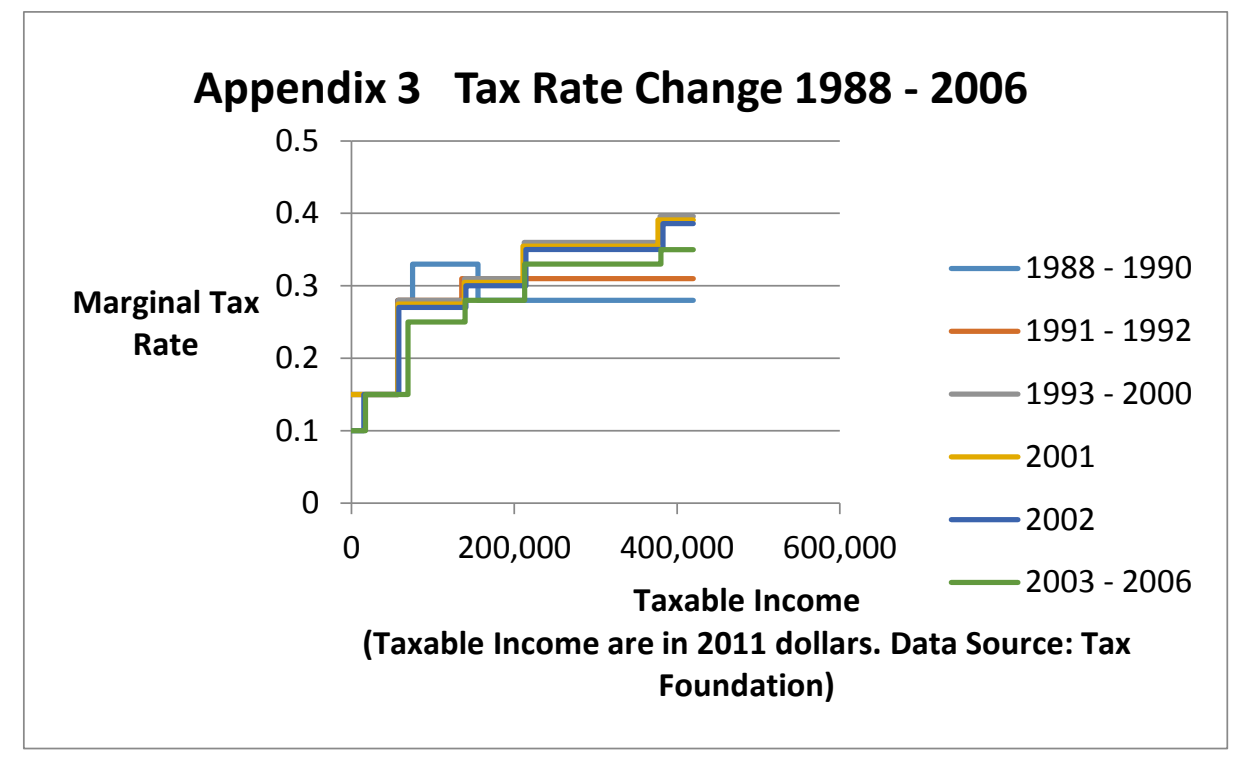

\section{Appendix 4 Accounting for the limit on home equity debt deduction}

By the tax code (see IRS publication 936), interest payment on home equity debt above $\$ 100,000$ are not tax deductible unless it is paid for investment activities (observed in the SCF). Suppose that a household's non-HELOC home equity loans' balance is $b$, then the limit left for their HELOC is $l=\$ 100,000-b$. For households with balance $B$ larger than the limit $l$ (and not borrowing to finance investment activities for which interest is deductible), the first $l \cdot r$ dollars of interest payment is deductible while the following $(B-l) \cdot r$ is not different from principal payment for tax purposes.

(1) For households (about 6\% of the sample) with $B>l$ and $Q \leq l$ (why $Q \leq l$ is included will be clear in (2)) (and not borrowing to finance investment activities for which interest is deductible), expression (5) is trivially different from other households. Simply replace $B \cdot r$ with $l \cdot r$. In other words, we have:

$$
p_{h}=\left\{\begin{array}{c}
1-\tau-r(1-\tau), Q<l \cdot r \\
1-\frac{l \cdot r \cdot \tau}{Q}-r(1-\tau), Q \geq l \cdot r . \quad \ldots(\text { A4.1) }
\end{array}\right.
$$

(2) For households (about $4 \%$ of the sample) with $B>l$ and $Q>l$ (and not borrowing to finance investment activities for which interest is deductible), their future interest saving benefit is different from the case discussed in the main text. Specifically, out of the total repayment of $Q$, if a household postpones the last $l$ dollars to the next year, these $l$ dollars will generate deductible interest. However, if a household postpones the last $l+1$ dollars to the next year, the $(l+1)$ th dollar postponed will generate non-deductible interest. In sum, the benefit of saving future interest for future after tax 
consumption is $r$ for each of the first $Q-l$ dollars and $r(1-\tau)$ for the last $l$ dollars. For the current year after tax consumption, each of the first $l \cdot r$ dollars of repayment forgoes $1-\tau$ dollar of after tax consumption and each of the last $Q-l \cdot r$ dollars of repayment forgoes 1 dollar of after tax consumption. So, if $Q-l \geq l \cdot r$, then the average price at $Q$ is

$$
p_{h}=\frac{l \cdot r \cdot(1-\tau-r)+(Q-l-l \cdot r)(1-r)+l \cdot[1-r(1-\tau)]}{Q}=1-r .
$$

If $Q-l<l \cdot r$, then the average price at $Q$ is

$$
p_{h}=\frac{(Q-l)(1-\tau-r)+(l+l \cdot r-Q)[1-\tau-r(1-\tau)]+(Q-l \cdot r)[1-r(1-\tau)]}{Q}=1-r .
$$

\section{Appendix 5 A discussion of sample selection bias}

As described in the literature review, I restrict my sample to "exogenous itemizers", defined as taxpayers who have more non-charity and non-HELOC-interest-payments than their standard deduction. Further, I restrict my sample to exogenous itemizers who have a HELOC with positive outstanding balance, so that they face the choice on how much to give and how much to repay on HELOCs. This could result in sample selection bias if an unobservable factor affects both the choice of whether to borrow and spending on donations and debt payments. The degree of one's impatience could be such a factor. For example, a household may face a high interest rate but, due to a high level of impatience, still decides to borrow money to buy a new piece of furniture, despite the fact that a high interest rate hurts future consumption. This impatience may also induce the household to donate instead of paying down debt (and being able to donate more in the future). Under this scenario, households in the selected sample that begin to borrowing under high interest rates are the more impatient ones and not representative. That they donate more and pay less on debt than an average household does will lead to an underestimate of the cross-price effect of interest rate on giving. However, concerns about this issue may be moderated by two reasons. First, HELOC interest rates are variable over time. Therefore, observing a high HELOC rate for a household does not necessarily imply high impatience. Second, impatient people do not always have much say in the choice of borrowing. In situations like replacing an old piece of furniture with a new one, more patient households may wait until a low interest year to borrow. But, in other situations such as repairing one's roof or borrowing for children's college education, one may not have the option to wait. 
Appendix 6 Comparing my HELOC borrower sample's statistics with a broader sample

\begin{tabular}{llrrrr}
\hline \hline & Label & \multicolumn{1}{c}{ Mean } & Median & \multicolumn{1}{c}{ P75\% } & \multicolumn{1}{c}{ P90\% } \\
\hline Charity & charitable giving & 3,564 & 1,303 & 3,339 & 7,439 \\
& & 4,356 & 908 & 3,028 & 7,570 \\
$\tau$ & marginal tax rate & $23 \%$ & $25 \%$ & $28 \%$ & $31 \%$ \\
& & $21 \%$ & $25 \%$ & $28 \%$ & $31 \%$ \\
wealth & Wealth & 990,888 & 442,409 & 927,725 & $2,054,249$ \\
& & $1,107,899$ & 310,544 & 771,002 & $2,041,820$ \\
income & disposable income & 120,847 & 90,653 & 136,477 & 206,292 \\
\multirow{2}{*}{ Age } & & 118,852 & 76,642 & 115,908 & 191,414 \\
& Age & 48 & 47 & 55 & 62 \\
edu & & 47 & 46 & 55 & 63 \\
& years of education & 15 & 16 & 17 & 17 \\
$u$ & & 15 & 16 & 16 & 17 \\
& unemployment rate & 5.3 & 5.5 & 6.0 & 6.1 \\
& & 5.3 & 5.5 & 6.0 & 6.8 \\
\hline
\end{tabular}

This table compares the summary statistics of my sample $(N=1,103)$ and the larger sample of all exogenous itemizers $(N=12,209)$. To the right of each variable name, I report my sample's statistics in the first row and the larger sample's in the second row.

\section{Appendix 7 Unweighted regression results}

\begin{tabular}{|c|c|c|c|c|c|c|}
\hline \multirow[b]{2}{*}{ Regressors } & \multicolumn{2}{|c|}{ Marginal Price } & \multicolumn{2}{|c|}{ Average Price } & \multicolumn{2}{|c|}{ Regular Giving Elasticity } \\
\hline & $\begin{array}{l}\text { Estimate } \\
\text { (Standard Error) }\end{array}$ & $\mathrm{p}$-value & $\begin{array}{l}\text { Estimate } \\
\text { (Standard Error) }\end{array}$ & $\mathrm{p}$-value & $\begin{array}{l}\text { Estimate } \\
\text { (Standard Error) }\end{array}$ & $\mathrm{p}$-value \\
\hline \multicolumn{7}{|l|}{ The $\operatorname{Ln}$ (charit) equation } \\
\hline Intercept & $-13.78(1.39)^{* * *}$ & $0.00 \%$ & $-13.60(1.34)^{* * *}$ & $0.0 \%$ & $-12.81(1.38)^{* * *}$ & $0.00 \%$ \\
\hline $\operatorname{Ln}\left(p_{\mathrm{g}}\right)$ & $-0.64(1.02)$ & $53.1 \%$ & $-1.23(1.24)$ & $32.2 \%$ & $-1.12(1.02)$ & $27.4 \%$ \\
\hline $\operatorname{Ln}\left(p_{q}\right)$ & $2.84(2.59)$ & $27.3 \%$ & & & & \\
\hline $\operatorname{Ln}\left(p_{h}\right)$ & & & $1.85(1.68)$ & $27.2 \%$ & & \\
\hline $\operatorname{Ln}($ wealth $)$ & $0.36(0.07)^{* * *}$ & $0.0 \%$ & $0.35(0.07)^{* * *}$ & $0.0 \%$ & $0.38(0.07)^{* * *}$ & $0.0 \%$ \\
\hline $\operatorname{Ln}($ disposable income $)$ & $0.74(0.15)^{* * *}$ & $0.8 \%$ & $0.74(0.15)^{* *}$ & $1.5 \%$ & $0.65(0.16)^{* * *}$ & $0.0 \%$ \\
\hline Dummy for middle aged & $0.47(0.27)^{*}$ & $8.1 \%$ & $0.54(0.26)^{* *}$ & $3.6 \%$ & $0.54(0.26)^{* *}$ & $3.7 \%$ \\
\hline Dummy for the elder & $0.74(0.47)$ & $11.6 \%$ & $0.87(0.45)^{*}$ & $5.5 \%$ & $0.84(0.45)^{*}$ & $6.2 \%$ \\
\hline Age & $0.01(0.01)$ & $41.2 \%$ & $0.01(0.01)$ & $55.6 \%$ & $0.01(0.01)$ & $55.1 \%$ \\
\hline Years of education & $0.20(0.04)^{* * *}$ & $0.0 \%$ & $0.20(0.04) * * *$ & $0.0 \%$ & $0.20(0.04) * * *$ & $0.0 \%$ \\
\hline Married & $0.70(0.21)^{* * *}$ & $0.1 \%$ & $0.70(0.21)^{* * *}$ & $0.1 \%$ & $0.75(0.20)^{* * *}$ & $0.0 \%$ \\
\hline $\operatorname{Ln}($ balance $)$ & $0.22(0.09)^{* *}$ & $1.5 \%$ & $0.24(0.10)^{* *}$ & $1.8 \%$ & $0.17(0.07)^{* *}$ & $2.0 \%$ \\
\hline Unemployment rate & $0.01(0.08)$ & $92.4 \%$ & $0.00(0.08)$ & $95.9 \%$ & $0.36(0.08) * *$ & $6.9 \%$ \\
\hline \multicolumn{7}{|l|}{ The $\operatorname{Ln}($ payment) equation } \\
\hline Intercept & $2.07(0.87)^{* *}$ & $1.7 \%$ & $1.66(0.69)^{* *}$ & $1.6 \%$ & & \\
\hline $\operatorname{Ln}\left(p_{q}\right)^{1}$ & $-6.38(1.64)^{* * *}$ & $0.0 \%$ & & & & \\
\hline $\operatorname{Ln}\left(p_{h}\right)$ & & & $-4.14(0.88)^{* * *}$ & $0.0 \%$ & & \\
\hline $\operatorname{Ln}\left(p_{\mathrm{g}}\right)$ & $-0.39(0.62)$ & $53.5 \%$ & $0.94(0.64)$ & $13.9 \%$ & & \\
\hline $\operatorname{Ln}($ wealth $)$ & $0.05(0.04)$ & $22.7 \%$ & $0.08(0.04)^{* *}$ & $2.8 \%$ & & \\
\hline $\mathrm{Ln}($ disposable income $)$ & $-0.10(0.09)$ & $25.0 \%$ & $-0.09(0.07)$ & $32.3 \%$ & & \\
\hline Dummy for middle aged & $0.26(0.17)$ & $12.2 \%$ & $0.11(0.14)$ & $41.0 \%$ & & \\
\hline
\end{tabular}




\begin{tabular}{lcrcr} 
Dummy for the elder & $0.22(0.30)$ & $45.0 \%$ & $-0.06(0.23)$ & $79.5 \%$ \\
Age & $-0.01(0.01)$ & $47.6 \%$ & $0.00(0.01)$ & $80.1 \%$ \\
Years of education & $0.00(0.02)$ & $95.7 \%$ & $0.01(0.02)$ & $66.5 \%$ \\
Married & $0.38(0.13)^{* * *}$ & $0.3 \%$ & $0.38(0.11)^{* * *}$ & $0.0 \%$ \\
Ln(balance $)$ & $0.54(0.06)^{* * *}$ & $0.0 \%$ & $0.50(0.05)^{* * *}$ & $0.0 \%$ \\
Unemployment rate & $0.08(0.05)$ & $11.6 \%$ & $0.09(0.04)^{* *}$ & $3.3 \%$ \\
\hline
\end{tabular}

Notes: $\mathrm{N}=1,103 \quad * * *$ Significant at $1 \%$ level $* *$ significant at $5 \%$ level $\quad *$ significant at $10 \%$ level

This table presents results for the two-equation regressions of $\operatorname{Ln}($ charity+10) and $\operatorname{Ln}$ (payment), defined in the text, on a group of covariates. The weights for the regression are used to make the results nationally representative. The sample consists of households who are "exogenous itemizers" (defined in the text) and whose largest line of credit is a home equity line of credit with a positive balance. The observations are drawn from the Surveys of Consumer Finances between 1989 and 2007.

Appendix 8 First stage results

\begin{tabular}{|c|c|c|c|c|}
\hline \multirow[b]{2}{*}{ Regressors } & \multicolumn{2}{|c|}{ Marginal Price $\left(\operatorname{Ln}\left(p_{q}\right)\right)$} & \multicolumn{2}{|c|}{ Average Price $\left(\operatorname{Ln}\left(p_{h}\right)\right)$} \\
\hline & $\begin{array}{l}\text { Estimate (Standard } \\
\text { Error) }\end{array}$ & p-value & $\begin{array}{l}\text { Estimate (Standard } \\
\text { Error) }\end{array}$ & p-value \\
\hline Intercept & $0.29(0.09) * * *$ & $0.18 \%$ & $0.35(0.08)^{* * *}$ & $0.00 \%$ \\
\hline $\operatorname{Ln}\left(p_{i n}\right)$ & $0.84(0.12)^{* * *}$ & $0.00 \%$ & $1.35(0.11) * * *$ & $0.00 \%$ \\
\hline $\operatorname{Ln}\left(p_{g}\right)$ & $-0.89(0.16) * * *$ & $0.00 \%$ & $-0.99(0.13) * * *$ & $0.00 \%$ \\
\hline $\operatorname{Ln}($ wealth $)$ & $3.04 \mathrm{E}-4(4.07 \mathrm{E}-3)$ & $94.04 \%$ & $0.01(3.18 \mathrm{E}-3) * * *$ & $0.42 \%$ \\
\hline $\operatorname{Ln}($ disposable income $)$ & $-0.02(0.01)^{* *}$ & $4.93 \%$ & $-0.01(0.01)$ & $11.67 \%$ \\
\hline Dummy for middle aged & $0.01(0.01)$ & $29.47 \%$ & $0.01(0.01)$ & $41.97 \%$ \\
\hline Dummy for the elder & $-2.48 \mathrm{E}-3(0.02)$ & $91.10 \%$ & $-2.07 \mathrm{E}-3(0.02)$ & $90.95 \%$ \\
\hline Age & $4.74 \mathrm{E}-4(6.48 \mathrm{E}-4)$ & $46.44 \%$ & 7.63E-4 (5.52E-4) & $16.74 \%$ \\
\hline Years of education & $-1.55 \mathrm{E}-3(1.75 \mathrm{E}-3)$ & $37.41 \%$ & $-2.91 \mathrm{E}-4(1.43 \mathrm{E}-3)$ & $83.95 \%$ \\
\hline Married & $0.01(0.01)$ & $16.78 \%$ & $0.02(0.01)^{* * *}$ & $0.25 \%$ \\
\hline $\operatorname{Ln}($ balance $)$ & $-0.02(3.66 \mathrm{E}-3) * *$ & $0.00 \%$ & $-0.04(2.92 \mathrm{E}-3) * * *$ & $0.00 \%$ \\
\hline Unemployment rate & $0.01(4.48 \mathrm{E}-3)$ & $17.58 \%$ & $0.01(3.25 \mathrm{E}-3) *$ & $7.08 \%$ \\
\hline
\end{tabular}

Notes: $\mathrm{N}=1,023 \quad * * *$ Significant at $1 \%$ level $* *$ significant at $5 \%$ level *significant at $10 \%$ level

This table presents the first stage results corresponding to the 3SLS regression results in Table 3. 


\section{Appendix 9 Kernel Density Estimation of HELOC Payments}

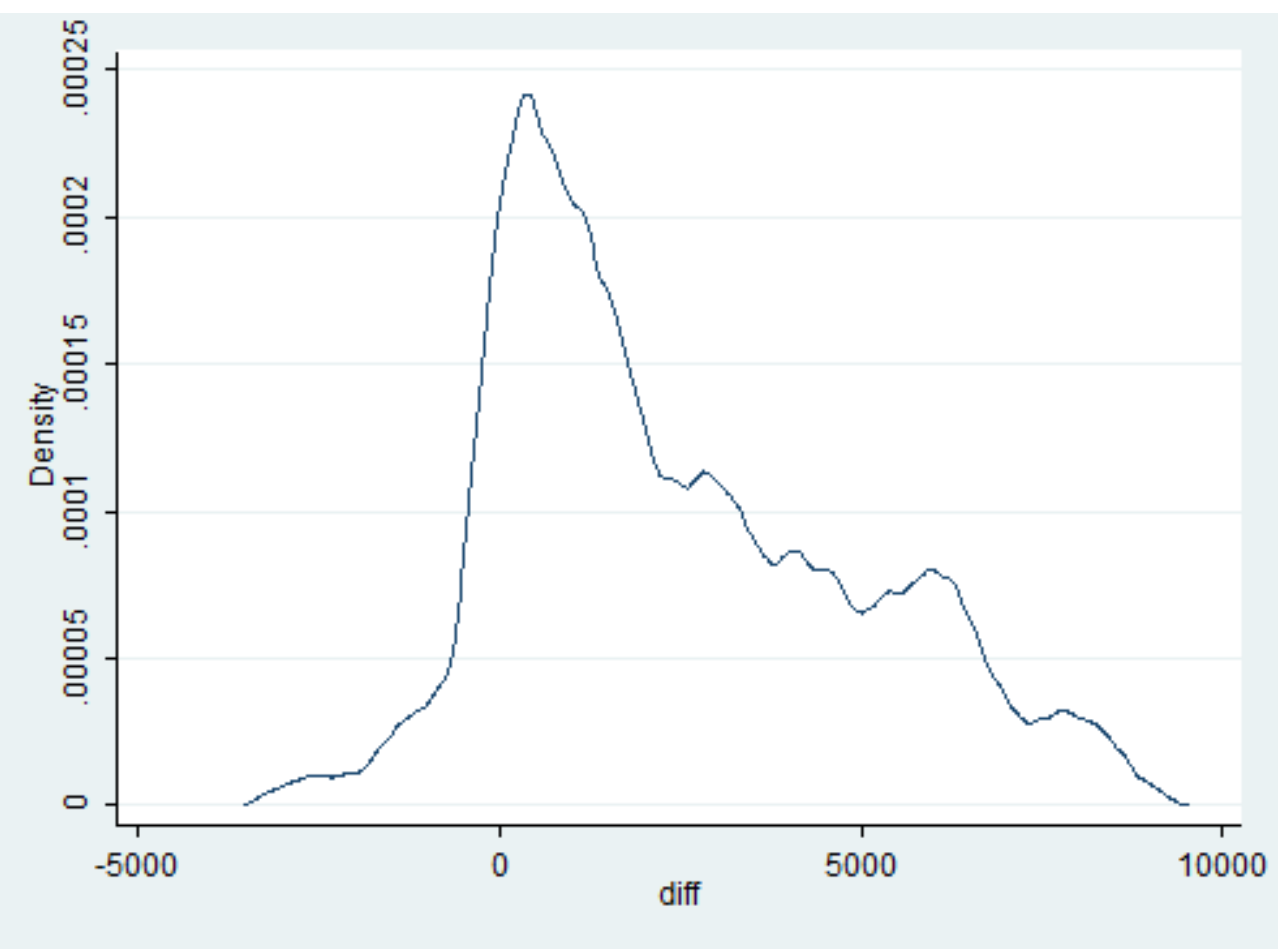

This graph shows that there is no bunching at paying exactly the interest due. This graph plots the kernel density estimation for HELOC payment for households whose principal payments are below 10000, using the first implicate dataset of the Survey of Consumer Finances. Other implicate datasets produce highly similar graphs which are therefore not presented here. The variable "diff" labeled on the horizontal axis is defined as the difference between payment and interest due. For example, 0 means paying exactly the interest amount due; 5,000 means paying interest and then paying down principle by 5,000 . I do not think that there is bunching at paying exactly interest: from both the left and the right of the peak the density curve is rising smoothly without having a sudden jump. Also, the peak is not exactly at zero, rather it is at a little to the right of zero.

Therefore, even though the density below zero is very low, this looks more like households paying interest due under minimum payment requirements and then on top of that paying a little of principal, than them responding to a price kink. I also do not observe minimum payment requirement on the households and cannot examine this further.

\section{Appendix 10 Tax-prices under partial deductibility}

In this appendix I provide a proof for the tax-price under partial deductibility, and corresponding changes in Equation (4). The proof is more rigorous than the one in the main text.

Under the existing tax system where $x \%=100 \%$, for each dollar of pretax income, if I spend it all 
on myself, I pay $\tau$ dollar as tax, and spend $(1-\tau)$ on personal consumption. To check that it's correctly calculated, I have Personal Consumption + Tax Liability $=(1-\tau)+\tau=1=$ Pretax Income. If I donate it to the charity, I pay zero dollar as tax, and the charities receive $\$ 1$. To check that it's correctly calculated, I have Charities' receipts + Tax Liability $=1+0=1=$ Pretax Income. These two scenarios suggest that for every $\$ 1$ given to charities, I forgo $\$(1-\tau)$ of personal consumption. By definition the tax-price of giving is $1-\tau$.

Now, suppose instead that only $x \%$ of giving are deductible. Then for each dollar of pretax income, if I spend it all on myself, I still have $(1-\tau)$ of personal consumption. If I do not spend any on myself and donate it, I will not be able to donate the full $\$ 1$ to charities, because I still have tax liabilities. Specifically, suppose that I do not spend on myself and donate as much of the $\$ 1$ to charities while also meet my tax liability. Suppose that I end up donating $g$ dollar to charities. My taxable income would be $1-x \% * g$ and my tax liability would be $\left(1-x \%^{*} g\right)^{*} \tau$. Now, Charities' receipts + Tax Liability $=g+\left(1-x \%^{*} g\right)^{*} \tau=1=$ Pretax Income yields $g=(1-\tau) /(1-x \% * \tau)$. These two scenarios suggest that for every $(1-\tau) /(1-x \% * \tau)$ dollar given to charities, I forgo $\$(1-\tau)$ of personal consumption. Proportionally, for every dollar given to charities, I forgo $\left(1-x \%^{*} \tau\right)$ of personal consumption. By definition the tax-price of giving is $p_{g}=\left(1-x \%^{*} \tau\right)$. It decreases in $x$. The old taxprice of $1-\tau$ is its special case at $x=100$, or when giving is fully deductible.

Similarly, the new tax-price for HELOC interest payment is $p_{h}=\left(1-x \%^{*} \tau\right)-r\left(1-x \%^{*} \tau\right)$. Equation (4)'s terms (e) and (f) contains $p_{g}$ and $p_{h}$, and thus varies in $x$. The exact relation is as follows.

$$
\begin{aligned}
& \operatorname{Term}(\mathrm{e})=\frac{\frac{d p_{g}}{p_{g}}}{\frac{d(1-\tau)}{1-\tau}}=\frac{\frac{d(1-x \% * \tau)}{(1-x \% * \tau)}}{\frac{d(1-\tau)}{1-\tau}}=\frac{d(1-x \% * \tau)}{d(1-\tau)} * \frac{1-\tau}{1-x \% * \tau}=\frac{d[x \%-x \% * \tau+(1-x \%)]}{d(1-\tau)} * \frac{1-\tau}{1-x \% * \tau}= \\
& \frac{d[x \%(1-\tau)+(1-x \%)]}{d(1-\tau)} * \frac{1-\tau}{1-x \% * \tau}=x \% * \frac{1-\tau}{1-x \% * \tau} \leq x \% \\
& \operatorname{Term}(\mathrm{f})=\frac{\frac{d p_{h}}{p_{h}}}{\frac{d(1-\tau)}{1-\tau}}=\frac{\frac{d[(1-x \% * \tau)-r(1-x \% * \tau)]}{(1-x \% * \tau)-r(1-x \% * \tau)}}{\frac{d(1-\tau)}{1-\tau}}=\frac{\frac{d[(1-r)(1-x \% * \tau)]}{(1-r)(1-x \% * \tau)}}{\frac{d(1-\tau)}{1-\tau}}=\frac{\frac{d(1-x \% * \tau)}{(1-x \% * \tau)}}{\frac{d(1-\tau)}{1-\tau}} \\
& =\operatorname{Term}(\mathrm{e})=x \% * \frac{1-\tau}{1-x \% * \tau} \leq x \%
\end{aligned}
$$




\section{Appendix 11 Dead Weight Loss and the ETI}

Feldstein (1999) derives a formula for calculating the dead weight loss of a tax system:

$$
D W L=0.5 \tau^{2}(1-\tau)^{-1} \epsilon_{T} T I,
$$

where $\tau$ is the marginal tax rate (his paper uses the notation $t$ but I have replaced with $\tau$ to keep consistency with notations in my main text). He has derived this formula for a tax system where a consumption item is either fully taxable, i.e. subject to a marginal tax rate of $t$ on the part of pre-tax income used to purchase it, or fully deductible. Below I explain that, in my proposed system which stipulates that deductible items are only partly deductible, the above result still approximately holds. Without loss of generality, I explain with the setup and notations in my main text: I consider three types of consumptions, ordinary consumption $C$, charitable giving $G$, and HELOC interest $h$.

Feldstein (1999) notices that, when consumption rather than the ordinary consumption are all fully deductible, the income tax $\tau$ is equivalent to an excise tax on ordinary consumption at rate $v$, with $1+v=(1-\tau)^{-1}$. (Again, these notations are different from what Feldstein(1999) uses.) Applying the Hicks-Harberger approximation, the deadweight loss in Feldstein (1999) is $D W L=-0.5 v d C$. A few steps transformed this expression into (A1), whereas the sufficient conditions underlying these steps are (1) $1+v=(1-\tau)^{-1}$; (2) when $\tau$ is zero, $T I=C$; and (3) the compensated change in $C$ equals the compensated change in $T I$, i.e. $d C=d T I$.

Now under my system, the equivalent excise tax rates are $U$ on $\mathrm{C}, \theta_{1}$ on $G$ and $\theta_{1}$ on $h$, with $1+\theta_{1}=\left[1-\left(1-x_{1}\right) \tau\right]^{-1}$ and $1+\theta_{2}=\left[1-\left(1-x_{2}\right) \tau\right]^{-1}$, where $x_{1}$ and $x_{2}$ are the deductible proportions of, respectively, $G$ and $h$. We have

$$
\begin{gathered}
\frac{\theta_{i}}{v}=\frac{\left(1-x_{i}\right) \tau /\left[1-\left(1-x_{i}\right) \tau\right]}{\tau /(1-\tau)}=\left(1-x_{i}\right) \frac{1-\tau}{1-\left(1-x_{i}\right) \tau} \approx\left(1-x_{i}\right), \quad(i=1,2) ; \text { or } \\
\theta_{i} \approx\left(1-x_{i}\right) v, \quad(i=1,2) .
\end{gathered}
$$

Also applying the Hicks-Harberger approximation, the deadweight loss is

$$
\begin{aligned}
D W L=-0.5\left(u d C+\theta_{1} d G+\theta_{2} d h\right) \approx-0.5\left[u d C+\left(1-x_{1}\right) u d G+\left(1-x_{2}\right) u d h\right] \\
\quad=-0.5 u\left[d C+\left(1-x_{1}\right) d G+\left(1-x_{2}\right) d h\right]=-0.5 v d\left[C+\left(1-x_{1}\right) G+\left(1-x_{2}\right) h\right]
\end{aligned}
$$


Notice that we have (1) $1+u=(1-\tau)^{-1}$; (2) when $\tau$ is zero, $T I=C+\left(1-x_{1}\right) G+\left(1-x_{2}\right) h$; and (3) the total compensated change of $C,\left(1-x_{1}\right) G$, and $\left(1-x_{2}\right) h$ equals the compensated change in $T I$, i.e. $d[C+$ $\left.\left(1-x_{1}\right) G+\left(1-x_{2}\right) h\right]=d T I$. Therefore, Feldstein (1999)'s Formula (A11.1) still holds. However, it holds only approximately as (A11.2) holds approximately. But the approximation error is small, especially when $\tau$ is small and/or $x$ is close to 1 . The direction of this approximation error is certain -Formula (A11.1) overestimates the dead weight loss under my partial deductibility system. To see why, notice that, based on the line above (A11.2), (A11.2) is in fact $\theta_{i}<\left(1-x_{i}\right) v$. Then I have $D W L=-0.5$ (udC $\left.+\theta_{1} d G+\theta_{2} d h\right)<-0.5\left[u d C+\left(1-x_{1}\right) v d G+\left(1-x_{2}\right) \cup d h\right]=\ldots=$ Feldstein (1999)'s (A11.1) value.

\section{Appendix 12 Theoretical results for optimal and uniform partial deductibility policies}

In this appendix I present some theoretical results associated with the optimal policy and the partial deductibility policy. Sections A12.1 to A12.5 are results for the two deduction case. Sections A12.6 and A12.7 make extensions to the general setting with $N$ components in taxable income.

\section{A12.1 The general expression of the ETI with deductible proportions}

As mentioned in the main text, given the tax authority's chosen tax base, an optimal base broadening policy chooses a set of optimal deductible proportions that minimizes the after reform ETI. The (general) ETI expression involving deductible proportions (the "general expression" hereinafter) will be longer than the ETI expression in (8), although the latter expression is in fact just a special case of the former. Specifically, notice that (8) is derived under the taxable income definition of taxable income $=$ income $-G-h$, while the general expression has taxable income $=$ income $-x_{G} * G-x_{h} * h$, with $x_{G}$ and $x_{h}$ being the deductible proportions of, respectively, $G$ and $h$. Consequently, applying the same kind of algebra in Appendix 1, I have derived that the general expression differs from Expression (8) in two ways: (1) explicitly, the only difference is that $G$ 's and $h$ 's in (8)'s Terms (g) and (h) become $x_{G} * G$ and $x_{h} * h$ in the general expression; (2) implicitly, $p_{g}$ 's and $p_{h}$ 's that appear in Terms (a) to (f) now depend on $x_{G}$ and $x_{h}$ in the way described in Appendix 10.

\section{A12.2 Solving for the optimal policy}

With the general expression of ETI, the set of optimal proportions solves the following problem:

$$
\begin{gathered}
\min _{x_{G}, x_{h}} E T I=-\varepsilon_{G G} * x_{G} * \frac{x_{G} * G_{0}}{T I_{0}}-\varepsilon_{G h} * x_{h} * \frac{x_{G} * G_{0}}{T I_{0}}-\varepsilon_{h h} * x_{h} * \frac{x_{h} * h_{0}}{T I_{0}}-\varepsilon_{h G} * x_{G} \\
* \frac{x_{h} * h_{0}}{T I_{0}} \quad \begin{aligned}
(A 12.1) \\
\text { s.t. }\left\{\begin{array}{c}
\text { Income }-x_{G} * G_{0}-x_{h} * h_{0}=T I_{0} \\
0 \leq x_{G} \leq 1 \\
0 \leq x_{h} \leq 1
\end{array}\right.
\end{aligned}
\end{gathered}
$$


The notations are as follows. $\varepsilon_{G G}, \varepsilon_{G h}, \varepsilon_{h h}$, and $\varepsilon_{h G}$ are, respectively, the own tax-price elasticity of $G$, the cross price elasticity of $G$ with respect to $h$ 's tax-price, the own tax-price elasticity of $h$, and the cross price elasticity of $h$ with respect to $G$ 's tax-price. $x_{G}$ and $x_{h}$ are the deductible proportions for, respectively, $G$ and $h . G_{0}$ and $h_{0}$ are the amounts of $G$ and $h$ when the tax rate is 0 . $T I_{0}$ is the tax authority's chosen tax base. Income is the pre-tax income. The minimization problem is a simple quadratic one, with lengthy discussion on corner solutions to ensure that both $x_{G}$ and $x_{h}$ fall on $[0,1]$ :

(1) Under the condition of $h_{0} \varepsilon_{G G}+G_{0} * \varepsilon_{h h}<G_{0} * \varepsilon_{G h}+h_{0} \varepsilon_{h G}$ (a condition likely to be met with own price elasticities (usually negative) on the left hand side and cross price elasticities (usually positive) on the right hand side), the solution is

$$
\begin{aligned}
& \left\{\begin{array}{c}
x_{G}=\frac{\left[-\varepsilon_{h h} * \frac{2 G_{0}}{h_{0}}+\varepsilon_{G h} * \frac{G_{0}}{h_{0}}+\varepsilon_{h G}\right]\left(\text { Income }-T I_{0}\right)}{2 G_{0} *\left[-\varepsilon_{G G}-\frac{G_{0}}{h_{0}} * \varepsilon_{h h}+\frac{G_{0}}{h_{0}} * \varepsilon_{G h}+\varepsilon_{h G}\right]} \\
x_{h}=\frac{\left[-\varepsilon_{G G} * \frac{2 h_{0}}{G_{0}}+\varepsilon_{h G} * \frac{h_{0}}{G_{0}}+\varepsilon_{G h}\right]\left(\text { Income }-T I_{0}\right)}{2 h_{0} *\left[-\varepsilon_{h h}-\frac{h_{0}}{G_{0}} * \varepsilon_{G G}+\frac{h_{0}}{G_{0}} * \varepsilon_{h G}+\varepsilon_{G h}\right]}
\end{array},\right.
\end{aligned}
$$

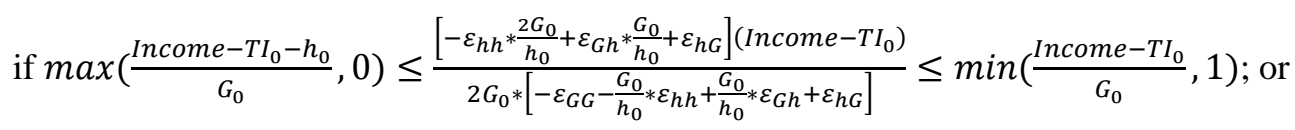

$$
\begin{aligned}
& \left\{\begin{array}{c}
x_{G}=\max \left(\frac{\operatorname{Income}-T I_{0}-h_{0}}{G_{0}}, 0\right) \\
x_{h}=\frac{\text { Income }-\max \left(\frac{\operatorname{Income}-T I_{0}-h_{0}}{G_{0}}, 0\right) * G_{0}-T I_{0}}{h_{0}}
\end{array}\right. \\
& \text { if } \frac{\left[-\varepsilon_{h h} * \frac{2 G_{0}}{h_{0}}+\varepsilon_{G h} * G_{0} h_{0}+\varepsilon_{h G}\right]\left(I n c o m e-T I_{0}\right)}{2 G_{0} *\left[-\varepsilon_{G G}-\frac{G_{0}}{h_{0}} * \varepsilon_{h h}+\frac{G_{0}}{h_{0}} * \varepsilon_{G h}+\varepsilon_{h G}\right]}<\max \left(\frac{\text { Income }-T I_{0}-h_{0}}{G_{0}}, 0\right) \text {; or } \\
& \left\{\begin{array}{c}
x_{G}=\min \left(\frac{\operatorname{Income}-T I_{0}}{G_{0}}, 1\right) \\
x_{h}=\frac{\text { Income }-\min \left(\frac{\operatorname{Income}-T I_{0}}{G_{0}}, 1\right) * G_{0}-T I_{0}}{h_{0}}
\end{array}\right. \\
& \text { if } \frac{\left[-\varepsilon_{h h} * \frac{2 G_{0}}{h_{0}}+\varepsilon_{G h} * \frac{G_{0}}{h_{0}}+\varepsilon_{h G}\right](\text { Income-TI })}{2 G_{0} *\left[-\varepsilon_{G G}-\frac{G_{0}}{h_{0}} * \varepsilon_{h h}+\frac{G_{0}}{h_{0}} * \varepsilon_{G h}+\varepsilon_{h G}\right]}>\min \left(\frac{\text { Income }-T I_{0}}{G_{0}}, 1\right) \text {. } \\
& \text { (2.1) the solution is (A12.4) if } 2 G_{0} * \varepsilon_{h h}>G_{0} * \varepsilon_{G h}+h_{0} \varepsilon_{h G} \text {, } \\
& \text { (2.2) if we have } 2 G_{0} * \varepsilon_{h h}=G_{0} * \varepsilon_{G h}+h_{0} \varepsilon_{h G} \text {, then the ETI is constantly }-\frac{\varepsilon B B}{B * T I} * \\
& \left(\text { Income }-T I_{0}\right)^{2} \text {. } \\
& \text { (2.3) the solution is } \mathrm{A}(12.3) \text { if } 2 G_{0} * \varepsilon_{h h}<G_{0} * \varepsilon_{G h}+h_{0} \varepsilon_{h G} \text {. }
\end{aligned}
$$


(3) Under the condition $h_{0} \varepsilon_{G G}+G_{0} * \varepsilon_{h h}<G_{0} * \varepsilon_{G h}+h_{0} \varepsilon_{h G}$ (unlikely)

(3.1) the solution is (A12.4) if $\frac{\left[-\varepsilon_{h h} * \frac{2 G_{0}}{h_{0}}+\varepsilon_{G h} * \frac{G_{0}}{h_{0}}+\varepsilon_{h G}\right](\text { Income-TI })}{2 G_{0} *\left[-\varepsilon_{G G}-\frac{G_{0}}{h_{0}} * \varepsilon_{h h}+\frac{G_{0}}{h_{0}} * \varepsilon_{G h}+\varepsilon_{h G}\right]} \leq \frac{1}{2}\left[\max \left(\frac{\text { Income }-T I_{0}-h_{0}}{G_{0}}, 0\right)+\right.$ $\left.\min \left(\frac{\operatorname{Income}-T I_{0}}{G_{0}}, 1\right)\right]$

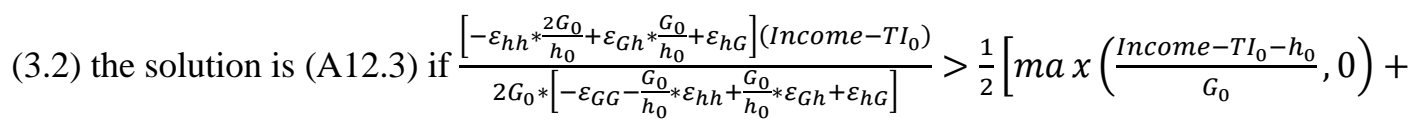
$\left.\min \left(\frac{\operatorname{Income}-T I_{0}}{G_{0}}, 1\right)\right]$

My estimated elasticities satisfy the condition in (1). Policy G2's deductible proportions are (Expression (A12.2))

$$
\left\{\begin{array}{l}
x_{G}=\frac{\left[-5.55 * \frac{2 * 2}{4}+4.02 * \frac{2}{4}+1.58\right](106-104)}{2 * 2 *\left[-(-2.89)-\frac{2}{4} *(-5.55)+\frac{2}{4} * 4.02+1.58\right]}=49 \% \\
x_{h}=\frac{\left[-(-2.89) * \frac{2 * 4}{2}+1.58 * \frac{4}{2}+4.02\right](106-104)}{2 * 4 *\left[-(-5.55)-\frac{4}{2} *(-2.89)+\frac{4}{2} * 1.58+4.02\right]}=25 \%
\end{array}\right.
$$

Policy h2's deductible proportions are (also Expression (A12.2))

$$
\left\{\begin{array}{l}
x_{G}=\frac{\left[-5.55 * \frac{2 * 2}{4}+4.02 * \frac{2}{4}+1.58\right](106-102)}{2 * 2 *\left[-(-2.89)-\frac{2}{4} *(-5.55)+\frac{2}{4} * 4.02+1.58\right]}=99 \% \\
x_{h}=\frac{\left[-(-2.89) * \frac{2 * 4}{2}+1.58 * \frac{4}{2}+4.02\right](106-102)}{2 * 4 *\left[-(-5.55)-\frac{4}{2} *(-2.89)+\frac{4}{2} * 1.58+4.02\right]}=51 \%
\end{array}\right.
$$

The ETI's under these two policies can then be computed using (A12.1).

\section{A12.3 An optimal policy guarantees reducing the before reform ETI}

From (A12.1), it is straightforward to prove that an optimal policy will reduce the before reform (in its meaning defined in Section VI) ETI. Specifically, suppose the tax authority decides to broaden the tax base to $T I_{0}$. Pick a feasible set of deductible proportions that meets the tax base requirement (i.e. a set of deductible proportions that satisfies the constraint below (A12.1)) as $x_{G}^{\prime}=x_{h}^{\prime}=$ $\frac{\text { Income }-T I_{0}}{G_{0}+h_{0}}$. Since the base is broadened, there is $0<\frac{\text { Income }-T I_{0}}{G_{0}+h_{0}}<\frac{\text { Income }-\left(\text { Income }-G_{0}-h_{0}\right)}{G_{0}+h_{0}}=1$.

Therefore both $x_{G}^{\prime}$ and $x_{h}^{\prime}$ lie between 0 and 1 . Below is the proof. Its basic idea is that the policy with $x_{G}^{\prime}$ and $x_{h}^{\prime}$ can already reduce the ETI, let alone the optimal policy: 
$0<$ before reform ETI

$$
\begin{aligned}
& =-\varepsilon_{G G} * \frac{G_{0}}{\text { Income }-G_{0}-h_{0}}-\varepsilon_{G h} * \frac{G_{0}}{\text { Income }-G_{0}-h_{0}}-\varepsilon_{h h} * \frac{h_{0}}{\text { Income }-G_{0}-h_{0}}-\varepsilon_{h G} \\
& * \frac{1}{\text { Income }-G_{0}-h_{0}}=\frac{1}{\text { Income }-G_{0}-h_{0}}\left(-\varepsilon_{G G} * G_{0}-\varepsilon_{G h} * G_{0}-\varepsilon_{h h} * h_{0}-\varepsilon_{h G} * h_{0}\right) \\
& >\frac{1}{\text { Income }-x_{G}^{\prime} * G_{0}-x_{h}^{\prime} * h_{0}}\left(-\varepsilon_{G G} * G_{0}-\varepsilon_{G h} * G_{0}-\varepsilon_{h h} * h_{0}-\varepsilon_{h G} * h_{0}\right) \\
& =\frac{1}{T I_{0}}\left(-\varepsilon_{G G} * G_{0}-\varepsilon_{G h} * G_{0}-\varepsilon_{h h} * h_{0}-\varepsilon_{h G} * h_{0}\right) \\
& >\frac{\left(x_{G}^{\prime}\right)^{2}}{T I_{0}}\left(-\varepsilon_{G G} * G_{0}-\varepsilon_{G h} * G_{0}-\varepsilon_{h h} * h_{0}-\varepsilon_{h G} * h_{0}\right) \\
& =-\varepsilon_{G G} * x_{G}^{\prime} * \frac{x_{G}^{\prime} * G_{0}}{T I_{0}}-\varepsilon_{G h} * x_{G}^{\prime} * \frac{x_{G}^{\prime} * G_{0}}{T I_{0}}-\varepsilon_{h h} * x_{G}^{\prime} * \frac{x_{G}^{\prime} * h_{0}}{T I_{0}}-\varepsilon_{h G} * x_{G}^{\prime} * \frac{x_{G}^{\prime} * h_{0}}{T I_{0}} \\
& =-\varepsilon_{G G} * x_{G}^{\prime} * \frac{x_{G}^{\prime} * G_{0}}{T I_{0}}-\varepsilon_{G h} * x_{h}^{\prime} * \frac{x_{G}^{\prime} * G_{0}}{T I_{0}}-\varepsilon_{h h} * x_{h}^{\prime} * \frac{x_{h}^{\prime} * h_{0}}{T I_{0}}-\varepsilon_{h G} * x_{G}^{\prime} * \frac{x_{h}^{\prime} * h_{0}}{T I_{0}} \\
& \geq \min _{x_{G}, x_{h}}\left\{-\varepsilon_{G G} * x_{G} * \frac{x_{G} * G_{0}}{T I_{0}}-\varepsilon_{G h} * x_{h} * \frac{x_{G} * G_{0}}{T I_{0}}-\varepsilon_{h h} * x_{h} * \frac{x_{h} * h_{0}}{T I_{0}}-\varepsilon_{h G} * x_{G} * \frac{x_{h} * h_{0}}{T I_{0}} \mid \text { s.t.constraints }\right\} \\
& =\text { the optimal policy's ETI }
\end{aligned}
$$

\section{A12.4 A uniform partial deductibility policy guarantees reducing the before reform ETI}

In the above proof, $x_{G}^{\prime}$ and $x_{h}^{\prime}$ are nothing but the deductible proportions under the uniform partial deductibility. The part of the above proof before the step of " $\geq \min _{x_{G}, x_{h}}\{\ldots\}$ " proves that the uniform partial deductibility can guarantee reducing the ETI.

\section{A12.5 The relation between the old and new ETIs before and after implementing a uniform partial deductibility policy}

After the uniform partial deductibility policy is in place, the new ETI has a simple relationship with the before reform ETI that does not depend on the own and cross price elasticities, as proved below: (suppressing notations as $x_{G}^{\prime}=x_{h}^{\prime} \equiv x^{\prime}$ )

uniform partial ETI

$$
\begin{aligned}
& =-\varepsilon_{G G} * x^{\prime} * \frac{x^{\prime} * G_{0}}{T I_{0}}-\varepsilon_{G h} * x^{\prime} * \frac{x^{\prime} * G_{0}}{T I_{0}}-\varepsilon_{h h} * x^{\prime} * \frac{x^{\prime} * h_{0}}{T I_{0}}-\varepsilon_{h G} * x^{\prime} * \frac{x^{\prime} * h_{0}}{T I_{0}} \\
& =\left(x^{\prime}\right)^{2}\left(-\varepsilon_{G G} * \frac{G_{0}}{T I_{0}}-\varepsilon_{G h} * \frac{G_{0}}{T I_{0}}-\varepsilon_{h h} * \frac{h_{0}}{T I_{0}}-\varepsilon_{h G} * \frac{h_{0}}{T I_{0}}\right) \\
& =\left(x^{\prime}\right)^{2} \frac{\text { income }-G_{0}-h_{0}}{T I_{0}}\left(-\varepsilon_{G G} * \frac{G_{0}}{\text { Income }-G_{0}-h_{0}}-\varepsilon_{G h} * \frac{G_{0}}{\text { Income }-G_{0}-h_{0}}\right. \\
& \left.-\varepsilon_{h h} * \frac{h_{0}}{\text { Income }-G_{0}-h_{0}}-\varepsilon_{h G} * \frac{h_{0}}{\text { Income }-G_{0}-h_{0}}\right) \\
& =\left(x^{\prime}\right)^{2} \frac{\text { income }-G_{0}-h_{0}}{T I_{0}} * \text { before reform ETI. }
\end{aligned}
$$


In other words, the relation is uniform partial ETI $=\left(x^{\prime}\right)^{2} \frac{\text { before reform tax base }}{\text { new (broader) tax base }} *$ before reform ETI.

Example (the same with the one in the last part of the main text's policy implication section, but more calculation details are provided)

Suppose that currently (1) the tax rate is $\tau=20 \%$; (2) the taxable income at the $20 \%$ tax rate is $T I$ $=\$ 1$; (3) the amount of itemized deductions at $20 \%$ tax rate of is $\$ 0.4$; and (4) the ETI is somewhere between 0.4 and 0.8 . Then the current revenue is $R_{C}=\tau \cdot T I$. For any uniform partial deductible proportion $x^{\prime}$, the new ETI will equal $\left(x^{\prime}\right)^{2} \frac{\text { before reform tax base }}{\text { new (broader) tax base }} *$ before reform ETI $=$ $\left(x^{\prime}\right)^{2} \frac{\$ 1 /(1-\tau)^{E T I}}{\$ 1+\$ 0.4-x^{\prime} \cdot\left[\$ 1+\$ 0.4-\$ 1 /(1-\tau)^{E T I}\right]} * E T I$. Therefore the new revenue will be $R_{N}=\tau \cdot\{\$ 1+\$ 0.4-$

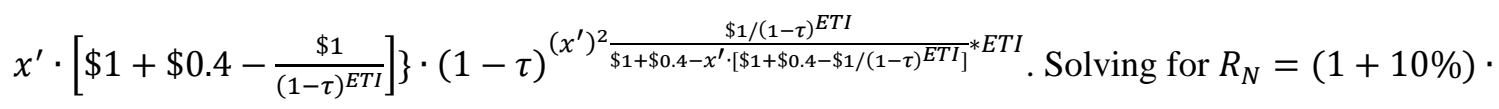
$R_{C}$ with ETI between 0.4 and 0.8 yields that $x^{\prime}$ is between $78.6 \%$ (for ETI $=0.4$ ) and $81.4 \%$ (for ETI $=0.8)$.

\section{A12.6 Extension to $N$-deduction taxable income}

Sections A12.1 to A12.5 consider the situation where the only two responsive components of taxable income are deductions $G$ and $h$. If instead, the responsive components of taxable income are $N$ deductions, with their amounts at tax rate of 0 denoted $D_{1}, D_{2}, \ldots, D_{N}$ and deductible proportions being $x_{1}, x_{2}, \ldots, x_{N}$. Results in previous sections can be extended. I discuss them one by one below. Basically, there is no longer closed form optimal policy solution but other things still holds (optimal policy solution exists; optimal and partial deductibility policies guarantee reducing the ETI).

\section{(1) Solving for the optimal deductible proportions}

To make later notations shorter, notice that the problem of minimizing (A12.1) can be rewritten as (in the spirit of the matrix form in Appendix 2's Expression (A.3) for ETI)

$$
\begin{gathered}
\min _{x_{G}, x_{h}} E T I=\left[\begin{array}{ll}
x_{G} & x_{h}
\end{array}\right]\left[\begin{array}{cc}
-\frac{G_{0}}{T I_{0}} \varepsilon_{G G} & -\frac{G_{0}}{T I_{0}} \varepsilon_{G h} \\
-\frac{h_{0}}{T I_{0}} \varepsilon_{h G} & -\frac{h_{0}}{T I_{0}} \varepsilon_{h h}
\end{array}\right]\left[\begin{array}{l}
x_{G} \\
x_{h}
\end{array}\right] \\
\text { s.t. }\left\{\begin{array}{c}
\text { Income }-x_{G} * G_{0}-x_{h} * h_{0}=T I_{0} \\
0 \leq x_{G} \leq 1 \\
0 \leq x_{h} \leq 1
\end{array}\right.
\end{gathered}
$$

with (A12.2) being the solution.

Writing down the problem of minimizing the $N$-deduction ETI can similarly invoke a matrix form (with $\varepsilon_{i j}$ being the elasticity of $D_{i}$ with respect to $D_{j}$ 's tax-price): 


$$
\begin{gathered}
\min _{x_{1}, x_{2}, \ldots, x_{N}} E T I=\left[\begin{array}{llll}
x_{1} & x_{2} & \cdots & x_{N}
\end{array}\right]\left[\begin{array}{cccc}
-\frac{D_{1}}{T I_{0}} \varepsilon_{11} & -\frac{D_{1}}{T I_{0}} \varepsilon_{12} & \cdots & -\frac{D_{1}}{T I_{0}} \varepsilon_{1 N} \\
-\frac{D_{2}}{T I_{0}} \varepsilon_{21} & -\frac{D_{2}}{T I_{0}} \varepsilon_{22} & \cdots & -\frac{D_{2}}{T I_{0}} \varepsilon_{2 N} \\
\vdots & \vdots & & \vdots \\
-\frac{D_{N}}{T I_{0}} \varepsilon_{N 1} & -\frac{D_{N}}{T I_{0}} \varepsilon_{N 2} & \cdots & -\frac{D_{N}}{T I_{0}} \varepsilon_{N N}
\end{array}\right]\left[\begin{array}{c}
x_{1} \\
x_{2} \\
\vdots \\
x_{N}
\end{array}\right] \\
\text { s.t. }\left\{\begin{array}{c}
\text { Income }-x_{1} * D_{1}-x_{2} * D_{2}-\cdots-x_{N} * D_{N}=T I_{0} \\
0 \leq x_{i} \leq 1 \text { for } i=1,2, \ldots N
\end{array}\right.
\end{gathered}
$$

The solution exists, since the minimized function is continuous, and the choice set of the deductible proportions is closed and bounded. However, I don't think that there are closed form expressions. (There are neat eigenvalue and eigenvector results if the constraint is like $\left[\begin{array}{llll}x_{1} & x_{2} & \cdots & x_{N}\end{array}\right] B\left[\begin{array}{llll}x_{1} & x_{2} & \cdots & x_{N}\end{array}\right]^{T}$, with $B$ being positive definite (see, for example, Cízek, Härdle, and Weron (2005)). But apparently my constraints are not in this form.)

\section{(2) An optimal policy guarantees reducing the before reform ETI}

As is similar with Section 12.3, pick a feasible set of deductible proportions that meets the tax base requirement (i.e. a set of deductible proportions that satisfies the constraint below (A12.1)) as $x_{1}^{\prime}=x_{2}^{\prime}=\cdots=x_{N}^{\prime}=\frac{I n c o m e-T I_{0}}{D_{1}+D_{2}+\cdots+D_{N}}$. Since the base is broadened, there is $0<\frac{I n c o m e-T I_{0}}{D_{1}+D_{2}+\cdots+D_{N}}<$ $\frac{\text { Income }-\left(\text { Income }-D_{1}-D_{2}-\cdots-D_{N}\right)}{D_{1}+D_{2}+\cdots+D_{N}}=1$. Therefore $x_{1}^{\prime}, x_{2}^{\prime}, \ldots$ and $x_{N}^{\prime}$ all lie between 0 and 1 . Below is the proof. Again, its basic idea is that the policy with $x_{1}^{\prime}, x_{2}^{\prime}, \ldots$ and $x_{N}^{\prime}$ can already reduce the ETI, let alone the optimal policy: $0<$ before reform ETI =

$$
\begin{aligned}
& {\left[\begin{array}{llll}
1 & 1 & \cdots & 1
\end{array}\right] \frac{1}{\text { Income }-D_{1}-D_{2}-\cdots-D_{N}}\left[\begin{array}{cccc}
-\frac{D_{1}}{1} \varepsilon_{11} & -\frac{D_{1}}{1} \varepsilon_{12} & \cdots & -\frac{D_{1}}{1} \varepsilon_{1 N} \\
-\frac{D_{2}}{1} \varepsilon_{21} & -\frac{D_{2}}{1} \varepsilon_{22} & \cdots & -\frac{D_{2}}{1} \varepsilon_{2 N} \\
\vdots & \vdots & & \vdots \\
-\frac{D_{N}}{1} \varepsilon_{N 1} & -\frac{D_{N}}{1} \varepsilon_{N 2} & \cdots & -\frac{D_{N}}{1} \varepsilon_{N N}
\end{array}\right]\left[\begin{array}{l}
1 \\
1 \\
\vdots \\
1
\end{array}\right]>} \\
& {\left[\begin{array}{llll}
1 & 1 & \cdots & 1
\end{array}\right] \frac{1}{\text { Income }-x_{1}^{\prime} D_{1}-x_{2}^{\prime} D_{2}-\cdots-x_{N}^{\prime} D_{N}}\left[\begin{array}{cccc}
-\frac{D_{1}}{1} \varepsilon_{11} & -\frac{D_{1}}{1} \varepsilon_{12} & \cdots & -\frac{D_{1}}{1} \varepsilon_{1 N} \\
-\frac{D_{2}}{1} \varepsilon_{21} & -\frac{D_{2}}{1} \varepsilon_{22} & \cdots & -\frac{D_{2}}{1} \varepsilon_{2 N} \\
\vdots & \vdots & & \vdots \\
-\frac{D_{N}}{1} \varepsilon_{N 1} & -\frac{D_{N}}{1} \varepsilon_{N 2} & \cdots & -\frac{D_{N}}{1} \varepsilon_{N N}
\end{array}\right]\left[\begin{array}{c}
1 \\
1 \\
\vdots \\
1
\end{array}\right]=} \\
& {\left[\begin{array}{llll}
1 & 1 & \cdots & 1
\end{array}\right] \frac{1}{T I_{0}}\left[\begin{array}{cccc}
-\frac{D_{1}}{1} \varepsilon_{11} & -\frac{D_{1}}{1} \varepsilon_{12} & \cdots & -\frac{D_{1}}{1} \varepsilon_{1 N} \\
-\frac{D_{2}}{1} \varepsilon_{21} & -\frac{D_{2}}{1} \varepsilon_{22} & \cdots & -\frac{D_{2}}{1} \varepsilon_{2 N} \\
\vdots & \vdots & & \vdots \\
-\frac{D_{N}}{1} \varepsilon_{N 1} & -\frac{D_{N}}{1} \varepsilon_{N 2} & \cdots & -\frac{D_{N}}{1} \varepsilon_{N N}
\end{array}\right]\left[\begin{array}{c}
1 \\
1 \\
\vdots \\
1
\end{array}\right]=}
\end{aligned}
$$




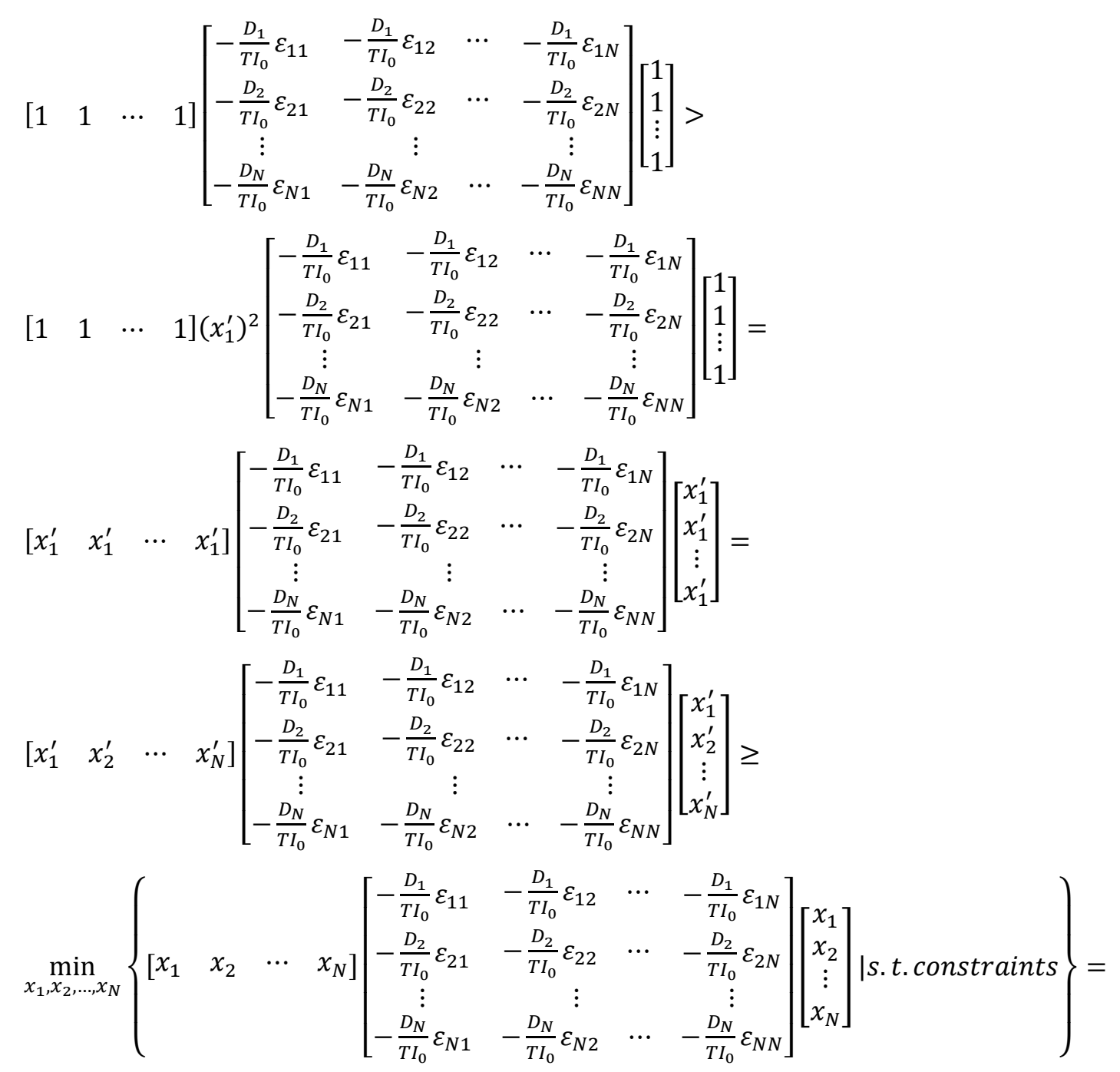

the optimal policy's ETI

(3) A uniform partial deductibility policy guarantees reducing the before reform ETI

This paragraph is similar with Section A12.4. In the above proof, $x_{1}^{\prime}, x_{2}^{\prime} \ldots$ and $x_{N}^{\prime}$ are nothing but the deductible proportions under the uniform partial deductibility. The part of the above proof before the step of " $\geq \min _{x_{1}, x_{2}, \ldots, x_{2}}\{\ldots\}$ " proves that the uniform partial deductibility can guarantee reducing the ETI.

(4) The relation between the old and new ETIs before and after implementing a uniform partial deductibility policy

Again, this is just rewriting Section A12.5 in the matrix form for an $\mathrm{N}$-deduction ETI. After the uniform partial deductibility policy is in place, the new ETI has a simple relationship with the before reform ETI that does not depend on the own and cross price elasticities, as proved below: (suppressing notations as $\left.x_{1}^{\prime}=x_{2}^{\prime}=\cdots=x_{N}^{\prime} \equiv x^{\prime}\right)$ 


$$
\begin{aligned}
& \text { uniform partial ETI }=\left[\begin{array}{llll}
x^{\prime} & x^{\prime} & \cdots & x^{\prime}
\end{array}\right]\left[\begin{array}{cccc}
-\frac{D_{1}}{T I_{0}} \varepsilon_{11} & -\frac{D_{1}}{T I_{0}} \varepsilon_{12} & \cdots & -\frac{D_{1}}{T I_{0}} \varepsilon_{1 N} \\
-\frac{D_{2}}{T I_{0}} \varepsilon_{21} & -\frac{D_{2}}{T I_{0}} \varepsilon_{22} & \cdots & -\frac{D_{2}}{T I_{0}} \varepsilon_{2 N} \\
\vdots & \vdots & & \vdots \\
-\frac{D_{N}}{T I_{0}} \varepsilon_{N 1} & -\frac{D_{N}}{T I_{0}} \varepsilon_{N 2} & \cdots & -\frac{D_{N}}{T I_{0}} \varepsilon_{N N}
\end{array}\right]\left[\begin{array}{c}
x^{\prime} \\
x^{\prime} \\
\vdots \\
x^{\prime}
\end{array}\right] \\
& =\left(\begin{array}{llll}
x^{\prime} & 2
\end{array}\left[\begin{array}{llll}
1 & 1 & \cdots & 1
\end{array}\right]\left[\begin{array}{cccc}
-\frac{D_{1}}{T I_{0}} \varepsilon_{11} & -\frac{D_{1}}{T I_{0}} \varepsilon_{12} & \cdots & -\frac{D_{1}}{T I_{0}} \varepsilon_{1 N} \\
-\frac{D_{2}}{T I_{0}} \varepsilon_{21} & -\frac{D_{2}}{T I_{0}} \varepsilon_{22} & \cdots & -\frac{D_{2}}{T I_{0}} \varepsilon_{2 N} \\
\vdots & \vdots & & \vdots \\
-\frac{D_{N}}{T I_{0}} \varepsilon_{N 1} & -\frac{D_{N}}{T I_{0}} \varepsilon_{N 2} & \cdots & -\frac{D_{N}}{T I_{0}} \varepsilon_{N N}
\end{array}\right]\left[\begin{array}{c}
1 \\
1 \\
\vdots \\
1
\end{array}\right]\right. \\
& =\left(x^{\prime}\right)^{2} \frac{\text { Income }-D_{1}-D_{2}-\cdots-D_{N}}{T I_{0}}\left[\begin{array}{llll}
1 & 1 & \cdots & 1
\end{array}\right] \frac{1}{\text { Income }-D_{1}-D_{2}-\cdots-D_{N}} \\
& {\left[\begin{array}{cccc}
-\frac{D_{1}}{T I_{0}} \varepsilon_{11} & -\frac{D_{1}}{T I_{0}} \varepsilon_{12} & \cdots & -\frac{D_{1}}{T I_{0}} \varepsilon_{1 N} \\
-\frac{D_{2}}{T I_{0}} \varepsilon_{21} & -\frac{D_{2}}{T I_{0}} \varepsilon_{22} & \cdots & -\frac{D_{2}}{T I_{0}} \varepsilon_{2 N} \\
\vdots & \vdots & & \vdots \\
-\frac{D_{N}}{T I_{0}} \varepsilon_{N 1} & -\frac{D_{N}}{T I_{0}} \varepsilon_{N 2} & \cdots & -\frac{D_{N}}{T I_{0}} \varepsilon_{N N}
\end{array}\right]\left[\begin{array}{c}
1 \\
1 \\
\vdots \\
1
\end{array}\right]} \\
& =\left(x^{\prime}\right)^{2} \frac{\text { income }-D_{1}-D_{2}-\cdots-D_{N}}{T I_{0}} * \text { before reform ETI. }
\end{aligned}
$$

In other words, the relation is uniform partial ETI $=\left(x^{\prime}\right)^{2} \frac{\text { before reform tax base }}{\text { new (broader) tax base }} *$ before reform ETI.

\section{A12.7 Extension to $N$-component taxable income}

The previous section makes extension to the case where the responsive components of taxable income are $N$ deductions. Now consider the most general case that incomes are also responsive. To extend the optimal and uniform partial deductibility policy results to this case, conceptually I need to do something similar to textbook models on labor supply to "deductionize" incomes, i.e. to view taxing incomes as deducting "leisure"s. For example, suppose that taxable income is defined as taxable income $=L-D_{1}-D_{2}-\ldots-D_{N-1}$, with $L$ being labor income. Suppose that one's total time is measured in such unit that the wage per unit of time is $\$ 1$. Suppose that one's total time is $T$ and that one's leisure time is $l$, both measured in the aforementioned time unit. Then the taxable income is taxable income $=T-l-D_{1}-D_{2}-\ldots-D_{N-1}$. It follows that, since $T$ is not responsive to tax, the responsive components of this taxable income are the $N$ deductions of $l, D_{1}, D_{2} \ldots$ and $D_{N-1}$. Then everything is exactly the same with A12.5. The only noteworthy thing is that to implement the optimal or uniform partial deductibility policy, $l$ is treated the same with other deductible consumptions $-l$ is only partially deductible now i.e. households pay taxes on leisure. 
This "deductionizing" concept can extend to other forms of incomes. As Saez, Slemrod and Giertz (2012) writes in their “Conceptual Framwork” section: “...individuals supply effort to earn income $z$ ", with $z$ being the tax base, not just labor income. In my view, whatever one forgoes when exerting more effort, be it leisure or relaxed mental state, can be regarded as deductions. This kind of thinking completes my theoretical discussion on the optimal and uniform partial deductibility policies; whether taxing leisure or relaxation is practical is a separate issue.

\section{References}

Auten, Gerald, Robert Carroll and Geoffrey Gee (2008), “The 2001 and 2003 Tax Rate Reductions: An Overview and Estimate of the Taxable Income Response", National Tax Journal, 61 (3), 345 364

Auten, Gerald and David Joulfaian (1996): "Charitable Contributions and Intergenerational Transfers", Journal of Public Economics, 59 (1), 55 - 68

Auten, Gerald E., Holger Sieg and Charles T. Clotfelter (2002), “Charitable Giving, Income, and Taxes, An Analysis of Panel Data", The American Economic Review, 92 (1), 371 - 382

Bakija, Jon and Bradley T. Heim (2011), "How Does Charitable Giving Respond to Incentives and Income? New Estimates from Panel Data”, National Tax Journal, 64 (2, Part 2), 615 - 650

Barrett, Kevin (1991): "Panel-data Estimates of Charitable Giving: A Synthesis of Techniques", National Tax Journal, 44 (3), 365 - 381

Blundell, Richard and Thomas MaCurdy (1999), "Labor supply: a review of alternative approaches." In O. Ashenfelter and D. Card (Eds.), Handbook of Labor Economics, Volume 3, Retrived from http://www.ucl.ac.uk/ uctp39a/Blundell-MaCurdy-1999.pdf

Boskin, Michael J. and Martin Feldstein (1977), "Effects of the Charitable Deduction on Contributions by Low Income and Middle Income Households: Evidence from the National Survey of Philanthropy", The Review of Economics and Statistics, 59 (3), 351 - 354

Citizens Financial Group, Inc (2015), “Understand your HELOC Freeze or Reduction”, Retrieved September 21, 2015, from https://www.citizensbank.com/home-equity/home-equity-linefreeze.aspx 
Cízek, P., Härdle, W., \& Weron, R. (2005, March 3), “Quadratic Forms”, Retrieved September 26, 2015, from http://sfb649.wiwi.hu-berlin.de/fedc_homepage/xplore/tutorials/mvahtmlnode16.html Clotfelter, Charles T. (1985), Federal Tax Policy and Charitable Giving, NBER Books, National Bureau of Economic Research, Inc, number clot85-1, September, retrieved from http://papers.nber.org/books/clot85-1

Davis, Carl, Kelly Davis, Matthew Gardner, Robert S. McIntyre, Jeff McLynch, and Alla Sapozhnikova Institute on Taxation and Economic Policy (2009), Who Pays? A Distributional Analysis of the Tax Systems in All 50 States (3rd Edition). Retrieved from website: http://www.itep.org/whopays3.pdf

Diamond, Peter and Emmanuel Saez (2011), “The Case for a Progressive Tax: From Basic Research to Policy Recommendations”, Journal of Economic Perspectives, 25 (4), 165 - 190

Federal Reserve Board (2012a), 1989 Survery of Consumer Finances, retrieved from http://www.federalreserve.gov/econresdata/scf/scf_1989documentation.htm (codebook) and http://www.federalreserve.gov/econresdata/scf/scf 1989survey.htm (survey data)

Federal Reserve Board (2012b), 1992 Survery of Consumer Finances, retrieved from http://www.federalreserve.gov/econresdata/scf/scf_1992documentation.htm (codebook) and http://www.federalreserve.gov/econresdata/scf/scf_1992survey.htm (survey data)

Federal Reserve Board (2012c), 1995 Survery of Consumer Finances, retrieved from http://www.federalreserve.gov/econresdata/scf/scf_1995documentation.htm (codebook) and http://www.federalreserve.gov/econresdata/scf/scf_1995survey.htm (survey data)

Federal Reserve Board (2012d), 1998 Survery of Consumer Finances, retrieved from http://www.federalreserve.gov/econresdata/scf/scf_1998documentation.htm (codebook) and http://www.federalreserve.gov/econresdata/scf/scf_1998survey.htm (survey data)

Federal Reserve Board (2012e), 2001 Survery of Consumer Finances, retrieved from http://www.federalreserve.gov/econresdata/scf/scf_2001documentation.htm (codebook) and http://www.federalreserve.gov/econresdata/scf/scf_2001survey.htm (survey data) 
Federal Reserve Board (2012f), 2004 Survery of Consumer Finances, retrieved from http://www.federalreserve.gov/econresdata/scf/scf_2004documentation.htm (codebook) and http://www.federalreserve.gov/econresdata/scf/scf_2004survey.htm (survey data)

Federal Reserve Board (2012g), 2007 Survery of Consumer Finances, retrieved from http://www.federalreserve.gov/econresdata/scf/scf_2007documentation.htm (codebook) and http://www.federalreserve.gov/econresdata/scf/scf_2007survey.htm (survey data)

Federal Reserve Board (2012h), What You Should Know about Home Equity Lines of Credit, retrieved Aug 01, 2015 from http://files.consumerfinance.gov/f/201204_CFPB_HELOC-brochure.pdf Federal Trade Commission (2012, August), “Home Equity Loans and Credit Lines”. Retrieved September 21, 2015, from http://www.consumer.ftc.gov/articles/0227-home-equity-loans-andcredit-lines

Feenberg, Daniel (1988), "Idenfication in Tax-Price Regression Models: The Case of Charitable Giving”, NBER Working Paper No. 988

Feldstein, Martin (1999), “Tax Avoidance and the Deadweight Loss of the Income Tax", The Review of Economics and Statistics, 81 (4), $674-680$

Friedberg, Leora (2000), “The Labor Supply Effects of the Social Security Earnings Test”, The Review of Economics and Statistics, 82 (1), $48-63$

Friedberg, Leora and Tianying He (2015), “The Impact of Taxation on Charitable Giving”, working paper

Giving USA Foundation and the Center on Philanthropy at Indiana University (2010), Giving USA 2010 - The Annual Report on Philanthropy for the Year 2009, Executive Summary, retrieved from http://www.gwpa.org/s_gwp/bin.asp?CID=4777\&DID=47565\&DOC=FILE...

Godfrey, Mike, (2013, Jul 25), US Study Looks At Tax Allowances Reform, Tax-News.com, Retrieved from http://www.taxnews.com/news/US_Study_Looks_At_Tax_Allowances_Reform__61506.html

Godfrey, Mike, (2013, Aug 1), Study Looks At Economic Effects Of 'Blank Slate' Tax Reform, TaxNews.com, Retrived from http://www.tax- 
news.com/news/Study_Looks_At_Economic_Effects_Of_Blank_Slate_Tax_Reform 61578.htm 1

Goldberger, Arthur S. (1991), A Course in Econometrics, Cambridge and London: Harvard University Press

Greeley, Brendan, with Richard Rubin, (2013, Aug 5 - Aug 11), An Actual Vault to Hide Senators' Secrets, Bloomberg Businessweek, August 5 -August 11, 2013, 25 - 26

Gruber, Jon and Emmanuel Saez (2002), “The Elasticity of Taxable Income: Evidence and Implications", Journal of Public Economics, 84 (2002), 1 - 32

Heim, Bradley (2008), “The Effect of Recent Tax Bradley T. Heim Changes on Taxable Income: Evidence from a New Panel of Tax Returns”, Journal of Policy Analysis and Management, 28 (1), $147-163$

Hendren, Nathaniel (2015), “The Policy Elasticity”, forthcoming Tax Policy and the Economy, Retrieved from http://scholar.harvard.edu/files/hendren/files/the_policy_elasticity.pdf?m=1442785171 Internal Revenue Service Data Book, 2012 Publication 55B, Washington, DC March 2013 Internal Revenue Service, Statistics of Income Division (July 2011), SOI Tax Stats - 2009 Individual Statistical Table 2.1 Returns with Itemized Deductions: Sources of Income, Adjustments, Itemized Deductions by Type, Exemptions, and Tax Items, by Size of Adjusted Gross Income, Tax Year 2009, retrieved from www.irs.gov/file_source/pub/irs-soi/09in21id.xls

Internal Revenue Service, Statistics of Income Division (Aug 2014), SOI Tax Stats - 2012 Individual Statistical Table 2.1 Returns with Itemized Deductions: Sources of Income, Adjustments, Itemized Deductions by Type, Exemptions, and Tax Items, by Size of Adjusted Gross Income, Tax Year 2012, retrieved from http://www.irs.gov/pub/irs-soi/12inalcr.pdf

Kennickell, Arthur and Loise Woodburn (1999): “Consistent Weight Design for the 1989, 1992 and 1995 SCFs, and the Distribution of Wealth", Review of Income and Wealth, 45 (2), 193 -215 Kopczuk, Wojciech (2005), “Tax bases, tax rates and the elasticity of reported income”, Journal of Public Economics, 89 (11-12), 2093 - 2119 
Kubik, Jeffrey D. (2004), “The Incidence of Personal Income Taxation: Evidence from the Tax Reform Act of 1986”, Journal of Public Economics, 88 (2004), 1567 - 1588

Liebman, Jeffery B. and Richard J. Zeckhauser (2004), "Schmeduling”, working paper McClelland, Robert and Shannon Mok (2012), “A Review of Recent Research on Labor Supply Elasticities", Congressional Budget Office Working Paper 2012-12, retrived from http://www.cbo.gov/sites/default/files/10-25-2012-

Recent_Research_on_Labor_Supply_Elasticities.pdf

Moffitt, Robert (1986), “The Econometrics of Piecewise-Linear Budget Constraints: A Survey and Exposition of the Maximum Likelihood Method”, Journal of Business \& Economic Statistics, 4 (3), $317-228$

Peloza, John and Piers Steel (2005): “The Price Elasticities of Charitable Contributions: A MetaAnalysis”, Journal of Public Policy \& Marketing, 24, 260 - 272

Reece, William S. (1979), “Charitable Contributions: New Evidence on Household Behavior”, The American Economic Review, 69(1), 142 - 151

Reece, William S. and Kimberly D. Zieschang (1985), "Consistent Estimation of the Impact of Tax Deductibility on the Level of Charitable Contributions", Econometrica, 53 (2), 271 - 293

Rudebusch, Glenn D. (2010), “The Fed's Exit Strategy for Monetary Policy”, FRBSF Economic Letter 2010-18, retrieved from http://www.frbsf.org/economic-research/publications/economicletter/2010/june/fed-exit-strategy-monetary-policy/

Saez, Emmanuel, Joel Slemrod and Seth H. Giertz (2012), “The Elasticity of Taxable Income with Respect to Marginal Tax Rates: A Critical Review", Journal of Economic Literature, 50:1, 3-50

Slemrod, Joel (1998), "Methodological Issues in Measuring and Interpreting Taxable Income Elasticities”, National Tax Journal, 51 (4), 773 - 788

Tax Foundation, U.S. Federal Individual Income Tax Rates History, 1913 - 2011

Tiehen, Laura (2001): “Tax Policy and Charitable Contributions of Money”, National Tax Journal, 54 (4), $707-723$

U.S. Bureau of Economic Analysis (BEA). (2015, June 24). National Data - GDP \& Personal Income. 
Retrieved July 16, 2015, from

http://www.bea.gov/iTable/iTable.cfm?ReqID=9\&step=1\#reqid=9\&step=1\&isuri=1

Varian, Hal R. (1992), Microeconomic Analysis, Third Edition, New York and London: W. W. Norton

\& Company 


\section{Chapter 2}

\section{The Impact of Taxation on Charitable Giving by Itemizers and Non-Itemizers (coauthored with Leora Friedberg)}

\section{Introduction}

According to The Annual Report on Philanthropy for the Year 2011, total charitable giving by individuals in the United States reached $\$ 217.70$ billion (Giving USA 2012), or approximately $1.5 \%$ of GDP. One of the most important policies affecting the giving economy is the deductibility of charitable giving from individual taxable income. The tax deduction effectively reduces the "price" of charitable giving, or the amount of personal income foregone for each dollar given to charity (Feldstein and Clotfelter 1976). Tax return itemizers deducted $\$ 170.24$ billion in contributions from their taxable income in

\section{1 (Internal Revenue Service).}

In valuing the tax revenue lost to the charitable giving deduction, it is critical to know whether deductibility generates more giving and, if so, how donations respond to changes in the tax rates (Brown 1997). The core parameter for answering both questions is the price elasticity of charitable giving, defined as the percentage change in charitable giving resulting from a $1 \%$ increase in the tax price of one minus an individual's marginal tax rate (MTR). Under certain assumptions, a key threshold is at -1 . At this level, the loss of tax revenue induced by deductibility equals the increase in individual giving; if the elasticity is larger than 1 in absolute value, the loss of revenue is smaller than the increase in giving. ${ }^{48}$

We make two principal contributions to the literature on charitable giving and taxation. First, we use the Survey of Consumer Finances (SCF), a data set previously unexplored for the purpose of estimating the price elasticity of charitable giving. The SCF spans decades with several major federal tax changes that can be used for identification, and we use data from 1988 to 2006. It also reports donation amounts for both tax itemizers and non-itemizers, and it oversamples high-income households. Non-

\footnotetext{
48 The threshold level also depends on the extent of (1) government provision of public goods crowding out private donations and (2) volunteer labor (Brown 1997).
} 
itemizers do not appear in administrative tax data, which have been used to yield our best estimates of the tax-price of giving. Besides, the SCF has detailed information on individual correlates of giving that allow us to impute marginal tax rates - key information that is otherwise observable in administrative data. ${ }^{49}$

Second, the existing literature focuses on "exogenous itemizers" (defined as taxpayers who have high enough non-charity deductions to itemize and face a reduced tax-price of giving regardless of the amount they give) because their tax price varies. Other taxpayers (whom we term "exogenous non-itemizers") face a marginal tax price of 1 for their first dollar of giving regardless of their marginal tax rate. While maintaining the assumption that non-charity deductions are determined exogenously from charitable giving, we study both exogenous itemizers and exogenous non-itemizers. The latter face a non-convex budget constraint in their price of charitable giving. We characterize the incentives of non-itemizers based on the tax-price they will face if they give enough to itemize, as well as the "distance" in giving required for them to reach this itemization threshold. This point applies broadly to other tax expenditures as well.

We estimate a log-linear specification as in the literature, with the log of charitable giving on the left-hand side and the logs of the tax-price, along with detailed income and wealth controls and other individual-level covariates on the right-hand side. When we consider the role of distance by including exogenous non-itemizers in the analysis, we also include distance and its interaction with the log tax-price on the right-hand side. Our estimation results show that both exogenous itemizers and exogenous non-itemizers respond to tax incentives. The price elasticity of charitable giving of exogenous itemizers is -1.228 with a $\mathrm{p}$-value of $2.6 \%$. This number is quite similar to the most recent estimates in the literature (Bakija and Heim 2011), which gives confidence that the SCF is useful for examining the charitable giving deduction. ${ }^{50}$ Further, we show that the estimate is mostly driven by the self-employed group, who have a tax price elasticity of

\footnotetext{
${ }^{49}$ Among recent papers on charitable giving elasticity, Auten, Sieg, and Clotfelter (2002), Bakija and Heim (2011) use tax return data, Tiehen (2001) uses survey data, and Karlan and List (2007) and Grossman (2003) use experimental data.

50 While we use rich household information, the use of the SCF involves measurement error in non-charity deductions and also precludes us from incorporating key contributions of Bakija and Heim, especially their inclusion of state tax rates, their focus on dynamic responses to tax rate changes in panel data, and their controls for time-varying heterogeneity in giving by income.
} 
-2.515 , significant at the $1 \%$ level. This result echoes the finding in Saez (2010) and Chetty, Friedman, and Saez (2013) that the self-employed react much more strongly to other aspects of the tax code, and it shows that their responsiveness is not limited to the amount of self-employment income that they report. On the other hand, the non-selfemployed group has an insignificant elasticity of -0.81 with a standard error of 0.76 .

When we pool the exogenous itemizers and non-itemizers, the tax price elasticity is somewhat more substantial, at -1.745 for exogenous itemizers. For exogenous nonitemizers, as distance increases, the tax price elasticity goes toward zero as predicted. The absolute value of the tax price elasticity decreases by about 0.11 when distance doubles for the entire sample, and more rapidly for the self-employed. We discuss issues concerning measurement error in detail and reach the following two conclusions. We are likely to have mean-zero measurement error in the major deductions besides charitable contributions because we observe some but not all information about them; this would lead us to misclassify some people's itemization status and probably attenuate our estimated effect of the tax price and distance. ${ }^{51}$ Second, we underestimate distance for a minority of households who take deductions that we have no information about. Some of them will actually be exogenous itemizers and the rest will be exogenous non-itemizers with smaller distance than we attribute to them, and for them we would underestimate the rate at which the tax price elasticity diminishes. These potentially offsetting sources of bias are the cost of using survey data, which allows us to examine charitable contribution responses of non-itemizers. Moreover, since our tax-price elasticity estimate for exogenous itemizers is close to those of the recent literature, we surmise that the bias in our approach is relatively minor.

This novel set of estimates shows the importance of considering those who might otherwise be non-itemizers if not for the charitable deduction when considering responses to tax reforms. In policy simulations, if the tax price of giving changes to 1 as a result of removing the charitable giving deduction, about $0.4 \%$ of all married-filing-jointly

\footnotetext{
51 These major deductions are the mortgage interest deduction and the deduction for state and local income and property taxes. Thus, some of our exogenous non-itemizers, who we treat as having positive distance, are actually exogenous non-itemizers with zero distance and thus are not reacting to the distance we attribute to them, while reacting more to the tax price we attribute to them. Similarly, some of our exogenous itemizers are actually exogenous non-itemizers, and so we are missing their response to distance while overestimating their response to the tax price.
} 
households would stop itemizing. Moreover, ignoring exogenous non-itemizers leads to an underestimate of the decline in charitable giving that would result from increasing the standard deduction. Based on our estimates, a $10 \%$ increase in the standard deduction would reduce giving by $\$ 1.93$ billion under the standard approach from the literature; but the reduction would only be $\$ 0.99$ billion if one recognizes the giving response of exogenous non-itemizers.

The rest of this paper is divided into five sections. Section II reviews the literature. Section III presents the empirical specifications and identification. Section IV describes the data. Section V gives the estimation results. Section VI concludes.

\section{Previous Estimation Approaches}

Our analysis uses repeated cross-sections from the Survey of Consumer Finances. Previous empirical studies on the tax-price elasticity of charitable giving fall into two categories: those using tax return data and those using survey data. To our knowledge, all survey data used in this literature have been single or short repeated cross-sections; tax return data have been panel or cross-sectional. ${ }^{52}$

In terms of other features, each type of data has advantages. Tax data provide more accurate measurement of charitable giving, while survey data may suffer from social desirability bias (Fisher 2000). Tax data report deductions, taxable income and the marginal tax rate, and tax liability, while most cross-sectional data do not report this. On the other hand, using tax return data restricts the sample to itemizers, eliminating from consideration non-itemizers, including most lower-income households (Feldstein and Clotfelter 1976, Reece 1979). ${ }^{53}$ Survey data can also provide much better information on wealth and demographic variables than can tax data. Such variables can help control for unobserved characteristics that may cause a correlation between income and tax price variables and would then bias estimates of the price elasticity (Feldstein and Clotfelter

\footnotetext{
${ }^{52}$ Individual fixed effects can be included when using panel data to control for heterogeneity across individuals. This is important if certain individual-specific characteristics affect giving and also correlate with the tax-price. When using cross-sections, the approach instead is to control for observable characteristics of individuals.

${ }^{53}$ The exception is during $1981-1986$, when non-itemizers were also allowed to deduct charitable contribution. See Duquette (1999) for a study of charitable giving by non-itemizers using tax data from this period.
} 
1976). Below, we review empirical studies based on the type of data and discuss sources of identification that they rely on.

\section{II.1. Studies with Tax Return Data}

Table 1 summarizes a few tax-data studies that are the most recent and/or are wellidentified, while Appendix Table A.1 reports a comprehensive list. Among them, Bakija and Heim (2011) have perhaps the best data and also the most complete combinations of regressors across specifications. They used a 1979 - 2006 panel of tax returns assembled from several confidential Treasury Department data sets and constructed tax prices with both federal and state tax rates. They tried models with current, past and future prices and incomes, with or without instruments, and allowing or not allowing coefficients to differ across income classes. The estimate of the price elasticity that they find most convincing is -1.10 .

Table 1. Summary of Important Studies Using Tax Returns Data

\begin{tabular}{lll}
\hline Study & $\begin{array}{l}\text { Price Elasticity } \\
\text { Estimate } \\
\text { (Standard Error) }\end{array}$ & Data \\
\hline Bakija and Heim (2011) & $-1.10(0.45)^{\mathrm{a}}$ & $1979-2006$ tax returns, panel \\
Auten, Sieg, and Clotfelter(2002) & $-1.26(0.04) ;-0.46^{\mathrm{b}}$ & $1979-1993$ tax returns, panel \\
Barrett (1991) & $-1.09(0.11)$ & $1979-1986$ tax returns, panel \\
\hline a: They estimated the elasticities for "persistent" price", "future" price, and "transitory" \\
price. -1.10 is the estimate for the persistent price elasticity. \\
b: -1.26, is their core estimate under certain econometric assumptions for the change of \\
permanent and transitory income and price; -0.46, which only appears in a footnote, is \\
from a pooled regression model using fixed effects and therefore more comparable to \\
other estimates in the literature.
\end{tabular}

A potential problem with studies using tax data is that many, if not all, construct the income variable in their regressions based on Adjusted Gross Income (AGI) instead of total income. Starting from AGI, some studies simply subtract tax liabilities to reach their income variable (for example, Auten and Joulfaian 1996; Barrett 1991). Other studies make a few but not complete adjustments towards total income (for example Bakija and Heim 2011). This is due to the limitations of reported tax data as taxable income definitions change; or, as is the case of Bakija and Heim, due to the intent to make the definition of income consistent over time and across individuals. In any event, the constructed income variables are not accurate measurements of true disposable income 
and its influence on giving. In this paper we compare results from specifications with both AGI and total income. While the distinction in the income definitions does not have a great effect, it increases the precision of some of the key coefficient estimates.

\section{II.2. Studies with Survey Data}

Among large, repeated, nationally representative surveys, the Consumer Expenditure Survey (CEX) reports charitable giving and has been used to study the price elasticity of giving (Reece 1979; Reece and Zieschang 1985; Bradley, Holden, and McClelland 1999). Other studies have relied on surveys conducted one time, on a limited subject matter, or in a limited location, as reported in Appendix Table A.2 (Boskin and Feldstein 1977, Schiff 1985, Feldstein and Clotfelter 1976, Tiehen 2001, Brown and Lankford 1992). A major problem with the majority of studies based on survey data is that their sample consists of observations from only one or two years, during which there was no variation in the federal tax schedule. In this case, these studies have to rely either solely on the assumption that income affects charitable giving linearly (while affecting the tax-price of giving nonlinearly) or additionally on tax rate variation across states. ${ }^{54}$ Studies that incorporate either federal tax law changes or state tax variation may be more reliable than those that only rely on the linearity assumption for identification. Table 2 lists the studies using survey data that are strongest in this dimension. Among these studies, Reece and Zieschang (1985) use a structural Hausman method and thus incorporate in their sample the "exogenous non-itemizers" whom we also include and who have a tax-price of giving of 1 . More generally, we use survey data that spans over a decade with three major federal tax law changes to achieve identification, though the SCF does not provide state identifiers that would allow us to use state tax variation. ${ }^{55}$

Table 2. Summary of Important Studies Using Survey Data

\begin{tabular}{lll}
\hline Study & $\begin{array}{l}\text { Price Elasticity Estimate } \\
\text { (Standard Error) }\end{array}$ & Data \\
\hline Tiehen (2001) & $-1.15(0.68)$ & $\begin{array}{l}1987-1995 \text { Independent Sector } \\
\text { Surveys on Giving and Volunteering }\end{array}$ \\
& \\
\hline 54 The linearity assumption is a problem if giving depends nonlinearly on income, generating omitted \\
variable bias that can be picked up by the tax price, which depends nonlinearly on income. The potential \\
problem with state tax rate variation is that state tax rates may be correlated with residential characteristics, \\
such as a preference for charitable giving and other public goods. \\
55 Bradley and Heim (2011) in particular show the value of taking advantage of state tax rate variation.
\end{tabular}




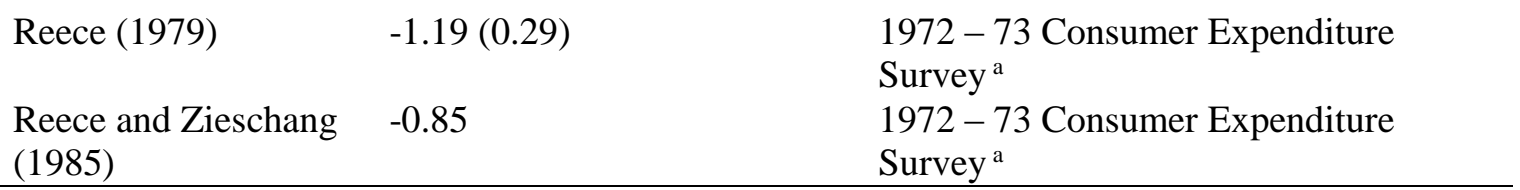

a: these two studies used the same data, but Reece (1979) does a reduced form regression while Reece and Zieschang (1985) uses the Hausman method.

A comparison of Table 1 and Table 2 shows that estimates with tax rate variation using either tax panel data or survey data yield similar results in the neighborhood of -1 . This similarity suggests that the abundant personal information available in some survey data, including the SCF, can control well for heterogeneity.

\section{II.3. Studies Using Unconventional Data Sources}

Other studies in the literature use novel data sets or methods that differentiate themselves from most other studies. For example, Kingma (1989) uses data collected for the National Public Radio stations and obtains an estimate of -0.43. Karlan and List (2007) and Eckel and Grossman (2003) run experiments to study the price elasticity. Karlan and List created prices by providing matching grants to potential donors in a field experiment. Their estimated price elasticity is -0.30 . However, this result is more comparable to "transitory" price elasticity estimates in the mainstream literature, not the core estimates we have been discussing, since the matching grants are one-time offers. Besides, the experiment by Eckel and Grossman shows that, although rebate and matching have the same structure, subjects view them differently and contribute more under matching. Therefore, one should be careful in applying results from an experiment on matching to tax environment.

\section{Empirical Approach and Identification}

We will test how the tax code affects charitable giving for two groups of taxpayers. As in the previous literature, people whose non-charity deductions are high enough that they would itemize anyway are "exogenous itemizers" and face a tax-price of $1-\tau$ for their first dollar of giving. The tax price represents the amount $1-\tau \leq 1$ of foregone potential consumption for each dollar given to charity. We will also consider the impact of the tax code on "exogenous non-itemizers", those whose non-charity deductions are too low for them to itemize. They face a non-convex budget constraint that may induce 
them to give a substantial amount in order to itemize; thus, they may respond to both the "distance" to the standard deduction as well as the tax-price available if they do itemize.

We will use the SCF to estimate the elasticity of giving with respect to the tax price and, for exogenous non-itemizers, to distance. The SCF covers a long time period with numerous tax changes, and it includes many household characteristics which allow us to control for factors that may influence both giving and income, and hence the marginal tax rate. Variation in the tax price arises from household income as well as tax reforms, but after controlling for year effects and for a quadratic term in household income, this variation largely arises from differences in tax rates for households with similar income across years.

\section{III.1 Tax-price Schedules}

Exogenous itemizers and exogenous non-itemizers differ in whether their first dollar of charitable giving has a tax price below 1. Exogenous itemizers are defined as taxpayers who have high enough deductions to itemize even without giving to charity. For an exogenous itemizer, the first dollar of charitable giving will reduce her taxable income and, as a consequence, her tax liability; we maintain the assumption, universal to this literature except for He (2015), that non-charity itemized deductions are exogenous to the decision to donate. We will discuss the exogeneity assumption more carefully later. Therefore, the tax-price for an exogenous itemizer's first dollar of giving is $1-\tau_{\text {first }}$, or one minus the marginal tax rate applied to taxable income at zero charitable giving; this is the key explanatory variable used in the literature because it abstracts from the endogenous decision of how much to give, which may influence the tax price. The higher someone's taxable income, the higher is $\tau_{\text {first }}$ for them, and hence the lower is their tax-price of giving.

Exogenous non-itemizers are taxpayers whose deductions except charitable giving are smaller than their standard deduction amount. For an exogenous non-itemizer, the first few dollars of giving will not reduce her taxable income or tax liability, so the firstdollar tax price for an exogenous non-itemizer is one. However, the marginal tax rate may still matter because, once an exogenous non-itemizer donates enough, she will begin to itemize. At that point, any further giving will reduce her taxable income and tax 
liability, and she will face a tax-price of $1-\tau_{\text {first }} .{ }^{56}$ How much she cares about this reduced tax-price as well as the average price of her total giving depends on how far away she is from the itemizing threshold.

For example, say that persons A and B both have a standard deduction of $\$ 5800$ and a marginal tax rate of $25 \%$ without itemization, but have a mortgage interest payment of $\$ 3300$ and $\$ 5300$, respectively. Then, person A will have to give $G=\$ 5800$ $\$ 3300=\$ 2500$ before her tax price of giving drops from 1 to $1-0.25=0.75$; and person $\mathrm{B}$ will have to give only $G=\$ 500$ before her tax price drops to 0.75 . The tax price of 0.75 is more relevant for $\mathrm{B}$, and $\mathrm{B}$ should give more than $\mathrm{A}$ does. We define this amount that an exogenous non-itemizer needs to donate before she can itemize ( $\$ 2500$ for $\mathrm{A}$ and $\$ 500$ for B) as distance to itemization. The distance determines how relevant the usual taxprice is. Continuing the above example, Figure 1 depicts the full tax price schedules of giving for $\mathrm{A}$ and $\mathrm{B}$. If, instead, $\mathrm{A}$ and $\mathrm{B}$ had more non-charity tax deductible spending than their standard deduction of $\$ 5,800$, they would have distance of zero as exogenous itemizers and their tax price schedules could be drawn by moving the vertical axis rightward (as illustrated by the thicker dashed line in the upper graph), leaving the price $=1$ segment out. The tax price drops when giving reaches distance and then rises in intervals because even more giving shifts someone to a lower tax bracket. ${ }^{57}$

However, in this paper we are not focusing on those later distances because it is reasonable to assume that people are more aware of switching itemization status than of crossing tax brackets, and in particular because the scale of the immediate tax price drop upon reaching distance is large.

\footnotetext{
56 To be precise, this is the tax-price of giving the first dollar after giving enough to reach the standard deduction threshold for itemizing.

57 To our knowledge, no research paper except, implicitly, Reece and Zieschang (1985) has analyzed the group of exogenous non-itemizers. The characterization of the tax incentives for this group of people in terms of both the tax price elasticity and distance $D$ is original. An alternative would be to estimate a structural piecewise-linear budget constraint model, as in Reece and Zieschang, but we have chosen an approach that involves fewer assumptions about functional form and focuses instead on individuals near the threshold of itemizing. MaCurdy, Green and Parsch (1990) emphasize the sensitivity of piecewise linear budget constraint estimation to inexact knowledge of the location of the kink points.
} 

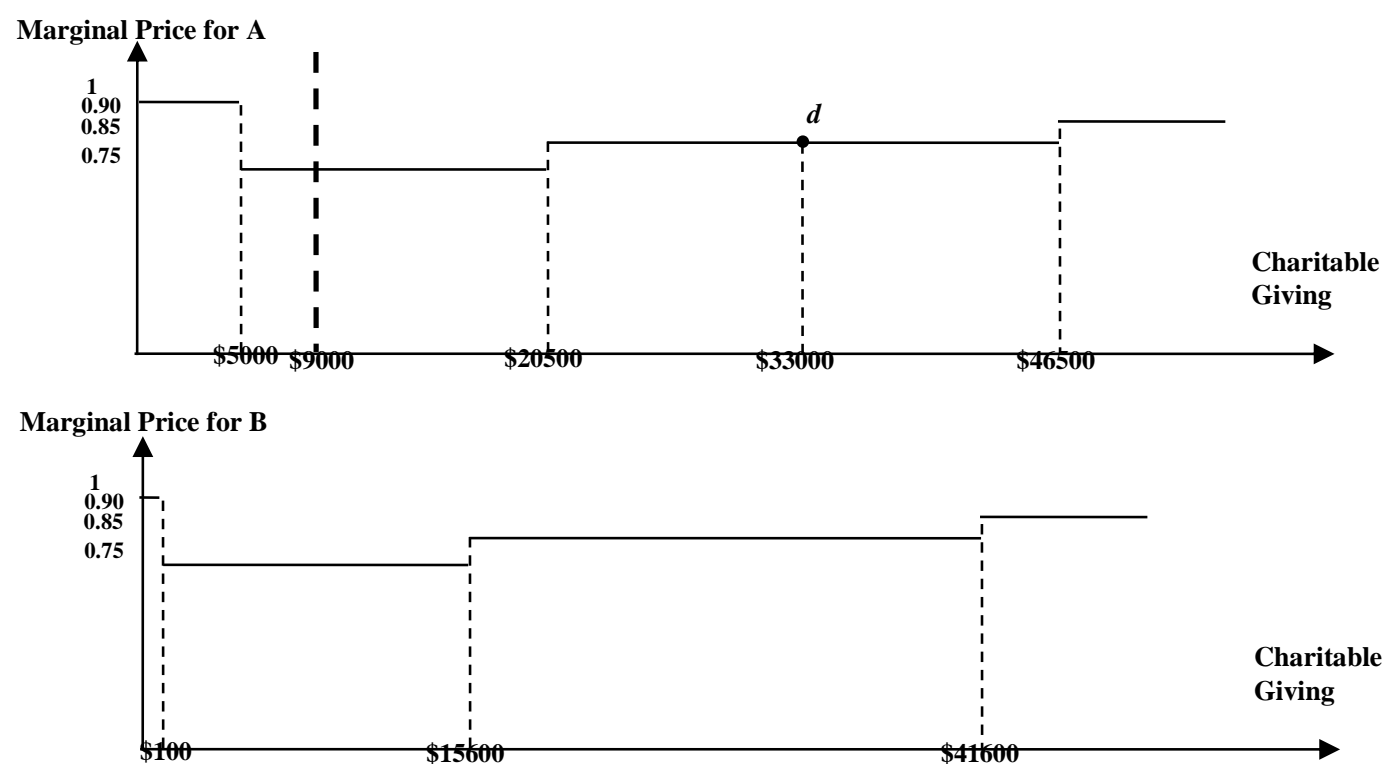

Figure 1 price schedules

This figure depicts the tax price schedules of giving for two hypothetical single taxpayers, A and B, in 2011 . They both have the following income level and tax schedule:

Adjusted Gross Income (AGI): \$59500; Personal exemption: \$3700; Standard deduction: \$5800;

Taxable Income $(\mathrm{TI})=$ AGI - personal exemption - Max (standard deduction, tax-deductible spending);

Marginal Tax Rate (MTR): $10 \%$ for TI between 0 and $\$ 8500,15 \%$ for TI between $\$ 8500$ and $\$ 34500$, and $25 \%$ for TI between $\$ 34500$ and $\$ 50000$.

They have different amounts of non-charity tax-deductible spending: A has $\$ 800$ and B has $\$ 5700$.

To see how the marginal prices are calculated: take, for instance, a representative point $d$ from A's price curve. At a charitable giving of $\$ 33000$, the taxable income will be reduced to AGI - personal exemption - Max (standard deduction, tax-deductible spending $)=\$ 59500-\$ 3700-(\$ 800+\$ 33000)=\$ 22000$ and fall into the $15 \%$ MTR bracket, and thus the tax-price for the next dollar of giving is $1-15 \%=0.85$.

\section{III.2 Identification}

As we said above, the tax-price elasticity is identified by variation in the tax-price observed for different taxpayers. This variation is induced by both policy changes and income differences. Between our SCF years of 1989 to 2007, federal individual income tax rates changed in 1991, 1993, 2001, 2002, and 2003, and tax brackets changed as well. These changes sometimes altered the tax-price of giving, either up or down, by substantial amounts. Tax rates were raised by 11.6 percentage points for top income earners during 1991-1993, new tax brackets were established in 1991, 1993, and 2001, brackets were widened for married filers in 2002 and 2003, and tax rates were cut by between 3 to 5 percentage points for most income groups during 2001-2003. Figure 2 plots the relationship between the tax-price $1-\tau_{\text {first }}$ and a married-filing-jointly 
household's taxable income at zero charitable giving at the points in time when our data from the SCF were collected. For example, a married-filing-jointly household with $\$ 100,000$ taxable income (measured in 2011 dollars) faced a tax price of giving of 0.75 in 2003-2006, compared to 0.72 in 1991-1992 and 0.67 in 1988-1990.

Also, in 2003 the standard deduction for married couples was raised, increasing the deductions and hence distance needed to reach itemization status. The standard deduction ranged between $\$ 9,000$ and $\$ 10,000$ in 2011 dollars until 2002 and then was raised to about $\$ 11,500 .^{58}$

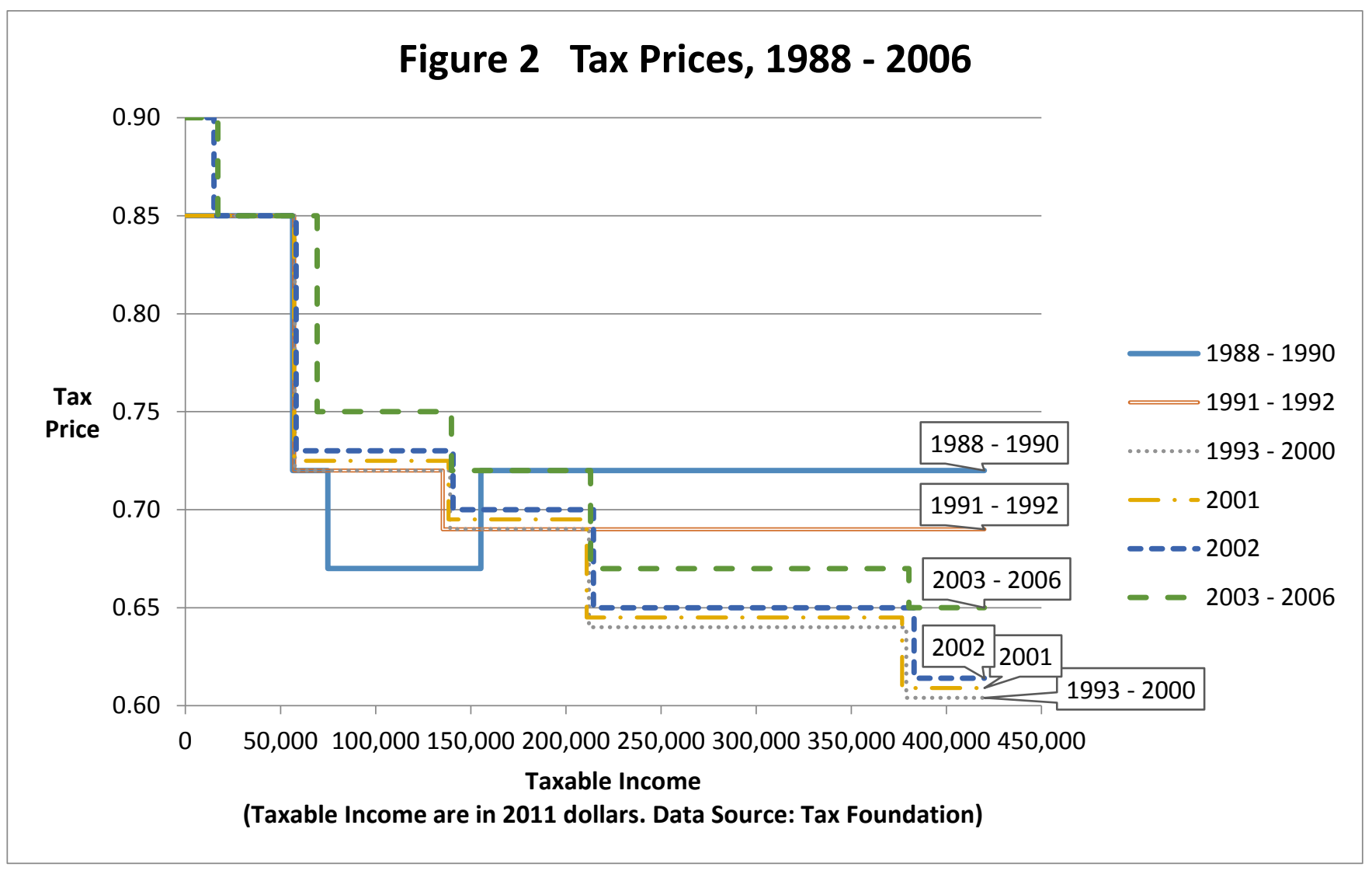

Figure 2 Tax price schedules $1988-2006$

This figure depicts the relationship between the first dollar tax-price $1-\tau_{\text {first }}$ and a married-filing-jointly household's taxable income at zero charitable giving, with $\tau_{\text {first }}$ being the marginal tax rate applied to taxable income at zero giving. Taxable income is in 2011 dollars.

\footnotetext{
58 We also account for some less consequential changes in itemized deductions that took place. Beginning in 1991 itemized deductions are reduced at high AGI levels; in 1988, 40\% of personal interest was deductible.
} 
Variation in the observed tax price also arises because higher income leads to a higher marginal tax rate and a lower tax price of giving. However, higher income also tends to raise charitable giving. Therefore, in the regression of the giving level on the tax price, it is important to adequately control for the effect of income to avoid omitted variable bias, a point that has occupied much of the literature (Bakija and Heim 2011; Feenberg 1982). We follow the literature in controlling for income and are further able to control for wealth, which is difficult using administrative data; and we also control for year effects to allow for aggregate changes in interest rates, other macroeconomic conditions, or government social policies to affect individual charitable giving (Randolph 1995). After controlling for year effects, a linear and a quadratic term in household income, and wealth, the identification relies primarily on differences in tax rates for households with similar income across years and on non-linearities that generate differences in tax rates for households with similar income in the same year.

Identification of the distance effect comes from the variation in distance observed for different taxpayers, again after controlling for year effects and quadratic household income. The variation comes from people spending different amounts on non-charity taxdeductible items and from tax reforms that change the standard deduction. This highlights another key identification assumption in the literature: for either exogenous itemizers or exogenous non-itemizers, the amount of non-charity deductions is treated as exogenous. In other words, taxpayers first make decisions on non-charity deductions such as how big a mortgage to take out, independently of how much they will donate. This assumption is not discussed but is implicit in the literature and requires that taxpayers do not simultaneously choose the tax-price schedule of giving and the amount of giving. This assumption could be violated if, for example, one needs to donate a large and fixed amount for religious purposes and instead alters home buying to reduce the tax price of giving, generating a negative estimated correlation between tax-price and giving. ${ }^{59}$

\footnotetext{
${ }^{59}$ This issue is explored further in He (2015), who focuses on joint decisions about charity and HELOC interest payments. He chooses those two particular tax expenditures because their tax prices differ (the HELOC tax price depends on the variable interest rate as well as the marginal tax rate), though he omits considerations of distance. He finds a significant cross-price elasticity between charitable giving and HELOC interest payments, but he also shows that the estimated own-price elasticity of charitable giving for his SCF sample is almost identical in the joint estimation as it is when he estimates an independent charitable giving regression, so ignoring other tax expenditures may not bias our estimates for charitable giving here.
} 


\section{III.3 Econometric Models for Exogenous Itemizers}

The first goal is to estimate the impact of the tax-price on charitable giving by exogenous itemizers. We employ a simple log-linear specification:

$$
\begin{aligned}
\operatorname{Ln}(\text { charity }) & =\beta_{0}+\beta_{1} \times \operatorname{Ln}(\text { tax price })+\beta_{2} \times \operatorname{Ln}(\text { wealth })+\beta_{3} \\
& \times \operatorname{Ln}(\text { disposable income })+\beta_{4} \times[\operatorname{Ln}(\text { disposable income })]^{2}+\beta_{5} \times \text { Age } \\
& +\beta_{6} \times 1(40 \leq \text { Age }<60)+\beta_{7} \times 1(\text { Age } \geq 60)+\beta_{8} \times \text { Education } \\
& + \text { Year Dummy Terms }+\varepsilon .
\end{aligned}
$$

We use natural logs of the variables, as most of the literature does, because the charitable contribution distribution is highly right skewed, and so that the estimated coefficient can be interpreted as an elasticity. To deal with zeroes, we try two approaches. Following studies such as Bakija and Heim (2011), we add \$10 to each giving amount to get the variable charity, so we can take logs even for zero donations. ${ }^{60}$ The variable tax price is the after-tax cost of the first dollar of giving that reduces the taxable income, defined as $1-\tau_{\text {first }}$, where $\tau_{\text {first }}$ is the marginal tax rate that applies to the first dollar of giving.

We control for wealth and disposable income because wealth and income determine available resources for both personal consumption and charitable giving. Including income and wealth, as discussed earlier, helps avoid omitted variable bias because income also determines a household's marginal tax rate. We also control for year dummies, which allows for aggregate changes in interest rates, other macroeconomic conditions, or government social policies to affect individual charitable giving (Randolph 1995). Including age allows for the impact of life cycle factors (Bakija and Heim 2011), and age is associated with higher levels of giving (Clotfelter 1985). We also include years of education, which may affect giving.

In addition to the log-linear specification above, we try estimating a Tobit model to deal with people who do not give to charity. Only a handful of the literature estimates a Tobit (Bradley, Holden and McClelland 1999). The Tobit version of the model recognizes the fact that zero giving levels are corner solutions for many individuals with

\footnotetext{
${ }^{60}$ A robustness check by Bakija and Heim (2011) shows that this specification works well. They analyzed the sensitivity of estimates to the size of the constant added to charity by varying the value of this constant and then run regressions. The values tried include $\$ 1, \$ 100$, and $\$ 1000$. Note, too, that we do not explore specifications that involve an income-varying price elasticity, as Bakija and Heim found little evidence to support this.
} 
negative optimal giving levels. Compared with the Tobit version, the basic linear regression model may underestimate the price elasticity because it does not consider the response by people with corner solutions. We switch from the log to a linear specification for the Tobit because the log function does not take negative inputs.

\section{III.4 Econometric Models for All Households}

The model for all households incorporating exogenous non-itemizers is similar, with the addition of distance, along with its interaction with tax price, as regressors. The interaction terms allow the tax-price elasticity to depend on distance, as is implied by a piecewise linear budget constraint. As distance decreases, tax price should matter more to an individual, and similarly as tax price falls, a given distance should matter more. Specifically, we have

$$
\begin{aligned}
\operatorname{Ln}(\text { charity })= & \beta_{0}+\beta_{1} \times \operatorname{Ln}(\text { tax price })+\beta_{9} \times \operatorname{Ln}(\text { distance }) \\
& +\beta_{10} \times \operatorname{Ln}(\text { distance }) \times \operatorname{Ln}(\text { tax price })+\beta_{2} \times \operatorname{Ln}(\text { wealth }) \\
& +\beta_{3} \times \operatorname{Ln}(\text { disposable_income })+\beta_{4} \times[\operatorname{Ln}(\text { disposable income })]^{2} \\
& +\beta_{5} \times \text { Age }+\beta_{6} \times 1(40 \leq \text { Age }<60)+\beta_{7} \times 1(\text { Age } \geq 60) \\
& +\beta_{8} \times \text { Education }+ \text { Year Dummy Terms }+\varepsilon .
\end{aligned}
$$

As discussed earlier, the variable distance shows how much a household would have to give in order to face a reduced marginal tax-price. It is 0 for exogenous itemizers and is the difference between the standard deduction and the sum of non-charity taxdeductible consumption for exogenous non-itemizers. In this specification the value of $\beta_{9}$, the coefficient on distance, should be 0 . This is because $\beta_{9}$ captures the effect of the increase in $\operatorname{Ln}($ distance) when $\operatorname{Ln}($ tax price) is 0 (so tax price is 1 ), which is its value before an exogenous non-itemizer passes the itemizing threshold. When tax price is 1 , whether donating more or less, distance does not matter (in terms of saving taxes), so $\mathrm{Ln}$ (charity) should not respond to $\mathrm{Ln}$ (distance). We define tax price when it appears as a regressor as the value that it then takes after the tax payer gives enough to pass the itemizing threshold.

As above, we also estimate a Tobit model. Again, the Tobit specification replaces the $\log$ terms with level terms. Also, to give the coefficient $\beta_{9}$ an interpretation similar to the linear regression equation, the price variable is (tax price -1$)$ instead of tax price. 


\section{Data}

In this section, we describe the SCF sample that we use to estimate the price and distance elasticities. We first describe the data source and how we select our sample. Then, we provide the definition of key variables and the sample statistics, focusing especially on the characteristics of distance in the sample.

\section{IV.1 Data Source and Sample Selection}

We use data from the Survey of Consumer Finances (SCF), a repeated cross-section conducted every three years since 1983 with detailed financial data for approximately 4,000 households each year. We exclude from our sample the 1983, 1986 and 2010 SCF because they lack necessary information. Consequently, we use the survey years 19892007, covering the tax years 1988-2006. These surveys give us a total of 29,031 observations. ${ }^{61}$ Then, we retain in our sample households that file joint returns. This means that we exclude taxpayers who do not file tax returns; couples who file separate returns, for whom we do not observe how the couple divide up their deductions; households where only the respondent or the respondent's spouse/partner files or where the respondent is not married, for which we do not observe the filing status. These selection rules, and others (elaborated in Section IV.4) that affect a smaller number of observations, leave us a sample of 15,830. The surveys oversampled high income individuals so as to obtain reasonable sample sizes of the wealthy, and we use survey weights to make sample statistics nationally representative.

\section{IV.2 Variables}

Our outcome variable is charitable giving. The key right-hand side variables are the tax price of charitable giving, the distance to facing a reduced tax price, and their interaction. Our other right-hand side variables control for wealth, income, age, and years of education (Feldstein and Clotfelter 1976). Lastly, we split the sample into four groups based on exogenous itemization status and self-employment. We separate exogenous itemizers because they are the focus of existing studies. We separate self-employed

\footnotetext{
${ }^{61}$ The 1986 and 2010 SCF do not report Adjusted Gross Income, which makes the computation of the marginal tax rate less accurate; moreover, Auten, Cilke, and Randolph (1992) note a very high transitory response to the Tax Reform Act of 1986. The 1983 SCF does not report charitable giving. The SCF includes five implicates, or replicas of the data set, to account for error introduced by imputing missing values of some responses. We use all five implicates of the sample size reported in the text, adjusting the standard errors as in Rubin (1987)
} 
people because previous studies found that they are much more tax-aware (Saez 2010), perhaps because their work status affords them more opportunities to adjust their taxable income. We construct the variables as follows:

charity - Following studies such as Bakija and Heim (2011) who settled on this specification after robustness checks, we add $\$ 10$ to each giving amount to get charity. We do this in order to take logs even for zero donations in our log-linear specification. tax price-The after-tax cost of giving to charity, the tax price, is defined as $1-\tau_{\text {first }}$, with $\tau_{\text {first }}$ being the household's marginal tax rate based on pre-charity taxable income and applying to the first dollar of charitable giving for exogenous itemizers and the first dollar after giving distance for exogenous non-itemizers. ${ }^{62}$ We do not observe a household's exact tax rate or (pre-charity) taxable income, so we calculate them using the equation pre-charity taxable income $=A G I-$ exemptions - Max $($ standard deduction, ,non-

$$
\text { charity itemized deductions). }
$$

We observe AGI in the data. Exemptions and standard deduction depend on the filing status (which we limit to married filing jointly) and the number of dependents, which we assume equals the number of "individuals in the household who are financially dependent on that couple" (reported by the SCF), the absolute majority of whom are children. We impute non-charity itemized deductions from the data, resulting in potential measurement error for this and related variables, as we discuss shortly. ${ }^{63}$ Imputed noncharity itemized deductions are the sum of the mortgage interest deduction, state income tax deduction, real estate tax deduction and vehicle property tax deduction. ${ }^{64} \mathrm{We}$ observe the amount of real estate tax for the household's principal residence. Using the observed

\footnotetext{
${ }^{62}$ We cannot follow the approach in the literature using administrative data of adjusting the tax price to account for the differential taxation of unrealized capital gains that are donated to charity; accounting for this requires assumptions of when the capital gains would otherwise be realized and taxed and how much further appreciation would occur by then.

${ }^{63}$ Other studies that use survey data also have to impute itemized deductions, and the SCF offers much more concrete information for doing so than many other types of surveys.

${ }^{64}$ The itemized deductions we are missing are medical and dental expenses in excess of $7.5 \%$ of AGI, home mortgage deductible points, investment interest, casualty and theft losses, job expenses and other miscellaneous deductions. According to IRS statistics, for 2010, the non-exclusive percentages of taxpayers that took these 6 types of deductions were, respectively, $7.3 \%, 2.0 \%, 1.1 \%, 0.07 \%$ and $9.07 \%$. In addition, we also miss non-vehicle personal property tax deduction, and the IRS statistics does not report categories of personal property tax deductions. However, the impact of missing this deduction should be very small, since vehicles are the major component of personal properties (which is defined not to include real properties).
} 
market values of all properties, we then impute the real estate tax paid on secondary properties assuming they are taxed at the same rate with the principal residence. We compute the mortgage interest deduction from information on loan balances at the time of the survey, the annual interest rates and total mortgage payments per period. ${ }^{65}$ The state income tax rate varies by state and the vehicle property tax rate varies by county, but we do not observe respondents' states or counties. Therefore, we set the state income tax rate based on the respondent's total income and based on Davis et al. (2009), which reports the average state income tax rates for different income groups. About 20 states have vehicle property taxes. We extensively surveyed these states and their counties' websites online, and set the national average at $0.44 \%$, applied to the value of vehicles reported in the data.

non-charity itemization status - We use this variable to determine who faces a reduced tax-price for giving any amount because their non-charity itemized deductions exceed the itemization threshold. We impute this status by comparing the imputed non-charity itemized deductions with standard deductions.

distance - This variable is calculated as distance $=\max$ [standard deduction $-\Sigma$ noncharity itemized deductions, 0]. It is always zero for exogenous itemizers and shows how much exogenous non-itemizers would have to give to charity in order to pass the itemization threshold. It is the positive part of the difference between the standard deduction and the sum of non-charity itemized deductions, both of which were described above.

wealth - This is calculated as the sum of all assets less the sum of all liabilities. disposable income - This is Adjusted Gross Income (AGI) less tax liabilities at zero giving. In our main specifications we base this calculation on AGI, as opposed to total income, to make our results comparable to the majority of the literature which uses tax data. In alternative specifications we replace AGI with total income. The tax liability is determined by the same observed and inferred variables needed to calculate tax price.

\footnotetext{
${ }^{65}$ From this information we compute the interest payment in the relevant tax year (one year before the survey) by first calculating the balance at the beginning of the tax year and then multiply the balance by the annual interest rate. We incorporate limits on deductibility of interest on large mortgages.
} 
We define age as the household head's age. We also define two age dummies, one for households with age between 40 (included) and 60, and the other one for age at or above 60. Education is a household head's years of education. For the variables charity, distance, wealth, and disposable income, all values are in 2011 dollars.

\section{IV.3 Measurement Error}

As discussed in the previous section, calculating non-charity itemized deductions involves some approximation. This is the principle disadvantage of using survey rather than tax-return data, although tax returns also involve some measurement error because non-taxed components of income are not observed, and potentially some omitted variable bias because non-tax household characteristics are not observed.

The sum of non-charity itemized deductions is used for three purposes in our analysis, compared to two purposes in earlier studies. We use it to compute the firstdollar tax-price of giving, to split the sample into exogenous itemizers (as in the rest of the literature) and exogenous non-itemizers (only used here), and to compute distance to itemization for the latter. In all but two of the SCF years, itemization status is reported directly, and for some of the estimates we restrict the sample to those years and obtain quite similar results. ${ }^{66}$ Nevertheless, while most studies of charitable contributions that use survey data do not consider the possible sources of measurement error, we first briefly summarize and then discuss them at length. We surmise that the main problems are false classification of non-itemization (for perhaps $12 \%$ of the sample) and overestimation of distance; besides that, tax prices may be wrong, but probably not for many households. We argue below that overestimating distance may lead to an underestimate of the rapidity at which the tax-price diminishes in importance for nonitemizers as they move farther below the itemizing threshold.

To continue, we detail the sources of error. First, the four types of non-charity deductions that we observe or impute (mortgage interest, real estate property tax, state income tax and vehicle property tax) comprise about $79.5 \%$ of the value of all non-

\footnotetext{
66 Observing itemization status does not give us the information we need on exogenous itemization status because we do not observe the amount that is itemized for itemizers. We would still have to impute the same set of itemized deductions in order to determine exogenous itemization status, tax price, and distance.
} 
charity deductions. ${ }^{67}$ Second, we assume a uniform state income tax rate for people in the same income group and a uniform vehicle property tax rate for everyone. As a result, a respondent's exogenous itemization status may not be inferred correctly. The first point results in underestimating non-charity itemized deductions and misclassifying some exogenous itemizers as exogenous non-itemizers (which we refer to as false nonitemization status). The second point could cause misclassification in both directions. In fact, SCFs of the years 1995-2007 (excluding only the first two surveys that we use) asked directly whether the households itemized or not. For these years, the inferred itemization status matches the true itemization status for $82.04 \%$ of the observations. Further, $65.88 \%$ of the misclassifications involve false non-itemization status. ${ }^{68} \mathrm{We}$ show later that, when we restrict the sample to 1995-2007 instead of using 1989-2007 (though the latter offers more variation in tax schedules), the estimated sensitivity to tax price is larger for the exogenous itemizers. For the exogenous non-itemizers, the results are similar.

Due to the same two explanations in the previous paragraph, we also cannot measure tax price and distance perfectly. For the same reason that false non-itemization status occurs more often than false itemization status, inaccurately measured tax price and distance tend to be, respectively, smaller (because the first-dollar marginal tax rate is actually lower) and larger (because deductions are actually higher than we impute), compared to their true values. tax price is much less likely to differ from its true value than distance is, since tax price is the same within each taxable income bracket, and measurement error in itemized deductions often does not result in inferring the wrong tax bracket.

Therefore, the estimation for exogenous itemizers is affected by measurement error through misclassification and measuring tax price inaccurately, but neither type of error is likely large. Our sample of exogenous itemizers will exclude some taxpayers with high

\footnotetext{
${ }^{67}$ This is taken from 2010 IRS statistics. This does not mean that we misclassify itemization status for $20 \%$ of the sample, because small numbers of people take other deductions, though if they do they deduct large values, as in the case of medical expenses in excess of $7.5 \%$ of AGI. Given the skewness of these deductions, we do not think it would work well to impute the same average value for all households.

${ }^{68}$ Notice that this is the proportion of false non-itemization errors for inferring itemization status. It is not exactly but approximates the proportion of false non-itemization errors for inferring exogenous itemization status.
} 
levels of deductions other than the four types that we calculate. The most common one among the omitted deductions is medical and dental expenses. ${ }^{69}$ This would mean that our sample of exogenous itemizers probably under-samples people with medical conditions. This is not classical measurement error and the direction of bias cannot be determined, although, to the extent that people with high medical expenses are less likely to donate to charity at the same time, it would lead to an overestimate of the tax-price elasticity compared to a fully representative sample. ${ }^{70}$

When we include exogenous non-itemizers in our analysis and determine the effect of distance, the estimation is affected by measurement error through misclassification and through measuring tax price and distance inaccurately. Again, incorrect inference of tax price should not occur often, in fact less so for exogenous non-itemizers than for exogenous itemizers. Because AGI is observed, then as long as a household's exogenous non-itemization status is correct, the tax price past the itemizing threshold is also correct. When non-itemization status is misclassified (the more common type of misclassification), some households classified as exogenous non-itemizers are in fact exogenous itemizers with zero distance, which will attenuate our estimated effect of distance.

Lastly, we discuss how measurement error in distance affects the interpretations of the estimation results. In our specification in Section III.4, distance affects the tax price elasticity (through $\beta_{10}$ ) - a household with a higher distance (farther away from itemizing) should be less sensitive to tax price than a household with a lower distance. However, under the false non-itemization classification errors, some households with a low distance are observed to have a higher value, distance $+\eta, \eta>0$, which would

\footnotetext{
${ }^{69}$ According to 2010 IRS statistics, of the various tax expenditures that are not on one of the four types we calculate, $40.5 \%$ are on medical and dental expenses deduction.

${ }^{70}$ Something can be said if there is only one regressor. Using notations from Greene (2012), consider a single regressor model $y^{*}=\beta x^{*}+\varepsilon$, with $x^{*}$ measured with error as $x=x^{*}+u$. It follows that $\operatorname{plim} b=$ $\frac{\operatorname{plim}(1 / n) \sum_{i=1}^{n}\left(x_{i}^{*}+u_{i}\right)\left(\beta x_{i}^{*}+\varepsilon_{i}\right)}{\operatorname{plim}(1 / n) \sum_{i=1}^{n}\left(x_{i}^{*}+u_{i}\right)^{2}}$. If $u$ is a classical measurement error, then this reduces to an attenuated estimate $\operatorname{plim} b=\frac{\beta}{1+\sigma_{u}^{2} / Q^{*}}$, where $Q^{*}$ is plim $(1 / n) \sum_{i} x_{i}^{* 2}$ and $\sigma_{u}^{2}$ is the variance of $u$. When $u$ is more often negative, then we have $\operatorname{plim} b=\frac{\beta}{{ }_{1+}\left(\sigma_{u}^{2}+Q_{x u}^{*}\right) /\left(Q^{*}+Q_{x u}^{*}\right)}$, where $Q_{x u}^{*}$ is plim $(1 / n) \sum_{i} x_{i}^{*} u_{i}$. In the case that $x_{i}^{*}$ is negative or zero (e.g. when $x_{i}^{*}$ is $\operatorname{Ln}(1-\tau)$ ), $Q_{x u}^{*}$ is positive and attenuation bias occurs. However, in a multiple regression model, the direction of bias is already uncertain in a classical measurement error case, while the expression for the coefficient estimate is only more complicated when $u$ is more often negative.
} 
mistakenly add to the sensitivity to tax price of households at distance $+\eta$ and lead to underestimating the difference in sensitivity to tax price at low distance levels. In other words, the estimation results tend to underestimate the diminishing rate of the absolute value of the tax price elasticity with respect to distance.

\section{IV.4 Sample Definition and Statistics}

As mentioned earlier, we use the surveys from 1989 to 2007, and we study married households that file joint returns (explained in Section IV.1), yielding 16,338 observations. ${ }^{71}$ Further, since in our specifications we take logs of wealth and disposable income, we delete observations with a zero or negative wealth or disposable income, after which we have a sample of 15,830 ; they are also likely to be unusual in other ways related to their tax status and charitable giving.

Of the 15,830 observations, $35.2 \%$ are non-self-employed, exogenous itemizers; $29.75 \%$ are self-employed, exogenous itemizers; $29.78 \%$ are non-self-employed, exogenous non-itemizers; and 5.29\% are self-employed, exogenous non-itemizers. The non-self-employed in the sample are younger and less wealthy. In addition, exogenous itemizers are wealthier than exogenous non-itemizers, which is not surprising because the wealthy are likely to have higher deductions (through home ownership, mortgage size, taxable state income, etc.).

We report sample statistics in Table 3 . The median first-dollar marginal tax rate is $15 \%$ and so the median tax price is 0.85 ; it reaches minimum values of $0.604,0.65,0.67$, or 0.69 , depending on the year, for $22.2 \%$ (unweighted) or $3.3 \%$ (weighted) of the sample. Both the mean and median of distance for exogenous non-itemizers are between $\$ 6,000$ and $\$ 7,000$, meaning that the typical non-itemizer would have to give over $\$ 6,000$ to charity in order to begin itemizing deductions. Within this group, the $10^{\text {th }}$ percentile value of distance is $\$ 1,463$, and the $5^{\text {th }}$ percentile is $\$ 683$; these represent the households

\footnotetext{
${ }^{71}$ Of the $29,031-16,338=12,693$ observations left out, $21 \%$ do not file tax returns, $62 \%$ file returns and do not have spouses, $15 \%$ are couples but file separate returns, $2 \%$ are couples with only one person of each couple filing. In fact, for any originally missing value (due to nonresponses), the SCF imputes it five times and stores the imputations as five successive implicates. Thus, the number of observations in the full datasets $(145,155)$ is five times the actual number of respondents $(29,031)$. For the rest of the paper, all numbers of observations shown are defined this way, i.e. as one fifth of the total number of implicates. We follow the SCF instructions for handling the multiple implicates. Specifically, for summary statistics for Table 3, we use all observations, including all implicates, but weight each observation with its sample weight. As for regression, the procedure is somewhat more complicated, which we explain in a later footnote.
} 
that are closest to itemization. The distributions of both wealth and charitable giving are highly right-skewed. The median giving level is $\$ 556$, while at $75 \%, 90 \%$, and $99 \%$ percentiles, giving is, respectively, $\$ 2,097, \$ 5,731$ and $\$ 28,767$.

Table 3 Summary Statistics for Married-Filing Jointly Households

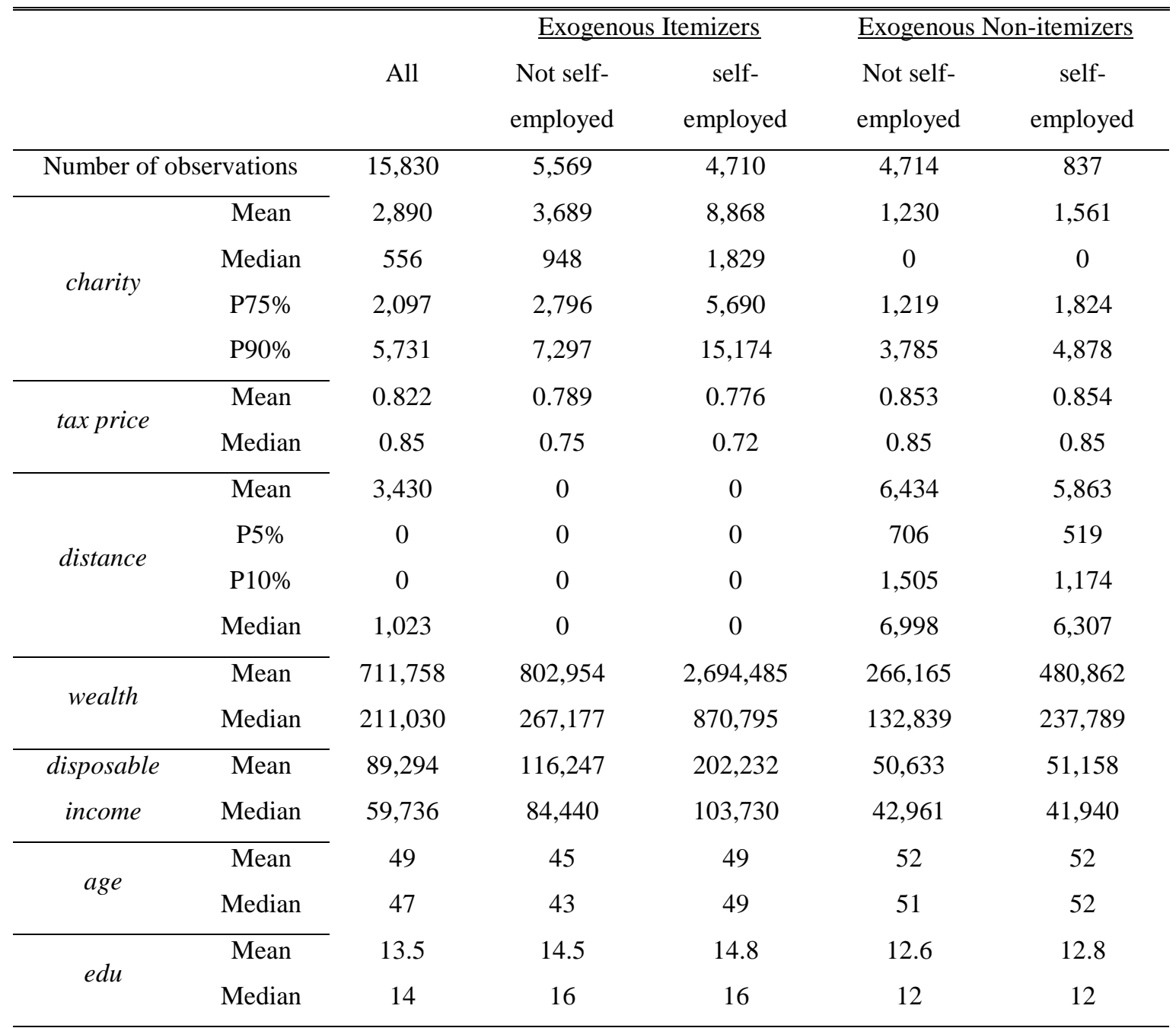

This table reports the summary statistics for a subsample of the married-filing-jointly households surveyed in the Survey of Consumer Finances between 1989 and 2007 that we use for regressions. It is only a subsample because it excludes households with negative wealth or disposable income. The means and the medians are weighted with the survey weights (variable X42001 in the SCF datasets). All monetary values are in 2011 dollars. Variable definitions are reported in the data section and the Appendix. In the linear regressions, charity is the original charitable giving level plus 10; but in this table, the charity statistics are for the original charitable giving levels. 
Exogenous non-itemizers and exogenous itemizers are very different, and so are the non-self-employed and the self-employed. Exogenous non-itemizers give less than exogenous itemizers, whether because their income is lower or their tax price is higher. The median, $75 \%$ and $90 \%$ percentiles of are, respectively, $\$ 0, \$ 1,303$ and $\$ 3,793$, for the former group and $\$ 1,049, \$ 3,339$ and $\$ 8,388$ for the latter. Exogenous non-itemizers' median income and median wealth are, respectively, $\$ 42,837$ and $\$ 142,998$, while exogenous itemizers' median income and wealth are, respectively, $\$ 86,898$ and $\$ 333,226$. The medians of giving, income, and wealth of the non-self-employed are, respectively, $0, \$ 58,241$, and $\$ 183,985$, while the same statistics are $\$ 1,113, \$ 71,129$ and $\$ 527,050$ for the self-employed.

Shedding more light on exogenous non-itemization, median distance is a few thousand dollars smaller for mortgage holders (43.15\% of exogenous non-itemizers) than for non-mortgage holders. ${ }^{72}$ The median distance is $\$ 4,017$ for mortgage holders and $\$ 8,422$ for others. The median of the ratio of distance to disposable income is 0.15 . The $10^{\text {th }}$ percentile value of the ratio is 0.02 , and the $5^{\text {th }}$ percentile is 0.01 . For mortgage holders alone, the ratio's median, $10^{\text {th }}$ and $5^{\text {th }}$ percentiles are, respectively, 0.08, 0.01 and 0.004; for non-mortgage holders, these numbers are 0.21, 0.06 and 0.03.

\section{Results}

This section discusses the results. We present results for exogenous itemizers in the first subsection and then results for the whole sample including exogenous non-itemizers in the second subsection. In both cases we also distinguish the self-employed from others. In each subsection we start with results under the log-linear specifications, including the main specification and others under certain sample restrictions and with an alternative income measure, followed by Tobit regression results.

\section{V.1 Results for Exogenous Itemizers}

In this section we present results for exogenous itemizers, corresponding to the specifications in Section III.3 for households whose filing status is married filing

\footnotetext{
72 "Mortgage holders" are defined to include second mortgage, home equity loan and line of credit holders. $43.15 \%$ is the weighted proportion. The un-weighted proportion of mortgage holders is $41.05 \%$.
} 
jointly. ${ }^{73}$ Table 4 gives results from the log-linear regression, which parallels the earlier literature; Table 5 shows results from alternative specifications including the Tobit, which has rarely been explored previously. ${ }^{74}$

As Table 4 shows, the estimated tax price elasticity for all exogenous itemizers, which is the population studied in most of the literature, is -1.228 and is statistically significant at the 5\% level. This number is similar to the estimates in studies listed in Table 1 and 2 that we regard as the most credible, for example -1.10 by Bakija and Heim (2011). The price elasticities estimated separately for the non-self-employed and the selfemployed are, respectively, -0.815 and -2.515 , with the former not statistically significant and the latter statistically significant at the $1 \%$ level. The larger size of the elasticity for self-employed taxpayers is a new finding in this literature and indicates greater sensitivity to tax rates, consistent with findings about other outcomes for this group from Saez (2010).

An elasticity of -1.228 means that, if the marginal net-of-tax rate rises by $10 \%$ (for example, if the marginal tax rate drops from $20 \%$ to $12 \%$ ), charitable giving would fall by $12.3 \%$. For an exogenously itemizing, married-filing-jointly household with a median weighted disposable income (in 2011 dollars) of $\$ 86,898$ and a median donation of $\$ 1,049$, the drop in their marginal tax rate that occurred between 2000 and 2003, from $28 \%$ to $25 \%$, i.e. a $4.2 \%$ increase in price, should decrease donations by about $5.2 \%$ to \$995.2. Separately for the non-self-employed and the self-employed, the predicted reductions resulted from the $4.2 \%$ increase in price are, respectively, $3.5 \%$ and $11.29 \%$.

Results in Table 4 also suggest that charitable giving increases significantly in wealth, income, age and education. A $1 \%$ increase in wealth is estimated to increase

\footnotetext{
${ }^{73}$ Regression results suggest that households with a single or head of household filing status are usually not responsive to tax price, except occasionally for the self-employed.

${ }^{74}$ As mentioned in Footnote 17, SCF has five parallel datasets because it stores five implicates (sets of imputations for missing values) for each surveyed household. In producing the results for all regression tables, the computation of the coefficients, standard errors and $t$ statistics follows a special procedure provided by the SCF website. First, we obtained coefficients and standard errors for each of the five parallel datasets. Second, we use SAS codes provided by SCF to compute the final coefficients, standard errors and t statistics. For each coefficient estimate, the SAS MACRO codes average the five coefficient estimates to generate the final coefficient. The final standard error is equal to the average of the five standard errors plus a specific measurement of the deviation of the five coefficient estimates from their average. Please refer to the SCF documentation for any year, for example http://www.federalreserve.gov/econresdata/scf/files/codebk2001.txt.
} 
giving by $0.47 \%$ for the non-self-employed and $0.55 \%$ for the self-employed. The income elasticity is about 0.400 at the sample median. One more year of education on average increases giving by $22 \%$, while one more year of age increases giving by $2 \%$.

Table 4 Linear Regression Results for Married-Filing-Jointly Exogenous Itemizers

\begin{tabular}{|c|c|c|c|c|c|c|}
\hline \multirow[b]{2}{*}{ Regressors } & \multicolumn{2}{|l|}{$\underline{\text { All }}$} & \multicolumn{2}{|c|}{ Not self-employed } & \multicolumn{2}{|c|}{ Self-employed } \\
\hline & $\begin{array}{l}\text { Estimate } \\
\text { (Std Error) }\end{array}$ & p-value & $\begin{array}{l}\text { Estimate } \\
\text { (Std Error) }\end{array}$ & p-value & $\begin{array}{l}\text { Estimate } \\
\text { (Std Error) }\end{array}$ & p-value \\
\hline Intercept & $0.776(2.135)$ & $71.6 \%$ & $1.058(3.297)$ & $74.8 \%$ & $-0.714(2.242)$ & $75.0 \%$ \\
\hline $\operatorname{Ln}($ tax price $)$ & $-1.228 *(0.551)$ & $2.6 \%$ & $-0.815(0.758)$ & $28.2 \%$ & $-2.515 * *(0.617)$ & $0.0 \%$ \\
\hline Ln (wealth) & $0.478 * *(0.028)$ & $0.0 \%$ & $0.470 * *(0.036)$ & $0.0 \%$ & $0.555 * *(0.052)$ & $0.0 \%$ \\
\hline $\operatorname{Ln}($ disposable income $)$ & $-1.361 * *(0.367)$ & $0.0 \%$ & $-1.415 *(0.561)$ & $1.2 \%$ & $-1.177 * *(0.376)$ & $0.2 \%$ \\
\hline$[\mathrm{Ln}(\text { disposable income })]^{2}$ & $0.077 * *(0.017)$ & $0.0 \%$ & $0.081 * *(0.025)$ & $0.1 \%$ & $0.063 * *(0.018)$ & $0.0 \%$ \\
\hline Dummy for middle aged & $-0.040(0.099)$ & $68.8 \%$ & $-0.094(0.128)$ & $46.5 \%$ & $0.243(0.141)$ & $8.5 \%$ \\
\hline Dummy for elder & $-0.073(0.192)$ & $70.4 \%$ & $-0.050(0.257)$ & $84.4 \%$ & $-0.037(0.253)$ & $88.3 \%$ \\
\hline Age & $0.019 * *(0.005)$ & $0.0 \%$ & $0.020 * *(0.007)$ & $0.6 \%$ & $0.019 *(0.008)$ & $1.2 \%$ \\
\hline Years of Education & $0.215^{* *}(0.011)$ & $0.0 \%$ & $0.217 * *(0.016)$ & $0.0 \%$ & $0.214 * *(0.022)$ & $0.0 \%$ \\
\hline Year dummy 91 & $0.153(0.116)$ & $18.9 \%$ & $0.188(0.145)$ & $19.5 \%$ & $0.014(0.210)$ & $94.7 \%$ \\
\hline Year dummy 94 & $-0.098(0.105)$ & $35.0 \%$ & $-0.012(0.136)$ & $93.3 \%$ & $-0.482 * *(0.207)$ & $2.0 \%$ \\
\hline Year dummy 97 & $0.173(0.115)$ & $13.2 \%$ & $0.352 *(0.149)$ & $1.8 \%$ & $-0.490 * *(0.165)$ & $0.3 \%$ \\
\hline Year dummy 2000 & $0.391 * *(0.109)$ & $0.0 \%$ & $0.447 * *(0.137)$ & $0.1 \%$ & $0.127(0.168)$ & $44.9 \%$ \\
\hline Year dummy 2003 & $0.244 *(0.109)$ & $2.5 \%$ & $0.318 *(0.138)$ & $2.2 \%$ & $-0.086(0.180)$ & $63.4 \%$ \\
\hline Year dummy 2006 & $0.194(0.104)$ & $6.3 \%$ & $0.272 *(0.132)$ & $3.9 \%$ & $-0.136(0.173)$ & $43.1 \%$ \\
\hline
\end{tabular}

**Significant at $1 \%$ level *significant at $5 \%$ level

Note: This table presents results for the weighted linear regressions of Ln (charity+10), defined in the text, on a group of covariates. The weights for the regression come from the X42001 variable from the datasets. The sample composes households with a married-filing-jointly status who are "exogenous itemizers" (defined in the text) drawn by the Surveys of Consumer Finances between 1989(included) and 2007(included). For more details in sample selection, please refer to the notes under Table 3 .

If we restrict our sample to the years 1995-2007, during which we can observe itemization status in the data and measure non-charity itemization status with more accuracy, the estimates are larger, even though the variation in tax price during this period is smaller. Specifically, as listed in the second row of estimates in Table 5, for all 
exogenous itemizers the elasticity estimate is -1.579 (p-value of $0.3 \%$ ), for the non-selfemployed it is $-1.204(14.6 \%)$, and for the self-employed exogenous itemizers it is -2.469 $(0.05 \%)$.

If, in the all-year regression, we replace the AGI-based disposable income with the total-income-based disposable income, then the three price elasticities are smaller but are all significant, at, respectively, $-1.263,-1.120$ and -1.487 (for all exogenous itemizers, the non-self-employed group, and the self-employed group), with corresponding p-values of $0.01 \%, 0.9 \%$, and $0.1 \%$ (Table 5 , the third row of estimates). The price elasticity estimate for the non-self-employed group becomes significant in this case; but a more prominent change is that the price elasticity of the non-self-employed group drops to -1.487 from -2.515. This difference between AGI-based results and total income-based results perhaps reflects the non-self-employed group's ability to shift income to nontaxable sources.

The fourth row of estimates in Table 5 presents the Tobit regression results, where the outcome variable is specified in levels rather than logs. In these results, both the nonself-employed and the self-employed appear more responsive to tax changes, and both price coefficients are significant at the $1 \%$ level. Similar to the linear regression results, the self-employed are much more sensitive to tax prices. The estimated price coefficient for the non-self-employed group is $-18,030$, and the implied elasticity is -3.191 , quite high. This number means that, if the marginal net-of-tax rate rises by 10 percentage points (for example, if the marginal tax rate goes down from $30 \%$ to $20 \%$ ), the expected giving level for a married household that has a P75\% level of each covariate in the year 2000 will drop by $\$ 805$, and the expected giving level conditional on a household gives a positive amount will drop by $\$ 605$. In the examples two paragraphs ago where marginal tax rates dropped by 3 percentage points from 2000 to 2003, the impacts on the expected giving level and the conditional expected giving level would be $-\$ 241.6$ and $-\$ 181.4$. The counterpart of the number $-\$ 241.6$ in the linear regression calculation is $2698-2796=$ 
-\$98. ${ }^{75}$ That said, this Tobit specification may not model charitable giving very well. As

illustrated in Appendix Figure A.3, it tends to over-predict giving by a large amount.

Table 5 Tax-price Elasticity Estimates for Exogenous Itemizers under Different Specifications

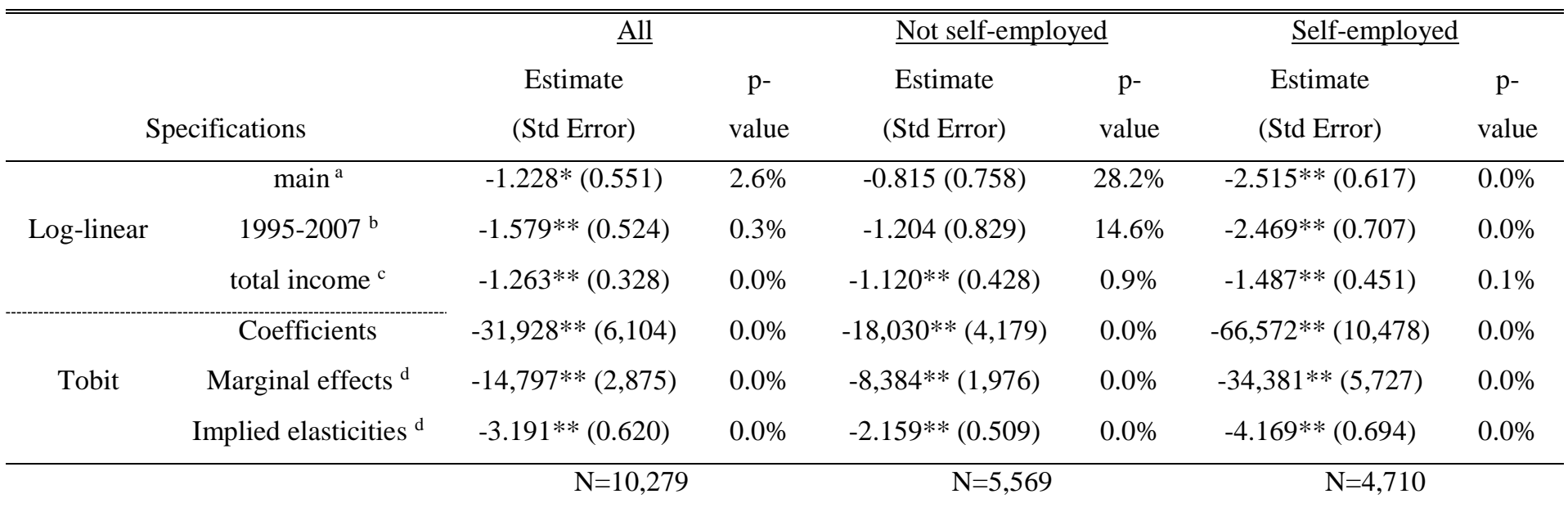

Note: This table presents results of key coefficients for the weighted linear regressions and for the weighted Tobit regressions of charity, defined in the text, on a group of covariates. The weights for the regression come from the X42001 variable from the datasets. The sample composes households with a married-filing-jointly status who are "exogenous itemizers" (defined in the text) drawn by the Surveys of Consumer Finances between 1989(included) and 2007(included), except for the case noted by ${ }^{\mathrm{b}}$. For more details in sample selection, please refer to the notes under Table 3.

**Significant at $1 \%$ level *significant at $5 \%$ level

${ }^{a}$ These are the price elasticity estimates presented in Table 4 for the main specification.

${ }^{\mathrm{b}}$ Sample restricted to surveys between 1995 (included) and 2007 (included). The numbers of observations are, respectively, 7860, 4245, and 3615 for all, the non-self-employed, and the self-employed.

c The AGI-based disposable incomes replaced with the total-income-based disposable incomes. The numbers of observations are, respectively, 10273, 5562, and 4711 for all, the non-self-employed, and the self-employed.

d Evaluated at the covariates' P75\% levels. Standard errors are computed by the Delta method.

\section{V.2 Results for Exogenous Non-itemizers}

In this section we present results when combining exogenous itemizers and exogenous non-itemizers corresponding to the specifications in Section III.4 for households whose tax status is married filing jointly. Table 6 gives the main log-linear regression results; Table 7 is for alternative specifications. This specification adds terms

\footnotetext{
75 The calculations of marginal effects from the Tobit estimates follow McDonald and Moffitt 1980. The relevant formulas are $\partial E y / \partial X_{i}=F(z) \beta_{i}$ and $\partial E y^{*} / \partial X_{i}=\beta_{i}\left[1-z f(z) / F(z)-f(z)^{2} / F(z)^{2}\right]$, where $z$ $=X \beta / \sigma$.
} 
that interact tax price and distance. Since distance is the amount one needs to donate before facing a reduced tax-price, exogenous itemizers' distance is simply zero and set to a negligible 1 in the regressions so $\operatorname{Ln}($ distance) is zero.

Table 6 Linear Regression Results for Married-Filing-Jointly Households

\begin{tabular}{|c|c|c|c|c|c|c|c|}
\hline \multirow[b]{2}{*}{ Regressors } & \multicolumn{2}{|l|}{$\underline{\text { All }}$} & \multicolumn{2}{|c|}{$\underline{\text { Not self-employed }}$} & \multicolumn{2}{|c|}{$\underline{\text { Self-employed }}$} & \multirow{2}{*}{$\begin{array}{c}\frac{\text { Self-employed, }}{\text { distance } \leq \mathbf{6 5 0 0}} \\
\text { Estimate } \\
\text { (Std Error) }\end{array}$} \\
\hline & $\begin{array}{l}\text { Estimate } \\
\text { (Std Error) }\end{array}$ & $\begin{array}{c}\mathrm{p}- \\
\text { value }\end{array}$ & $\begin{array}{l}\text { Estimate } \\
\text { (Std Error) }\end{array}$ & $\begin{array}{c}\mathrm{p}- \\
\text { value }\end{array}$ & $\begin{array}{l}\text { Estimate } \\
\text { (Std Error) }\end{array}$ & $\begin{array}{c}\mathrm{p}- \\
\text { value }\end{array}$ & \\
\hline Intercept & $-0.602(1.347)$ & $65.5 \%$ & $-0.497(1.751)$ & $77.6 \%$ & $-1.240(2.421)$ & $60.8 \%$ & $-3.441(2.134)$ \\
\hline Ln (distance) & $-0.020(0.014)$ & $14.2 \%$ & $-0.039 *(0.016)$ & $1.8 \%$ & $0.047(0.024)$ & $5.0 \%$ & $0.016(0.035)$ \\
\hline $\operatorname{Ln}($ tax price $)$ & $-1.745^{* *}(0.504)$ & $0.1 \%$ & $-1.611 * *(0.618)$ & $0.9 \%$ & $-2.179 * *(0.626)$ & $0.1 \%$ & $-2.027 * *(0.624)$ \\
\hline $\operatorname{Ln}($ distance $) \times \operatorname{Ln}($ tax price $)$ & $0.164 * *(0.062)$ & $0.8 \%$ & $0.095(0.074)$ & $20.0 \%$ & $0.415^{* *}(0.101)$ & $0.0 \%$ & $0.198(0.147)$ \\
\hline Ln (wealth) & $0.379 * *(0.019)$ & $0.0 \%$ & $0.367 * *(0.023)$ & $0.0 \%$ & $0.403 * *(0.041)$ & $0.0 \%$ & $0.506 * *(0.039)$ \\
\hline $\operatorname{Ln}($ disposable income $)$ & $-0.890 * *(0.227)$ & $0.0 \%$ & $-0.848 * *(0.306)$ & $0.6 \%$ & $-0.913 *(0.398)$ & $2.2 \%$ & $-0.676(0.355)$ \\
\hline$[\mathrm{Ln}(\text { disposable income })]^{2}$ & $0.058 * *(0.011)$ & $0.0 \%$ & $0.055 * *(0.015)$ & $0.0 \%$ & $0.059 * *(0.019)$ & $0.2 \%$ & $0.046 * *(0.017)$ \\
\hline Dummy for middle aged & $-0.052(0.073)$ & $47.3 \%$ & $-0.035(0.088)$ & $69.5 \%$ & $-0.118(0.132)$ & $37.1 \%$ & $0.008(0.134)$ \\
\hline Dummy for elder & $0.083(0.137)$ & $54.5 \%$ & $0.217(0.169)$ & $19.9 \%$ & $-0.414 *(0.235)$ & $7.8 \%$ & $-0.217(0.237)$ \\
\hline Age & $0.023 * *(0.003)$ & $0.0 \%$ & $0.021 * *(0.004)$ & $0.0 \%$ & $0.030 * *(0.007)$ & $0.0 \%$ & $0.021 * *(0.007)$ \\
\hline Years of Education & $0.187 * *(0.008)$ & $0.0 \%$ & $0.184 * *(0.010)$ & $0.0 \%$ & $0.209 * *(0.015)$ & $0.0 \%$ & $0.218 * *(0.016)$ \\
\hline Year dummy 91 & $-0.029(0.083)$ & $73.1 \%$ & $0.046(0.100)$ & $64.6 \%$ & $-0.435^{* *}(0.157)$ & $0.6 \%$ & $-0.190(0.188)$ \\
\hline Year dummy 94 & $-0.138(0.079)$ & $8.0 \%$ & $-0.094(0.095)$ & $32.4 \%$ & $-0.374 *(0.153)$ & $1.4 \%$ & $-0.454 *(0.192)$ \\
\hline Year dummy 97 & $-0.007(0.076)$ & $92.4 \%$ & $0.078(0.092)$ & $40.1 \%$ & $-0.461 * *(0.141)$ & $0.1 \%$ & $-0.291(0.167)$ \\
\hline Year dummy 2000 & $0.192 *(0.078)$ & $1.4 \%$ & $0.207 *(0.094)$ & $2.9 \%$ & $0.076(0.142)$ & $59.3 \%$ & $0.114(0.165)$ \\
\hline Year dummy 2003 & $0.098(0.076)$ & $19.9 \%$ & $0.126(0.093)$ & $17.8 \%$ & $-0.045(0.142)$ & $75.2 \%$ & $-0.009(0.168)$ \\
\hline \multirow[t]{2}{*}{ Year dummy 2006} & $0.103(0.077)$ & $17.8 \%$ & $0.215^{*}(0.093)$ & $2.0 \%$ & $-0.447 * *(0.144)$ & $0.2 \%$ & $-0.328(0.169)$ \\
\hline & \multicolumn{2}{|l|}{$\mathrm{N}=15,830$} & $\mathrm{~N}=10,283$ & & \multicolumn{2}{|l|}{$\mathrm{N}=5,547$} & $\mathrm{~N}=5,195$ \\
\hline \multicolumn{8}{|c|}{ **Significant at $1 \%$ level $*$ significant at $5 \%$ level } \\
\hline \multicolumn{8}{|c|}{$\begin{array}{l}\text { Note: This table presents results for the weighted linear regressions of } \operatorname{Ln}(\text { charity }+10) \text {, defined in the text, on a group of covariates. The } \\
\text { weights for the regression come from the X42001 variable from the datasets. The sample composes households with a married-filing-jointly } \\
\text { status, including both "exogenous non-itemizers" (defined in the text) and "exogenous itemizers" (defined in the text). The households were } \\
\text { surveyed by the Surveys of Consumer Finances between 1989(included) and } 2007 \text { (included). For more details in sample selection, please } \\
\text { refer to the notes under Table } 3 \text {. }\end{array}$} \\
\hline
\end{tabular}

In Table 6, the coefficients for the Ln (distance) term, interpreted as the effect of distance on giving while holding tax price at 1 , are small and insignificant for both the 
whole sample and the self-employed, as expected. For the non-self-employed group, it is significant at the $5 \%$ level but very small. This reassures us that, other than affecting the tax price elasticity, distance does not capture any additional omitted factor influencing charitable giving.

The coefficients for Ln (distance) $\times \operatorname{Ln}($ tax price) are positive, suggesting that the tax price elasticity decreases in absolute value as distance increases, as predicted earlier. For the whole sample, the coefficient for the tax price is 1.745 and for the interaction term is 0.164 ; both are statistically significant, and they imply that the price elasticity is $-1.745+0.164 \times \operatorname{Ln}($ distance). So, as distance increases from $\$ 1$ to around $\$ 2,000$, the price elasticity shrinks from -1.745 to -0.498 . Afterwards the estimated elasticity shrinks slowly and zero lies within one standard error, but the point estimate never reaches zero within the meaningful range of distance. The self-employed group has a larger coefficient for the interaction term, in other words a faster reduction in the tax price elasticity with respect to distance, suggesting that they are more aware of and sensitive to distance. A closer examination of the self-employed group shows that its large drop off rate of 0.415 is partly driven by observations with very large distances. The drop-off rate is smaller over the low and medium range of distance. As recorded in the last column of Table 6, the rate is 0.198 under the sample restriction of distance $\leq 6500$, which reduces the influence of outliers, and is smaller than for all the self-employed while still a little larger than for the non-self-employed. ${ }^{76}$

The estimates mean that, if the marginal net-of-tax rate rises by $10 \%$ (for example, if the marginal tax rate drops from $20 \%$ to $12 \%$ ), charitable giving would fall by between $10 \% *|-1.611+0.095 * \operatorname{Ln}(13872)|=7.0 \%$ and $10 \% *|-1.611+0.095 * \operatorname{Ln}(1)|=16.1 \%$ for the non-self-employed, and by between $10 \% *|-2.027+0.198 * \operatorname{Ln}(13233)|=1.5 \%$ and $10 \% * \mid-$ $2.027+0.198^{*} \operatorname{Ln}(1) \mid=20.3 \%$ for the self-employed, depending on the distance ${ }^{77}$ For

\footnotetext{
${ }^{76}$ This result is robust when we replaced 6500 with other sample restrictions below 8500 . In addition to the specifications and results described in this paragraph and Table 6 , we also tried other specifications such as varying coefficient models to allow the tax-price elasticity to depend more flexibly on distance. They suggest that (1) the elasticity-distance curve does exhibit more wiggling when kinks are allowed, but specifications in the main text captures the overall trends well; (2) There is much irregularity like wrong signs of elasticities at small distances, i.e. near the itemizing threshold, perhaps reflecting measurement errors.

${ }^{77}$ Given distance, the percentage drop is $10 \% * \mid-1.611+0.095 * \operatorname{Ln}$ (distance) | for the non-self-employed and $10 \% * \mid-2.027+0.198 * \operatorname{Ln}($ distance $) \mid$ for the self-employed. 13,872 is the maximum distance among the nonself-employed and 13,233 is the maximum distance among the self-employed.
} 
example, at a distance of $\$ 2,000$, the changes are, respectively, $8.9 \%$ and $5.2 \%$. Notice the latter, smaller reaction by the self-employed, whose sensitivity to the tax price has been reduced more by their distance to itemizing. Moreover, the self-employed nonitemizers have a smaller reaction at a distance of $\$ 2,000$ than self-employed itemizers for the same change in the tax rate, perhaps reflecting their tax awareness; in contrast, the non-self-employed who are exogenous non-itemizers have a greater reaction than do exogenous itemizers. For a non-self-employed (self-employed) exogenously nonitemizing married-filing-jointly household with a P90\% income \$85,835 (\$97,107), a P90\% donation $\$ 3,785(\$ 4,878)$, and a distance of $\$ 2,000$, the drop of their marginal tax rate from $28 \%$ to $25 \%$ from 2000 to 2003 should decrease donations by about $3.709 \%$ $(2.167 \%)$ to $\$ 3,644.6(\$ 4,772.3)$.

The estimates also measure the effect of changes in distance on giving. If distance rises by $10 \%$, for example because of an increase in the standard deduction, charitable giving would fall by between 0 and $0.48 \%$ for the non-self-employed, and by between 0 and $1.00 \%$ for the self-employed, depending on the marginal tax rate. ${ }^{78}$ Under a marginal tax rate of $25 \%$, the changes are, respectively, $0.27 \%$ and $0.57 \%$. This means that, for a non-self-employed (self-employed), married household with a P90\% donation $\$ 3,785$ $(\$ 4,878)$ and a marginal tax rate of $28 \%$, the tax reform in 2003 that increases the standard deduction to $\$ 9,500$ from the 2002 level of 7850 (an $18.3 \%$ increase after accounting for inflation) should decrease the donation by about $0.494 \%(1.043 \%)$ to $\$ 3,766(\$ 4,827) .^{79}$

\footnotetext{
${ }^{78}$ Since these effects are small, to filter out the impact of the noise of the coefficient estimate for $\operatorname{Ln}($ distance), when calculating these percentages we have treated the estimated coefficient of $\operatorname{Ln}($ distance $)$ as zero. More specifically, using notations in the model equation $\operatorname{Ln}\left(\right.$ charity) $=\beta_{0}+\beta_{1} \times \operatorname{Ln}($ tax price $)+\beta_{9} \times$ $\operatorname{Ln}($ distance $)+\beta_{10} \times \operatorname{Ln}($ distance $) \times \operatorname{Ln}($ tax price $)+$ other terms, the "distance elasticity" is $\partial \operatorname{Ln}($ charity) / $\partial \operatorname{Ln}($ distance $)=\beta_{9}+\beta_{10} \times \operatorname{Ln}$ (tax price $) . \beta_{9}$ is in theory 0 and also estimated to be small and mostly insignificant, but its estimates are large and noisy enough to obscure the estimates of the truly relevant term $\beta_{10} \times \operatorname{Ln}$ (tax price) as well as the contrast between the non-self-employed and the self-employed. Therefore we suppress the $\beta_{9}$ 's estimates in computing the percentages. If not, the percentages would be between $0.39 \%$ and $0.87 \%$ for the non-self-employed, and between $-0.16 \%$ and $0.84 \%$ for the selfemployed.

${ }^{79}$ As noted in the result tables, regressions presented in the main texts are weighted by the survey weights. Un-weighted regressions produce results that are similar but have differences worth noticing. The price elasticity estimates for all, non-self-employed and self-employed exogenous itemizers are, respectively, $1.180(0.362,0.1 \%),-1.190(0.553,3.1 \%)$ and $\quad-1.380(0.398,0.1 \%)$, with standard errors and p-values in the parentheses. Note that the elasticity estimate for the non-self-employed becomes significant and the estimated elasticity of the self-employed is smaller. The un-weighted regression for the whole sample incorporating exogenous non-itemizers produce coefficient estimates of $-0.004(0.013,74.6 \%)$ for the
} 
Table 7 reports additional specifications. If we restrict our sample to the years 1995-2007, when we observe itemization status for the sample, the effect of distance interacted with tax price becomes a little smaller, so the effect of the tax price fades a little more slowly. The tax price elasticities with zero distance also are a bit smaller than in the main specification.

If, in the all-year regression, we replace the AGI-based disposable income with the total-income-based disposable income, the results remain very similar. As seen in Table 7 , the biggest change is that the drop-off rate for the non-self-employed group falls to 0.031 from 0.095 . However, both are in a range below 0.1 and smaller than the drop-off rates for the self-employed, so the basic implications still hold.

The Tobit regression results are also shown in Table 7. The coefficients for tax price have the correct negative signs and are significant. For the self-employed group, the marginal effect of tax price on giving diminishes as distance increases, showing a similar picture with before. However, as we found earlier, other results differ substantially from those of the log-linear regressions. First, the coefficients for distance are significantly different from zero, indicating that the households respond to distance changes even when tax price is 1 . Second, for the non-self-employed group, the coefficients for the interaction terms suggest that the sensitivity to tax price enlarges as distance increases. It seems that some of the effect of distance on sensitivity to tax price was captured as the effect of distance itself on giving. Since the common practice in this literature is to use log-linear regressions as opposed to Tobit regressions, and since the Tobit model does not seem to fit the SCF data well (Appendix Figure A.3), the log-linear regression results appear to be more reliable.

regressor $\operatorname{Ln}($ distance $),-1.736(0.323,0.0 \%)$ for $\operatorname{Ln}($ tax price $)$, and $0.242(0.055,0.0 \%)$ for $\operatorname{Ln}($ distance $) \times$ $\mathrm{Ln}($ tax price). These are very close to the estimates in the main text, except that the coefficient estimate for $\mathrm{Ln}$ (distance) is even smaller and more insignificant, indicating more strongly that distance does not capture any additional omitted factor influencing charitable giving other than affecting the tax price elasticity (through the interaction term in the regression). 
Table 7 Key Estimates for Married-Filing-Jointly Households

\begin{tabular}{|c|c|c|c|c|c|}
\hline & \multicolumn{2}{|c|}{ Regressors } & $\frac{\text { All }}{\text { Estimate }}$ & $\frac{\text { Not self-employed }}{\text { Estimate }}$ & $\frac{\text { Self-employed }}{\text { Estimate }}$ \\
\hline \multirow{9}{*}{$\begin{array}{l}\text { Log- } \\
\text { linear }\end{array}$} & \multirow{3}{*}{ main $^{a}$} & Ln (distance) & $-0.020(0.014)$ & $-0.039 *(0.016)$ & $0.047(0.024)$ \\
\hline & & $\operatorname{Ln}($ tax price $)$ & $-1.745^{* *}(0.504)$ & $-1.611 * *(0.618)$ & $-2.179 * *(0.626)$ \\
\hline & & $\operatorname{Ln}($ distance $) \times \operatorname{Ln}($ tax price $)$ & $0.164 * *(0.062)$ & $0.095(0.074)$ & $0.415 * *(0.101)$ \\
\hline & \multirow{3}{*}{$1995-2007^{b}$} & $\operatorname{Ln}($ distance $)$ & $-0.028 *(0.014)$ & $-0.047 *(0.018)$ & $0.051 *(0.026)$ \\
\hline & & Ln (tax price) & $-1.639 *(0.513)$ & $-1.405 *(0.682)$ & $-1.747 *(0.733)$ \\
\hline & & $\operatorname{Ln}($ distance $) \times \operatorname{Ln}($ tax price $)$ & $0.142 *(0.062)$ & $0.078(0.083)$ & $0.375 * *(0.120)$ \\
\hline & \multirow{3}{*}{ total income ${ }^{c}$} & Ln (distance) & $-0.017(0.013)$ & $-0.035 *(0.015)$ & $0.063 *(0.027)$ \\
\hline & & $\operatorname{Ln}($ tax price $)$ & $-1.644 * *(0.343)$ & $-1.417 * *(0.441)$ & $-2.083 * *(0.511)$ \\
\hline & & $\operatorname{Ln}($ distance $) \times \operatorname{Ln}($ tax price $)$ & $0.106(0.055)$ & $0.031(0.065)$ & $0.439 * *(0.115)$ \\
\hline \multirow{9}{*}{ Tobit $^{\mathrm{g}}$} & \multirow{3}{*}{ Coefficients } & distance & $-2.510 * *(0.138)$ & $-1.737 * *(0.132)$ & $-1.563 * *(0.470)$ \\
\hline & & tax price -1 & $-19,076^{* *}(5,342)$ & $-11,660 * *(3,797)$ & $-52,488 * *(11,389)$ \\
\hline & & distance $\times($ tax price -1$)$ & $-3.332 * *(0.843)$ & $-2.594 * *(0.745)$ & $5.352(3.185)$ \\
\hline & \multirow{3}{*}{$\begin{array}{l}\text { Marginal } \\
\text { Effects }\end{array}$} & distance $^{\mathrm{d}}$ & $-0.786^{* *}(0.044)$ & $-0.552 * *(0.041)$ & $-0.578 * *(0.166)$ \\
\hline & & tax price $-1^{\mathrm{e}}$ & $-8,350 * *(2,314)$ & $-5,319 * *(1,728)$ & $-21,103 * *(4,395)$ \\
\hline & & distance $\times(\text { tax price }-1)^{\mathrm{f}}$ & $-0.653 *(0.267)$ & $-0.539 *(0.237)$ & $1.991 *(0.992)$ \\
\hline & \multirow{3}{*}{$\begin{array}{c}\text { Implied } \\
\text { elasticities }\end{array}$} & distance $^{\mathrm{d}}$ & $-3.598 * *(0.188)$ & $-2.659 * *(0.182)$ & $-2.060 * *(0.564)$ \\
\hline & & tax price ${ }^{\mathrm{e}}$ & $-5.447 * *(1.509)$ & $-3.708 * *(1.204)$ & $-9.833 * *(2.048)$ \\
\hline & & distance $\times$ tax price ${ }^{\mathrm{f}}$ & $-2.059 *(0.965)$ & $-1.785 *(0.892)$ & $5.610 *(2.746)$ \\
\hline & & & $\mathrm{N}=15,830$ & $\mathrm{~N}=10,283$ & $\mathrm{~N}=5,547$ \\
\hline
\end{tabular}

**Significant at $1 \%$ level *significant at $5 \%$ level

Note: This table presents results of key coefficients for the weighted log-linear regressions and for the weighted Tobit regressions of charity, defined in the text, on a group of covariates. The weights for the regression come from the X42001 variable from the datasets. The sample composes households with a married-filing-jointly status, including both "exogenous non-itemizers" (defined in the text) and "exogenous itemizers" (defined in the text). The households were surveyed by the Surveys of Consumer Finances between 1989(included) and 2007(included), except for the case noted by ${ }^{b}$. For more details in sample selection, please refer to the notes under Table 3.

a These are reproduced from Table 5 .

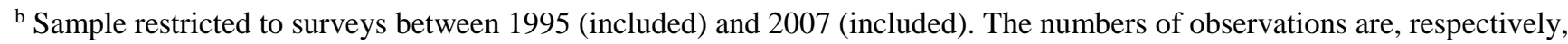
11825,7610 , and 4215 for all, the non-self-employed, and the self-employed.

${ }^{c}$ The AGI-based disposable income replaced with the total-income-based disposable income. The numbers of observations are, respectively, 15798, 10258, and 5540 for all, the non-self-employed, and the self-employed. 
${ }^{\mathrm{d}}$ Evaluated at price $=1$, the distance values of $0,500,1000, \ldots, 13500$, the P75\% levels of other covariates with the year set at 2000 , then averaged over distance.

${ }^{\mathrm{e}}$ Evaluated at distance $=0$ and P75\% levels of other covariates, with the year set at 2000.

${ }_{\mathrm{f}}^{\mathrm{f}}$ The marginal effect of the interaction term is defined as $\partial \frac{\partial E y}{\partial(\text { price-1) }} /$ distance, with the meaning of the effect of distance on the marginal effect of the tax price. The corresponding elasticity is $\partial \frac{\partial \operatorname{Ln}(E y)}{\partial \operatorname{Ln}(\text { price-1) }} / \partial \operatorname{Ln}$ (distance), or the effect of Ln(distance) on the price elasticity. They are first evaluated at distance equal to $0,500,1000, \ldots, 13500$ and the P75\% levels of other covariates, with the year set at 2000 , then averaged over distance.

${ }^{\mathrm{g}}$ For the marginal effects and the implied elasticities, the Delta method is used to calculate the standard errors.

\section{Policy Implications}

We already reported the impact of a tax reform that increases the tax price of giving by $10 \%$ or that raises distance by $10 \%$ due to an increase in the standard deduction. For exogenous itemizers, a $10 \%$ increase in the marginal net-of-tax rate would reduce charitable giving by $12.3 \% .{ }^{80}$ Calculations like these are routinely undertaken in the previous literature that estimates the charitable giving elasticity exclusively for this group.

Here, we discuss the implication of omitting consideration of exogenous nonitemizers when predicting the effect of tax reforms on charitable giving. In the example of an increase in the tax price by $10 \%$, we pointed out above that this would increase giving by exogenous non-itemizers by up to $0.48 \%$. As a consequence, the reduction would be underestimated.

Similarly, we can flesh out the policy implication of raising the standard deduction. If it increases by $10 \%$, then if we just focused on exogenous non-itemizers, we would predict a $\$ 0.99$ billion decline in charitable giving because some of them would no longer itemize their deductions. In fact, charitable giving would actually decline by $\$ 1.93$ billion - almost twice as much - when we consider how the increase in distance affects exogenous non-itemizers as well.

${ }^{80}$ All of these calculations are based on our most recent SCF sample, from tax year 2006. 


\section{Conclusions}

This paper estimates the price elasticity of charitable giving using a dataset that was previously unexploited for this purpose. This data set, the Survey of Consumer Finances, reports donation amounts for both tax itemizers and non-itemizers; information on giving by the latter is not observable in the administrative data that has been used in many studies on this topic. The SCF also has detailed information on demographics such as income, wealth, age, and education that could affect charitable giving, and we find that having a full measure of income affects the estimates, in comparison to studies that use more limited measures from administrative data sets. The specification that is the most comparable to the existing literature, i.e. the linear regression for "exogenous itemizers", yields an estimated tax-price elasticity of -1.228 , which is similar to the estimates from key earlier papers, particularly those that use administrative tax data. Breaking down the sample of exogenous itemizers into the non-self-employed and the self-employed groups suggests that the responsiveness to the tax price is greater among the self-employed, in line with Saez (2010), but is still substantial for others.

A key contribution of this paper is to show that "exogenous non-itemizers", a group of taxpayers that have not gotten attention in the previous literature, also respond to tax incentives. We characterize their incentives in terms of both the tax price and their "distance" to itemization if they give enough to charity. Households that are close to the itemizing threshold may give more than they would otherwise, as they respond to the lower tax-price for giving above a certain amount. Our results show that exogenous nonitemizers are, in fact, responsive to tax incentives despite the fact that their first dollar of contribution has the marginal price of 1 . In analyzing their responses to tax changes, their distance to itemizing at zero giving is an important parameter, as their tax-price sensitivity declines with this distance. The tax price elasticity is near -1.745 for those with very small values of distance, and its absolute value decreases by about 0.11 when distance doubles for the entire sample, or about 0.14 for the self-employed and 0.07 for the non-self-employed.

The consequence of omitting consideration of exogenous non-itemizers is that changes in charitable giving due to tax reforms may be substantially underestimated. 
Decreases in marginal tax rates or increases in the standard deduction will cause giving to decline by more.

In sum, these results show that tax reforms can alter charitable giving, and not just for tax itemizers. Recent increases in marginal tax rates are thus expected to induce more charitable donations. They may also induce more people to itemize. Both will decrease taxable income. That the sensitivity to tax price declines with the distance indicates that it is important to consider the decision to itemize together with the decision to donate.

\section{References}

Alabama Department of Revenue (n.d.), Calculating Your Property Taxes, Accessed Dec 31, 2012 at http://revenue.alabama.gov/advalorem/other/caltax.cfm

Alabama Department of Revenue (Oct 2012), Millage Rates, Retrieved Dec 31, 2012, from http://revenue.alabama.gov/advalorem/MILLS12.pdf

Alaska Department of Commerce (Jan 2009), Alaska Taxable 2008, Municipal Taxation

- Rates and Policies, Full Value Determination, Population and G.O. Bonded Debt, Retrieved from http://www.commerce.state.ak.us/dca/osa/pub/08Taxable.pdf

Arizona Department of Revenue (Revised May 2009), Arizona Personal Property Tax, Retrieved from http://www.azdor.gov/portals/0/brochure/545.pdf

Auten, Gerald, James Cilke, and William Randolph (1992). "The Effects of Tax Reform on Charitable Contributions." National Tax Journal, 45 (3), 267-290.

Auten, Gerald and David Joulfaian (1996), "Charitable Contributions and Intergenerational Transfers", Journal of Public Economics, 59 (1), 55 - 68

Auten, Gerald E., Holger Sieg and Charles T. Clotfelter (2002), "Charitable Giving, Income, and Taxes, An Analysis of Panel Data", The American Economic Review, 92 (1), $371-382$

Bakija, Jon and Bradley T. Heim (2011), "How Does Charitable Giving Respond to Incentives and Income? New Estimates from Panel Data", National Tax Journal, 64 (2, Part 2), $615-650$

Barrett, Kevin (1991), "Panel-data Estimates of Charitable Giving: A Synthesis of Techniques", National Tax Journal, 44 (3), 365 - 381

Barrett, Kevin Stanton, Anya M. McGuirk and Richard Steinberg (1997), "Further Evidence on the Dynamic Impact of Taxes on Charitable Giving", National Tax Journal, 50 (2), 321 - 334

Boskin, Michael J. and Martin Feldstein (1977), "Effects of the Charitable Deduction on Contributions by Low Income and Middle Income Households: Evidence from the National Survey of Philanthropy", The Review of Economics and Statistics, 59 (3), $351-354$ 
Bradley, Ralph, Steven Holden and Robert McClelland (1999), “A Robust Estimation of the Effects of Taxation on Charitable Contibutions", Working Paper, http://fmwww.bc.edu/RePEc/es2000/1144.pdf

Brown, Eleanor (1997), “Taxes and Charitable Giving: Is There a New Conventional Wisdom?” 1996 Proceedings of the Eighty-ninth Annual Conference on Taxation, 153 $-159$

Brown, Eleanor and Hamilton Lankford (1992), "Gifts of Money and Gifts of Time: Estimating the Effects of Tax Prices and Available Time", Journal of Public Economics, 47 (3), 321 - 341

Bureau of Economic Analysis, U.S. Economic Accounts, Gross Domestic Product, Current-dollar and "real" GDP, http://www.bea.gov/national/xls/gdplev.xls

California State Board of Equalization (Nov 2012), California Property Tax An Overview, retrieved from http://www.boe.ca.gov/proptaxes/pdf/pub29.pdf

Chetty, Raj, John N. Friedman, and Emmanuel Saez (2013), "Using Differences in Knowledge across Neighborhoods to Uncover the Impacts of the EITC on Earnings." American Economic Review, 103(7), 2683-2721

Clotfelter, Charles T. (1985), Federal Tax Policy and Charitable Giving, NBER Books, National Bureau of Economic Research, Inc, number clot85-1, September, retrieved from http://papers.nber.org/books/clot85-1

Colorado Department of Local Affairs (n.d.), Personal Property Tables, http://www.colorado.gov/cs/Satellite?c=Page\&childpagename=DOLAMain\%2FCBONLayout\&cid=1251590389358\&pagename=CBONWrapper

Davis, Carl, Kelly Davis, Matthew Gardner, Robert S. McIntyre, Jeff McLynch, and Alla Sapozhnikova Institute on Taxation and Economic Policy (2009), Who Pays? A Distributional Analysis of the Tax Systems in All 50 States (3rd Edition). Retrieved from website: http://www.itep.org/whopays3.pdf

Duquette, Christopher M. (1999), "Is Charitable Giving by Nonitemizers Responsive to Tax Incentives? New Evidence", National Tax Journal, 52(2), 195 - 206

Eckel, Catherine C. and Philip J. Grossman (2003), "Rebate Versus Matching: Does How We Subsidize Charitable Contributions Matter?" Journal of Public Economics, 87 (34), $681-701$

Federal Reserve Board (2012), 1989 Survery of Consumer Finances, retrieved from http://www.federalreserve.gov/econresdata/scf/scf_1989documentation.htm (codebook) and http://www.federalreserve.gov/econresdata/scf/scf_1989survey.htm (survey data)

Federal Reserve Board (2012), 1992 Survery of Consumer Finances, retrieved from http://www.federalreserve.gov/econresdata/scf/scf_1992documentation.htm (codebook) and http://www.federalreserve.gov/econresdata/scf/scf_1992survey.htm (survey data)

Federal Reserve Board (2012), 1995 Survery of Consumer Finances, retrieved from http://www.federalreserve.gov/econresdata/scf/scf_1995documentation.htm (codebook) and http://www.federalreserve.gov/econresdata/scf/scf_1995survey.htm (survey data)

Federal Reserve Board (2012), 1998 Survery of Consumer Finances, retrieved from http://www.federalreserve.gov/econresdata/scf/scf_1998documentation.htm 
(codebook) and http://www.federalreserve.gov/econresdata/scf/scf_1998survey.htm (survey data)

Federal Reserve Board (2012), 2001 Survery of Consumer Finances, retrieved from http://www.federalreserve.gov/econresdata/scf/scf_2001documentation.htm (codebook) and http://www.federalreserve.gov/econresdata/scf/scf_2001survey.htm (survey data)

Federal Reserve Board (2012), 2004 Survery of Consumer Finances, retrieved from http://www.federalreserve.gov/econresdata/scf/scf_2004documentation.htm (codebook) and http://www.federalreserve.gov/econresdata/scf/scf_2004survey.htm (survey data)

Federal Reserve Board (2012), 2007 Survery of Consumer Finances, retrieved from http://www.federalreserve.gov/econresdata/scf/scf_2007documentation.htm (codebook) and http://www.federalreserve.gov/econresdata/scf/scf_2007survey.htm (survey data)

Feenberg, Daniel (1982), "Identification in Tax-Price Regression Models: The Case of Charitable Giving", NBER Working Paper No. 988

Feldstein, Martin and Charles Clotfelter (1976), "Tax Incentives and Charitable Contributions in the United States: A Microeconometric Analysis", Journal of Public Economics, 5(1-2), 1 - 26

Fisher, Robert (2000), "The Future of Social Desirability Bias Research in Marketing”, Psychology \& Marketing, 17 (2), 73 - 77

Giving USA Foundation and The Center on Philanthropy at Indiana University, The Annual Report on Philanthropy for the Year 2011, Executive Summary, http://store.givingusareports.org/2012-Giving-USA-The-Annual-Report-onPhilanthropy-for-the-Year-2011-Executive-Summary-P43.aspx

Greene, William H. (2012). Econometric Analysis (Seventh ed., pp. 280-281), Pearson Education Limited.

Internal Revenue Service, Statistics of Income - 2010, Individual Income Tax Returns, (Page 89), Washington, DC

He, Tianying (2015), "Substitutability among Tax Deductions: Implications for Optimal Tax Policy", Working Paper

Kansas Policy Institute \& SSB Consulting Group, LLC (n.d.), 1997-2011 Change in Tax, Average Mill Rate and Population by County, retrieved from http://www.kansasopengov.org/PropertyTax/9709ChangeinTaxRateandPopulation/tabid/1560/Default.as px

Karlan, Dean and John List (2007), "Does Price Matter in Charitable Giving? Evidence from a Large-Scale Natural Field Experiment", The American Economic Review, 97 (5), $1774-1793$

Kingma, Bruce Robert (1989), "An Accurate Measurement of the Crowd-out Effect, Income Effect, and Price Effect for Charitable Contributions", Journal of Political Economy, 97 (5), 1197 - 1207

MaCurdy, Thomas, David Green, and Harry Paarsch, (1990), “Assessing Empirical Approaches for Analyzing Taxes and Labor Supply, Journal of Human Resources 25, $415-490$

McDonald, John F. and Robert A. Moffitt (1980), "The Uses of Tobit Analysis", The Review of Economics and Statistics, 62 (2), 318-321

Miller, Wayne P., Vuko Karov, University of Arkansas System (Nov 2012), Arkansas Property Tax: 
Revenue, Assessments \& Rates, Arkansas County, Retrieved from

$\mathrm{http} / / /$ www.arcommunities.org/taxes/property/Arkansas.pdf

Nebraska Dept. of Property Assessment \& Taxation (June 2010), Personal Property Taxation

Summary, retrieved from

http://www.revenue.ne.gov/PAD/infoguide/personal_property_taxation_summary.pdf

North Carolina Department of Revenue (Jan 2008), 2007 Personal Property Appraisal and

Assessment Manual, retrieved from

http://www.dor.state.nc.us/publications/appraisal_assessment.html

North Carolina Department of Revenue (Sep 2012), County and Municipal Effective Tax Rates, retrieved from http://www.dor.state.nc.us/publications/effective_rates.html

North Carolina Department of Revenue (June 2012), County Taxable Real Property, Personal

Property, and Public Service Company Valuations, retrieved from

http://www.dor.state.nc.us/publications/valuations.html

North Carolina Department of Revenue (June 2012), Municipal Taxable Real Property, Personal

Property, and Public Service Company Valuations, retrieved from

http://www.dor.state.nc.us/publications/municipal_valuations.html

North Carolina Department of Revenue (Aug 2012), Property Tax Rates, retrieved from http://www.dor.state.nc.us/taxes/property/rates.html

Peloza, John and Piers Steel (2005), "The Price Elasticities of Charitable Contributions: A MetaAnalysis", Journal of Public Policy \& Marketing, 24, 260 - 272

Randolph, William C. (1995), "Dynamic Income, Progressive Taxes, and the Timing of Charitable Contributions", Journal of Political Economy, 103 (4), 709 - 738

Reece, William S. (1979), "Charitable Contributions: New Evidence on Household Behavior", The American Economic Review, 69(1), 142 - 151

Reece, William S. and Kimberly D. Zieschang (1985), "Consistent Estimation of the Impact of Tax Deductibility on the Level of Charitable Contributions", Econometrica, 53 (2), 271 - 293

Rossi Law Offices, LTD (n.d.), Rhode Island Tangible Property FAQ's, http://www.payrossilaw.com/FAQ/RITangiblePropertyFAQ.htm

Rubin, Donald B (1987), Multiple Imputation for Nonresponse in Surveys. New York: Wiley \& Sons

Saez, Emmanuel (2010), "Do Taxpayers Bunch at Kink Points?", American Economic Journal:

Economic Policy 2, August 2010, $180-212$

Schiff, Jerald (1985), "Does Government Spending Crowd Out Charitable Contributions?" National Tax Journal, 38(4), 535 - 546

Slemrod, Joel and Shlomo Yitzhaki (2002), "Tax Avoidance, Evasion, and Administration”, in Handbook of Public Economics, Volume 3, 1425 - 1470

South Carolina Association of Counties (Jan 2008), South Carolina Property Tax Rates By County 2007, retrieved from http://sccommerce.com/sites/default/files/document_directory/Property_Tax_Rates_by_County_in_ South_Carolina_2007.pdf

South Carolina Association of Counties (Jan 2008), South Carolina Property Tax Rates By County 2011, retrieved from http://sccommerce.com/sites/default/files/document_directory/property_tax_rates_by_county_in_so uth_carolina_2011.pdf

St. Louis Regional Chamber (n.d.), Illinois Property Taxes, http://www.stlrcga.org/x489.xml

St. Louis Regional Chamber (n.d.), Missouri Property Taxes, http://www.stlrcga.org/x494.xml

State of Connecticut Office of Policy and Management, Mill Rates, http://www.ct.gov/opm/cwp/view.asp?a=2987\&q=385976

State of Georgia Department of Revenue (n.d.), Millage Rate Manuals, retrieved from http://motor.etax.dor.ga.gov/forms/motor.aspx

State of Mississippi Department of Revenue (n.d.), Ad Valorem Tax, http://www.dor.ms.gov/taxareas/property/advalor.html

State of Mississippi Department of Revenue (n.d.), Property Tax, Millage Rates, retrieved from http://www.dor.ms.gov/taxareas/property/main.html 
Tiehen, Laura (2001), “Tax Policy and Charitable Contributions of Money”, National Tax Journal, 54 (4), $707-723$

U.S. Census Bureau (1994). 1992 Census of Governments, Volume 2 Taxable Property Values, Number 1 Assessed Valuations for Local General Property Taxation, Retrieved January 2, 2013, from http://www.census.gov/prod/2/gov/gc/gc92_2_1.pdf.

Virginia Department of Taxation (n.d.), Local Tax Rates, retrieved from http://www.tax.virginia.gov/site.cfm?alias=LocalTaxRates

Appendix Table A.1 Summary of the Studies in the Meta-Analysis (This table is reproduced from Table 1 in Peloza and Piers Steel (2005).)

\begin{tabular}{|c|c|c|c|c|c|}
\hline Study & Elasticity(Range) & $\begin{array}{c}\text { Permanent / } \\
\text { Temporary } \\
\text { Tax } \\
\text { Measure }\end{array}$ & $\begin{array}{l}\text { Panel/Cross- } \\
\text { Sectional Data }\end{array}$ & $\begin{array}{l}\text { Tax- } \\
\text { Filer/Survey } \\
\text { Data }\end{array}$ & $\begin{array}{l}\text { Donation } \\
\text { Type }\end{array}$ \\
\hline Abrams and Schitz (1978) & -1.1 & Temporary & Cross-section & Tax filer & Donation \\
\hline Abrams and Schitz (1984) & -1.44 & Temporary & Cross-section & Tax filer & Donation \\
\hline $\begin{array}{l}\text { Apinunmahakul and Devlin } \\
(2004)^{\mathrm{a}}\end{array}$ & -1 & Temporary & Cross-section & Survey & Donation \\
\hline Auten and Rudney (1984) & -0.78 & Temporary & Panel & Tax filer & Donation \\
\hline Auten and Rudney (1990) & -.14 to -1.4 & Permanent & Panel & Tax filer & Donation \\
\hline $\begin{array}{l}\text { Auten, Cilke, and Randolph } \\
\text { (1992) }\end{array}$ & -1.11 & Temporary & Panel & Survey & Donation \\
\hline Auten and Joulfaian (1996) & -1.1 to -2.50 & Temporary & Cross-section & Tax filer & $\begin{array}{c}\text { Donation/ } \\
\text { bequest }\end{array}$ \\
\hline $\begin{array}{l}\text { Auten, Clotfelter, and } \\
\text { Schmalbeck (2002) }\end{array}$ & -.52 to -.95 & Permanent & Panel & Survey & Donation \\
\hline $\begin{array}{l}\text { Auten, Sieg, and Clotfelter } \\
(2002)\end{array}$ & -.4 to -1.26 & Temporary & Panel & Tax filer & Donation \\
\hline Bakija (2002) & -.2 to -2.52 & $\begin{array}{l}\text { Permanent/te } \\
\text { mporary }\end{array}$ & Panel & Tax filer & Donation \\
\hline $\begin{array}{l}\text { Bakija, Gale, and Slemrod } \\
(2003)\end{array}$ & -0.162 & Temporary & Cross-section & Tax filer & Bequest \\
\hline Barrett (1991) & -1.09 & Temporary & Panel & Tax filer & Donation \\
\hline $\begin{array}{l}\text { Barrett, McGuirk, and } \\
\text { Steinberg (1997) }\end{array}$ & -0.47 & Temporary & Panel & Tax filer & Donation \\
\hline Barthold and Plotnick (1984) & -0.75 & Temporary & Panel & Tax filer & Bequest \\
\hline Boskin (1976) & -1.2 & Temporary & Cross-section & Tax filer & Bequest \\
\hline Boskin and Feldstein (1977) & -2.14 to -2.44 & Temporary & Cross-section & Survey & Donation \\
\hline $\begin{array}{l}\text { Bradley, Holden, and } \\
\text { McClelland (2000) }\end{array}$ & -.78 to -2.56 & Temporary & Panel & \multicolumn{2}{|c|}{ Survey Donation } \\
\hline Broman (1989) & -0.39 & Temporary & Panel & Tax filer & Donation \\
\hline Brooks $(2002)^{\mathrm{a}}$ & -6.68 & Temporary & Cross-section & Survey & Donation \\
\hline Brown (1987) & -2.57 to -3.62 & Temporary & Cross-section & Survey & Donation \\
\hline Brown and Lankford (1992) & -1.62 to -1.79 & Temporary & Cross-section & Survey & Donation \\
\hline Choe and Jeong (1993) & -2.45 & Temporary & Panel & Survey & Donation \\
\hline $\begin{array}{l}\text { Christian and Boatsman } \\
\text { (1990) }\end{array}$ & -2 & Temporary & Cross-section & Tax filer & Donation \\
\hline $\begin{array}{l}\text { Christian, Boatsman, and } \\
\text { Reneau (1990) }\end{array}$ & -.99 to -1.56 & Temporary & Panel & Tax filer & Donation \\
\hline
\end{tabular}




\begin{tabular}{|c|c|c|c|c|c|}
\hline Chua and Wong (1999) ${ }^{\mathrm{a}}$ & -.98 to -6.15 & Temporary & Cross-section & Tax filer & Donation \\
\hline Clotfelter (1980) & -.24 to -1.55 & $\begin{array}{c}\text { Temporary/p } \\
\text { ermanent }\end{array}$ & Panel & Tax filer & Donation \\
\hline Clotfelter (1983) & +.06 to -1.60 & Temporary & Cross-section & Tax filer & Donation \\
\hline Clotfelter (1985) & -.35 to -2.66 & Temporary & Panel & Tax filer & $\begin{array}{c}\text { Donation/ } \\
\text { bequest }\end{array}$ \\
\hline Clotfelter and Steuerle (1981) & -1.27 & Temporary & Panel & Tax filer & Donation \\
\hline Dunbar and Phillips (1997) & -3.36 & Temporary & Panel & Tax filer & Donation \\
\hline Duquette (1999) & -.64 to -1.24 & Temporary & Panel & Survey & Donation \\
\hline Dye (1978) & -2.25 & Temporary & Cross-section & Survey & Donation \\
\hline Dye (1980) & -0.6 & Temporary & Cross-section & Survey & Donation \\
\hline Feenberg (1987) & -1.63 & Temporary & Panel & Survey & Donation \\
\hline Feigenbaum (1980) & -0.44 & Temporary & Panel & Tax filer & Donation \\
\hline Feldstein (1975a) & -.29 to -1.8 & Temporary & Panel & Tax filer & Donation \\
\hline Feldstein (1975b) & -1.24 & Temporary & Panel & Survey & Donation \\
\hline Feldstein and Clotfelter (1976) & -1.15 & Temporary & Cross-section & Survey & Donation \\
\hline Feldstein and Taylor (1976) & -1.09 to- 1.28 & Temporary & Panel & Survey & Donation \\
\hline Fisher (1977) & -2.3 & Temporary & Cross-section & Tax filer & Donation \\
\hline $\begin{array}{l}\text { Glenday, Gupta, and Pawlak } \\
(1986)^{\mathrm{a}}\end{array}$ & -0.15 & Temporary & Panel & Survey & Donation \\
\hline $\begin{array}{l}\text { Greene and McClelland } \\
\text { (2001) }\end{array}$ & -0.54 & Permanent & Cross-section & Survey & Bequest \\
\hline Greenwood (1993) & -0.43 & Temporary & Cross-section & Tax filer & Donation \\
\hline $\begin{array}{l}\text { Hood, Martin, and Osberg } \\
(1977)^{\mathrm{a}}\end{array}$ & -0.86 & Temporary & Panel & Tax filer & Donation \\
\hline Jones $(1983)^{\mathrm{a}}$ & -0.6 & Temporary & Cross-section & Survey & Donation \\
\hline Jones and Posnett $(1991)^{\mathrm{a}}$ & -0.07 & Temporary & Panel & Survey & Donation \\
\hline Joulfaian (1991) & -3 & Temporary & Cross-section & Tax filer & Bequest \\
\hline Joulfaian (2000) & -.74 to -2.58 & Temporary & Cross-section & Survey & Bequest \\
\hline Joulfaian and Rider (2004) & -1.14 to -2.15 & Temporary & Cross-section & Tax filer & Donation \\
\hline Kingma (1989) & -0.43 & Temporary & Cross-section & Survey & Donation \\
\hline Lawrence and Saghafi (1984) & -1.18 & Temporary & Panel & Survey & Donation \\
\hline Lindsey (1987) & -1.23 to -2.56 & Temporary & Cross-section & Tax filer & Donation \\
\hline McClelland (2004) & -1.85 to -2.14 & Temporary & Cross-section & Tax filer & Bequest \\
\hline $\begin{array}{l}\text { Newsome, Blomquist, and } \\
\text { Romain (2001) }\end{array}$ & -.27 to -.58 & $\begin{array}{l}\text { Temporary } \\
\text { Panel }\end{array}$ & Tax filer & Donation & \\
\hline $\begin{array}{l}\text { O'Neil, Steinberg, and } \\
\text { Thompson (1996) }\end{array}$ & -.47 to -2.24 & $\begin{array}{l}\text { Temporary } \\
\text { Panel }\end{array}$ & Survey & Donation & \\
\hline Randolph(1995) & -.51 to -1.55 & $\begin{array}{l}\text { Temporary/p } \\
\text { ermanent }\end{array}$ & Panel & Tax filer & Donation \\
\hline Reece (1979) & -1.19 & Temporary & Cross-section & Survey & Donation \\
\hline Reece and Z ieschang(1985) & -0.85 & Temporary & Cross-section & Survey & Donation \\
\hline Reece and Z ieschang(1989) & -2.72 & Temporary & Panel & Survey & Donation \\
\hline Ricketts and W estfall(1993) & -1.06 & Permanent & Panel & Tax filer & Donation \\
\hline Robinson(1990) & -1.43 to -7.07 & Temporary & Panel & Survey & Donation \\
\hline Rudney (1985) & -0.61 & Temporary & Panel & Tax filer & Donation \\
\hline Schiff (1985) & -2.79 to -4.97 & Temporary & Cross-section & Survey & Donation \\
\hline Schwartz(1970) & -.376 to -1.23 & Temporary & Cross-section & Tax filer & Donation \\
\hline Slemrod(1989) & -2.04 to -2.34 & Temporary & Cross-section & Tax filer & Donation \\
\hline Steinberg(1985) & -0.08 & Temporary & Cross-section & Survey & Donation \\
\hline
\end{tabular}


Taussig (1967)

Tiehen (2001)

Wu andR icketts(1999)

$$
0 \text { to }-.1
$$$$
.02 \text { to }-2.41
$$$$
+.12 \text { to }-.2
$$

Temporary

Temporary

Temporary/p ermanent
Cross-section

Cross-section

Panel
Tax filer Survey/tax filer

Tax filer
Donation

Donation

Donation

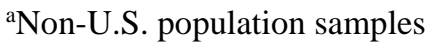

Source: Peloza, John and Piers Steel (2005), "The Price Elasticities of Charitable Contributions: A Meta-Analysis", Journal of Public Policy \& Marketing, 24, 260 - 272

\section{Appendix Table A.2 Studies using survey data}

\begin{tabular}{cc}
\hline Study & Data \\
\hline Boskin and Feldstein (1977) & The 1974 National Survey of Philanthropy \\
Schiff (1985) & The 1974 National Survey of Philanthropy \\
Feldstein and Clotfelter & The 1962 Survey of Financial Characteristics and the 1963 Survey of \\
(1976) & Changes in Family Finance \\
Tiehen (2001) & The Independent Sector Surveys on Giving and Volunteering \\
Brown and Lankford (1992) & The Florida Consumer Attitude Survey \\
\hline
\end{tabular}

Note: This table reports surveys that were used to study the price elasticity of charitable giving except the Consumer Expenditure Survey.

\section{Appendix Figure A.3 Distributions of actual givings vs. predicted givings by} Tobit

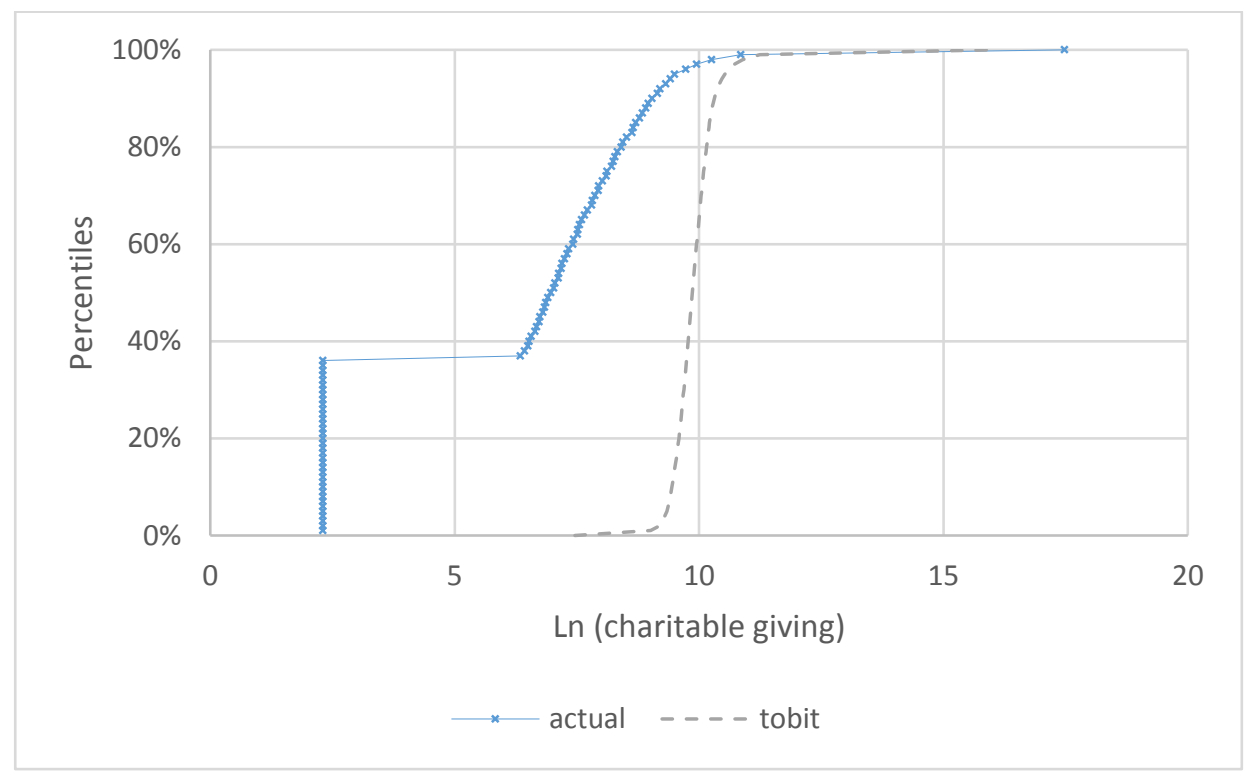

This figure compares the Cumulative Distribution Functions (CDF) of exogenous itemizers' actual giving amount and the predicted giving amounts by the Tobit regression 
described at the end of Section III.4. The figure shows that the Tobit regression tends to overestimate giving. To see the magnitudes with a specific example, while the median actual giving is $\$ 1,059$, the median of all predicted giving amounts is $\$ 19,181{ }^{81}$ The predicted giving amount for a hypothetical household with median wealth, income and other covariates is $\$ 21,976$, while actual households with median characteristics give $\$ 2,158$ on average. ${ }^{82}$ Tobit takes care of zero giving levels as corner solutions, but as it is a linear specification, its results are affected more by extreme values of giving, compared to a log-linear specification. In addition, the Tobit model's assumption that the standard deviation of giving does not vary in the values of the covariates may or may not be true. For example, the standard deviation of giving by wealthier households may be larger simply because they give larger amounts. In contrast, the log-linear specifications fit the data well. Analysis of the whole sample incorporating exogenous non-itemizers yield very similar pictures and numbers.

${ }^{81}$ The predicted giving by a household is calculated based on the formula $E y=X \beta F(X \beta / \sigma)+\sigma f(X \beta / \sigma)$, shown by Tobin and as cited in McDonald and Moffitt (1980).

${ }^{82}$ These are eight exogenous itemizers with income between $\$ 70,000$ and $\$ 100,000$, wealth between $\$ 250,000$ and $\$ 400,000$, the head's age between 40 and 50 and years of education equal to 16 . 


\section{Chapter 3}

\section{Do Mortgage Borrowers Gain the Full Benefit of the Mortgage Interest Deduction?}

\section{Introduction}

Mortgage debt outstanding in the United States is roughly $\$ 9$ trillion, equivalent to almost one-half of the market capitalization of publicly listed companies. Total mortgage interest deductions were $\$ 354$ billion in 2012, resulting in forgone tax revenue of roughly \$68 billion (IRS 2014, Joint Committee on Taxation 2013). Surprisingly, little research has been done to examine whether homeowners - the supposed beneficiaries of this policy - receive all the benefits of this tax expenditure. If lending institutions charge higher mortgage interest rates than they otherwise would in the absence of the deduction, then they recoup some of the benefits. Thus, my research questions are the following. Does the mortgage interest deduction result in higher mortgage interest rates? If so, by how much?

Answers to these incidence questions will not only help us understand whether the deduction achieves its intended effect of reducing the borrowing cost for home purchasers, but also help us understand how taxable income and tax revenue are influenced by both marginal tax rates and tax deductions. Specifically, I aim to examine whether and by how much the early 2000s decrease in tax rates during the Bush tax cuts decrease, and whether and by how much the 2013 increase in top marginal tax rates increase a particular type of market price, the mortgage interest rates. As mortgage interest payments are tax-deductible, increasing mortgage interest rates decrease taxable income and tax revenue.

To answer these questions, I will examine newly released data from Fannie Mae and Freddie Mac. Fannie Mae and Freddie Mac release their loan data separately, but in what follows for simplicity I will refer to them as the "Fannie-Freddie dataset". The Fannie-

Freddie dataset consists of over 38 million loan originations and the related performance records about the loans' delinquency status, remaining balance over time, etc, after their origination. The type of mortgage that I focus on is single-family, conventional (i.e. not 
government insured), 30-year fixed rate mortgage, the sole type that both Fannie Mae and Freddie Mac report for the years of 1999 and after. My study will also rely on the Home Mortgage Disclosure Act Dataset, which contains hundreds of millions of loan records. My goal is to establish the causal relationship between the mortgage interest deduction and mortgage rates, specifically whether the mortgage interest deduction causes an increase in mortgage rates. The deduction encourages mortgage consumption through a price effect and an income effect. With the mortgage interest deduction in place, for itemizers each dollar of mortgage interest payment above the standard deduction costs only 1- $\tau$ dollar of ordinary, non-deductible consumption. This price effect of the mortgage interest deduction makes a mortgage interest payment more favored relative to ordinary, non-deductible consumption. The income effect is that the deduction reduces tax liability and increases households' after tax income. Both the price effect and the income effect are in the direction of increasing mortgage interest rates. The mortgage interest deduction has been in place for a century and I do not have the data to compare mortgage interest rates when there was and was not the deduction in the tax code. Instead, I focus on the price effect by examining the relation between tax rate $\tau$ and mortgage interest rate under the existence of the MID, with income controls in place. Then I can obtain the deduction's total effect by summing up the price effect and the income effect.

To implement my main empirical strategy where I regress mortgage interest rates on the tax price $1-\tau$, with $\tau$ being the marginal tax rate, I match loans recorded in the FannieFreddie dataset with loans in the HMDA dataset. The former data record the loans' interest rates but not borrowers' incomes, with the latter necessary for me to impute the marginal tax rates of the borrower. The latter data record income but not interest rates (except for interest rate spread over treasury for a small proportion of high spread loans). I match the two datasets using the set of variables that they both report, such as loan balance. This matching process involves, for each of the tens of millions of loans recorded the Fannie-Freddie dataset, searching among the hundreds of millions of loans in the HMDA dataset for record(s) that have the same loan, borrower, and property characteristics (including year, loan purpose, number of borrowers, income, state residence and other geographic information, lending institution, purchaser, occupancy 
status, and acceptance/denial) and thus are potentially the same loan with the FannieFreddie loan. I find that decreasing tax rates significantly decrease mortgage interest rates. The magnitude of my results suggest lenders capture between $3.2 \%$ and $4.8 \%$ of the MID's benefit.

I also notice that a change in tax rate should have different effects on itemizers and non-itemizers. For non-itemizers whose total itemized deductions are below the standard deduction, each dollar of their itemized deductions, including the mortgage interest payment, costs 1 dollar (rather than $1-\tau$ as for itemized deductions above the standard deduction) of ordinary, non-deductible consumption. So a change in tax rate does not alter the relative price between ordinary consumption and the mortgage interest payment, and does not have the price effect discussed earlier. Therefore the effect of tax rate should be larger among higher income borrowers who are more likely to itemizers. I find that, in contrast to the above $3.2 \%$ to $4.8 \%$ incidence result, the result for borrowers with disposable income above $\$ 100,000$ is larger, or between $8.5 \%$ and $12.7 \%$.

In addition to my main empirical strategy, I use an alternative empirical approach with the Fannie-Freddie dataset alone. After imputing each borrower's income and marginal tax rate, I find again that the mortgage interest deduction raises mortgage interest rates by a similar amount, with between $6.2 \%$ and $9.3 \%$ of the deduction's benefit falling on lenders.

My results are similar to Hanson (2012)'s incidence estimate of $9 \%$ to $17 \%$. To my knowledge, Hanson (2012) is the only existing study on the incidence of MID. He uses a narrower source of identification, as I detail in the next section. In sections that follow, I present my empirical approach and results, and also discuss the implication for the relation between tax rate and taxable income.

\section{Literature Review}

To my knowledge, Hanson (2012) is the only existing study on the incidence of the mortgage interest deduction. My study is different in the source of identification, data and sample. Below I summarize these aspects of his work and highlight the differences with mine. 
First, Hanson (2012) uses the deduction limit as the source of identification. Specifically, as Hanson (2012) recounts, "any interest paid on a mortgage over \$1 million is not tax deductible". ${ }^{83}$ Using both OLS estimation and a regression kink design, he compares the interest rates on loans with a balance larger than $\$ 1$ million and the interest rates on loans with a balance smaller than $\$ 1$ million, and attributes the difference to the mortgage interest deduction. ${ }^{84}$

In contrast, I use the early 2000s and 2013 changes in the federal tax rate schedule as the source of identification. Letting $\tau$ denote the tax rate, then the existence of the mortgage interest deduction means that each dollar paid on mortgage interest brings a tax benefit of (or equivalently speaking, reduces one's tax liability by) $\tau$ dollar. I estimate how the interest rate changes in response to $\tau$ to identify how borrowers and lenders split up the tax benefits. If the interest rate does not rise as a result of a rising $\tau$, then borrowers are keeping all the benefits; if, instead, lenders keep at least some of the benefits, a rising tax rate will push up the interest rate.

Second, pertaining to his source of identification, Hanson (2012) studies the population of loans with a large enough balance; specifically, he only looks at jumbo loans, which are above "conforming loan limits" that Fannie Mae and Freddie Mac do not buy. ${ }^{85}$ In contrast, I look at loans with balance below the "conforming loan limits" purchased by Fannie Mae and Freddie Mac. Based on the HMDA data during 1999-2006, about $8 \%$ of all loans are jumbo loans and $92 \%$ are not.

Third, Hanson (2012) uses the 2004 Home Mortgage Disclosure Act (HMDA) dataset that has 6.4 million observations of mortgages. The data only report the mortgage rate spread (defined as mortgage interest rate - comparable term Treasury bond rate) for rate spreads that are larger than 3\%, representing only $14 \%$ of the loans. He further restricts the sample to loans with balance above the "conforming loan limit" of $\$ 333,700$

\footnotetext{
${ }^{83}$ To my knowledge, this is a simplified account of the more complicated IRS rules regarding deduction limit. But, it does capture the main part of the rule.

84 Notably, a household may have two mortgages each less than 1 million but with a total of over 1 million. In this case a mortgage with balance below 1 million may not qualify for the mortgage interest deduction, but would be regarded as qualifying for the deduction under Hanson (2012)'s method. Hanson (2012) does not address this issue. The implicit assumption must be that such concern has little effect on the estimation results.

85 "Conforming loan limits" vary by year and by loan type. For example, for single family loans since 2006, the limit is $\$ 417,000$ for most areas and $\$ 625,500$ for high cost areas.
} 
and has a sample of 32,715 . This is a distinctive sample that may have limited external validity.

I use Fannie Mae's and Freddie Mac's recently released single family loan level dataset that contains observations of loans between 1999 and 2014. It reports the interest rate for every loan originated, over 38 million in total. One disadvantage of this dataset compared to the HMDA data though is that it does not report borrowers' income, which is necessary for me to calculate the marginal tax rate. My two empirical strategies address this issue in different ways. Under the main strategy, I match loans in the Fannie-Freddie dataset with loans in the HMDA dataset, using the set of variables that the two datasets have in common, i.e. $A=\{$ year, lending agency, property type, loan purpose, occupancy status, loan amount, state, rate spread (in excess of 3\%), number of borrowers $\}$. To be more specific, for each loan in the Fannie-Freddie dataset, I look for a loan in the HMDA dataset with the same values of variables in $A$ (i.e. a loan "match"), and regard the two as the same loan. ${ }^{86}$ Often I find multiple "matches" for each Fannie-Freddie loan, and I describe in details how I deal with this multiple-match issue in Section III. Through matching, I merge the two datasets into one. The merged dataset provides both interest rate and income information, and more abundant other information than the FannieFreddie or HMDA dataset alone, for each matched loan record.

Apart from the above approach of merging the two datasets, I implement an alternative strategy using Fannie-Freddie data alone. As mentioned, Fannie-Freddie data do not record income. However, I can impute a borrower's income's lower bound using a few other variables in the Fannie-Freddie dataset (more details in Section V), and provide empirical analysis based on the Fannie-Freddie dataset alone.

Hanson (2012) finds that once a loan is larger than \$1 million, the interest rate drops as the loan balance increases. In contrast, my methods control for loan balance and compare loans with similar characteristics but different borrower tax rates. He finds that

\footnotetext{
${ }^{86}$ In my empirical work, I do not use "property type" and "rate spread (in excess of 3\%)" to do the matching. This is because these two variables only exist in HMDA's post-2004 data. In order to keep the matching algorithm consistent across all years, I exclude them in my matching process. In addition, I have used information in addition to that in $A$ to do the matching. Specifically, the Fannie-Freddie data have 3digit zip code, and the HMDA data have census tract. I generate zip codes based on HMDA data's census tract and match with Fannie-Freddie's zip codes.
} 
lenders capture between 9 and 17 percent of the subsidy created by the mortgage interest deduction. My empirical strategies find similar results.

Although the literature on the mortgage interest deduction's incidence is thin, my empirical strategies draw upon the larger tax literature and the mortgage literature. My main empirical strategy adopts the regression framework by Courchane, Darolia, and Gailey (2015), which is typical in the literature on mortgage pricing and fair lending analysis. The main regression equation also resembles the one used in the study of wage incidence by Kubik (2004).

\section{The data}

The datasets I use are the following: the Fannie Mae Single Family Loan Level Dataset; the Freddie Mac Single Family Loan Level Dataset; and the Home Mortgage Disclosure Act (HMDA) Dataset. I use the years between 1999 and 2006. Since the Fannie Mae dataset and the Freddie Mac dataset have similar variables and that I always use them in combination in my empirical work, in what follows I will refer to them as one, Fannie-Freddie dataset.

\section{III.1 Overview of the two datasets}

The rules regarding which loans must be reported under the Home Mortgage Disclosure Act and thus incorporated in the HMDA dataset were complicated and had changes overtime. For the time period 1999-2006 that I focus on in my main empirical strategy, the general rules are that, in each calendar year, depository institutions (i.e. banks, credit unions, and savings associations) with an office in a Metropolitan Statistical Area (MSA) and with assets above that year's "coverage threshold" (see footnote), and nondepository institutions with assets above $\$ 10$ million that have an office or loan activity in a MSA, must report all loan originations, purchases, and applications in that calendar year (FFIEC 1998, $2003 \& 2015$ ) ${ }^{87}$ Overall, the HMDA dataset represents a large majority (e.g. 80\% in 2004) of home loans, and are broadly representative of all home purchase, refinance, and home improvement loans in the United States (Avery, Canner, \& Cook 2005; Avery, Brevoort, \& Canner 2012). The Fannie-Freddie dataset is also fairly representative, as the total mortgages held or securitized by Fannie Mae and

\footnotetext{
${ }^{87}$ The depository institution "coverage thresholds" for the years of 1999 to 2006 were, respectively, \$29 million, \$30 million, \$31 million, \$32 million, \$32 million, \$33 million, \$34 million, and \$35 million.
} 
Freddie Mac are between $38.8 \%$ and $46.3 \%$ of residential mortgage debt outstanding during 1999-2006 (Federal Housing Finance Agency 2016). For the years of 1999 to 2006, the Fannie-Freddie dataset reports all single-family, 30-year fixed rate, nongovernment insured loans that Fannie Mae and Freddie Mac purchased.

A closer look at the datasets confirms the broader picture above. The 1999-2006 HMDA dataset contains 246,668,679 observations of loan applications. Not all of these 246,668,679 applications were accepted; only 152,634,858 went through. Not all of these $152,634,858$ loans are qualified to be purchased by Fannie Mae and Freddie Mac. Fannie Mae and Freddie Mac are restricted by law to purchasing single-family mortgages with origination balances below a specific amount, known as the "conforming loan limit" (Federal Housing Finance Agency 2016). ${ }^{88}$ Out of these 152,634,858 loans, 140,069,153 were below such limits. Out of these 140,069,153 loans, 14,762,147 were either government insured loans or multifamily loans, the kind of loans not included in the Fannie-Freddie dataset. Among the remaining 140,069,153-14,762,147=125,307,006 loans, approximately $48.5 \%$, or 60,771,409 loans, are 30 year fixed rate mortgages, almost the sole type of mortgage in the 1999-2006 Fannie-Freddie dataset that I use (Fannie Mae 2016; Freddie Mac 2015). ${ }^{89}$ The 1999-2006 Fannie-Freddie data contain 23,371,881 single-family, conventional (i.e. not government insured), 30-year fixed rate mortgages. This is $23,371,881 / 60,771,409=38.5 \%$ of the loans of the same kind recorded in HMDA. This percentage of $38.5 \%$ that I computed from my downloaded datasets agree well with the overall Federal Housing Finance Agency (FHFA) statistics of $38.8 \%$ to $46.3 \%$ that I listed in my previous paragraph.

\footnotetext{
${ }^{88}$ The conforming loan limit varies over time. It was 240,000 in $1999,252,700$ in $2000,275,000$ in 2001, 300,700 in 2002, 322,700 in 2003,333,700 in 2004, 359,650 in 2005, and 417,000 in 2006.

${ }^{89}$ I have estimated the number $48.5 \%$ based on Federal Housing Finance Agency's data and the Surveys of Consumer Finances. Specifically, out of the conventional (i.e. not government insured) single-family mortgages between 1999 and 2006, about $79.6 \%$ of the balance are fixed rate mortgages (Federal Housing Finance Agency 2016). Based on the 2001, 2004, and 2007 Surveys of Consumer Finances conducted by the Federal Reserve Board, $60.9 \%$ of all main mortgages has a 30 -year term. So about $79.6 \% \times 60.9 \%=48.5 \%$ of the $125,307,006$ conventional, single-family loans recorded in HMDA are $30-$ year fixed rate mortgages. By "almost the sole type", I am referring to the fact that Freddie Mac recently released 15 and 20 year mortgages for loans originated on and after Jan 1, 2005 (see Freddie Mac's Mar 2016 version of its "Single Family Loan-Level Dataset General User Guide"). I do not use these newly released 15 and 20 year loan records.
} 


\section{III.2 Matching the Fannie-Freddie dataset and the HMDA dataset}

The Fannie-Freddie dataset contains interest rate information but no income, while the HMDA dataset contains income but no interest rate (except for about $10 \%$ of the observations in and after 2004). For each loan recorded in Fannie-Freddie data, I look for the same loan in the HMDA dataset, to supplement the Fannie-Freddie data with borrowers' incomes which are necessary to impute marginal tax rates. This process goes as follows. For each Fannie-Freddie loan record, I examine every HMDA loan record. An HMDA loan record that meets the following "consistency criteria" is called a "match" with the Fannie-Freddie loan record. More than one "match" may be found, and I discuss later how I deal with this multiple-match issue.

Criterion \#1: the two loans' year information is consistent

For example, for a loan in Fannie-Freddie's Year (of loan origination) 1999 data, only loans in HMDA's Year (of loan origination, application denial, or loan purchase, etc) 1999 data were searched for a "match". Other years' data are not considered.

Criterion \#2: the two loans' loan purpose information is consistent

If the Fannie-Freddie loan's purpose is “purchase", then a HMDA loan's purpose has to be "home purchase" to be considered for a "match".

If the Fannie-Freddie loan's purpose is not "purchase", then a matched HMDA loan's purpose must also not be "home purchase". More specifically, if the FannieFreddie loan's purpose is "Cash-out Refinance", "No Cash-out Refinance", or "Refinance - Not Specified", then a matched HMDA loan's purpose has to be "Home improvement" or "Refinancing".

Criterion \#3: the two loans' number of borrowers information is consistent

If the Fannie-Freddie loan has 2 or more borrowers, then a matched needs also to have 2 or more borrowers. ${ }^{90}$ I only consider loans with 2 or more borrowers, for the ease in imputing tax rates. See Appendix 1 for more details.

\footnotetext{
${ }^{90}$ The number of borrowers information is stored in the datasets in the following way. The Fannie-Freddie data report directly the "number of borrowers" information. The HMDA dataset does not report this information directly, but for each loan it reports the first borrower's race and sex as well as the second borrower's race and sex, if there is a second borrower. Therefore I could tell whether a loan in HMDA has 1 borrower or $\geq 2$ borrowers. If an HMDA loan's race and sex information are both missing, than I consider it consistent with any Fannie-Freddie loan under this Criterion \#3, but they will be considered a lower quality match. I explain how I account for match quality later in this section.
} 
Criterion \#4: The two loans' borrower income information is consistent

The Fannie-Freddie dataset does not contain an "income" variable, but a lower bound for a loan's borrower income can be imputed. I explain the algorithm's full details in Section V. The HMDA dataset has an "income" variable. Every HMDA loan's income has to be larger than the Fannie-Freddie's loan's income lower bound, if neither information is missing. If either information is missing, the two loans will be considered as consistent under this Criterion \#4, but they will be considered a lower quality match (see the footnote for reasons of missing values). ${ }^{91}$ I explain how I account for match quality later in this section.

Criterion \#5: The two loans' state of residence is consistent

Both the Fannie-Freddie dataset and the HMDA dataset provide state of residence information, which must be consistent for the two loans to be a match.

Notice that a loan's collateral property's location may have changed its state affiliation over time. This change may happen when, for example, the boundary between the two Carolinas were redrawn with more accurate modern technology (GPS and computers) during around 2012-2014 and tens of properties switched from South Carolina to North Carolina (Carbone 2012; Kelly 2014). As a result, the loan's state may be recorded differently in the two datasets. I account for this issue in the following way. I use the Census Bureau data, specifically the Census 2000 - Population-based Census Tract Relationship File (National) and the 2010 Census Tract Relationship File (National), to compile all cases of state switches. For example, there may exist a location (more specifically, a census tract) that belongs to State X in Census 1990 (or Census 2000, or Census 2010) but belongs to State $\mathrm{Y}$ in another Census. In this case, I consider

\footnotetext{
${ }^{91}$ HMDA's income (specifically "gross annual income" [same across two periods]) information is missing for 13.9\% of the observations between 1999 and 2006, for various reasons as follows. Income is not provided if the lending institution "does not take the applicant's income into account", or "if the loan or application is for a multifamily dwelling" (thus irrelevant for this study since I only look at single-family loans), or if "the transaction is a loan purchase" and the lending institution "choose not to collect" the income information" (Federal Financial Institutions Examination Council (FFIEC) 1998 \& 2003). In addition, a lending institution may also not provide the income information for loans to its employees to protect their privacy (FFIEC 1998, 2003). During 1998-2003, "a bank, thrift, or credit union with assets of $\$ 30$ million or less is not required by HMDA to report this (income) information" (FFIEC 1998). During 2004-2008, income is not provided if "the borrower or applicant is a corporation, partnership, or other entity that is not a natural person" (FFIEC 2003).
} 
an HMDA loan in State $\mathrm{X}$ as consistent in state information with not only a FannieFreddie loan in State X but also a Fannie-Freddie loan in State Y.

If either loan's state information is missing, the two loans will be considered as consistent under this Criterion \#5, but they will be considered a lower quality match. I explain how I account for match quality later in this section.

Criterion \#6: The two loans' geographic information other than state information is consistent

Two loans meet this Criterion \#6 as long as they have the same Metropolitan Statistical Area (MSA) code or they have the same zip code. The MSA matching process could have very minor errors; while the zip code matching is more prone to errors, which are also minor. I explain these in details in the following 3 paragraphs.

The Fannie-Freddie dataset provides 5-digit MSA codes. The HMDA dataset sometimes provides the older 4-digit MSA codes, therefore I use the HMDA's county information instead to produce the 5-digit MSA code, which I match with the FannieFreddie dataset's 5-digit MSA codes. As counties' boundaries may change, occasionally this generating-MSA-from-country method may produce errors. As for the zip codes, the Fannie-Freddie dataset has the first three digits of each loan's collateral property's zip code. The HMDA dataset does not provide zip codes directly, but it records census tracts. The 1999-2003 HMDA data report census tract numbers as they are assigned in the 1990 census. The 2004-2006 HMDA data report census tract numbers as they are assigned in the 2004 census. Then I use a census tract data file that maps census tract numbers to zip codes. More specifically, this is the "2010 ZCTA to Census Tract Relationship File" that reports the most frequently occurring ZIP code (5 digit) for each 2010 census tract (U.S. Census Bureau 2015d). Errors could creep in here as a census tract could have more than one zip code while this file only reports the most frequently occurring ZIP code.

However, I believe that these errors are minor as well, since there are over 70,000 census tracts in the United States but less than 999 3-digit ZIP codes. Therefore, each 3-digit ZIP code should cover a large number of census tracts.

The detailed process of generating 3-digit zip codes from census tracts for HMDA loans goes as follows (summarized in Figure 1). The key step is using the "2010 ZCTA to Census Tract Relationship File" to generate zip codes from census tract numbers assigned 
in 2010 census. However, as mentioned earlier, the 1999-2003 HMDA data use census tract numbers assigned in 1990 census and the 2004-2006 HMDA data use census tract numbers assigned in 2000 census. Therefore, for each loan's census tract number reported in HMDA, I first generate their (possibly different) 2010 census tract numbers using the aforementioned Census 2000 - Population-based Census Tract Relationship File (National) which reports the (possibly new) 2000 census tract number(s) for each 1990 census tract number, and the 2010 Census Tract Relationship File (National) which reports the (possibly new) 2010 census tract number(s) for each 2000 census tract number.

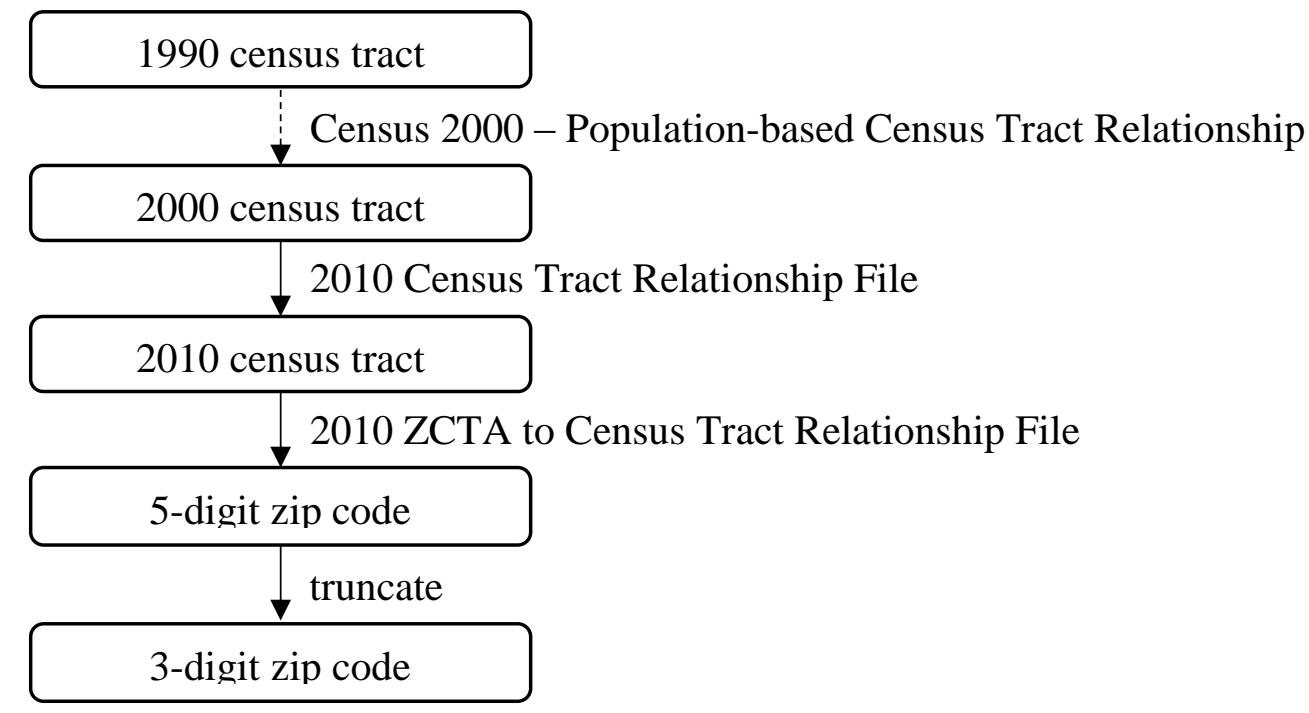

Figure 1 Generating zip codes from census tract

If either loan's MSA and zip code information are both missing, the two loans will be considered as consistent under this Criterion \#6, but they will be considered a lower quality match. I explain how I account for match quality later in this section.

Criterion \#7: The two loans' lending institution information is consistent

The HMDA dataset reports the loans' lending institutions, and the Fannie-Freddie dataset reports "seller" institutions that sold the loans to Fannie Mae or Freddie Mac, and "servicer" institutions that serviced the loans. I require that an HMDA loan's lending institution be consistent with either the "seller" or the "servicer" of a loan in the FannieFreddie dataset for the two loans to be a match.

The lending institutions may go through mergers or acquisitions and thus have name changes over time. In matching the lending institutions, I have noticed that the HMDA 
dataset uses concurrent names and that the Fannie-Freddie dataset tends to use the newer names. Thus, if an HMDA loan's lending institution's name is the same with a FannieFreddie loan's seller's/servicer's old name, I consider them consistent under this Criterion \#7. Also, Fannie Mae’s data document says explicitly, "In instances of mergers or acquisitions, the Seller Name may reflect the acquiring entity" (Fannie Mae 2016). Therefore, if an HMDA loan's lending institution is the subsidiary of a Fannie-Freddie loan's seller/servicer, I also consider them consistent.

Criterion \#8: The two loans' purchaser information is consistent An HMDA loan's "type of purchaser" must be "Fannie Mae" or "Loan was not originated or was not sold in calendar year covered by register" to match with a Fannie Mae loan in the Fannie-Freddie dataset. Similarly, an HMDA loan's "type of purchaser" must be "Freddie Mac" or "Loan was not originated or was not sold in calendar year covered by register" to match with a Freddie Mac loan in the Fannie-Freddie dataset.

Criterion \#9: The two loans' occupancy information is consistent

The Fannie-Freddie dataset reports whether a loan's occupancy status as "principal residence” (term used by Fannie Mae)/“owner occupied” (term used by Freddie Mac), "second home", or "investment property". The HMDA dataset has a "Occupancy" variable that codes a loan as "Owner-occupied as a principal dwelling", "Not owneroccupied as a principal dwelling", or "Not applicable". However, under HMDA's reporting guides, if a lending institution purchased a single-family loan whose loan documentation does not indicate whether the borrower plans to occupy the residence, the lending institution could always report it as "owner-occupied as a principal dwelling" (Federal Financial Institutions Examination Council 1998). This means that a principal residence loan in HMDA could in fact be a second home or investment property. Therefore, in order to be deemed match, if a Fannie-Freddie loan is "principal residence" or "owner occupied", an HMDA loan must also be coded as "Owner-occupied as a principal dwelling". But if a Fannie-Freddie loan is a "second home", or an "investment property", an HMDA loan could be coded as anything to be a match.

If either loan's occupancy information is missing or coded as "unknown", the two loans will be considered as consistent under this Criterion \#9, but they will be considered a lower quality match. I explain how I account for match quality later in this section. 
Criterion \#10: An HMDA loan application record must not be denied application, withdrawn by applicant, closed for file incompleteness, or not accepted by applicant.

After having found HMDA matches that meet the above 10 criteria for each FannieFreddie loan, I score the "match quality" of each pair of match, in the following way. As mentioned in the explanations of the matching rules, under each of the Criteria \#3, \#4, \#5, \#6, \#9, an HMDA loan and a Fannie-Freddie loan may be considered consistent because either loan has missing information under that criterion, or because the two loans have non-missing and consistent information. For a pair of match, if under $N$ of these 5 criteria the two loans are considered consistent because the two loans have non-missing and consistent information (and, correspondingly, under 5- $N$ of these 5 criteria the two loans are considered consistent because either loan has missing information), then the "match quality score" of this pair of match is $N$, with $N$ ranging between 0 and 5 . For each Fannie-Freddie loan, I may find more than 1 matches in the HMDA dataset, with different match quality scores. In such multiple-match cases, for each Fannie-Freddie loan, I only keep the match(es) with the highest "match quality score". Notice that, after filtering out the lower score matches, there may still be more than 1 matches for each Fannie-Freddie loan. Multiple-match exists for two reasons. First, there are similar loans that are indistinguishable given the available loan characteristics reported under HMDA. Second, a loan may be reported under HMDA when it was originated, and then reported again when it was purchased. As a result, the same loan may appear twice. In Subsection III.4 I will discuss how I obtain the final sample where each Fannie-Freddie loan produces only one observation.

\section{III.3 Disposable income, tax-price, house value, and interest rate premiums}

I compute or impute the following variables to generate the final sample and to run my regression. To compute these variables, I need to discard HMDA records with missing income (or about $13.9 \%$ of all HMDA records; see an earlier footnote for more information) and Fannie-Freddie records with missing loan-to-value ratio information (or about $0.003 \%$ of all Fannie-Freddie records; see the footnote for more information). ${ }^{92}$

\footnotetext{
${ }^{92}$ Fannie Mae and Freddie Mac do not report the exact values of the loan-to-value (LTV) ratio for loans with extreme LTV values. Specifically, Fannie Mae's LTVs are right censored at $97 \%$ and Freddie Mac's LTVs are left censored at $6 \%$ and right censored at $105 \%$.
} 
Disposable income and tax-price - For each loan, the HMDA dataset provides the "gross annual income" of the borrower(s). This is not a rigorous tax concept; rather, it is the gross annual income that a lending institution "relied on in making the credit decision" (Federal Financial Institution Examination Council 1998 \& 2003). For the purpose of computing the borrowers' federal income tax liability and tax rates, I treat this "gross annual income" as the "adjusted gross income", a defined tax concept. I then subtract the personal exemption and standard deduction from it to obtain taxable income, the corresponding federal income tax liability and marginal income tax rate $\tau$ applied to this taxable income. I define disposable income as "gross annual income" - tax liability, and tax-price as 1- $\tau$. Notice that the choice of this particular $\tau$ (out of many under a borrower's progressive tax schedule) means that I am simply using the tax price for the first dollar of any itemized deduction for the itemized deduction dollars in excess of the standard deduction. The mortgage interest deduction is a major type of itemized deduction (e.g. mortgage interest deduction amount is $32.4 \%$ of all itemized deduction in 2010), so this first dollar (in excess of the standard deduction) price for "any" itemized deduction is relevant for the mortgage interest deduction. I also notice that this tax-price is more relevant for itemizers than non-itemizers, as non-itemizers' itemized deductions do not reduce their tax liabilities. I don't observe other itemized deductions and cannot determine one's itemization status, but I run regressions separately for the whole sample and for higher income borrowers, with the latter group more likely to be itemizers. I find that higher income borrowers are more responsive to tax rate changes.

House value - This is calculated as the original unpaid principal balance divided by the original loan-to-value ratio. The "original unpaid principal balance" is the "original amount of the mortgage loan", and the "original loan-to-value ratio" is calculated as the original loan amount divided by the mortgaged property's value or sales price (Fannie Mae 2016).

Mortgage interest rate premium - This is calculated as a loan's interest rate minus the 20 year Treasury bond's rate two months prior to the first payment month of the loan. I apply this two-month lag because in the Fannie Mae data I see that the month of loan origination month is often two months earlier than the first payment month. Freddie Mac only provides the first payment month, but not the origination month. Therefore, I use the 
first payment month to compute the mortgage interest rate premium. I use the mortgage interest rate premium rather than the raw mortgage interest rate, as a way to control for the effect of the general trend of the interest rate movement. Alternatively, I could use the raw mortgage interest rate as the dependent variable, while control for the 20 year Treasury bond's rate. The regression results are highly similar (not listed in this paper).

Corporate bond interest rate premium - This is the average Aaa corporate bond rate minus 20 year Treasury bond rates, with both series of monthly rates published by the Federal Reserve Board under its "Selected Interest Rates (Daily) - H.15" series.

Both disposable income and house value are in 2012 dollars.

\section{III.4 Obtaining the final sample}

As emphasized at the end of Subsection III.2, for each Fannie-Freddie loan, I may have multiple HMDA matches, which are loans with similar characteristics or even the same loan appearing multiple times. These different HMDA matches could have different incomes and different tax-prices computed based on the incomes. To generate the final sample where each Fannie-Freddie loan is assigned only one income and one tax-price, for each Fannie-Freddie loan I first calculate the mode of the tax-prices of all its HMDA matches. I use this modal tax-price as the one tax-price that I assign to the corresponding Fannie-Freddie loan. In other words, as I do not observe directly which tax-price is the true tax-price when there are multiple matches, I let these matches "vote" to obtain the most often imputed tax-price. Then, I delete the matches with non-modal tax-prices. Then, $20.1 \%$ of the observations have exactly 1 match while the rest $79.9 \%$ have multiple matches. The median number of matches is 4 . Secondly, I compute the average of the remaining matches' disposable incomes. I use this average disposable income, together with the modal tax-price, as the unique income and unique tax-price that I match with each Fannie-Freddie loan and use in my regression.

\section{III.5 Summary statistics}

My final sample has 10,565,848 observations. Table 1 lists the summary statistics. The combined loan-to-value ratio is the ratio of the total amount of all loans secured by a mortgaged property to the property's value. FICO credit score is "a number, prepared by third parties, summarizing the borrower's creditworthiness, which may be indicative of the likelihood that the borrower will timely repay future obligations" (Freddie Mac 
2015). Debt-to-income ratio is the borrower's total monthly debt payments divided by his or her totally monthly income. All other variables' definitions are in Subsections III.3 and III.4. The tax-price's minimum, P5\%, P10\%, and P25\% are, respectively, 0.604, 0.695, 0.700 , and 0.725 .

Table 1 Summary Statistics

\begin{tabular}{lrrrrr}
\hline \hline Variable & Mean & Median & Standard deviation & P75\% & P90\% \\
\hline Mortgage rate premium* & 118 & 116 & 050 & 146 & 179 \\
Original unpaid principal balance & 170,237 & 159,000 & 75,529 & 220,000 & 275,000 \\
Loan-to-value ratio** & 72.6 & 78 & 15.9 & 80 & 90 \\
Combined loan-to-value ratio** & 73.8 & 78 & 16.4 & 84 & 95 \\
Debt-to-income ratio & 33.8 & 33 & 11.9 & 42 & 50 \\
FICO credit score & 721.3 & 729 & 54.5 & 766 & 786 \\
Tax-price & 0.75 & 0.73 & 0.058 & 0.73 & 0.85 \\
Disposable income & 96,196 & 92,912 & 51,705 & 103,663 & 137,019 \\
House value & 304,922 & 268,701 & 178,388 & 382,193 & 509,010 \\
Aaa corporate bond premium* & 89 & 75 & 37 & 120 & 147 \\
\hline$N=10,565,848 \quad *$ In basis points & $* *$ In percentage points & & &
\end{tabular}

\section{Empirical strategy and results}

\section{IV.1 Regression specification}

My goal is to understand the effect of changing marginal tax rates on mortgage interest rates. This effect could happen through two different mechanisms. Perhaps banks, since they observe households' income, know the households' tax rates and price their mortgage based on the tax benefits households could get. Or perhaps the demand for mortgages rises when households face higher tax rates, and more demand bids up the mortgage interest rates. I will use a linear regression equation that regresses interest rates on tax rates. This is similar to the fair lending analysis that regresses interest rates on minority status to detect whether lending institutions discriminate based on minority status. In this sense, the linear regression I run can be considered a test of the former mechanism, i.e. a test of whether lenders consciously "discriminate" based on 
households' tax rates. However, even if the latter rather than the former mechanism is in place, my regression equation could still detect a non-zero effect of tax rates on mortgage interest rates. So ultimately in this study I do not try to tell which mechanism is in place.

For a household that deducts its mortgage interest payment, each dollar of interest payment forgoes 1- $\tau$ dollar of ordinary, non-deductible consumption. Therefore, the higher $\tau$ is, the more mortgages are favored or subsidized relative to ordinary consumption, and the higher the mortgage interest rates are expected to be. Again, in this paper I do not try to tell whether this subsidy's incidence result is realized through lending institutions' active price discrimination or simple supply-demand effect.

I regress the mortgage interest rate premium on the tax-price and other variables that indicate loan characteristics, borrower characteristics, and property characteristics. Specifically, the regression equation is

$$
\begin{aligned}
\text { premium }= & \beta_{0}+\beta_{1} * \text { tax price }+\beta_{2} * \text { upb }+\beta_{3} * \text { ltv }+\beta_{4} * \text { cltv }+\beta_{5} * d t i \\
& +\beta_{6} * \text { fico }+\beta_{7} * \operatorname{Ln}(\text { disposable income })+\beta_{8} * \operatorname{Ln}(\text { house value }) \\
& +\beta_{9} * \text { cor premium }
\end{aligned}
$$

In this equation, premium is the mortgage interest rate premium above the 20 -year Treasury bond interest rate. $U p b$ stands for original unpaid principal balance. $L t v$ stands for loan-to-value ratio. Cltv stands for combined loan-to-value ratio. Dti stands for debtto-income ratio. These loan characteristics could be endogenous as they are jointly determined with the mortgage interest rate. Yezer (2010) discusses these issues in detail. However, models that just regress the price of credit on loan characteristics and other control variables are commonly used by researchers and government regulators to examine discrimination (Courchane, Darolia, and Gailey 2015). A more sophisticated specification would consider different outcomes jointly, in the way that Merry (2001) considers the LTV and housing demand jointly. Fico stands for FICO credit score. Cor premium stands for Aaa corporate bond premium. Cor premium controls for the overall trend in financial instruments' risk premiums.

\section{IV.2 Identification}

The source of identification is the variation in the borrower tax-price for different loans. This variation is induced by both policy changes and income differences. My main empirical strategy uses data during 1999-2006, when the federal income tax rates and tax 
brackets changed in 2001, 2002, and 2003. New tax brackets were established in 2001, brackets were widened for married filers in 2002 and 2003, and tax rates were cut by between 3 to 5 percentage points for most income groups during 2001-2003.

I control for house value as a way to control for wealth. I control for disposable income in order to avoid omitted variable bias, as it could affect both the interest rate one gets and one's tax rate and, as a result, tax-price.

\section{IV.3 Results}

Table 2 shows the regression results for the whole sample and for borrowers with disposable income large than or equal to $\$ 100,000$ (in 2012 dollar).

Table 2 Regression Results

\begin{tabular}{|c|c|c|c|c|}
\hline Regressors & $\begin{array}{l}\text { Estimate } \\
\text { (Standard error) }\end{array}$ & p-value & Estimate (Standard error) & p-value \\
\hline & Whole sample & & High income & \\
\hline Intercept & $735.7(1.7)$ & $<0.01 \%$ & $941.2(3.3)$ & $<0.01 \%$ \\
\hline tax-price & $-40.2(0.4)$ & $<0.01 \%$ & $-105.9(1.1)$ & $<0.01 \%$ \\
\hline$U p b$ & $0.000181(5.52 \mathrm{E}-7)$ & $<0.01 \%$ & $0.000219(9.35 \mathrm{E}-9)$ & $<0.01 \%$ \\
\hline$L t v$ & $-0.589(3.36 \mathrm{E}-3)$ & $<0.01 \%$ & $-0.877(5.65 \mathrm{E}-3)$ & $<0.01 \%$ \\
\hline Cltv & $0.0580(3.00 \mathrm{E}-3)$ & $<0.01 \%$ & $0.0991(4.71 \mathrm{E}-3)$ & $<0.01 \%$ \\
\hline$D t i$ & $0.335(1.18 \mathrm{E}-3)$ & $<0.01 \%$ & $0.324(1.98 \mathrm{E}-3)$ & $<0.01 \%$ \\
\hline Fico & $-0.0727(0.25 \mathrm{E}-3)$ & $<0.01 \%$ & $-0.0629(0.45 \mathrm{E}-3)$ & $<0.01 \%$ \\
\hline $\operatorname{Ln}($ disposable income $)$ & $0.464(7.53 \mathrm{E}-2)$ & $<0.01 \%$ & $0.693(0.128)$ & $<0.01 \%$ \\
\hline $\operatorname{Ln}($ house value $)$ & $-48.1(8.88 \mathrm{E}-2)$ & $<0.01 \%$ & $-60.4(0.179)$ & $<0.01 \%$ \\
\hline Cor premium & $0.639(3.68 \mathrm{E}-4)$ & $<0.01 \%$ & $0.629(6.91 \mathrm{E}-4)$ & $<0.01 \%$ \\
\hline
\end{tabular}

The estimate for the key coefficient of tax-price, -40.2 , has the expected sign and is highly significant. The interpretation is as follows. When the tax-price increases by 1 (i.e. when the tax rate decreases by 100 percentage points), the mortgage interest rate would decrease by 40.2 basis points. Equivalently, when the tax price increases by 0.03 (i.e. when the tax rate decreases by 3 percentage points, as were the case for many tax 
brackets during the Bush tax cut), the mortgage interest rate would decrease by $40.2 * 0.03=1.21$ basis point. This means that lenders capture between $3.2 \%$ and $4.8 \%$ of the mortgage interest deduction's benefit (calculations and explanations to follow in Section V). For higher income borrowers, a 100-percentage point decrease in the tax rate would increase the mortgage interest rate by 105.9 basis points. This means that lenders capture between $8.5 \%$ and $12.7 \%$ of the deduction's benefit from loans made to higher income borrowers.

In contrast to the negative signs above, the raw correlation between premium and tax price is positive. This highlights the importance of controlling for loan characteristics and the corporate bond premium.

\section{Empirical strategy relying solely on the Fannie-Freddie dataset}

In this section I present the empirical analysis and results under an alternative approach that only uses information from the Fannie-Freddie datasets. My main approach makes use of more information supplemented by the HMDA data, whereas this alternative approach imputes a lower bound of income but makes use of all observations in the Fannie-Freddie data.

\section{V.1 Imputing incomes}

The Fannie-Freddie data do not contain borrowers' incomes. The first step under this approach is to impute income, as they are necessary to compute a borrower's marginal tax rate. Other variables in the Fannie-Freddie data provide a way to approximate income. Specifically, the data report the borrowers' debt-to-income (DTI) ratios, defined as the ratio of total debt payments and income. Meanwhile, the data also tell us the annual payments on the mortgage observed. So I can compute

$$
\text { Imputed income }=\frac{\text { annual payments on the observed mortgage }}{D T I}
$$

To understand the relation between this imputed income and borrowers' true income, notice that

$$
\text { True income }=\frac{\text { annual payments on all household debt }}{D T I}
$$


As the numerator in (1) is weakly smaller than that in (2), it is certain that imputed income is a lower bound for true income. So, there is systematic error between imputed income and true income. To shed light on the magnitude of such error, I have used the Surveys of Consumer Finances 2001, 2004, and 2007 to examine the debt holding of $46+58+39=143$ married households who took out home mortgages in those years. Out of these households, there are $19+15+10=44$ households, or $31 \%$ of the 143 households whose only debt payments are for their main mortgage. For the rest of the households, the average ratio of their main mortgage debt payment to their total debt payment is 0.619 .

\section{V.2 Empirical approach and results}

To examine the relation between marginal tax rate and mortgage interest rate, I use proposed and actual tax rate changes during 2010 - 2013 as my source for identification. I use a difference-in-difference approach to utilize the tax rate hike at the top tax bracket in 2013. In 2013, the top tax rate rose, from 35\% to 39.6\%. Therefore in 2013, as was analyzed in the previous section, the top income group's interest rate spread (defined as interest rate - 20 year Treasury bond's rate) should rise relative to other income groups that are not affected by the tax rate change. Also, at the end of 2010, after long debate, the Bush-era tax cuts were extended and no tax rate changed; it also seemed that prior to the decision, what mostly debated was whether the tax rate for top earners should rise (Montgomery, Murray, and Branigin 2012). So for people who had been expecting the rate to rise, the tax rate's staying the same came as a surprise. Therefore 2011 should see the top income group's interest rate premium dropping relative to other groups.

In Figures 2 to 9 I have plotted the differences between the average interest rate premium of the income group with top $1 \%$ of imputed income (most borrowers in this group were likely to have experienced the tax rate hike in 2013) and the average interest rate premiums of other income groups (in these other groups, it should be the case that fewer borrowers experienced the tax rate hike in 2013), together with the differences' one standard error bands. In the figure, I call the top 1\% group "Group 100", and call an income group having the $x$ th quantile of imputed income "Group $x$ ". For example, I call the median income group "Group 50". The larger $x$ is, the higher the group's incomes is. In Figures 4 to 11, I have compared Group 100 respectively with Group 1, Group 10, 
Group 20, Group 30, Group 40, Group 50, Group 60, and Group 70. The unit of measurement in these graphs is percentage point.

The graphs show that Group 100's interest rate premium indeed dropped relatively beginning 2011, and is higher in 2013 than during 2011 and 2012. The pattern is also less and less apparent as we go from Group 1 to Group 70. This aligns well with the nature of imputed income. The higher $x$ is, the more in-top-tax-bracket borrowers are there in Group $x$, and the more Group $x$ resembles Group 100. For Group 70, I suspect that there are a good number of borrowers in Group 70 who experience the tax rate hike as Group 100 do, so Group 100 did not really change that much relative to Group 70. The difference fluctuates over time, even when tax rates are not changing. The identifying assumption here is that such fluctuations are uncorrelated with tax rate changes over time. 


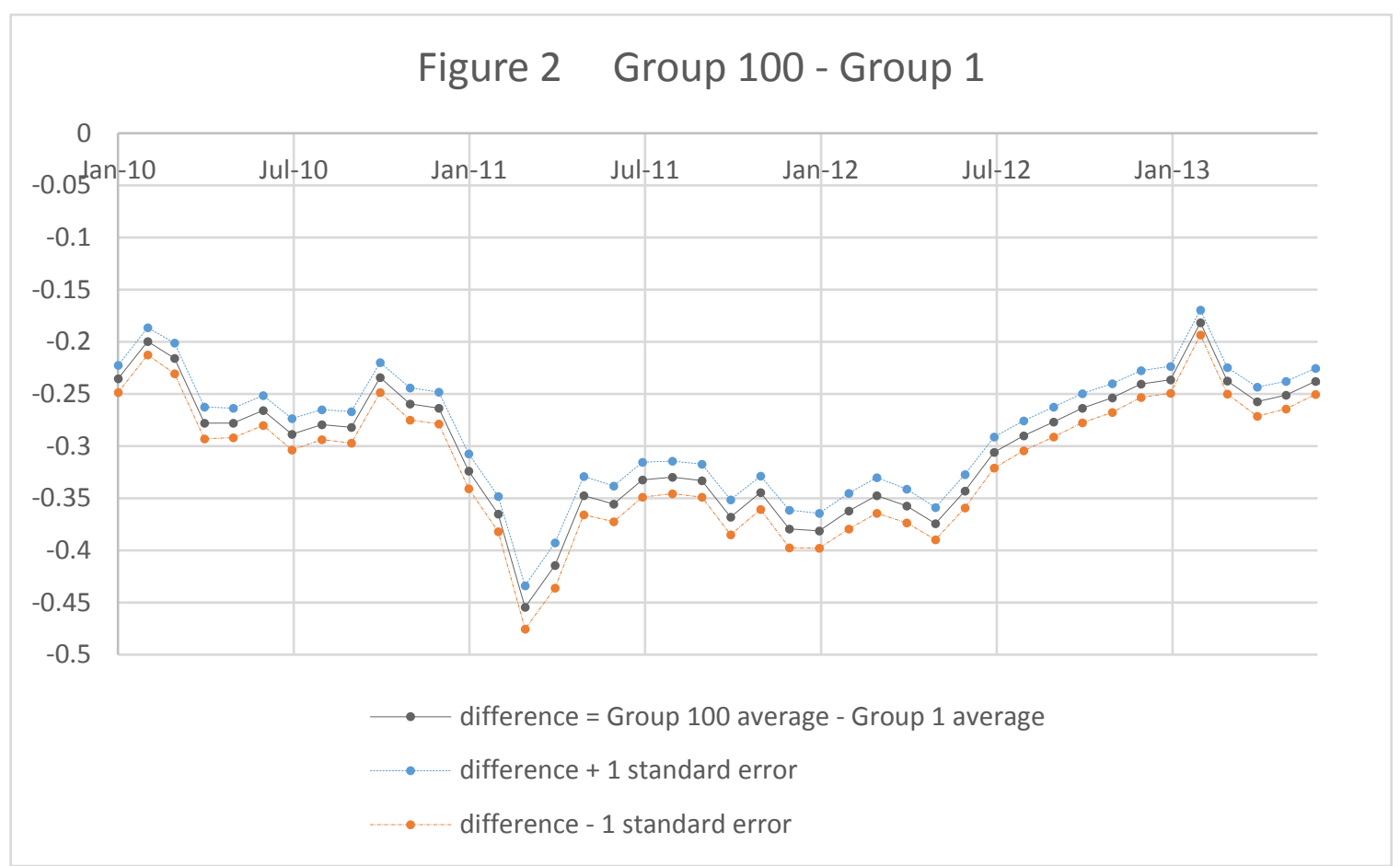

Figure 2 plots the interest rate premium difference (in percentage point) between the average premium of Group 100 and the average premium of Group 1 between Jan 2010 and June 2013.

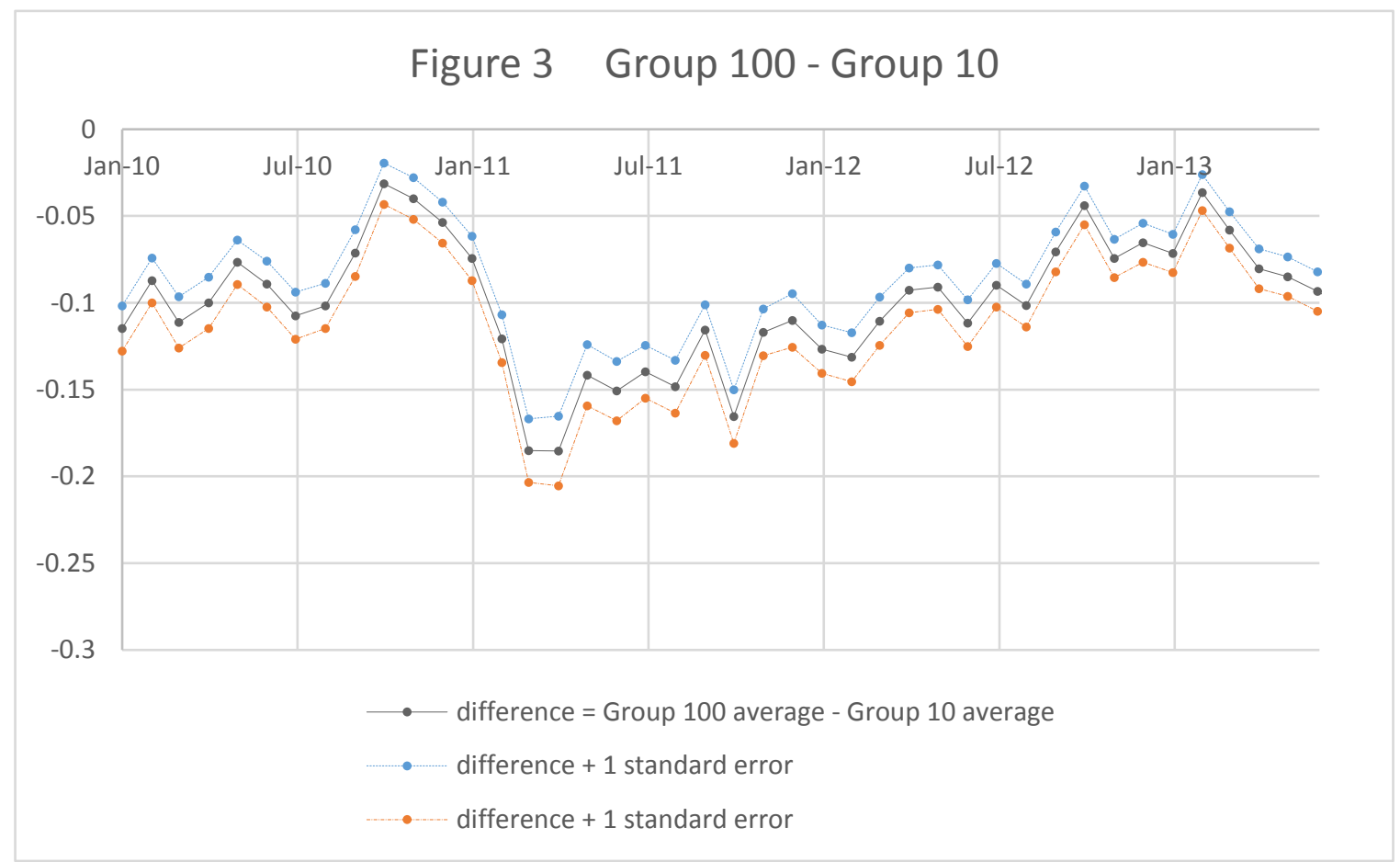

Figure 3 plots the interest rate premium difference (in percentage point) between the average premium of Group 100 and the average premium of Group 10 between Jan 2010 and June 2013. 


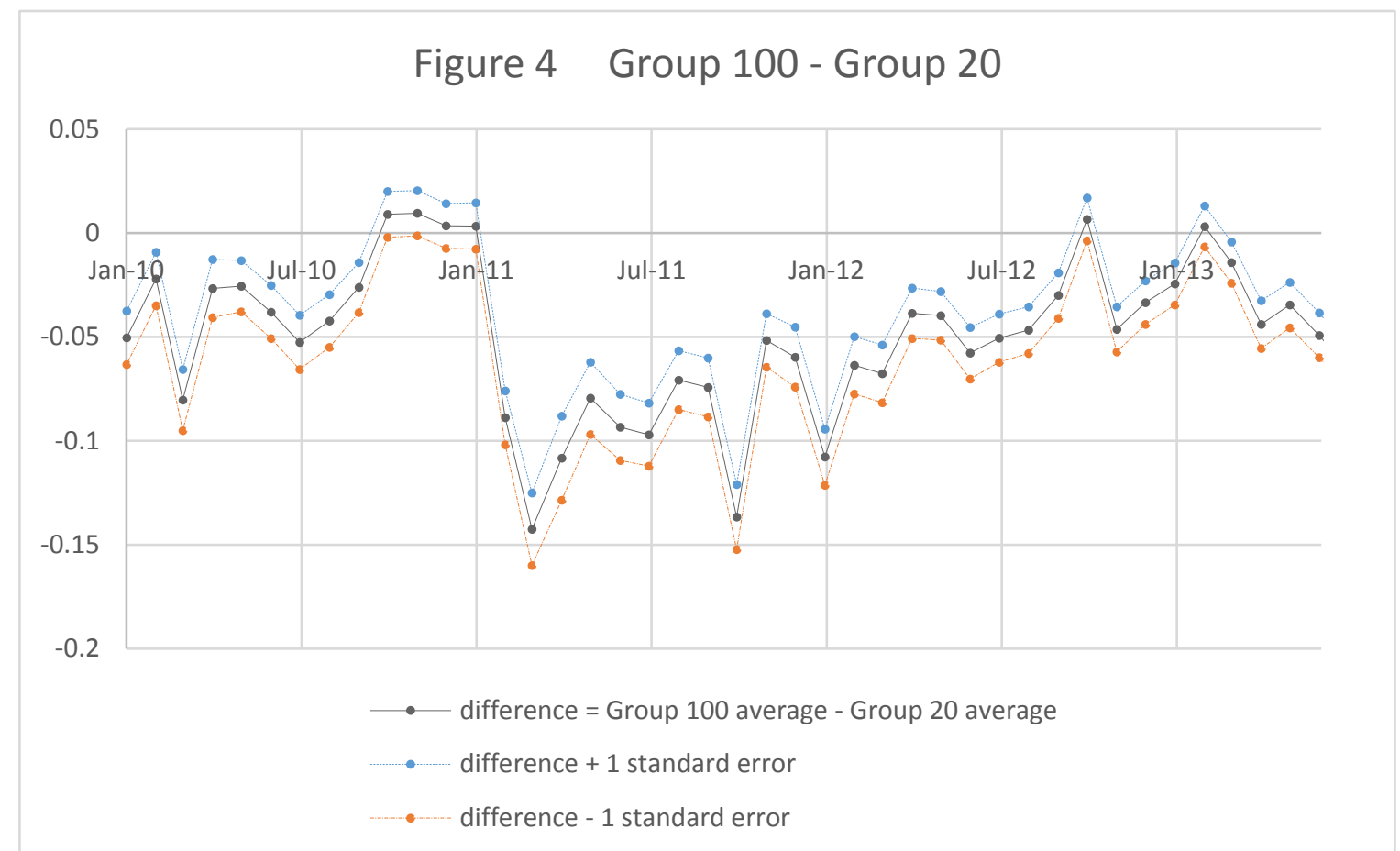

Figure 4 plots the interest rate premium difference (in percentage point) between the average premium of Group 100 and the average premium of Group 20 between Jan 2010 and June 2013.

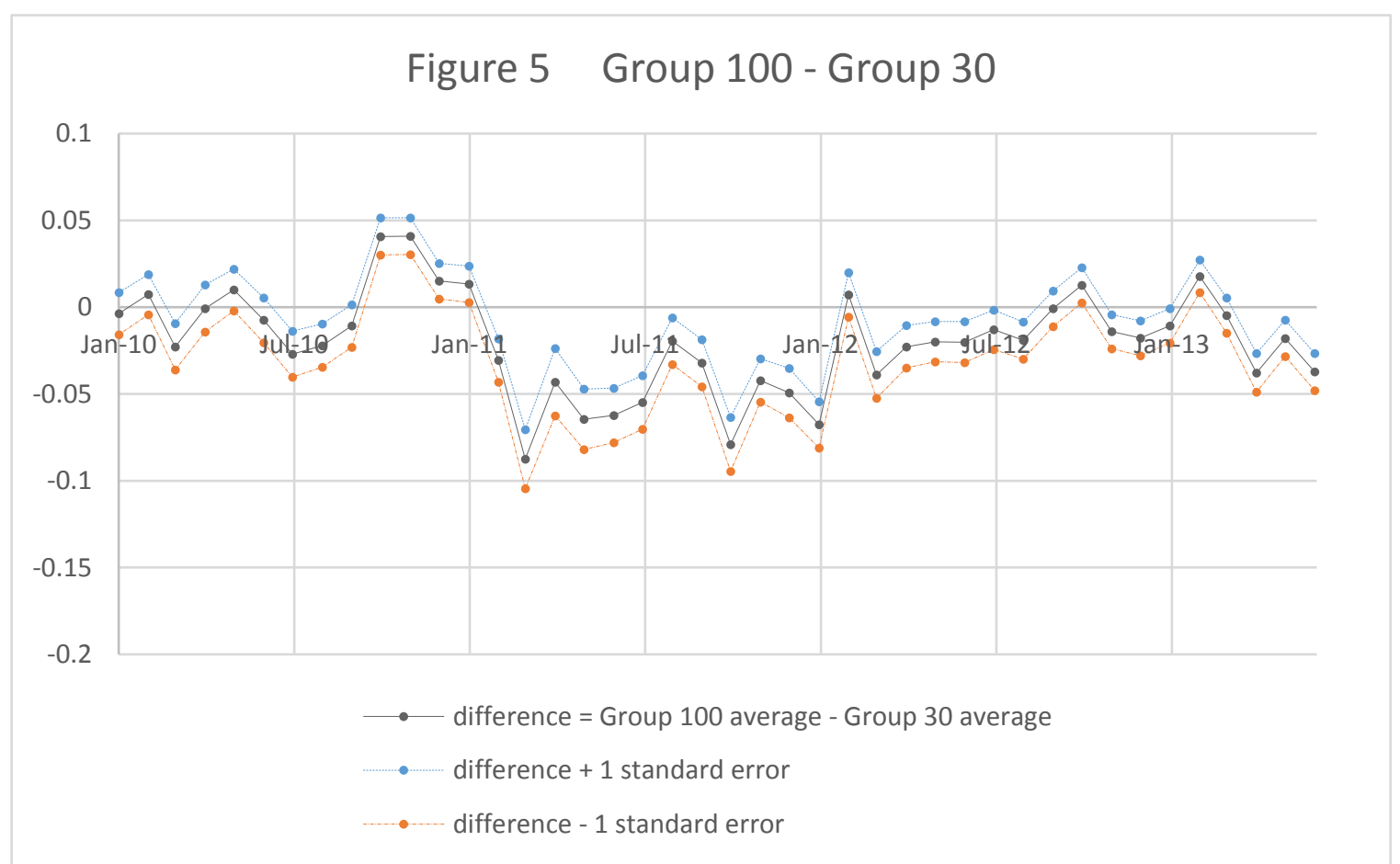

Figure 5 plots the interest rate premium difference (in percentage point) between the average premium of Group 100 and the average premium of Group 30 between Jan 2010 and June 2013. 


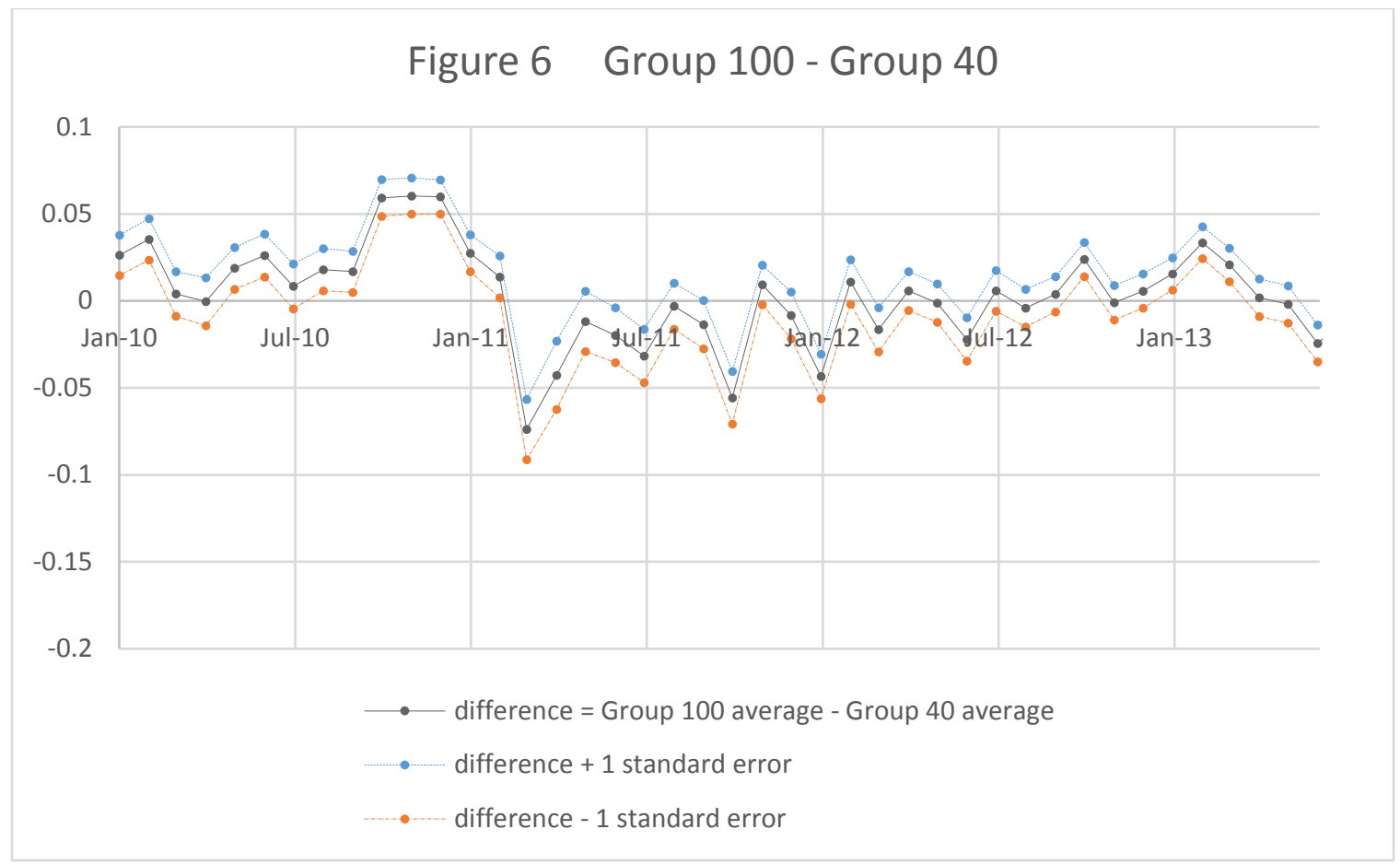

Figure 6 plots the interest rate premium difference (in percentage point) between the average premium of Group 100 and the average premium of Group 40 between Jan 2010 and June 2013.

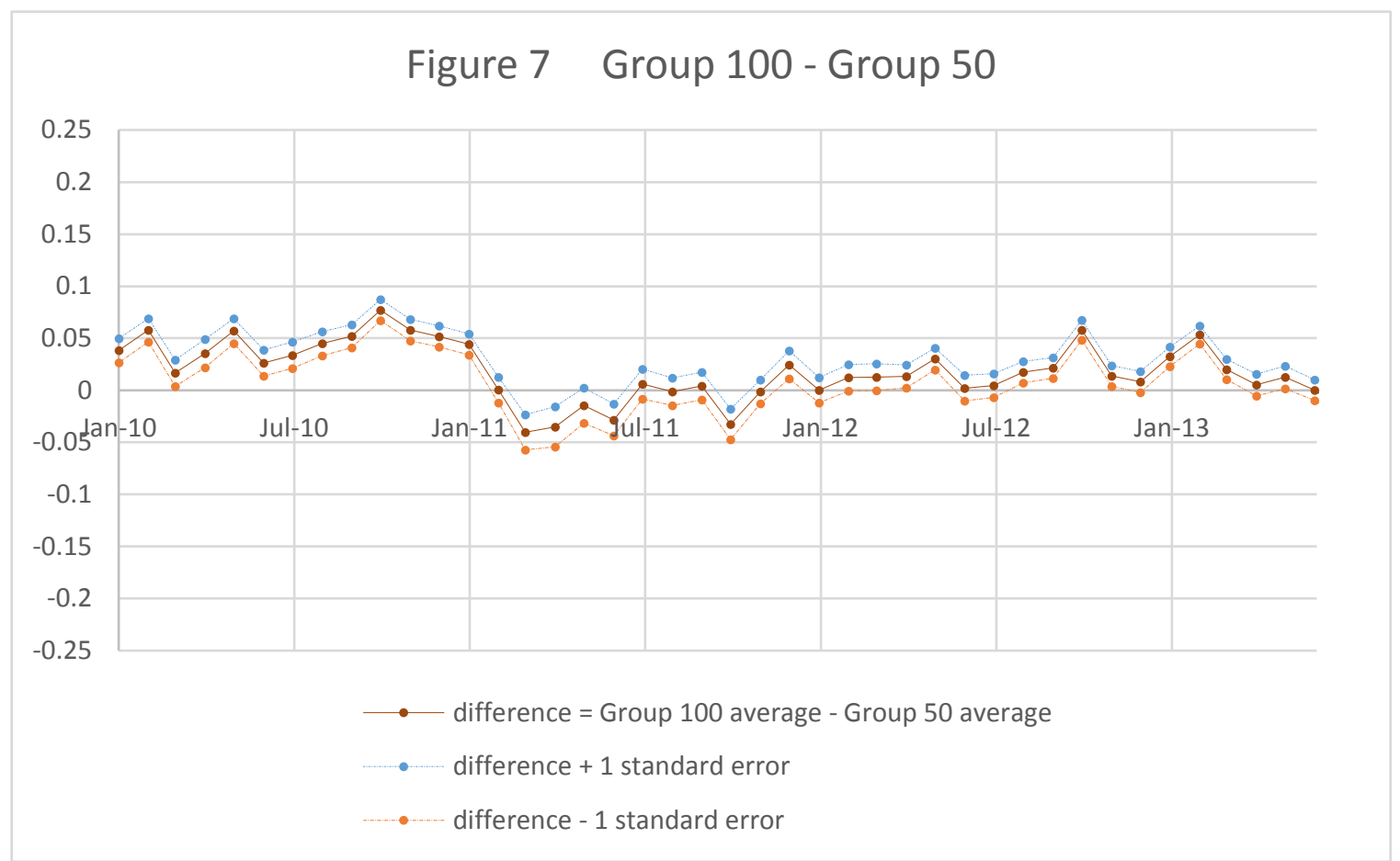

Figure 7 plots the interest rate premium difference (in percentage point) between the average premium of Group 100 and the average premium of Group 50 between Jan 2010 and June 2013. 


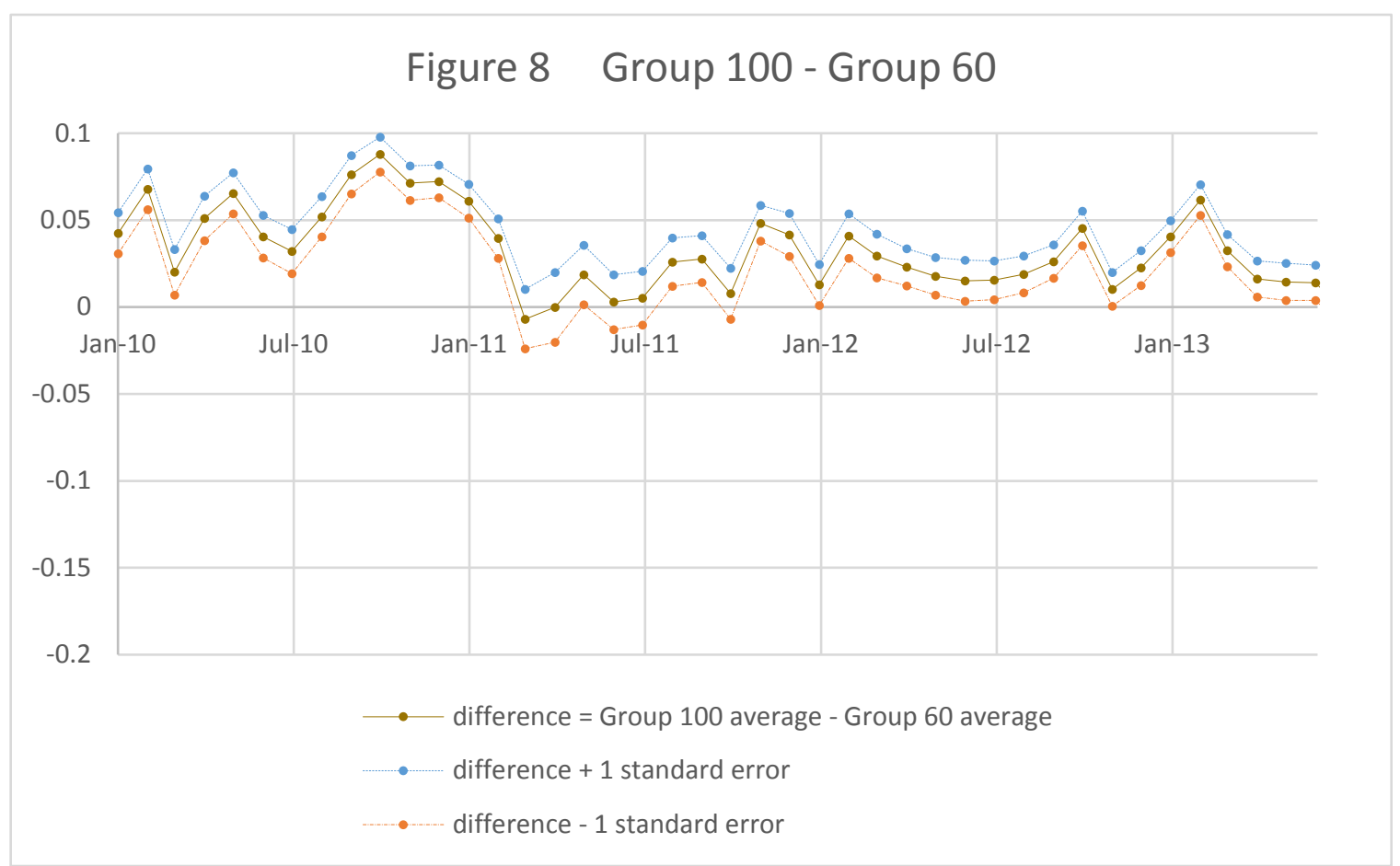

Figure 8 plots the interest rate premium difference (in percentage point) between the average premium of Group 100 and the average premium of Group 60 between Jan 2010 and June 2013.

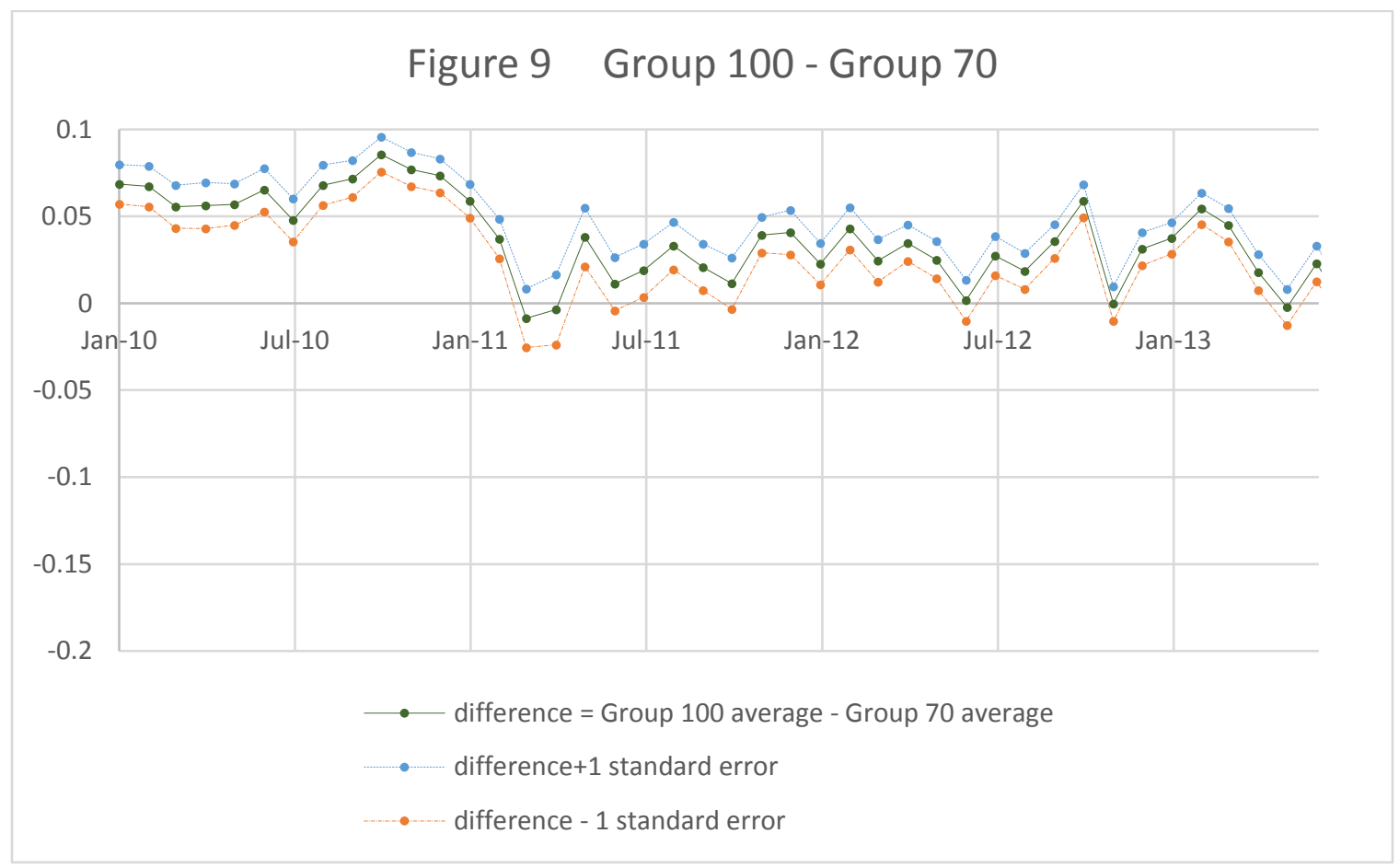

Figure 9 plots the interest rate premium difference (in percentage point) between the average premium of Group 100 and the average premium of Group 70 between Jan 2010 and June 2013.

Now I perform formal statistical tests to test and quantify the effect of tax rate on interest rate. For each of the comparisons represented in Figures 2 - 9, I perform a formal 
2-sample $t$ test to estimate and test for the effect of the tax rate hike on risk premium. Specifically, when comparing Group $x$ (with $x=1,10,20,30,40,50,60,70$ ) and Group 100 , let $\overline{r_{x, 2}}, s_{x, 2}^{2}$, and $N_{x, 2}$ denote, respectively, the mean, the variance, and the number of observations of Group $x$ 's interest rate premiums after the top tax rate hike, i.e. during January 2013 to June 2013. Also let $\overline{r_{x, 1}}, s_{x, 1}^{2}$, and $N_{x, 1}$ denote the mean, the variance, and number of observations of Group $x$ 's interest rate premiums before the top tax rate hike, i.e. during January 2011 to December 2012. Notations for Group 100 are similar. $\overline{r_{100,2}}$, $s_{100,2}^{2}$, and $N_{100,2}$ denote the mean, the variance, and number of observations of Group 100 's interest rate premiums between January 2013 and June 2013, and $\overline{r_{100,1}}, s_{100,1}^{2}$, and $N_{100,1}$ denote the mean, the variance, and the number of observations of Group 100's interest rate premiums between January 2011 and December 2012.

With these notations, the difference-in-difference estimator for performing a 2sample $t$ test is then $\left(\overline{r_{100,2}}-\overline{r_{x, 2}}\right)-\left(\overline{r_{100,1}}-\overline{r_{x, 1}}\right)$. This represents the difference in the difference between Group 100's and Group x's premium. The estimator's standard error is $\sqrt{\frac{s_{100,2}^{2}}{N_{100,2}}+\frac{s_{x, 2}^{2}}{N_{x, 2}}+\frac{s_{100,1}^{2}}{N_{100,1}}+\frac{s_{x, 1}^{2}}{N_{x, 1}}}$. Table 3 presents the estimates.

\begin{tabular}{|c|c|c|c|c|c|c|c|c|}
\hline $\begin{array}{l}\text { Comparing } \\
\text { Group } 100 \\
\text { with... }\end{array}$ & $\overline{r_{x, 2}}$ & $s_{x, 2}^{2}$ & $N_{x, 2}$ & $\overline{r_{x, 1}}$ & $s_{x, 1}^{2}$ & $N_{x, 1}$ & Effect $^{a}$ & $\begin{array}{l}\% \text { of benefits } \\
\text { captured by lenders }{ }^{b}\end{array}$ \\
\hline \multicolumn{9}{|c|}{$\overline{r_{100,2}}=0.866, s_{100,2}^{2}=0.0796, N_{100,2}=8,474, \overline{r_{100,1}}=1.210, s_{100,1}^{2}=0.329, N_{100,1}=22,641$} \\
\hline Group 1 & 1.0998 & 0.171 & 7,711 & 1.594 & 0.393 & 22,919 & $0.150 * \quad(0.00795)$ & $40.0 \% \sim 60.0 \%$ \\
\hline Group 10 & 0.943 & 0.111 & 7,531 & 1.338 & 0.350 & 22,618 & $0.0500 *(0.00736)$ & $13.3 \% \sim 20.0 \%$ \\
\hline Group 20 & 0.896 & 0.0969 & 7,585 & 1.288 & 0.342 & 22,647 & $0.0469 *(0.00720)$ & $12.5 \% \sim 18.8 \%$ \\
\hline Group 30 & 0.889 & 0.0909 & 7,416 & 1.253 & 0.333 & 22,980 & $0.0193 *(0.00712)$ & $5.1 \% \sim 7.7 \%$ \\
\hline Group 40 & 0.860 & 0.0839 & 7,644 & 1.235 & 0.330 & 22,668 & $0.0305 *(0.00703)$ & $8.1 \% \sim 2.2 \%$ \\
\hline Group 50 & 0.846 & 0.0791 & 7,427 & 1.214 & 0.322 & 22,629 & $0.0232 *(0.00698)$ & $6.2 \% \sim 9.3 \%$ \\
\hline Group 60 & 0.837 & 0.0782 & 7,602 & 1.195 & 0.334 & 22,284 & $0.0135 * *(0.00701)$ & $3.6 \% \sim 5.4 \%$ \\
\hline Group 70 & 0.842 & 0.0800 & 7,539 & 1.191 & 0.324 & 22,649 & $0.00422(0.00699)$ & $1.1 \% \sim 1.7 \%$ \\
\hline
\end{tabular}


Notes:

*Significant at $1 \%$ level **significant at $5 \%$ level

This table compares the difference between the average interest rate premium of Group 100, defined as the group with top $1 \%$ imputed income, with the average premium of, respectively, Group 1, Group 10, Group 20, Group 30, Group 40, Group 50, Group 60, and Group 70, with Group $x$ defined as the group with $x$ th quantile of imputed income $(x=1,10,20,30,40,50,60,70)$. The meaning of the notations are as follows. $\overline{r_{x, 2}}, s_{x, 2}^{2}$, and $N_{x, 2}$ are, respectively, the mean, the variance, and the number of observations of Group $x$ 's interest rate premiums after the top tax rate hike, i.e. during January 2013 to June $2013 . \overline{r_{x, 1}}, s_{x, 1}^{2}$, and $N_{x, 1}$ are the mean, the variance, and number of observations of Group $x$ 's interest rate premiums before the top tax rate hike, i.e. during January 2011 to December 2012. $\overline{r_{100,2}}, s_{100,2}^{2}$, and $N_{100,2}$ denote the mean, the variance, and number of observations of Group 100's interest rate premiums between January 2013 and June 2013, and $\overline{r_{100,1}}, s_{100,1}^{2}$, and $N_{100,1}$ denote the mean, the variance, and the number of observations of Group 100's interest rate premiums between January 2011 and December 2012.

In this table, interest rate premiums are measured in percentage point.

a This is calculated as $\left(\overline{r_{100,2}}-\overline{r_{x, 2}}\right)-\left(\overline{r_{100,1}}-\overline{r_{x, 1}}\right)$. Numbers in parentheses are standard errors.

${ }^{\mathrm{b}}$ For the method of calculation in this row, please refer to the last several lines in the paragraph in the main text right below this table.

With measurements of the effect of tax rate on interest rate in Table 3, I now proceed to translate these measurements into incidence results. Results in Table 3 suggest that choosing different groups as control groups to compare with Group 100 gives different estimates for the effect of the 2013 tax rate hike on the top income borrowers' interest rates. Similar to patterns displayed in the graphs, as $x$ gets larger, the effect estimated with Group $x$ gets smaller, again because Group $x$ contains more and more top income bracket borrowers as $x$ gets larger, and thus resembling Group 100 more and more. However, this does not mean that $x$ should be small and that Group 1 is the best control group. In fact, Group 1, and Group 10 or Group 20 like, may differ from Group 100 in important and unobservable ways (e.g. being different in tastes etc that cannot be controlled for with data) and thus do not serve as good control groups. With all these in mind the estimates obtained by Group 50, 0.0232 may be more reliable than others.

Now I interpret the numbers in Table 3's “effect" column, e.g. Group 50's 0.0232. In order to reveal their incidence meaning, I have first computed after tax mortgage payments under different tax rates, and reached the following approximation. If all tax benefits associated with mortgage deduction by the 2013 tax hike go to lenders, the mortgage interest rate is likely to rise between 0.25 and 0.375 percentage point. To see 
how I have reached this conclusion, see Figures 10, 11 and 12. Figure 10 plots annual after-tax repayments (computed as nominal repayment - tax benefit $=$ nominal payment interest payment $\times$ marginal tax rate) for $t=35 \%$ and $t=39.6 \%$, holding the interest rate at $5 \%$. For example, the numbers behind the dotted 35\% line are as follows. For a 30-year $5 \%$ fixed rate loan with the balance of $\$ 200,000$, the monthly payment is constant at 1073.64 thus the annual payment is always 12883.72. However, as the balance goes down over time, interest payments also goes down. Therefore the tax benefits associated with interest payments go down over time as well. Since the after-tax payment is 12883.72-tax benefits, as tax benefits go down, after-tax payment goes up. For example, the after-tax payment during the first 3 years are $\$ 9407.17, \$ 9460.01$, and $\$ 9515.55$. The $39.6 \%$ repayments are below the 35\% repayments. In Figure 11 and 12, the 36\% repayments are under higher interests, namely $5.25 \%$ and $5.375 \%$, and the two series more or less align with each other.

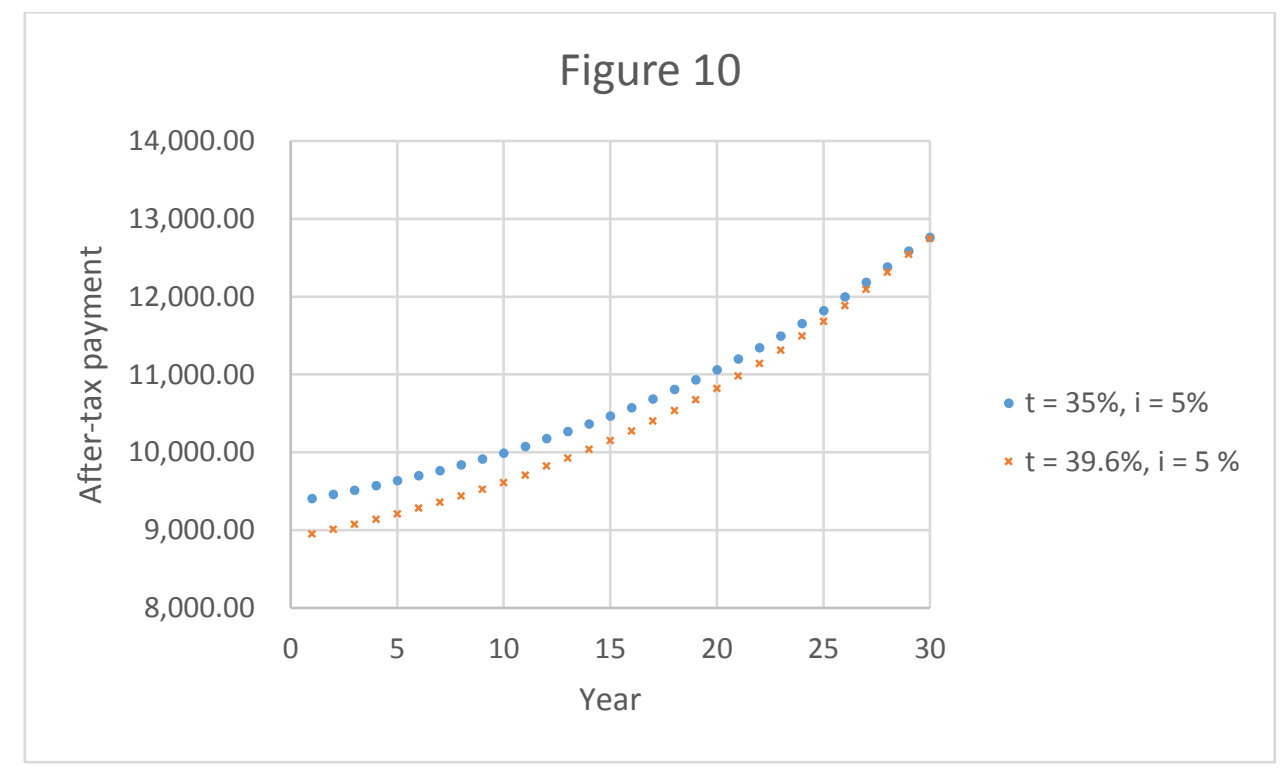



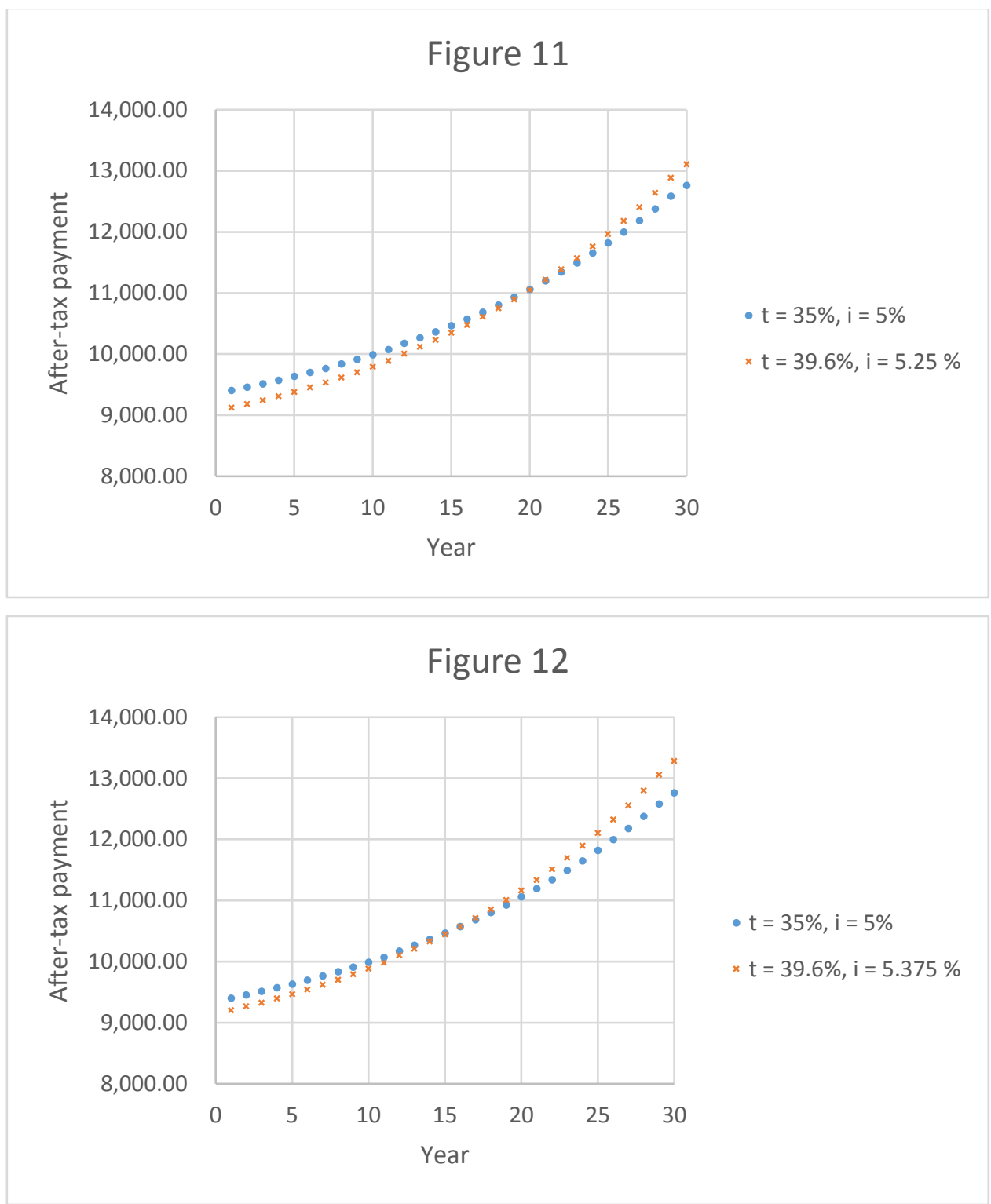

(In both Figures, the original balance is $\$ 200,000$.) Meaning under the $35 \%$ marginal tax rate, the interest rate could rise to about $5.25 \%$ or $5.375 \%$ if all benefits are transferred to lenders. I also tried other interest rates, the results are similar; if the interest rate is higher, then the interest rate could rise by larger. For example, if the original interest rate is $12 \%$, then the new interest rate could rise by $0.5 \%$ to $12.5 \%$.

Now according to the estimated effect of a rise of 0.0232 percentage point by the Group 50 results, the lenders capture between $0.0232 / 0.375=6.2 \%$ and $0.0232 / 0.25=$ $9.3 \%$ of the mortgage interest deduction benefit. I computed the incidence results of between $3.2 \%$ and $4.8 \%$ under the main strategy in the same way. These results are near the low end of Hanson (2012)'s estimate of between 9\% and 17\%. If I go with results 
from lower income Groups, my incidence estimates will begin to overlap with Hanson (2012)'s results. But in any case, most of my results so far, except that from Group 1, agrees with Hanson (2012) in that lenders capture below $20 \%$ of the tax benefits from mortgage deductions. Thus far we are reassured that most of the benefits, though perhaps not all, of the deduction go to households instead of lenders. In the next section I will put this result into the context of ETI and examine the implications for revenue raising and efficiency cost of taxation.

\section{Implications for the Elasticity of Taxable Income (ETI)}

My results not only answers the question regarding the incidence of the mortgage interest deduction, but also enhances our understanding of the Elasticity of Taxable Income.

First, the results that lenders capture only below $10 \%$ of the incidence benefits suggest that, incidence-wise, the mortgage interest deduction is fulfilling its purpose of reducing the cost for homeownership for borrowers, instead of handing out money to lenders.

Second, my results reveal an important part of the relation between tax rate and taxable income. This relation is often characterized by the Elasticity of Taxable Income, defined with respect to the net of tax rate $1-\tau$, with $\tau$ being the marginal tax rate. When the marginal tax rate increases, taxable income tends to decrease (Gruber and Saez 2002). This happens because a rising tax rate makes tax-deductible consumption more favored relative to ordinary, non-deductible consumption. As a result, the charitable giving deduction for example could rise following an increase in tax rate (Friedberg and $\mathrm{He}$ 2016); moreover, there is evidence that households make joint decisions on different deductions simultaneously in response to tax rate changes (He 2015). This paper adds to the above literature in revealing another channel through which tax rate affects taxable income: tax rate could affect the market prices of deductible consumptions, which then affect the amount spent on such deductions and, as a result, the amount of taxable income. Below I will do a sample calculation to see how much this "market price" channel, or specifically the effect of the tax rate on the mortgage interest rate contributes to the ETI. This is not a comprehensive examination. Where I need inputs for tax rate, 
mortgage rate, etc, I will just plug in some reasonable, representative numbers. My purpose is to obtain some baseline guess and see how relevant the effect of tax rate on interest rates is for ETI.

Consider a $1 \%$ rise in the net of tax rate, $1-\tau$. I will compute how much the tax base will shrink following this. Along the way I will simply use numbers of $\tau=0.25$ and $r=4 \%$. My goal is to compute that, out of the overall magnitude of the Elasticity of Taxable Income, say 0.4 as estimate by Gruber and Saez (2002), what percentage of this elasticity is contributed by the "market price" channel.

Suppose that $1-\tau$ drops from 0.75 by $1 \%$ to 0.7425 . This is equivalent to $\tau$ rising to 0.2575. Some simulations of after-tax payments suggest that, if the incidence falls fully on lenders, the interest rate will rise by about $0.125 \%$. Now say that lenders capture $10 \%$ of the benefits, the interest rate will rise by about $0.0125 \%$. Suppose that annual mortgage interest payment amounts to $5 \%$ of taxable income. Then, based on the ETI decomposition formula provided in the first chapter of my dissertation, interest payment would increases by $0.0125 / 4=0.3125 \%$. So mechanically the tax base shrinks by $5 \% * 0.3125 \%=0.015625 \%$. In other words, out of the ETI - say 0.4 as estimated in the literature, the "market price" effect could contribute to $0.015625 / 0.4=3.9 \%$ of it. So indeed this incidence channel can be consequential in adding up the ETI.

\section{Future work}

This paper opens up avenues for future research, such as the following.

1. In Subsection IV.1 I mentioned two possible mechanisms for the tax rate to affect the mortgage interest rate: conscious price discrimination by lenders or borrowers bidding up the prices. One way to test which mechanism is in place is to compare the mortgage interest rate obtained by single households and married households with similar incomes and other characteristics. A single person with income $X$ normally has a higher tax rate than a married couple with joint income $X$. Suppose that the single person and the married couple have the same values of other loan, property, and borrower characteristics such as FICO, DTI, LTV, etc. Then, if the former mechanism is in place, i.e. if lenders consciously price discriminate, the single person would get a higher mortgage interest rate than the married couple. If the latter mechanism is in place, they will get the same mortgage interest 
rate. If the former mechanism is in effect, then my incidence result means that single borrowers have to pay higher after-tax rates, i.e. get less of the incidence of the deduction than married borrowers do.

2. Merry (2001) models the nonlinearity of the tax schedule in studying the impact of the mortgage interest deduction on house demand. Friedberg and He (2016) introduce the concept of "distance" to itemization threshold in describing non-itemizers' incentives. I could adopt these kinds of specifications rather than use an overall indicator of 1- $\tau$ in describing the tax incentives.

3. An issue in matching the Fannie-Freddie dataset and the HMDA dataset is that a Fannie-Freddie record could be matched with multiple HMDA records. I could try to find out what kind of loans could more often generate unique match. For example, perhaps loans made by a small institution could often generate unique match because there are relatively few loans in both datasets that are created by this small institution. Then, I can focus on studying these accurately matched records, and conduct a case study regarding that small institution.

4. There are measurement errors associated with matching and imputing incomes and tax rates. I can potentially explicitly model such measurement errors. I expect that considering such measurement errors could have impact on standard errors and make the statistical results less significant.

5. Regarding the multiple-match issue mentioned in 1, it could actually be the case that $N$ Fannie-Freddie records are matched with $M$ HMDA records. For example, perhaps each of 2 very similar Fannie-Freddie loan records is matched with 2 similar HMDA records. In this case, considering these 2 Fannie-Freddie loans together may produce better insight than considering them 2 separately.

6. I could do an analysis by submarket, for example, by considering refinanced loans and new originations separately.

7. As some Fannie-Freddie loans are matched and used in the regression, while others are not, I could model sample selection. In addition, I could also consider model sample selection to deal with missing information in income, DTI and other variables.

8. Loan characteristics such as LTV and interest rate are jointly determined, so regressing mortgage interest rates on LTV and other loan characteristics could be 
problematic (Yezer 2010). In the future I could consider model interest rates as jointly determined together with LTV etc.

9. The Fannie-Freddie dataset does not include government insured loans, and in this paper I do not consider those loans. However, there could be substitution between government insured loans and conventional loans, and both loans are included in the HMDA dataset. I could potentially study such substitution between these two types of loans, and study the substitution between government insurance and private insurance (the Fannie-Freddie dataset records mortgage insurance percentages).

10. In this paper I have not considered expectations for future tax rates. There exist studies on this topic, such as Kueng 2014. I could draw on such studies in future research.

\section{References}

Avery, R, Canner, G., \& Cook, R. (2005). New Information Reported under HMDA and Its Application in Fair Lending Enforcement. Federal Reserve Bulletin, Summer 2005. Retrieved May 12, 2016, from https://www.federalreserve.gov/pubs/bulletin/2005/summer05_hmda.pdf

Avery, R., Brevoort, K., \& Canner, G. (2012). The Mortgage Market in 2011: Highlights from the Data Reported under the Home Mortgage Disclosure Act. Federal Reserve Bulletin, 98(6). Retrieved October 2, 2015, from http://www.federalreserve.gov/pubs/bulletin/2012/PDF/2011_HMDA.pdf

Carbone, Nick. (2012). Border Shift Between North and South Carolina Switches States for 93 Properties. TIME, 24 Mar. 2012. Retrieved May 23, 2016, from http://newsfeed.time.com/2012/03/24/border-shift-between-north-and-south-carolinaswitches-states-for-some/

Courchane, M., Darolia, R., \& Gailey, A. (2015). Borrowers from a different shore: Asian outcomes in the U.S. mortgage market. Journal of Housing Economics, 28, 7690. Fannie Mae. (2016). Fannie Mae Single-Family Loan Performance Data Glossary [January 2016]. Retrieved Mar 6, 2016 from http://www.fanniemae.com/portal/funding-the-market/data/loan-performancedata.html

Federal Financial Institutions Examination Council. (1998). A Guide to HMDA 
Reporting. Retrieved Jan 20, 2015 from http://www.archives.gov/research/catalog/

Federal Financial Institutions Examination Council. (2003). A Guide to HMDA

Reporting. Retrieved Jan 20, 2015 from http://www.archives.gov/research/catalog/

Federal Financial Institutions Examination Council. (2015). History of HMDA. Retrieved

May 23, 2016 from https://www.ffiec.gov/hmda/history2.htm

Federal Housing Finance Agency. (2016). Conforming Loan Limits. Retrieved May 12,

2016, from http://www.fhfa.gov/DataTools/Downloads/pages/conforming-loan-

$\underline{\text { limits.aspx }}$

Federal Housing Finance Agency. (2016). Enterprise Share of Residential Mortgage Debt Outstanding 1990 - 2010. Retrieved May 12, 2016, from

http://www.fhfa.gov/DataTools/Downloads/Pages/Current-Market-Data.aspx

Federal Housing Finance Agency. (2016). Single-Family Mortgages Outstanding, 1990 2011 Q2 [revised 11/2/11]. Retrieved May 13, 2016, from

http://www.fhfa.gov/DataTools/Downloads/Pages/Current-Market-Data.aspx

Freddie Mac. (2015). Single Family Loan-Level Dataset General User Guide [June 2015]. Retrieved Oct 25, 2015 from http://www.freddiemac.com/news/finance/sf_loanlevel_dataset.html

Freddie Mac. (2016). Single Family Loan-Level Dataset General User Guide [Mar 2016]. Retrieved May 13, 2016 from http://www.freddiemac.com/news/finance/pdf/user_guide.pdf

Friedberg, Leora and Tianying He (2016). The Impact of Taxation on Charitable Giving. Working paper

Gruber, Jon and Emmanuel Saez (2002). The Elasticity of Taxable Income: Evidence and Implications. Journal of Public Economics, 84 (2002), 1 - 32

Hanson, A. (2012). The Incidence of the Mortgage Interest Deduction: Evidence from the Market for Home Purchase Loans. Public Finance Review, 40 (3), 339 - 359

He, Tianying (2015). Substitutability among Federal Income Tax Deductions: Implications for Optimal Tax Policy. Working paper

Kelly, Stephen R. (2014). How the Carolinas Fixed Their Blurred Lines. The New York Times, AUG. 23, 2014. Retrieved May 23, 2016 from http://www.nytimes.com/2014/08/24/opinion/sunday/how-the-carolinas-fixed-theirblurred-lines.html?_r=1

Kubik, J. (2004). The incidence of personal income taxation: evidence from the tax reform act of 1986. Journal of Public Economics, 88 (7-8), 1567 - 1588

Kueng, Lorenz. (2014). Tax News: Identifying Tax Expectations from Municipal Bonds with an Application to Household Consumption. NBER Working Paper No. 20437

Merry, Ellen Alicia (2001). The Effect of the Mortgage Interest Deduction on Mortgage Debt and Housing Demand (Doctoral Dissertation). Retrieved Mar 9, 2016 from http://search.proquest.com.proxy.its.virginia.edu/docview/304727671

U.S. Census Bureau (2013a). Core Based Statistical Areas (CBSAs) and Combined Statistical Areas (CSAs), February 2013. Retrieved Oct 12, 2015 from https://www.census.gov/population/metro/files/lists/2013/List1.xls 
U.S. Census Bureau (2013b). File Format and Record Layouts for the Census 2000 Census Tract Relationship Files. Retrieved Oct, 2015 from https://www.census.gov/geo/maps-data/data/2000tract_rel_layout.html

U.S. Census Bureau (2015a). 2010 Census Tract Relationship File - National File. Retrieved Oct 21, 2015 from http://www2.census.gov/geo/docs/mapsdata/data/rel/trf txt/us2010trf.txt

U.S. Census Bureau (2015b). Census 2000 - Population-based Census Tract Relationship File - National File. Retrieved Oct 19, 2015 from http://www2.census.gov/geo/relfiles/tract/us/us2kpop.txt

U.S. Census Bureau (2015c). File Format and Record Layouts for the 2010 Census Tract Relationship Files. Retrieved Oct, 2015 from https://www.census.gov/geo/mapsdata/data/tract_rel_layout.html

U.S. Census Bureau (2015d). ZIP Code ${ }^{\mathrm{TM}}$ Tabulation Areas (ZCTAs ${ }^{\mathrm{TM}}$ ). Retrived May 15, 2016 from https://www.census.gov/geo/reference/zctas.html

U.S. Census Bureau. 2010 ZCTA to Census Tract Relationship File. Retrieved Oct 19, 2015 from http://www2.census.gov/geo/docs/maps-data/data/rel/zcta_tract_rel_10.txt

Yezer, Anthony M. (2010). A Review of Statistical Problems in the Measurement of Mortgage Market Discrimination and Credit Risk. Retrieved Jan 17, 2016 from http://papers.ssrn.com/sol3/papers.cfm?abstract_id=1684216

\section{Appendix 1 Sample restriction on the number of borrowers and the imputation of tax rates}

I only consider loans with 2 or more borrowers, and assume that each loan's borrowers are a married couple with married-filing-jointly tax return status. (Freddie Mac's number of borrower variable is censored at 2, and Fannie Mae's is censored at 10. But 2000-2006 Fannie Mae data suggest that only about $0.6 \%$ of the loans have more than 2 borrowers.) This is assumed for the purpose of computing marginal tax rates. I do not consider loans with only one borrower because I would not know whether to assign them single or head of household tax return status. 